\title{
A SOCIOLOGY OF MĀORI EDUCATION - BEYOND MEDIATING STRUCTURES
}

\section{WALTER TAKAHA PENETITO}

\begin{abstract}
A thesis submitted in fulfilment of the requirements of the degree of Doctor of Philosophy in Education, Victoria University of Wellington
\end{abstract}

December 2005 
This thesis is the original work, under the sole authorship, of Walter Takaha Penetito.

Walter Takaha Penetito

December 2005. 


\section{Acknowledgements}

Thinking about those to whom I owe a debt for the story that is told throughout these pages fills me with mixed emotions. My late father, mother and sister were the first to see me enter the world of higher education and they have frequently been in my thoughts at those times I considered giving up through lack of motivation, failure of purpose or some other excuse that took me away from the sometimes desperate struggle of completing the task at hand.

Kei a koutou oku tūpuna, anei toku koha ki a koutou.

To the hundreds of students I have had the good fortune to have in my classes for more than 40 years, who have challenged me and compelled me to seek out better ways of helping them to learn and understand, I have nothing but respect and a warm sense of mutuality that comes from the gift of sharing.

Nāu te rourou, nāku te rourou, ka akongia ai tātou.

I have also had the good fortune in my career of having worked alongside many hundreds of teachers at every level of the education system. Some of them had a profound influence on me and I list such geniuses from out of the school sector as Jim Laughton, Alwyn Richardson and Anne Lopdell. In the Māori education world were other giants like John Rangihau, Ranginui Walker, Katarina Mataira and John Tapiata. The most inspirational academics for me at tertiary level have been foreigners like Basil Bernstein, Paulo Freire, and Pierre Bourdieu, while within New Zealand, Richard Benton, Judith Simon, Richard Harker, and Roy Nash strengthened my resolve with each work they produced. The contributions they all made to my thinking, my writing, and my teaching for more than four decades has been huge.

Ko te pae tawhiti, whaia ki tata, ko te pae tata, whakamaua kia tina. 
To my supervisors, Dr Geraldine McDonald, Dr Keith Sullivan and Professor Cedric Hall I owe a special debt of gratitude. They persisted with me even when I faulted believing in myself. They challenged me to learn how to write like an academic while continuing to think like a Māori educationist. They gave me the faith needed to convert the subjectivity of a relatively comprehensive educational experience into the scholarly requirements of a doctoral thesis. I thank them for the generosity of spirit they shared with me.

To my immediate family, Sheena, Kim, Grant and Dougal who put up with, and tolerated my deep resolve to understand what was happening for Māori in education in Aotearoa New Zealand I owe a debt I cannot really repay. On many occasions for more years than I care to think about, I was not as intimately available to them as a husband, as a father, and as a friend and companion as they or I would have liked. I look forward to a wealth of new exchanges and new opportunities with them, with my mokopuna, and with my extended family.

No reira, tōku whānau me te whānau whānui, tēnei tōku koha aroha ki a koutou. No reira, tēnā koutou, tēnā koutou, kia ora tātou katoa. 


\begin{abstract}
The history of the relationship between Māori (the indigenous minority) and Pākehā (the dominant majority) is one that is encapsulated in processes of mediation. Pākehā resolve issues that favour kawanatanga solutions (article 1 of the Treaty) while Māori recommendations almost always line up with solutions that uphold questions to do with tino rangatiratanga (article 2 of the Treaty). Each takes into account forms of accommodation of the other but these compromise positions are usually the tasks for the public servants who are by definition, working for the government of the day, and therefore, on the side of kawanatanga. The point of articulation is critical in the nature of the relationship between Māori and Pākehā. The legal academic, Alex Frame (2002) describes this position as important for those New Zealanders "who have tried to walk in both worlds, thereby not only honouring and strengthening their own and each other's cultures, but also bringing to life a third and co-existing culture of interaction in Aotearoa". A study of a variety of mediating structures, explores the relationship between Māori and Pākehā and analyses the effects these have on both parties, especially as these pertain to developments in Māori education. An approach to settling the conundrum of prioritising one agenda without creating new grievances for redress is argued throughout the study. It is argued, further, that a major re-think is needed of what an education will mean in order to meet the requirements of a contemporary Polynesian/Western society that both honours the tenets of its foundation document as well as providing a rational basis for meeting commitments in the modern global society.
\end{abstract}


Table of Contents

Acknowledgements i

Abstract iii

Table of contents iv

Preface viii

Organisation of thesis - Parts I - III 1

PART I Framework for analysis $\quad 2$

Introduction to Part I - The problem 2

Chapter 01 Introduction to the Study 6

1.1 The Argument 6

1.2 Conceptual Orientation of the Study 8

$\begin{array}{lll}1.3 & \text { Research Questions } & 27\end{array}$

1.4 Propositions, Evidence and Outcomes 34

1.5 Māori and Mainstream Education: summary 37

Chapter 02 The Ideology of Māori Education 39

$\begin{array}{lll}2.1 & \text { Introduction } & 39\end{array}$

2.2 Two political philosophies 42

2.3 Two epistemological traditions 46

2.4 Native Schools as transition 56

2.5 Systemic contribution to Māori education pathology 58

2.6 Education or socialisation - reflection on experience 65

2.7 Mãori agency and relative autonomy: a conclusion 72

Chapter 03 The Socio-Cultural Construction of Māori Identity $\quad 75$

$\begin{array}{lll}3.1 & \text { Introduction } & 75\end{array}$

3.2 Postmodernism and 'The Politics of Identity' 78

3.3 Academic Influences: Scoping the Literature (1970-2000)

3.4 Who is a Marori- 81 positions 103

3.5 Tuakiri Tangata: Identity and the Evolution of
Consciousness

3.6 Agency and Culture: summary 110

Chapter 04 A Theory of Mediating Structures in

Māori Education $\quad 112$

$\begin{array}{lll}4.1 & \text { Introduction } & 112\end{array}$

4.2 Mediating Structures 115

4.3 The Nature of New Zealand Society and its 
Education System

4.4 Mediating Structures - Function in Māori -Pākehā

Relations

127

4.5 Mediating Structures in Māori Education

135

4.6 Propositions for a Theory of Mediating Structures

in Māori Education

140

PART II Mediating structures in the development of Māori education

Introduction to Part II - The data

Chapter 05 'Our Māoris' - Reports on Māori

education (1960-2000)

5.1 Introduction

5.2 Methodology and argument

153

5.3 The functionalist terms of reference 156

5.4 Characteristics of reports 157

5.5 Selection of reports 158

5.6 Committee membership $\quad 159$

5.7 Focus on purposes and discourses 160

THE REPORTS - PART ONE (1960-1977):

$\begin{array}{lll}5.8 & \text { Background } & 161\end{array}$

5.9 The reports 162

5.10 Summary analysis, purposes and discourses - Part One 179

THE REPORTS - PART TWO (1978-2000):

$\begin{array}{lll}5.11 & \text { Background } & 180\end{array}$

$\begin{array}{lll}5.12 & \text { The reports } & 182\end{array}$

5.13 Summary analysis, purposes and discourses - Part Two 200

5.14 Māori education reports as mediating structures 201

Chapter 06 'We're all New Zealanders' - The

process of consultation in Mãori education $\quad 204$

$\begin{array}{ll}\text { 6.1 Introduction } & 204\end{array}$

$\begin{array}{ll}\text { 6.2 We're all New Zealanders } & 207\end{array}$

6.3 What is consultation? 209

$\begin{array}{lll}\text { 6.4 Education Strategy for Mãori (ES4M): } & \\ \text { Methodological considerations } & 214\end{array}$

6.5 An initial analysis of the data 225

6.6 Policy or politics? 232

6.7 A fiduciary relationship and consultation as a mediating structure 
Chapter 07 'Tangata-whenua, Tangata-tiriti'

- Institutional marae

7.1 Introduction

7.2 What is a marae?

7.3 The case for institutional marae 246

7.4 Life-style or life-chances 251

7.5 Institutional marae as mediating structures 252

Chapter 08 'Our Pākehās' - The rise and rise of Māori-medium schooling

8.1 Introduction

8.2 'Our Pākehās'

8.3 Functionalist sociology

8.4 The rise of Māori medium education - a catalyst for transformation

8.5 What is kaupapa Mãori schooling? 261

8.6 Kaupapa Māori schools as mediating structures $\quad 269$

PART III Place and the politics of whānau, hapū, iwi and Māori education - Education for all

Chapter 09 Towards a theory of education for Aotearoa/

9.1 Summary

New Zealand - Beyond mediating structures $\quad 281$

9.2 An education 'to be Māori'

9.3 Toward a theory of schooling

9.4 Whānau, hapū, iwi education

9.5 The best of both worlds - Toward a theory of education

9.6 Whānau/hapū/iwi 'identity' as the locus for intervention

9.7 Being Mãori 'goes all the way down'

Appendices

5A Reports on Mãori education

Part 1 (1960-1977): Ka awhi noa i waho

5B Reports on Māori education

Part 2(1978-2000): Ma te kanohi miromiro

5C Subsidiary reports

6 Consultation documents

7 Institutional marae

\section{Bibliography}

Texts

Theses 


\section{List of tables and figures}

Table 1.1 Sociological paradigms and mediating structures

Table 1.2 Kaupapa Māori education institutions and umbrella organisations

Table 1.3 Research questions and organisation of chapters

Table 1.4 Cultural regulation, controlling processes and the mediating structures

Table 2.1 History of socio-cultural control in Māori education

Table 2.2 Liberal education and 'social control'

Table 2.3 Comparative performance-Māori and non-Māori

Table 4.1 Primary concerns of four sociological orientations

Table 4.2 The emergence of different cultural capitals

Part II Outline of structure

Table 5.1 Discourse analysis - Commission on education in New Zealand, 1962

Table 5.2 D/A - NACME, 1970

Table 5.3 D/A - Mãori children and the teacher, 1971

Table 5.4 D/A - Communication between schools and parents, 1973

Table 5.5 D/A - Secondary education - Towards partnership, 1973

Table 5.6 D/A - NACME, 1980

Table 5.7 D/A - Review of the core curriculum, 1984

Table 5.8 D/A - Taskforce for review of educational administration, 1988

Table 5.9 D/A - Māori participation and performance in education, 1996

Table 5.10 D/A - Māori education commission, 1998-99

Table 6.1 Concerns about the consultation - perspectives

Table 8.1 Historical moments in the emergence of kaupapa Māori schooling

Table 8.2 Interventions, catalysts for change and strategic focus

Fig.2.1 Māoritanga model (Rangihau)

Fig.3.1 Māori identity formation

Fig.3.2 Matching levels of consciousness between learning and organisation
Abbreviations
$\mathrm{ME}$ = Māori Education
MME = Māori medium education
MSE = Mainstream Education
MS = Mediating Structures
KKM = Kura Kaupapa Māori
$\mathrm{KME}=$ Kaupapa Māori Education
KMS = Kaupapa Māori Schools
WK = Wharekura
WAN = Wānanga 


\section{Preface}

This is a reflexive study of education in New Zealand viewed as through graduated lenses that are part Māori, part mainstream, and part imbricated. Although I would not consider myself an expert in any of these perspectives, I have, nevertheless, toiled for more than 40 years to try to understand something of the world of Mãori education in New Zealand and how it works for Māori, and in many instances, why it does not work. It has been a major longitudinal study and at times a preoccupation when I thought I was doing other things. In trying to understand the complexities of Māori education I have always begun from my own stance as a Māori person and from what I perceived other Māori people saw was happening in the process of schooling. Having to draw on other perspectives as found in disciplines like sociology, philosophy, history, psychology, social geography and anthropology happened almost like a natural progression. However, if there was an orientation that I found most appealing and insightful it was the sociological, especially that brand of sociology that practises a 'reflexive' approach (Bourdieu, 1990:34). In basic terms it is a sociology that sets out to oppose the falseness of dichotomous, dualistic ways of viewing reality "because they lead to mutilations", for example, between theorists and empiricists, between subjectivists and objectivists, and notably, between structuralists and interactionists. I have learned to see sociological perspectives within the folds of these other disciplines.

Sociology entails, as Berger maintains, 'a way of looking at the world'. From my point of view, and unlike many other disciplines, sociology sets out to apply a scientific ethic to an exploration of social phenomena without seemingly having to replace or diminish the magic of those who hold strongly to metaphysical interpretations of the world. It is this deliberate interface between what Becker calls the sacred and the secular that most appeals to me. Every other appeal to analysis in Māori education pales into significance compared with what is going on at the precise juncture between what Māori are demanding in education and what the mainstream education system is prepared to accede. Māori education like 
sociology encourages and even demands that the researcher learn to mix categories, to indulge in inter-disciplinary approaches, to seek out alternative understandings and meanings to critical concepts. Some of these concepts like science, rationality, objectivity, relativity, power and authority are rarely central themes in research on Māori education and that is a major weakness in a field that has for generations been thought of as an educational problem area. Even though discourse in education, outside the academy, chooses to set these critical concepts aside in preference to notions like curriculum, pedagogy, assessment and evaluation, it cannot and should not avoid the deeper and often more abstract debates that constitute the thinking associated with first principles. It is contended that the prioritising of the latter set of concepts (curriculum, pedagogy etc.) over the former (science, rationality etc.) is a serious part of the problem experienced in Māori education. For example, there is always unnecessary haste to address the concerns of curriculum without first considering the implications of a selection of knowledge outside the asymmetrical power relationships between Māori and Pākehā. The decisions that flow from that limited discourse hinder rather than help Māori participation in education.

Contrary to the existing orthodoxy ${ }^{1}$, it is argued that an education system that sets out to prioritise a particular set of characteristics - an English-speaking New Zealander, strong-willed as an individualist, a go-getter who sees him/herself as self-sufficient with a have-a-go attitude to life, fair-minded with a strong inclination toward the practical, and totally committed to moving forward - is as much essentialist as it is open.

Many of the policies, practices and strategies to encourage Māori participation in mainstream ${ }^{2}$ education are derived from attempts to match the practices to the

\footnotetext{
${ }^{1}$ The NZ education system is based on the principles of an 'open society' and as a result, so we are to understand, is defensibly scientific and rational and, therefore, culturally neutral ${ }^{2}$ What makes an education system 'mainstream' is not about the medium of instruction in its institutions but rather whether those institutions come under the auspices of the Education Act 1989. In this sense there is only one education system in New Zealand, the mainstream one. The so-called Māori education system is a convenience for talking about those schools, policies etc. that
} 
identity of a New Zealander, that is, one who is English-speaking, independent, acquisitive, practical, fair-minded, consumer-and future-oriented. In other words, what we do in education is justified by who we are as New Zealanders. This is the orthodoxy of scientific and rational education spelled out in terms of cornerstone values.

Māori education, like the Māori people, has survived as a distinct entity with a distinct culture, albeit, modified comprehensively after more than a century of colonial domination. In today's world, the bulk of the Māori population continue to view themselves complexly as Mãori with whakapapa (genealogies) and whānau/hapū/iwi (tribal) identities, as well as being New Zealanders with the status of tangatawhenua (indigeneity).

Māori education is not about prioritising its practices over others, indeed, one of the major criticisms I make of mainstream education is the assumption it makes in prioritising Pākehā New Zealand education over any others. If I have a conviction it is that agency has far more to offer society when culture and structure are seen as part of an equation that supports and promotes the individual. An education like this helps to open people's minds to the increased possibilities of keeping cultures intact and strengthening them rather than distorting them through different policies of co-option like assimilation, integration, multiculturalism and so forth.

Education is an art form as much as it is a science, a practical activity and a legal requirement. As such, it operates according to a number of different logics. Given the practical nature of education through schooling, teachers become involved in what could be called a 'logic of praxis'. Teachers are often criticised for not having a deeper understanding of the theories that underline their practices. The praxis of New Zealand educationalists is a mixed-bag of often contradictory beliefs. The educational bureaucrat is keen to maintain in her work a 'logic of

are specifically designed to address Māori interests and concerns and such like; at least that is the system's claim. 
authority' to ensure policies align with the desires of the minister of education as well as within regulation and law. In the eyes of others involved in education, government officials are considered powerful but remote from reality. The educational researchers and academics are seen as being in continuous pursuit of valid evidence and are only satisfied when they can produce research that either substantiates or refutes their claims. Theirs is a 'logic of evidence'. Academics are prone to intellectual fashion as are bureaucrats. Academics are also perceived by the educational world as being powerful if not often overly-zealous about ideas and theories they have no idea will work or not in practice. The practitioner is preoccupied with a 'logic of what works' and takes into account questions of authority and evidence only when there is irrefutable evidence that what they do for certain groups or categories of students is not working. Together, bureaucrats, academics and teachers make up the 'logic of praxis' that determine the shape and direction of Māori education and they do this through what are called in this research, mediating structures.

The four mediating structures analysed in this study are Māori education reports, the processes of consultation, institutional marae, and kaupapa Māori schooling. Māori play an important role in each of these and therefore acquiesce to some degree in the exploitation of themselves. The first two arise out of official, mainly Pākehā sources, while the latter two are from mainly Māori sources. They are all instituted in the official interests of Māori students. They each succeed in some way and fail in others. It is argued that jointly, they are successful as mediating structures in that they give Māori an authentic sense of participation in the education system without encouraging any full-blown challenge to the status quo. Mediating structures are mechanisms for maintaining equilibrium between Māori and Pākehā, between officials and practitioners, and between the state and Māori communities. A problem arises if one of the parties to the mediation is repeatedly placed in the position of having to acquiesce in order to assure equilibrium. It is a hypocritical compromise when acquiescence is assumed on the grounds that the minority partner to an historical agreement constitutes a necessary condition in 
order for democracy to prevail. There doesn't have to be a policy or a regulation to maintain this position if ideological mechanisms, such as, mediating structures can be relied on to deliver the same result. A similar point was made by Marx and Engels more than 150 years ago:

The ideas of the ruling class are in every epoch the ruling ideas; i.e. the class which is the ruling material force of society is at the same time its ruling intellectual force. The class which has the means of material production at its disposal has control at the same time over the means of mental production, so that thereby, generally speaking, the ideas of those who lack the means of mental production are subject to it. The ruling ideas are nothing more than the ideal expression of the dominant material relationships (Marx and Engels, 1846/1974).

In New Zealand, and from the perspective of Māori, it is culture rather than social class that plays the prominent role in shaping the nature of the relationship between Māori and all others. It is argued that the 'logic of the market' coupled with the promises of 'secular salvation' through liberal education, so much loved by Western societies, will always keep Māori in a subordinate position vis-à-vis mainstream society. Real salvation for both societies requires Māori to move away from uni-directional mediating structures and to implement a true acculturation, that is, one that legally and ethically operates as a two-way process. To achieve this goal there needs to be two recognised, officially mandated education systems which have some aspects that operate independently of each other, other aspects that are integrated and require co-operation from each other, and other aspects that remain intact within the parent body but have areas of negotiated overlap where collaboration is required in order for either party to meet its requirements. I have referred to this overlap as an imbricated form of acculturation.

There is no question about the fact that Māori as tangata-whenua (the indigenous people of Aotearoa New Zealand) are demanding the right to be treated equally under the law. In most cases this right is recognised although often challenged by Māori. But Māori are asking for more than that; as tangata-Māori (those who choose to assert their heritage as Māori, 
those who choose to live their lives as Māori) they want to be treated as equals. The two principles are similar but they are not the same. Where the justice system has a critical role to play in ensuring the former principle is upheld, it is the education system that has the paramount role to play in giving substance to the latter principle. On those grounds, there is much that remains to be done. 


\section{A Sociology of Mãori Education: Beyond Mediating Structures}

\section{Organisation of Thesis - Parts I - III}

The study is presented in three parts. Part I establishes a framework for the analysis of mainstream and Māori education and hypothesises a theory of mediating structures. Part II is made up of the data or evidence used to argue the case about mediating structures as major limiting entities in the development of both mainstream and Māori education, while Part III suggests a practical outcome of the research and what might be required to move beyond the constraints of mediating structures as discussed in the thesis. This is an ambitious project but one the researcher has been professionally involved in for more than 40 years and is in that sense, more than what is usually considered the brief for a doctoral thesis.

Part I comprises Chapters 1 to 4 and provides the theoretical, philosophical, sociological, and international contexts.

Part II is made up of a further four chapters and is a mixture of literature-based data (Chapters 5 and 8), empirical data (Chapter 6), and archival data (Chapter 7).

Part III has an overview summary and a final chapter (Chapter 9) that serves as a recommended way-forward for education in Aotearoa-New Zealand.

Introductions to Parts I, II and III are included in the appropriate places within the text. 


\section{PART I Framework for analysis}

\section{Introduction to Part I - The problem}

This study is about how Māori education (ME) has developed over the last 40 years (1960-2000). The purpose is to show how this object called Māori education, beginning in the Native Schools and in an unbroken sequence to today, is being used by the state, as a mechanism of cultural control rather than for educative purposes. In the same period under investigation, Māori have used Māori education as a mechanism for cultural revitalisation. In this sense, both mainstream and Māori have appropriated schooling away from its educational purposes. Described in these terms, Māori education is an 'ideology' in that it serves the interests of particular parties or groups (Chapter 1). It is not suggested that the appropriation of Māori education to serve cultural control and cultural revitalisation perspectives is used exclusively for these purposes but it is maintained that cultural control and cultural revitalisation are the central themes respectively instead of the mandated purpose, that is, education of the young. A prior question might be, assuming both these assertions to be true, what is the problem? Given that there is a hierarchy of cultures within New Zealand society where relations of domination/subordination operate should we be surprised that the dominant culture is seeking to maintain control or that the subordinate culture is ambivalent over these attempts at control by taking the offensive and promoting the revitalisation of their own culture? Neither of these actions is surprising but what is, is the remarkable level of apparent consensus from both parties as to the balance of compliance-resistance, usually the result of the quantity and quality of Māori knowledge and practice incorporated into educational agendas. Is it a consensus? If it is, then how is that consensus arrived at? What is the consequence of the consensus? The answers to these questions make up the substance explored in the four selected mediating structures.

\section{Structure of Part 1}

Part I of the thesis explores the status of Māori and Māori education within New Zealand society. Three broad questions are discussed as part of a contextualising of the thesis: 
- What is Māori education in relation to mainstream education?

- How has Māori and mainstream education contributed to the construction of Māori identity? and

- By what means has the state been able to constitute a subject - Mãori - that thinks of itself as being free and autonomous and acts as though its responses to the system are the consequences of principles it itself has chosen?

Subsidiary and related questions are also addressed such as:

- Why a sociological approach?

- What is meant by ideology?

- Why notions of identity remain central concerns for Māori? and

- How the construct of mediating structures contribute to Māori internalising subordination?

Chapter 1 sets out the argument the thesis addresses. It identifies the key concepts of the study and how these concepts will be interpreted. There are four major research questions. A background is given for each in order to clarify the context of the study. All of the above is then organised around a set of five propositions which is the argument reinterpreted to show the sort of evidence used to reach the conclusions stated in Part III of the thesis.

Chapter 2 focuses on the definition of the problem in Māori education. It outlines the thinking behind the thesis and what is meant by 'Māori education as ideology'. Explanations of key concepts like social control, cultural control, and cultural revitalisation are discussed within a broad political philosophy. The question of how the education system contributes to a Māori educational pathology is explained via a theory provocatively entitled, 'the success of biased failure'.

Chapter 3 theorises a postmodernist politics of identity. The objective is to try to understand how a new conception of ethnicity and culture might be constructed. The procedure for exploring this understanding is via a 'socio-biographical' 
narrative of the researcher. The researcher's story is not intended to be taken as representative of the socio-cultural construction of Māori identity in general but it is suggested that it does typify the variation that exists within those who selfidentify as Māori. The socio-biography tells the story of the researcher but it is not a straight forward autobiographical piece; it is written to represent the backgrounds of many other Māori of the same generation.

Chapter 4 outlines a theory of mediating structures. Mediating structures are defined, the functions they serve are discussed, and the role they play in MāoriPākehā relations, beginning with what is now being referred to as New Zealand's founding document, the Treaty of Waitangi, are explained.

In order to contextualise the role of mediating structures within education two major dimensions are clarified. The first relates to the highest ideals shaping the development of New Zealand society, and the second, the nature and characteristics of the education system that it nurtures. ME is a microcosm of these developments both effecting and being affected by them. It is appreciated that $\mathrm{ME}$ and mainstream education (MSE) are not equivalent entities and that in the final analysis, a modern, democratic, capitalist society such as exists in New Zealand, will evolve institutions such as we have in education (Carnoy, 1974; Archer,1984), in law (Sheleff,1997:309), and in most other ideological state apparatuses, where social control is at the heart of each structure. The key question then becomes, as we are reminded by Sheleff (ibid.p.310), "whether social control (through education) is to be extensively imposed and rigidly enforced, or whether it is to be no more than a flexible guideline for action".

From the assumptions about the nature of New Zealand society and its education system three distinctive cultural capitals (one Mãori and the other Pākehā) and one an over-lapping or imbricated cultural capital are hypothesised. 
Chapter 4 also provides some explanation of sociological paradigms (Burrell \& Morgan, 1979) that are used to frame the mediating structures explored in Chapters 5-8. 


\section{Chapter 01}

\section{Introduction to the study}

This study is a theoretical and philosophical critique of the New Zealand mainstream education system as that relates to Mãori education. It is argued that mainstream education (MSE) has had a profoundly distorting effect on the cultural, economic and educational development of Māori to the degree that over the last four decades Māori have been exploring the possibility of establishing an alternative system of education. Their search is based on principles and practices that derive from a Māori worldview or kaupapa Māori on the grounds that they cannot achieve the education they believe they are entitled to within existing philosophies, policies, structures and practices.

The Native/Māori Schools of the period 1867-1969 could be perceived as being the original alternative education system for Māori. Despite the view that these schools evolved in a manner that received the approval of most Māori associated with them, the fact that they were established, implemented, resourced and controlled by the state means that they cannot be accurately described as an alternative to the education system because they were bound by the same philosophical premises, similar legislative frameworks, and more or less the same professional expectations as the mainstream system.

\subsection{The argument}

I argue that Māori education (ME) is appropriated and misrepresented by the advocates of mainstream education. It takes as its starting point the notion that $\mathrm{ME}$ is an ideological construct in which the vested interests of the dominant Pākehā society, represented in a variety of critical mediating structures, is virtual insurance that $\mathrm{ME}$ will operate in a deficit, marginalised and failure mode, usually in the position of 'catching up' with the MSE system but never quite achieving it. ME is about Māori culture within the education system but only where a selection of that 
culture is of sufficient quantity to not pose any threat to the dominant hegemony. Throughout the 1960s and 70s ME became more and more associated with differential achievement and in particular with the politics of disparity and 'closing gaps'. The process under which $\mathrm{ME}$ is carried out is called schooling. ME is a Pākehā invention created through the influence of politicians, the scholarship of academics, the conservatism of public servants, the pragmatism of teachers, the imagination of artists and writers and the ambivalence of Māori themselves. Through the actions of each of these groups of players they have created a style of thought and a way of operating that has its own tradition beginning with the mission schools of the early nineteenth century, evolving into the Native/Māori Schools of the middle nineteenth and twentieth centuries, and metamorphosing into contemporary bilingual schools and kura kaupapa Māori (KKM).

The focus for the study is on how ME has developed over the last 40 years (19602000). The problem is to show how this object called ME, is traditionally and currently being used by the state as a mechanism of cultural control rather than for educative purposes. Running along side this argument I want to show that during the last 20 years Mãori have also distorted ME, not for any control function, but rather as a mechanism for cultural revitalisation. Both cultural control and cultural revitalisation are substitutes for educative purposes. There has been a constant struggle for the dual agendas of cultural control on the one hand and cultural revitalisation on the other. Given the power differentials between the two adversaries, the less powerful group either has a really compelling reason for the agenda it is promoting or the revitalisation agenda holds some basic social justice appeal which, if or when satisfied, some argue, will benefit both parties. Described in this manner, $\mathrm{ME}$ is an ideology in that it serves the interests of particular parties or groups. This is the theme of the next chapter. It is not suggested that ME from either perspective (cultural control or cultural revitalisation) is used exclusively for these purposes since experience tells us, that is clearly not the case but it is maintained that cultural control and cultural revitalisation are the central themes nevertheless. A prior question might be, assuming both these assertions to be true, 
what is the problem? Assuming that there is a hierarchy of cultures within New Zealand society where relations of domination/subordination operate should we be surprised that the dominant culture is seeking to maintain control or that the subordinate culture is ambivalent over these attempts at control by taking the offensive and promoting the revitalisation of their own culture? Neither of these actions is surprising but what is, is the level of apparent consensus from both parties as to the balance of compliance-resistance. Historically, Māori want more of their knowledge, values, practices and such like, injected into the system but they tolerate, albeit grudgingly, what they are actually permitted (systemic authorities usually expect Māori expertise to offer new knowledge, directions, and practices from their culture but remain vigilant about what they perceive as being enough to retain hegemony). Is it a consensus? If it is, then how is that consensus arrived at? What is the consequence of the consensus? The answers to these questions are revealed through an exploration of four mediating structures explored in Chapters 5-8 in Part II.

\subsection{Conceptual orientation of the study}

There are seven general themes that intertwine throughout the study. They are introduced here in advance as signposts.

\section{The problem of mediating structures}

The concept of 'mediating structures' defined by the American sociologist, Berger (1979:169) as "those institutions which stand between the individual in his (sic) private sphere and the large institutions of the public sphere". They have been applied as a central analytical tool to explore the key research questions. Where Berger uses structure in the narrow sense of institution I have engaged a more critical definition of structure in the sense of relationships of power as used by Jones in her research (1992). In short, mediating structures will mean institutions and practices that mediate relationships of power, in this case between Māori and 
Pākehā modes of regulation and change (socio-cultural production and reproduction).

A critical appraisal of mediating structures and the processes associated with each is central to the argument of this research. The mechanism of mediating structures is used by the state in order to impose a definition of the everyday world of education on Mãori, consistent with its interests without seemingly having to exercise overt power (rules and regulations). By installing in Māori a sense of relative autonomy the official culture of the powerful group functions to legitimate its own tastes, knowledges, discourses and experiences while simultaneously subjecting Mäori people to its control and dependence by tying them to a regulated, colonised identity. This dependence is a form of symbolic violence that is manifest in what is being labeled mediating structures for example, education reports (Chapter 5), and the practice of consultation (Chapter 6).

The data basis of the thesis (Part II, Chapters 5 to 8 ) is an analysis of the struggle to define the purpose of the education system and thus the meaning of what it means to acquire an education. This approach, where the data are derived from the theory rather than the theory from the data is somewhat unconventional but is a reasonable approach, given that the researcher has had more than 40 years in the mainstream education system. ${ }^{1}$ The British educational sociologist, Davies describes Durkheim's extensive works in a similar vein where he 'derived' the theory not from data but the data from theory (1994:9). Of course, I am not comparing the quality of my thesis with Durkheim's contribution to education except to draw the parallel with one small matter of procedure.

In order to achieve 'buy-in' from a revitalised Māori interest group to the overarching philosophical and policy direction of mainstream education, two further types of mediating structures are incorporated, institutional marae (Chapter 7) and

\footnotetext{
${ }^{1}$ As teacher, adviser to teachers on Māori education, education officer for Northern Region schools, manager development/analytical services within the Education Review Office, Dean of Mãori teacher education, project manager for the Ministry of Education and Te Puni Kokiri, and academic in the school of education within a university.
} 
Māori medium schooling (MMS) (Chapter 8). The last two mediating structures incorporate a much more subtle form of dividing practice to co-opt and encapsulate Māori by intensifying their involvement in the process while maintaining control over the purposes and outcomes of education. The focus is always on mediation or process rather than outcome, that is, policies of equality of educational opportunity are about opportunity rather than equality or education. Opportunities are made available through access to education but neither equality nor education is ever seriously contemplated let alone achieved. The effect of this cultural encapsulation is a fragmented genuine Māori subjectivity, which, at the very deepest level of consciousness, is thoroughly structured by an imposed middle-class Western symbolic order that for most Māori is not achievable even if such a level of consciousness was considered desirable.

The cultural revitalisation of Mãori which emerged through the early 1980s has been an attempt by Māori to address at least one critical question among many, namely, what is Māori about ME and to answer the question in their own terms. The success or otherwise of this revitalisation, at least as it is positioned at present, will either be reflected in the 'system, ${ }^{2}$ or in an 'alternative system'3. It is this last point about the effects of the struggle between cultural control and cultural revitalisation and the history of consensus politics between Māori and Pākehā that will influence whether mediating structures will continue to work as they have and as they are, or whether they will be modified or substituted in the light of the contest for the hearts and minds of Māori young people.

\footnotetext{
${ }^{2}$ The system refers to all sectors (early childhood to tertiary), and all education state departments/agencies.

3 An alternative system for the schooling of Māori students has existed in earlier times (the Native/Mäori Schools system, 1867-1969) but there is a new and radically different 'alternative" system that has been emerging in New Zealand since the early 1980s. In that this system operates under the jurisdiction of the state monopoly it is part of the mainstream, however, it is an alternative system to the degree that it offers an education in Mãori across all sectors (kohanga reo to wānanga), with a management/administrative infra-structure at each level (National Trust, Te Rūnanga-nui o Ngā Kura Kaupapa Māori o Aotearoa, Te Tauihu). This system is seeking to establish, through the idea of 'education authorities' philosophical and structural coherence at iwi tribal and national levels.
} 
It is argued that the major construct by which dominant Pākehā forces have influenced, shaped, transformed and distorted any attempt to reproduce an authentic ME, is found in what is described as mediating structures. Mediating structures provide a way of both including and excluding Mãori at the same time through allowing them a say, indeed, officially sponsoring comment as in advisory committees (Chapter 5) yet over-riding the decisions Māori feel most compelled to offer. Mediating structures play an important role as a consultation device to elicit from Māori their preferences in any number of policy areas (Chapter 6) but not before the substantive decisions have been made with regard to what will count as consultation data. The notion of a mediating structure is the rationale for giving Māori institutional cultural space (Chapter 7) but limiting how that space can be generalised thus ghettoising the activities for which the space will be used. Mediating structures can be seen as accepting that there are Mãori ways of operating in education (Chapter 8) but co-opting those operations in the interests of maintaining power and authority.

The accumulation of decades of policies and practices in which the effects of mediating structures, such as those alluded to above and detailed in Chapters 5 to 8 , constitute the data-base for this thesis. These effects are discussed in the chapter on Māori identity (Chapter 3) and in the final chapter that call for a redefining of ME beyond the constraints of mediating structures (Chapter 9).

It is argued that only by moving beyond mediating structures and establishing a 'full-blown' Kaupapa Māori Education system (KME) operating in tandem with a profoundly more Māori inclusive MSE system, will Aotearoa New Zealand be able to claim an education that works in the interests of both signatories to the Treaty of Waitangi. Theoretically, at least, it will then be possible to talk about what an education might mean for all New Zealanders without the qualifiers, Mãori and mainstream. The theory of mediating structures that lies behind this thinking about what counts as education, is outlined and discussed in Chapter 4. 


\section{The sociological imagination}

Sociology, or more accurately, the sociological imagination is the academic approach to which I have some intellectual affinity. Sociology has inspired me and offered me another frame, another set of eyes, another way of thinking about the relationship between ME and MSE. We learn from European history that with the industrial revolution, the emergence of scientific method, the spread of universal literacy, and the development of a social scepticism, earlier traditions encompassing the sacred, the magical, collectivist and holistic worldviews came under serious threat ${ }^{4}$. Sociology came into existence as one of the emerging social sciences that set out to achieve secular, scientific, and rationalist acceptance as the best way for shaping future society ${ }^{5}$. When Pākehā began to colonise New Zealand they found Mãori occupying the place and stage in the evolution of society where they themselves had been some centuries before. Māori were observed to keenly grasp 'the tools of the Pākehā' such that the provision of cultural space to accommodate, if not to totally assimilate the natives was seen as a real possibility. Such tools included superior technology especially weapons; it included what was perceived as an enlightened cosmology as contained in the Bible; and it included an enhanced system of communications in the form of literacy.

The sociological tradition is of course, a European invention. It is said "the master's tools will never dismantle the master's house". The African-America poet, Audre Lorde (Collins, 1992:79) maintains that "they may allow us temporarily to beat him at his own game, but they will never enable us to bring about genuine change". I argue that this act of dismantling is precisely what one must do if education is to be more than merely an instrument for the purpose of conveying the dominant definition of truth, or to justify (or legitimate) the

\footnotetext{
${ }^{4}$ See Martindale (1974) especially chapter 6 on 'Humanism, Scientism and the Types of Sociological Theory, pp.195-240; see also Mazrui (1986) and his description of the three interrelated European movements of the Renaissance, the Protestant Reformation, and The Enlightenment.

${ }^{5}$ There are several texts available but Zeitlin (1968) especially Part 1 on the Enlightenment and Part 2 on Post-Revolutionary Thought; and Nisbet (1973), in particular, chapter 2, The Two Revolutions, provide useful accounts of this historical period.
} 
prevailing distribution of power and wealth. We must use, according to this study, the power of the system to get the system to obey its own rules, to follow its own dictates, or preferably, to negotiate inclusive rules and practices so as to minimise dictates.

I do not believe that sociology, as a discipline, has any inherent major philosophical or methodological advantage over any other academic discipline, nor that it is intrinsically more critical or liberating than any other intellectual practice but it speaks to me in a voice that gives critique an edge that can be readily "sharpened into an effective tool for cutting through the illusions that dog (Māori) political life" to paraphrase from Reiman (1979:159).

The sociological imagination is not considered a conventional type of research methodology but for the purposes of this study it provides a frame that helps to accommodate some of the inherent difficulties of juxtaposing the theory and practice of kaupapa Māori alongside the theory and practice of Western philosophy. The concept of the sociological imagination is borrowed from the classical text of the same name written by the American Marxist sociologist of the 1960s and 70s, Mills (1977). Five statements are illustrative of the sociological imagination's relevance to this study:

- The individual can understand his (sic) own experience and gauge his own fate only by locating himself within his period, that he can know his own chances in life only by becoming aware of those of all individuals in his circumstances (p.12);

- $\quad$ the capacity to shift from one perspective to another (p.13);

- to understand the difference between 'the personal troubles of milieu' and 'the public issues of social structure' (p.14);

- $\quad$ to be aware of the idea of social structure and to use it with sensibility is to be capable of tracing such linkages among a variety of milieux (p.17); and

- a quality of mind that seems most dramatically to promise an understanding of the intimate realities of ourselves in connexion with larger social realities (p.22).

From my stance, Mills' work has relevance to ME because of its mixture of humanism and left-wing collectivism (Martindale,1974:229) along with an 
emphatic endorsement of a Marxist approach to social science. In the last of his several publications Mills wrote:

\begin{abstract}
The social scientists study the details of small-scale milieus (sic); Marx studied such details, too, but always within the structure of a total society. The social scientists, knowing little history, study at most short-run trends; Marx, using historical materials with superb mastery, takes as his unit of study entire epochs. The values of the social scientists generally lead them to accept their society pretty much as it is; the values of Marx led him to condemn his society - root, stock, and branch (Mills, 1977:12-13).
\end{abstract}

With relevance to $\mathrm{ME}$, several critical themes are pertinent from this quote: the relevance of the whole context; the need for macro-structural level analyses as well as micro-ethnographic level analyses; the tendency of social scientists (read public servants and teachers) to be mainly interested in short-term and quite often ad hoc solutions; and ahistorical and conservative advocacy of the status quo.

In very general terms I strongly believe that Māori must develop a more modern, rational and scientific approach to their understandings and experiences of the social world, and that Pākehā society, on its part, must develop a more imaginative approach to their understandings and experiences of the cultural world. The sociological imagination will contribute to that in a way that focusing on a specific sociological perspective such as 'realist sociology' (Nash, 1997; Hall, 1981; Archer, 1995) for example, could never achieve by itself. Realist theory finds difficulty in accommodating something as intangible as imagination or wairua (spirituality) yet it would be impossible to understand Māori ways of thinking and acting without an adequate theory of such intangibles. What $I$ think the sociological imagination gives us a license to do, is to put the secular and the sacred together in a dialectical relationship. The relational ontological world that modern Māori live in demands a dialectical approach to realist and idealist epistemologies. Such a world is perpetually struggling with the dynamics and 
tension of the double-bind hypothesis ${ }^{6}$, of anomie ${ }^{7}$, of a double-consciousness ${ }^{8}$, and of alienation. These conditions are discussed further in Chapter 3 on Māori identity.

Another American scholar who has also figured prominently in my deliberations over many years has been the interpretivist sociologist, Berger who describes sociology as "a way of seeing" (1971:32-33). In his own words,

The fascination of sociology lies in the fact its perspective makes us see in a new light the very world in which we have lived all our lives. This also constitutes a transformation of consciousness.

And again,

Human phenomena don't speak for themselves; they must be interpreted. There needs to be a determination to see the social world as it is regardless of one's own wishes and fears, that is, to separate what is from what one believes ought to be (emphasis in original, p.17).

Berger's work, like those of Durkheim and Mills provides a vocabulary, and more importantly, a way of perceiving ME and its relationship with MSE, which is generative and empowering in a way that little of what I had read in educational psychology was ever able to inspire in me. Sociology as practised by those who stand in the spaces between left and right politics, sacred and secular orientations, positivism and relativism, order and conflict theories and so forth, help to overcome what I perceive as the misplaced notion of the dichotomy, of having to choose between opposites. In theoretical terms the construct of dichotomous approaches is undoubtedly a useful mechanism but such constructs have a way of becoming reified and thus losing their potential for transformation.

\footnotetext{
${ }^{6}$ As a first interpretation of the double-bind hypothesis it refers to the situation where one is damned if one does and damned if one doesn't - See Sampson, 1976:503-4.

${ }^{7}$ In simple terms anomie refers to not being able to decipher the rules or norms of appropriate behaviour.

${ }^{8}$ Double-consciousness is the sense of always looking at oneself through the eyes of others - See Harris, 1995:2.
} 
Berger's appeal is tied up with his works on social constructions of reality and relativism (1967, 1982), humanism (1971), political ethics and social change (1977), as well as the sacred and the secular (1979). All of these themes resonate within the Māori context. The popular mass media frequently caricature Māori values, customs and institutions as though firstly, they were peculiar to Māori, and secondly, as though they were irrelevant to modern society. The education system, through its profoundly liberal stance, can offer little more to Māori than the hope that matters will gradually improve from one generation to the next. Whether they actually do or not, that is, whether matters actually improve or not over time seem less important than the fact that the question should be raised from time to time. What matters is also a question dependent on the mood of the times. The American educationalist, Strike argues that in a liberal view of education,

society must address three issues about education. First, it must have a view of the characteristics of people it wishes to produce. Second, it must have a view of the role of education in maintaining or altering the institutions of society. Third, it must have a view of the role of education in the distribution of the goods and services that society produces (1989:30-3I).

An important presupposition argued is that MSE is manifestly liberal in the view of education it espouses and practices. Mediating structures are the mechanisms that are used to ensure the liberal view of eduction is the view that will be promulgated in the interests of all children.

The sociological framework outlined by Burrell \& Morgan (1979) has been modified to explore the mediating structures identified for this research. Although the framework suffers from at least two of the shortfalls just introduced, namely, establishing dichotomies (subjective versus objective) and constructs perceived as representing something real (change versus regulation) it nevertheless, draws clear analytical distinctions across alternative models.

(a) Sociology can be seen to occupy four relatively distinct paradigms: functionalist, interpretive, humanist and structuralist;

(b) These paradigms can be seen in terms of being change or transformation oriented or regulation or equilibrium oriented; and 
(c) The sociological paradigms can also be seen to portray particular assumptions about the nature of the social world along a continuum of subjective-objective dimensions.

The case studies explored in Part II, Chapters 5 to 8 have been organised in terms of the three criteria listed above. The framework is explained in more detail in Chapter 4 as part of the discourse around the theory of mediating structures.

Table 1.1 Sociological paradigms and mediating structures

\begin{tabular}{|l|l|l|l|l|}
\hline $\begin{array}{l}\text { Sociological } \\
\text { paradigms }\end{array}$ & Functionalist & Interpretive & Humanist & Structuralist \\
\hline $\begin{array}{l}\text { Mediating } \\
\text { structures }\end{array}$ & $\begin{array}{l}\text { Reports on Mãori } \\
\text { Education }\end{array}$ & $\begin{array}{l}\text { Process of } \\
\text { Consultation }\end{array}$ & $\begin{array}{l}\text { Institutional } \\
\text { Marae }\end{array}$ & $\begin{array}{l}\text { Mãori Medium } \\
\text { Schooling }\end{array}$ \\
\hline
\end{tabular}

\section{The relevance of sociology of education}

Much of the research and writing in ME up to the end of the 1970s came from public servants and scholars whose academic allegiances were in fields like anthropology (Fitzgerald, 1977), psychology (Ritchie, 1978), history (Barrington and Beaglehole, 1974), social anthropology (Schwimmer, 1973), linguistics (Benton, 1973), and of course, education (Bray and Hill, 1973). Few were writing on ME from sociological perspectives although they were beginning (Watson, 1967; Adams, 1973; Garrett, 1973) and even fewer from Māori perspectives, although those that did (Kawharu, 1965; Walker, 1972) had an important influence on the rising generation of Mãori scholars.

Those scholars who used sociological perspectives entered very slowly into the ME field, and like most of the other works mentioned above, stayed within paradigms which did little to challenge what is often taken-for-granted.

The 1980s was a watershed period for the sociology of education in New Zealand. By the start of the 80s all the universities were offering classes in the sociology of education in the wake of developments from Britain in what became known as the 'new' sociology of education. This signalled a shift away from the school as a 
'black box' to researching the relationship between schools and society where questions like these were being asked:

- what actually goes on in schools;

- how is knowledge selected;

- who controls the schools; and

- who benefits from 'streaming'?.

Questions like these were no longer taken-for-granted but indeed became highly problematic. Walker was virtually the single Māori voice at the academic level pushing issues in ME into this new arena of scholarship. However, other astute non-Mãori scholars saw many opportunities to research and write in a field that at almost every turn provided virgin ground for critical analysis.

Most of the universities had lecturers in sociology of education who at least dabbled, and some who did a great deal more than that, in ME. For example, Bates, Harker and Nash at Massey; Middleton and Ramsay at Waikato; Diorio and Olssen from Otago; Freeman-Moir at Canterbury; Jones and McNaughton at Auckland; and Shallcrass and Grace at Victoria. They introduced a new public of Māori students into the domains of the 'new' sociology of education which, at the time, were dominated by scholars from Britain like (Bernstein, Young, Willis, Arnot), the United States of America (Apple, Giroux, Bowles \& Gintis), in France (Bourdieu, Boudon), and in Australia, by (Connell, and Smith).

Many of the Mãori students in those sociology of education classes of the $1980 \mathrm{~s}$ are now occupying prominent positions themselves in developments related to ME: Graham Smith (Professor and Pro Vice-Chancellor at Auckland University), Linda Smith (Associate Professor and Director of International Indigenous Research Unit at Auckland University), Tania Ka'ai (Professor of Māori at Otago University), Russell Bishop (Professor of Education at Waikato University), Arohia Durie (Professor in Education at Massey University), Kathie Irwin (Manager Research at the Kohanga Reo National Trust), and Joanna Kidman and Wally Penetito (Senior Lecturers in Education at Victoria University). 
This relatively lengthy preamble is by way of providing some history in the relationship between $\mathrm{ME}$ and the sociology of education, some of the key figures in their separate developments, and where the two fields overlap.

It is argued that concepts like cultural capital, hegemony, ideology, cultural reproduction and such like are already used extensively in the literature related to ME but too often these concepts are not explored in any depth. The concepts are often appropriated, frequently distorted, and rarely used to maximise their radical potential for change. Many of the problems in ME originate in the mainstream system and it is in this sphere that sociology's radical potential to investigate below surface meanings, to get at the heart of the matter, need systematic study. It is hoped that this research contributes to this latter purpose.

\section{The problem of Māori education}

$\mathrm{ME}$ in everyday as well as in professional and academic usage usually refers to the education of Māori children or Māori young people, that is, that section of the New Zealand population that are either Māori by descent or are ethnically Māori. And by education is usually meant, that proportion of the population involved at some level of formal learning at early childhood, schools, or tertiary institutions. Virtually everything that is dealt with in mainstream education (MSE) can be discovered in some form in ME. Hence, policies in MSE will have a version which is designed to address related concerns in ME; curriculum statements in MSE will have a parallel statement in the perceived interests of ME; pedagogical practices recommended for MSE will have a matching set of practices identified with Mãori students specifically in mind; and where methodologies for the assessment and evaluation of MSE institutions have been drafted, another set has been outlined for use in institutions that cater predominantly for Māori immersion education. The parallelling of policy, curriculum, pedagogy, assessment and evaluation has gradually increased over the last 40 years as the bilingual and then kaupapa Māori movement found its voice and increased its tempo for reproducing itself. An 
education about Māori, advocated in the Taha Māori policies of the 1970s and 80s, might have held some satisfactions for a significant proportion of the New Zealand population but they did little to excite the imagination of most Māori who saw such policies as tokenistic (Smith, G.H., 1990:188).

With the introduction of the first Mãori-English bilingual school at Ruatoki in 1977 (Benton, 1981:60) and a further three at Tawera, Hiruharama, and Omahu by 1982 (Department of Education, 1988:32), the dye was cast in order to facilitate an acceleration in ME developments in a direction which up to then was struggling to gain the attention of either Māori or Pākehā, politicians or bureaucrats, academics or practitioners. Of course, there were some notable exceptions among these groupings, for example, Benton, Hohepa, Smith, Tom and Kaa Williams as well as the members of the National Advisory Committee on Māori Education (NACME). Research by Benton (1981) and Benton (1989) had shown unequivocally that unless drastic action was taken Māori language was going to die. The incentive and motivation to focus future ME developments in the direction of Māori language revitalisation rather than in the direction of equally established evidence in other areas, such as academic underachievement (Harker, 1971), was the result of a deeper yearning among many Māori to maintain the sense of being Māori rather than knowledge about the moribund state of the language. Where the state needed to take responsibility and resource Māori language initiatives in schools it was clear that following the liberal ethic of piecemeal intervention through policies advocating gradualism (eg. four already established schools being redesignated as four bilingual schools, over five years) was not going to rescue the language. In order to redress the injustices associated with a century of schooling as a "civilising mission" (Simon \& Smith, 2001) Māori needed to be the prime movers. It was this notion, described above as a deeper yearning, combined with the idea of the rectification of past injustices that the second notion of prime movers begins to take shape. An awakening among Māori that unless they take direct action, that unless they become the prime movers in the education of their young people, MSE will either completely appropriate $\mathrm{ME}$ and conclude the civilising mission or ME 
will become, using the words of Mills, "banalised and in the process emptied of moral force and intellectual cogency" (1977:23), that is, become defunct. The sentiments expressed in these words have weighed heavily on my mind throughout a substantial part of my career in education. This thesis is an attempt to clear the way before setting out to attempt reconstructive surgery on a system pre-occupied with cosmetic piecemeal intervention.

Where an education about Māori and a minimum of an education in Māori had been the norm in ME from at least the beginnings of the Native Schools system, we note a significant increase in an education in Māori from the 1970s onward.

$\mathrm{ME}$ is the area of my professional expertise; it provides me with the experiential base upon which to assess and evaluate different educational theories, philosophies and practices, as well as being the source of much of my emotional sustenance. From the very earliest association Māori were sufficiently habituated by what Pākehā had to offer to accept their 'tools' without any suggestion that their own ancestral treasures would ever need to be compromised, let alone replaced by a completely foreign agenda. Three such treasures included te reo rangatira, the chiefly language; whānau, hapū, iwi as the major form of social organisation; and whakapapa as the genealogical links that constitute consciousness of self. Yet, compromise has been one of the defining characteristics of the historical development of ME: Māori wanted what Pākehā had, but in order to satisfy this want they had to surrender something. For example, in order to acquire English language competence, it was made clear that Māori language must cease from being used. As another example, Māori wanted to establish schools for their people but before they could do so they had to "give at least two acres of land suitable for a school site" (Simon \& Smith, 2001:322-6).

The theoretical juxtaposition of these two fields of endeavour (Māori and sociology) conjure up an exciting set of possibilities for investigation: does whakapapa operate like hierarchy? Can a culture with a predominantly sacred- 
orientation survive alongside a culture with a predominently secular-orientation without one becoming disadvantaged? ME in its post-colonialist garb, is as different from its pre-European roots as modern sociology is from its Comtean positivist scientific beginnings.

Perhaps the most transformative cultural space made available to Māori through colonisation was the institutionalisation of schooling. The Native Schools Act of 1867 established "a national, state-controlled system of village primary schools for Māori under the supervision of the Native Department" and by 1879 transferred to Department of Education control (Simon, 1998: xvi).

\section{Possibilities of a sociology of Māori education}

Why a sociology of ME? Has sociology something to offer ME and if it has what is it? These are difficult questions to answer and decidedly more problematic as the Mãori 'renaissance' of the last four decades seeks ways to 'shake-off' the colonial baggage of the last 160 years and assert its own updated definitions of knowing about the world and beyond, as well as knowing about oneself and one's place in the world, about what of Māori culture is real and what we can know about it, and how one might decide how to act in the world. These statements about knowledge, about reality, and about methodology are philosophical questions and they are as important to an understanding of ME and the contribution of sociology as any other discipline. But I am interested in sociology and philosophy to the degree that they can shed light on our understanding of the relationship between MSE and ME. In that sense then, it is probably more precise to describe the approach taken in this thesis as deriving from what Mills (1977) refers to as the sociological imagination as described above, in conjunction with what we might refer to as a philosophical imagination; the mix or over-lap generated through the sacred and the secular, the experiential and the scientific, belief and knowledge. 
It is the sceptical edge that the sociological imagination generates through its programme of action that is needed to dramatically transform ME. In this respect, my thesis is, that ME exists as a system in its own right, arguably, because the New Zealand education system is fundamentally flawed. There would not be this object called ME if the system was successful in educating Māori. A system that espouses overtly an education in the interest of all students would be inclusive of Māori if it was successful. This is the same point Bernstein made in his critique of 'compensatory' education when he remarked:

I do not understand how we can talk about offering compensatory education to children who in the first place have not, as yet, been offered an adequate education environment (1973: 215).

The preference for the New Zealand orthodox or mainstream education system is to be inclusive of all New Zealanders. Nowhere is this preference more succinctly stated than in the words of the Minister of Education of the day, Right Honourable Peter Fraser in 1939:

The Government's objective, broadly expressed, is that every person, whatever his level of academic ability, whether he be rich or poor, whether he live in town or country, has a right, as a citizen, to a free education of the kind for which he is best fitted and to the fullest extent of his powers. (Report of the Commission on Education in New Zealand -Currie Report, 1962:11).

Because consecutive governments have been unable to achieve this goal they sanction instead numerous sub-systems that over time become legitimated and so we get, among other kinds of education, Catholic education, Pacific education, and ME. My contention is that knowing Māori, is knowing New Zealand. Unfortunately, knowing New Zealand, however comprehensively, without including Mãori knowledge, values, institutions, practices and processes at the historical and everyday community level is an education that can do everything except attach people knowingly to the land they call home. An education for New Zealanders that includes in-depth studies of Māori, the land, and their relationship with non-Māori in a fully integrative fashion is not 'Māori' education, it is education in its fullest and most meaningful sense. 


\section{Critiquing mainstream education}

It is argued that the mainstream education system needs to be more Māoriinclusive. This assertion begs at least two questions: more than what, and for what reasons. To answer the second question first, two reasons are offered in terms of curriculum (Māori knowledge base):

(a) because the majority of Māori students in the compulsory sector are in mainstream schools and these schools need to dramatically improve their ability to satisfy the educational needs of these students. An important way to do that is to ensure that teachers are familiar with the Māori knowledge base of the communities they find themselves in. The proportion of students moving into KMS are likely to increase with the increased availability of these schools where there is demonstrated interest from Māori communities; and

(b) because it is the Māori knowledge base that creates the distinctive and unique place of New Zealand in the world. All citizens of New Zealand have the right to know something of this knowledge base. This could be in the nature of heritage studies and include the history of relationships between Māori and Pākehā/non-Māori peoples.

The idea of an education system being more Māori inclusive suggests that what counts as Māori knowledge does not play a prominent role in schools in this country. This has been the case since the Native Schools Act of 1867. Apart from specific moments in history dating from the earliest period of assimilation, much as the cultural adaptation era of the 1930s (Simon \& Smith, 2001: 174-202), the bilingual era of the 1970s (Department of Education, 1970) and the taha Māori period of the 1980s (New Zealand Educational Institute, 1981; Scott, 1986), Māori knowledge has struggled to find a substantive place within the official curriculum of New Zealand schools. More Māori inclusive suggests not only more content 
than what already exists but content which is seen as important by Māori for the maintenance and promotion of what it means to be Māori in today's and tomorrow's worlds.

More content, in itself, is also seen as insufficient. A Māori inclusive system would prioritise a knowledge base but it would also need to take into account Māori 'ways of knowing' (language, organisation), 'ways of thinking' (evaluations, accountability), and 'ways of doing' (pedagogy, reciprocity).

\section{The politics of Mãori medium education}

It is argued that the Māori medium education (MME) system is profoundly inhibited by the umbilical attachment it has to mainstream curriculum, pedagogy, assessment, and control. The nature of this attachment has its roots in Western philosophy and emancipatory individualism, in colonialism and cultural imperialism. The link or relationship is fundamentally racist and paternalistic. The case made by the British scholars, Verma and Bagley (1979:108) applies equally to the New Zealand context:

The central problem is that we live, not only in a multi-ethnic, culturally plural society, but in a racist one....A society that features socially structured racerelated inequalities can accurately be thus described, whatever the state of its rhetoric of intent'.

The MME system, it is argued, needs to be more Māori-centred for two main reasons:

(a) because it can only truly be an alternative system to the mainstream when it can develop under the requisites of whānau, hapū and iwi-based curriculum, pedagogy, assessment and control; and

(b) because the standards of what it means to be educated in Māori terms and through Mãori criteria must come through a MME system for all students. They must establish the standards and be party to their assessment and evaluation if accountability is to have any meaning in this context. 
A MME system is envisaged as a parallel system to the mainstream. It already exists now in a 'de facto' form and by that is meant, most of the components of an education system exist as material facts now, but in the eyes of officials, these are all parts of the existing education system not a separate or parallel system. The KME system is constituted by institutions and by umbrella administrative structures. These are Te Köhanga Reo and its umbrella organisation, The National Trust ("early childhood"10 sector); KKM and Wharekura and their umbrella organisation, Te Rūnanga-nui-o-ngā Kura Kaupapa Māori o Aotearoa (compulsory schooling sector); and Wānanga and their umbrella organisation, Te Tauihu o ngā Wānanga (tertiary sector).

Table 1.2 Kaupapa Māori education institutions and umbrella organisations

\begin{tabular}{|ll}
\hline INSTITUTIONS & UMBRELLA ORGANISATIONS \\
Ngā Kōhanga Reo $\longrightarrow$ & The National Trust \\
Kura Kaupapa Māori/Wharekura $\longrightarrow$ & Te Rūnanga-nui-o-ngā Kura Kaupapa Māori \\
Wānanga $\longrightarrow$ & Te Tauihu
\end{tabular}

These educational structures represent all kaupapa Māori institutions from early childhood, through the compulsory sector, to tertiary levels. In theoretical terms, all that needs to be added to complete a parallel system is some form of overarching, whakaruruhau, or administrative parent body/bodies. Such a structure will be discussed in Chapter 8 although it should be recognised that KME is only one of the Māori medium forms of provision Chapter 8 deals with.

New Zealand is probably too small in terms of population, too centralised in terms of its educational administration, and too culturally dominated by its mainstream to accommodate a fully-fledged parallel education system without imposing constraints on the kaupapa Māori system that would lead to an inevitable derailing of its agenda. Nevertheless, the kaupapa Mãori system is likely the only authentic 
system of education that will really work in the interests of Māori. If the mainstream system works because it reproduces from one generation to the next, people who identify with the values, customs, mores, laws and institutions espoused by the sponsors of that system, and if it is also true, that the reason Māori as a category or as an aggregate do not do as well in that system because they have difficulty identifying and owning those same values, customs, mores etc., then a parallel system makes sense. Māori cannot continue to be the disproportionate failures of the system (Chapter 2) while the system seeks more and better ways to accommodate Māori aspirations.

\subsection{Research questions (RQ)}

\section{RQ 1: the success of biased failure}

Why is it that differential achievement has persisted for so long within ME ?

Attendance at schools in New Zealand has been compulsory for Māori since 1894 . Therefore, the system has been obligated to ensure the education of all Māori students but it has not. Why? Part of the answer to this questions rests with the observation that "education has the characteristics it does have because of the goals pursued by those who control it" (Archer, 1984:1). The problem for Māori in education began with the 'Native Schools' where the emphasis was on the 'schooling' of the Māori child and her whānau in conjunction with the community. It is argued that a theory of the schooling of Māori, has always been the priority rather than a theory of Māori schooling based on a philosophy of ME. It will be argued that this is not a mere semantic play on words but is at the heart of understanding what the problem is and how to go about transforming it. The answer to the question is introduced in Chapter 2 and extended in Chapter 8 in a discussion around a theory of Māori schooling called kura kaupapa Māori.

Throughout the thesis frequent shifts are made between macro and micro level analyses because of a reluctance to privilege one form over the other. A case is argued for the 'success of biased failure' that is about systemic failure as well as 
individual failure. It is biased because failure falls more consistently on those who are brown and those who are poor. For such failure to be long-term as well as consistent, the question is raised whether someone must be benefiting, hence, the success of biased failure. Of course, not all Māori children fail in schools and of all those students who do fail, most are not Māori because most students are not Māori. Despite the negative nature of the statement, the success of biased failure, what is really intended is a search for explanations and causes that lead to success as well as those which lead to failure. Behind the statement is a consideration of the key parties (education system, schools, teachers, parents, curricula, students), key explanatory theories (deficit, cultural difference, social inequality, educational deviance) and the relations between them.

\section{RQ 2: dividing practices - manipulated consensus}

How does the mainstream education system, through the mechanism of compulsory formal schooling, go about its business of transforming Māori students into subjects from one generation to the next?

The first two questions deal with the common mechanism of subjectification. The common theme which arises is that of collusion between Mãori and Pākehā as a form of consensus albeit, a manipulated normative consensus. What is in the best interests of the mainstream ought to be also in the best interests of Mãori.

Foucault (1982:777-778) discusses three 'modes of objectification' (dividing practices, modes of inquiry, and self-subjectification). They are those constructions that transform human beings into subjects and for the purposes of this thesis, the process of transforming Māori into non-Māori, or at least shadows of their actual potential. Within a similar but different context, Nader et al (1997:1) describes how 'controlling processes' (the transformative nature of central ideas that emanate from institutions operating as dynamic components of power) construct and institutionalise culture. She examines examples of different types of control (manipulated consensus, constructive dialogue, cultural control, immanent 
transformation) to show how individuals and groups are influenced and persuaded to participate (or resist) in their own domination. Nader's examples of controlling processes have been modified in the light of the case studies on mediating structures. The effect of modes of objectification plus controlling processes within each of the mediating structures explored produces a 'double-whammy' on the vulnerable participants in each case, that is, those who have less institutional power in an asymmetrical relationship of dominant/subordinate players. Each of these pairings is discussed briefly.

The first mode of objectification is what Foucault calls 'dividing practices'. An interpretation of official reports on ME (Chapter 5) will be the case study used to explore this mode. Dividing practices are forms of co-option. Co-option occurs every time Māori subjects are brought into decision-making bodies or pseudoscientific groups to discuss ME matters where they are placed in a position where they are either divided inside themselves or divided from others. If they are to operate as Māori they must first of all either educate their non-Māori group members about things Māori or be prepared to 'turn-the-other-cheek' in order not to be challenging every transgression against Māori ways of thinking and acting.

The micro-processes for resocialisation involved in those working intimately on reports provide many opportunities for members to debate issues, for conciliation and compromise, and to 'get under the skin' of what the American sociologist Mills distinguishes as the "personal troubles of milieu" versus "public issues of social structure" (1977:14). When those in positions of power want to do what is right but confuse or distort the personal over the structural in matters of Māori/Pākehā relations, the oxymoron of coercive harmony or manipulated consensus seem like a pragmatic solution to a problem for the 'too hard basket'.

\section{modes of inquiry- constructive dialogue}

An analysis of the role of consultation in ME (Chapter 6) will be discussed to illustrate this mode. Consultations have been widely used by government 
departments for many years to take their views on future directions directly to Māori communities to get a sense of the strength of support for those views. The problem with consultation between governments and Māori are obvious in two senses. Firstly, every government department (except perhaps Treasury and the State Services Commission) is required to consult with Māori. For every round of consultations the Māori groups remain relatively the same in terms of membership (members of a marae community, a hapū, an iwi) but every government department is different in terms of those members attending consultation hui. Over a 10 year period this problem is multiplied. The government department wants to know what the Mãori community thinks about proposals a, b, and c while the Mãori community wants to know what happened to their recommendations $\mathrm{x}, \mathrm{y}$, and $\mathrm{z}$ which they offered at the last five consultation hui. The second problem relates to the clear disadvantage one party has in terms of a negotiation process; it feels like there is no negotiation. What governments choose to have on the agenda defines what counts as grievances and what counts as new directions. What is wanted from the consultation is a process - how do we convince you of our definition of the problem; and what strategies are the winning strategies for us in order to achieve the new direction.

As in dividing practices, the micro-processes for re-socialisation within the role of consultation provide some (although not as many) opportunities to build familiar relationships to at least 'put a face' to the participants on both sides of the inquiry. This is not a trivial outcome. The need for 'constructive dialogue' before, during and after a consultation will depend seriously on the elements of a constructive dialogue, namely, mutual learning, information sharing, co-operation, and a harmonisation of the major outcomes.

\section{self-subjectification - cultural control}

The third mode talks about the way a human being turns oneself into a subject. To illustrate this mode an analysis of what is described as institutional marae is explored. In its traditional sense a marae is a Māori kin-based institution. Since the 
massive migration of Māori from rural to urban settings following the Second World War, the phenomenon of urban marae came into existence everywhere Māori found themselves in close approximation in city areas. These marae were in many ways like traditional rural marae except that most were not kin-based and all were situated on land that belonged to some other tribe. During the 1970s tertiary institutions and a growing number of secondary schools began constructing what $I$ have called institutional marae that operated like half-way houses, bridging institutions or mediating structures to accommodate Māori students into the host institution. They also served to accommodate the wider Mãori community into the host institution as well as being a focal point for the promotion of Māori values and custom within the host institution.

In some cases (perhaps most) institutional marae reflect the place of Māori within the institutions where they exist. Over a relatively short period in the late 1970s institutional marae appeared on campuses (secondary and tertiary institutions) throughout the country. They appeared almost unnoticed by the general public and in short time became institutionalised, or considered a natural and normal part of those institutions. However, within the separate institutions, debates were far from idealised versions of race relations, harmonised and consensual, as detail from the discussions from the review of tertiary marae attest (see Chapter 7). Questions about who was to benefit from the appearance on campus of such a marae remains problematic. Issues of cultural control, of 'getting inside people's heads' is, on the surface, at least, questioning the university's role of 'critique and conscience of society'. Is the institutional marae another way of exercising that critical role, like the role played by the science laboratory, or the library, or the lecture theatre?

\section{RQ 3: what knowledge - how distributed?}

How does mainstream society and its education system influence Māori education? 
The third key question signals a shift from the earlier consensus model in that Māori have realised that the 'powers-that-be' would never have created kōhanga reo or KKM, left to their own devices, and Māori have, therefore, had to devise these structures of their own volition. The problem is a question of difference, for example (a) how Māori is a KKM? (b) How Māori can a KKM be? (c) Is a kaupapa Māori curriculum in itself sufficient? (d) What is the difference between a school where everything is taught in Māori and another school where everything is taught in English, or Samoan, or Tongan? To answer the research question, one must ask about a theory of schooling, a philosophy of education, and a politics of society. My argument is that the current Māori medium movement in education has to be able to address the questions (a to d) above if the alternative system is to be an educational as well as a liberatory one for Māori. As Rata (1991:41) has argued most perceptively,

\footnotetext{
Any challenge by an indigenous colonised society to the dominant capitalist colonising society would need to include a challenge to (the) concept of the stages and means of human liberation.
}

The question is mainly about process but the process is not perceived in a vacuum, it relates fundamentally to the question of what is to count as educational knowledge, an epistemological as well as a political question. The epistemological questions to be answered could include what Māori knowledge should be available in the curriculum; in Māori thinking, is knowledge distinctive from belief; and what is the difference between fact and opinion in the Māori world? The political questions are, if "knowledge is a selection from the cultures" (Lawton, 1983), whose knowledge is being selected/ignored; how can change be brought about in the curriculum; and is it possible to share power and authority and how might that happen? This question is the focus for Chapters 3 and 4 .

\section{RQ 4: what is the difference kaupapa Mãori makes?}

Is the kaupapa Māori response to the distribution of power and the principles of social control through education likely to make a real difference to Māori student performance as well as create a better education system for all? 
It is clearly provocative to think of MME as another mediating structure yet it is possible to see it in that light. In the eyes of those staunch advocates of the KME movement there are those who see it as the salvation of te reo Māori (the Māori language) and therefore, the survival of a distinct cultural identity while others see it as a banner for tino rangatiratanga (self-determination) and the fore-runner for an alternative education system alongside mainstream education. KME as practiced in KKM is therefore an institution intermediate between the whānau and hapū and the world at large. They exist as a bridge between a fractured Māori traditional society and the secular state. On the other hand, KME is a positive assertion of Māori aspiration and is therefore more than a resistance movement. KME follows the notion of an immanent transformation within Māori society despite the stated intent of mainstream New Zealand. Immanent transformation is nothing like "measuring up and falling into line" to quote from Nash (1983), but a direct challenge to both mainstream hegemonic institutions and practices as well as to those Māori caught in the malaise of inevitable assimilation into 'Kiwi-culture'.

This question is explored in the final part of the thesis under the heading of the place and politics of whānau, hapū and iwi education and attempts by Māori to establish what is commonly referred to as a Māori Education Authority. Māori should not hold any illusions about how difficult, perhaps even impossible, this alternative system will be to establish and successfully sustain over time. However, a numerically growing and vocal faction within Māori society, which itself is continuing to grow, is taking more measured and bolder steps to get better organised at local, regional, national and international levels. Māori are responding to capacity-building recommendations by governments by seeking higher levels of training and education on a broader front than previously experienced. Māori are pushing ahead with the kaupapa Māori agenda in education, law, business, health, communications and politics. They begin by transforming existing institutions, and, if education can provide an exemplary model, move on to the creation of alternative institutions. The kaupapa Māori goal in simple terms is, to socially and 
culturally reproduce Mãori society not as a cultural group set in concrete about 1840 but as a dynamic cultural entity which retains what Māori have always wanted since the beginning of the colonising period, namely, the best of both/all worlds.

Table 1.3 Research questions and organisation of chapters

\begin{tabular}{|l|l|l|l|}
\hline $\begin{array}{l}\text { RQ1. Why is it that } \\
\text { differential } \\
\text { achievement has } \\
\text { persisted for so long } \\
\text { within Māori } \\
\text { education? }\end{array}$ & $\begin{array}{l}\text { RQ2. How does } \\
\text { mainstream society } \\
\text { and its education } \\
\text { system influence } \\
\text { Māori education? }\end{array}$ & $\begin{array}{l}\text { RQ3 How does the } \\
\text { mainstream education } \\
\text { system, through the } \\
\text { mechanism of } \\
\text { compulsory formal } \\
\text { schooling, go about its } \\
\text { business of } \\
\text { transforming Māori } \\
\text { students into } \\
\text { 'subjects' from one } \\
\text { generation to the next? }\end{array}$ & $\begin{array}{l}\text { RQ4. Is the Māori } \\
\text { medium response to } \\
\text { the distribution of } \\
\text { power and the } \\
\text { principles of social } \\
\text { control through } \\
\text { education likely to } \\
\text { make a real difference } \\
\text { to Māori student } \\
\text { performance as well as } \\
\text { create a better } \\
\text { education system for } \\
\text { all? }\end{array}$ \\
\hline Chapters 2 & Chapters 3-4 & Chapter 5-8 & Chapter 9 \\
\hline
\end{tabular}

\subsection{Propositions, evidence and outcomes}

\section{Proposition 1 - The success of biased failure}

The history of ME is the history of what Pākehā believe Māori need, in order to become 'full citizens' of New Zealand (article 3 of the Treaty of Waitangi). The process is more about socialising and propagandising than about educating, and what is more, is relatively successful judging by the proportion of Māori who fail in the system and who blame their failure on themselves or on their culture.

The establishment by the Crown of policies, institutions, practices, and structures that define what will count as full citizenship and by default, what will not, diminishes Māori at the outset. In education the question is not, why do Māori fail in the system and others do not, but, why some acts/behaviours are defined as achievements and others not. 
Māori are disadvantaged within the system to the degree that the system can be accurately described as being based on the success of biased failure. He rākau morimori, e kore e taea te piki (a tree shorn of branches cannot be climbed) expresses this sentiment in Māori terms (Mead \& Grove, 2001:113).

\section{Proposition 2 - The application of mediating structures}

Full citizenship for Māori, according to the Crown, requires that Māori learn to prioritise the Pākehā agenda and to set aside their own preferences (article 1 of the Treaty). The Crown has achieved this goal through the application of what are called mediating structures through controlling processes which operate to draw Māori in, to include them in the MSE system without risking power, authority or control over the educational agenda. Indeed, mediating structures/controlling processes, when operating successfully, will give Māori the illusion of having power, exercising authority, and being in control of their destiny in education. This illusion is like having the shadow without the substance.

Three modes of cultural regulation along with the controlling processes for each are discussed within the contexts of four mediating structures:

Table 1.4 Cultural regulation, controlling processes and the mediating structures

\begin{tabular}{|l|l|l|}
\hline Modes of cultural regulation & Controlling processes & Mediating structures \\
\hline dividing practices & manipulated consensus & $\begin{array}{l}\text { Ch.5 Reports on Māori } \\
\text { education }\end{array}$ \\
\hline modes of inquiry & constructive dialogue & Ch.6 Process of Consultation \\
\hline self-subjectification & cultural control & $\begin{array}{l}\text { Ch.7 Institutional Marae } \\
\text { Ch.8 Māori Medium Schooling }\end{array}$ \\
\hline
\end{tabular}

Reinterpretation of these modes of cultural regulation or usages and practices away from the tyranny of participation as exercised historically through mediating structures and we are left with Māori blaming themselves for their own condition. Tahuparae captures this state in the apt aphorism: Ko au te taupā, kïhai i puawai aku moemoea (I am the obstacle to the fruition of my dreams) (Tahuparae, 1995). 


\section{Proposition 3 - Using the creative tension in a relationship}

Māori preferences in education, as they are in life, are three-fold: (i) to survive as Māori, (ii) to be in community with whānau, hapū and iwi, and (iii) to contribute to the well-being of the society as a whole and the world at large - these are the problems to be addressed by all peoples in every era (article 2 of the Treaty). It should be obvious that schooling alone cannot achieve this goal. The relationship, for example, between schooling and the economy need to meet, in terms of the Treaty of Waitangi, a 'fiduciary standard' (Wardill, 2001) that disadvantages neither party.

The rise of the 'MME agenda' may have taken more than a hundred years to eventuate but there is a sense where such an agenda surfacing was virtually inevitable, so long as there was an identifiable group of people who self-defined as Māori and did so proudly. Another contributing sense of the inevitable is the notion that mainstream education would never have invented kohanga reo and KKM. Not because they lacked the vision or wit but rather because of the false belief that mainstream education so defined was only in need of modification to make it right for all learners.

The 'creative tension' in the fiduciary relationship between the Crown and Iwi Māori is based on the flawed notion of being like a partnership without the legal or constitutional substance associated with partnership. However, it is the creative tension within the relationship that a theory of cultural/educational change must exploit. Again, Māori fully understand this position: Hui tātou ka tū! Wehewehe tātou ka hinga (United we stand! Divided we fall - Mead \& Grove, 2001:142).

\section{Proposition 4 - An hypothesised dual education system}

Article 3 of the Treaty (full citizenship) can only be attained when the means by which citizenship for Māori is achieved (ie. the mediating structures) are called into question as neo-colonial forms of domination and are, therefore, unjust and dysfunctional to Māori. 
Attempts by Māori groups to establish a separate education system on the grounds of mainstream systemic failure of Māori in education, will not, in the long-term solve the problem because an asymmetrical power relationship exists between Māori and Pākehā which will in time force the system to deconstruct the Māori alternative.

What is proposed is a continuing emphasis on issues of participation, communication, achievement, accountability etc. but through an agenda of placebased learning acting as a buffer to mainstream hegemonic excesses.

\section{Proposition 5 - What it means to be educated}

A difference model accepts the fact that cultures are different, that notions of justice and fairness, no less than what it means to be educated, are different for different peoples and that difference does not mean deficit.

What it means to be educated is the question to be answered; what is the purpose of education; and how these questions are to be addressed is the agenda for the future.

The Crown seems to be in some trepidation in what Mahuta (1979) referred to as "te hurihanga o te hinengaro" (the revolution of the mind or the intellectual revolution being experienced by Māori). One wonders what there is to fear in an education for all.

\subsection{Māori and mainstream education: summary}

The research for this work is fundamentally theoretical and exploratory but there is some attempt to be part of the initiatory practice of conducting fieldwork and gathering data especially in the case studies of consultation and institutional marae. But a significant proportion of the theorising herein is deduced from the 
experiences of a lifetime in the educational profession and made more intensive through enjoying the privilege of working in a university and in one sense, being able to escape from the confinement of schools, teachers, students, curriculum and parents and an opportunity to concentrate on libraries, lectures, ministerial offices, conference presentations, research and writing. The question of which comes first among theory, experience, and data has not been that important in my thinking. Experience weighs heavily because that signals one's entry into the world of formal education and schooling however, deriving data from theory rather than theory from data, as discussed earlier, has also proven a fruitful exercise for the insights produced. Further comments on research methodology are inserted in appropriate places related to the mediating structures Chapters 5 to 8 .

As with other indigenous peoples of the modern world (Australian Aboriginal, Native Americans, First Nations peoples of Canada, Inuit of Alaska) Māori share similar problems, which in short-hand terms can be defined as problems of identity which can be seen as the function of asymmetrical power relations. The problems are seen to originate in acts of separation as a result of nineteenth century or earlier forms of colonisation. The separations are numerous, for example, from traditional lands, language, cosmologies, economies, sources of power and authority, knowledge and customs, food supplies and much more. Chapters 2 and 4 establish a 'way of looking' at these problems (through a sociological and philosophical imagination) and investigating them. Chapter 3 will examine in some depth the issues surrounding Māori identity with the researcher's own experiences as evidence. The questions addressed include: Is there a problem of identity among Māori? Are there modes of objectification? What are they? How are Māori identities transformed? 


\section{Chapter 02}

\section{The ideology of Mãori education}

\subsection{Introduction}

The two aims of this chapter are, first, to show that the ideological foundations of the development of Māori education, are directly conditional upon a political philosophy of racial and cultural superiority. The second aim, is to demonstrate how ideology - particularly as it is manifested in differential achievement - has developed as a result of successive iterations of policies and practices that assume Māori are dependent on Pākehā goodwill without any reciprocal intention on the part of the mainstream. Māori want and need what Pākehā have to offer, but Pākehā can choose whether they will accept anything that Māori have to offer the system. In other words, the asymmetrical power relationships between Māori and Pākehā must be taken into account if policy and practice in Māori education is to make any substantial difference in the social relations represented in school practices such as school attendance, academic performance, participation in the life of the school and so on. Simon (1986) has already researched and written, what is undoubtedly the most lucid work, on the issues of ideology in the schooling of Māori children. I acknowledge her scholarship in this field.

To get a balanced view about cause and effect it is probably sensible to set out with relatively neutral premises like (a) Māori generally want as good an education as anybody else wants, and (b) the education system, through its teachers, would like to deliver to Māori students as good an education through schooling as they are capable of. The next step is to ask is how well do Māori students perform in the system and how does that compare with non-Māori? The fourth step relates to teachers and asks how successful they have been in delivering an education to Māori in comparison to non-Māori? If the answers to these first four steps throw 
up discrepancies in performance, two further enquiries would need to follow: (i) what it is that Māori want from the system, and (ii) what is the role the wider system plays in Māori educational performance.

Even a preliminary investigation of some of the critical literature in the narrow field of differential achievement in Māori education (Harker, 1978; Department of Education, National Advisory Committee on Māori Education, 1980; Nash, 1983) as well as the statistical data produced and disseminated annually by the Ministry of Education for example, Ngā Haeata Mātauranga, (2001) leave little doubt that simplistic, top-down, linear explanations for Māori under-achievement is a nonsense. Reductionist explanations like, it's because they're dumb or lazy or disorganised, or their culture doesn't value achievement' are at least as dismissive as other explanations like, 'it's because the teachers are racist, or the curriculum is not relevant, or assessment is biased, or the environment is culturally insensitive'. The educational field is as diverse and as complex as the multitude of peoples and influences within it. One would expect that analysis and explanation need to at least model that complexity.

This study has set out to find some of the truths underlying developments in Māori education, without compromising, as objective a scientific approach as practicable within the limits of the thesis. In brief, the thesis argues that the system is loaded against Māori from the outset. Even the Native/Māori School system which lasted for 102 years was really a system-in-transition, a place-holder until such time as Māori young people were seen to be sufficiently socialised into the Pākehā world to join the mainstream. With regard to the mainstream system it has always accepted Māori students and it has always treated Māori students paternalistically as capable of being as good as Pākehā. Achievements have usually been assessed and evaluated in comparative terms. For Māori, the message is, to achieve any comparability in any aspect of the education system, you are to set aside your 
Mãoritanga (qualities that distinguish you as a Māori) in favour of acquiring Pākehatangā (the qualities that will distinguish your socialisation into the world of the Pākehā). The politics behind this assertion are explained below under the subheading, two political philosophies and the philosophies as they pertain to education under the sub-heading, two epistemological traditions.

The chapter concludes with a brief discussion on Māori agency and relative autonomy. Much of what is contained in this chapter and the following two is a critique of the mainstream education system. The system is represented in a 'big brother' adversarial role manufactured out of consensus (that is, with both mainstream and Māori agreement). The consensus is seen (by mainstream) as being neither coercive nor oppositional to Māori but simply different. One is individualist-oriented, the other relational-oriented. There is no intention to coerce but the effect is the same. So long as Māori do not get to exercise their rangatiratanga and mana they see themselves caught up in the determinism of victim-hood and fatalism. The coercion, outlined in the section on the ideology of biased failure is meant to convey the message that coercion is a feature of structures not as a product of intentions, which only individuals can have.

The complexity of actors and influences is organised around what are being called in this study, mediating structures (Part II). The complexity inherent in methods of procedure, include the application of a sociological imagination (introduced in Chapter 1), socio-biographical data (especially Chapter 3 ) but also throughout each of the chapters, with the sub-heading, reflections on experience, and conventional approaches as found in hermeneutical analysis (Chapter 5), empirical field-work (Chapter 6), and archival documentation (Chapter 7). The concluding chapter to the thesis (Chapter 9) is an attempt to suggest a way ahead in developing a truly complex education system for Aotearoa New Zealand. Such a system will be based on equality as both a 'legal' and 'ethical' activity. It is a system premised on the 
acceptance of the need for all New Zealand citizens to be able to walk confidently and knowingly in at least the two cultures that are the founding cultures of this nation.

\subsection{Two political philosophies}

The sociologist Mills (1977:15) explains the idea of a political philosophy in terms of ideals by which we can make choices about positionality and directionality. In the context of this study political philosophy refers to a set of ideals or an ethic used to make judgements about people and activities as well as help articulate goals and guidelines for their aspirations and policies. More importantly a political philosophy

contains theories of man, society and history, or at least assumptions about how society is made up and how it works; about what are held to be its most important elements and how these elements are typically related; its major points of conflict and how these conflicts are resolved. It suggests the methods of study appropriate to its theories. From these theories and with these methods, expectations are derived (ibid)

Educationalists in the West have traditionally steered clear of notions of politics in education and never more so than in education systems that are centrally administered, organised and controlled such as exists in New Zealand. Educationalists like to think that what they do is culturally neutral, non-aligned politically, ahistorical, and atheoretical. The notion of a child-centred progressive education has been a central tenet of New Zealand educational practice since at least the 1940s. Even in today's world, the Education Review Office motto that appears on their literature is Ko te tamaiti te pütake o te kaupapa (The child - the heart of the matter). There is a sense that so long as the child has priority, the political world of adults will have to play a secondary role. Interestingly enough, even one of the founding fathers of progressive education, the American philosopher, Dewey (1938 cited in Bowen \& Hobson, 1974:208-13), wrote a 
chapter on progressive education in which he outlined his thinking on the topic of 'social control'.

\title{
Social control and cultural revitalisation
}

The comparative educationalist, Epstein (1978) tells us that within the social control thesis the basic proposition is the idea that,

\begin{abstract}
avowedly humanitarian and reformist action by elites is a disguised effort to protect its privileged position in the social structure against working class people, who are taught to ascribe their inferior status to their own lack of ability or desire to work hard (ibid. p.255).
\end{abstract}

Epstein's social class analysis easily translates in this context to the issue of cultural control. The distinction between social and cultural theories is often difficult to differentiate. I am using cultural almost as a synonym for social except that the former is a more limited version than the latter. Cultural control is a limited version of social control; within the social will be a variety of cultures only some of which might be under the influence of external controls as described in the context of education. What might be seen as external controls by some, others see as a necessity for civil life and a reality to be faced up to. For example, the Canadian educationalist, Friedenberg (1982:xx) argues in favour of the latter with his proclamation that:

Schools have no option but to bow to the particular culture from which they spring, to teach that culture's ideology through an efficient core curriculum, and at least to do it well, without pretending that it is anything but cultural hegemony that they serve.

From a Mãori perspective external control in Mãori education has a long history and most of it is viewed in a negative light. The definition of Māori education has seen several shifts over the period of a hundred years plus, from Māori education as the 'civilising' of the natives in the period 1816-1860; Māori education as the 'pacification' of the natives in the period 1860-1880; Māori education as 
'assimilation' in the period 1880-1930; Māori education as 'cultural adaptation' from 1930-1960; Māori education as 'integration' in the period 1960-1970; Māori education as 'taha Māori' and 'bilingual education' in the 1970-1980 period; Māori education as 'bilingual education' and 'kaupapa Māori' in the period 1980$1990^{1}$. Each of these periods is also marked with a shift in emphasis in the knowledge base taught in schools:

History captured in this linear fashion is a distortion of the reality of each period but such an arrangement does make it possible to see a shift in the nature of the influences. It was believed that Mãori would be civilised through the process of formal education and eventually assimilated into Pākehā society. As the British academic, Archer wrote, "Education is fundamentally about what people (those in power) have wanted of it and have been able to do to it" (1984, p.xx).

Table 2.1 History of socio-cultural control in Māori education 1816-1990.

\begin{tabular}{|l|l|l|}
\hline Period & Ideology & Knowledge emphasis \\
\hline $1816-1860$ & Civilising mission & $\begin{array}{l}\text { Literacy, biblical, religious conversion, } \\
\text { Māori reo }\end{array}$ \\
\hline $1860-1880$ & Pacification, formal schooling & $\begin{array}{l}\text { Knowledge as universal, secular, } \\
\text { scientific, move to English }\end{array}$ \\
\hline $1880-1930$ & Assimilation, universal schooling & $\begin{array}{l}\text { Agriculture, English increased, industrial, } \\
\text { formal, academic }\end{array}$ \\
\hline $1930-1960$ & Cultural adaptation & $\begin{array}{l}\text { Practical, functional (rural), local, manual } \\
\text { training, domestic science }\end{array}$ \\
\hline $1960-1970$ & Integration, Māori disadvantage & $\begin{array}{l}\text { Literacy, numeracy, English language } \\
\text { emphasis }\end{array}$ \\
\hline $1970-1980$ & Taha Māori, bilingual education & $\begin{array}{l}\text { Basic te reo for everybody, general } \\
\text { knowledge of mātauranga Māori }\end{array}$ \\
\hline $1980-1990$ & Bilingual education, kaupapa Māori & $\begin{array}{l}\text { Māori language for all; mātauranga Māori } \\
\text { for Māori }\end{array}$ \\
\hline
\end{tabular}

The New Zealand education system is no exception to this assertion even when the only system that existed was the missionary village schools for Mãori. The Education Act of 1877 set up the shape of the system, the way it was to be

\footnotetext{
${ }^{1}$ I have relied heavily on the published works of Barrington \& Beaglehole (1974), Simon (1998) and Simon \& Smith (2001) for this summary of the history of Māori education.
} 
financed, what was to be taught, and who was to control which aspects (Butchers, 1932:70-81; Campbell, 1941:45-49).

What the linear presentation also reveals (Table 2.1) is a gradual shift away from the forces for assimilation, a strengthening of Māori resolve to assert their culture, and an incorporation of the mainstream into the core of Māori culture. This shift has been described by some as the Māori renaissance (Webster, 1998), while I prefer to use the concept of 'revitalisation' which conveys a more focused and revolutionary transformation than does renaissance. The shift in emphasis in Māori education has occurred over a very short time-span (1980-90) even though the platform for change has built up steadily from the 1960s. According to the anthropologist, Wallace (1956:265), revitalisation implies:

\begin{abstract}
A deliberate, organised, conscious effort by members of a society to construct a more satisfying culture. Revitalisation is thus, from a cultural standpoint, a special kind of culture change phenomena: the persons involved in the process of revitalisation must perceive their culture, or some major areas of it, as a system (whether accurately or not); they must feel that this cultural system is unsatisfactory; and they must innovate not merely discrete items, but a new cultural system, specifying new relationships as well as, in some areas, new traits.
\end{abstract}

Not only has the kaupapa Māori ideology come about as a planned, organised and conscious attempt to provide an alternative to mainstream education (Smith, G.H. 1997), the years between the emergence of kura kaupapa Māori (1995) and 2000 has had a marked effect on developments in mainstream education, for example, as these pertain to Māori language provision, Māori-oriented approaches to governance of schools and Treaty of Waitangi education at tertiary levels to name just a few contemporary developments. These components of political philosophy have also been played out within the intersection of Māori and Western educational philosophies. These are discussed in the next section. 


\subsection{Two epistemological traditions}

The thesis is that education through the process of schooling can equip all students in New Zealand into at least two epistemological traditions, one with its roots historically embedded in the West and the other with its origins firmly established in the Pacific and Aotearoa. In Māori terms the shorthand labels for these two epistemological traditions are Pākehā education and Māori education, the first representing the early settlers from Britain and the second, the tangatawhenua/indigene of New Zealand. There is no assumption that these traditions should be treated as equal although it is understood that they could be, that they are inherently capable of being treated as equal. Built into this understanding is the reality of colonialism that advantaged Pākehā knowledge over Māori knowledge. This says nothing of the potential that Māori knowledge retains in terms of its capacity to be an advantage for all. To argue that all students in New Zealand schools can be given the opportunity to learn according to the tenets of at least two epistemological traditions does not necessarily imply that those traditions should be either Pākehā or Māori although one could hardly expect a New Zealand education system to not have its basis in at least one of either Māori or Pākehā traditions. These are the educational traditions that belong to New Zealand. Having an education system based on two epistemological traditions does not occur to me to be in the least bit exaggerated given the ethnic and cultural diversity of most modern states, appreciating the complexities of modern technologies, and accepting the democratic principle of being able to choose, which most New Zealanders demand as a right. It can be a matter of choice except that in a very limited case, as in the education of Māori, the choice does not exist. Most New Zealanders prefer to remain closeted in their English language, European philosophical traditions and customs rather than indulge too far into the intricacies of te ao Māori (the Māori world). Māori, on the other hand, must acquire a reasonable facility in most things deriving from te ao Pākehā (the Pākehā world) simply in order to move with some comfort in the everyday world of the New 
Zealander. Māori language became virtually moribund before it received anything like what was necessary for it to revitalise. I am reminded of the words I heard spoken at a conference by a very distinguished Indian linguistics scholar, Pattanayak (1983). He remarked:

\begin{abstract}
Where a dominant monolingual situation existed, two languages are considered a nuisance, three languages are considered uneconomic; and many languages are considered absurd. Countries where multi-lingual situations predominate, many languages are considered a fact of life, any restriction on the choice of language is considered a nuisance, while one language is considered uneconomic and absurd.
\end{abstract}

For more than a century of formal education, this has been the message to Māori from the dominant monolingual Pākehā society. Māori language revitalisation arising out of 1970s politics has been the thin edge of the wedge. If Māori language is resourced so that it can become a fully recognised and used language within New Zealand society, then other aspects of Māori culture will have a much better chance of surviving as well. But this is getting a bit ahead. The foundations for this cultural revitalisation came a little earlier.

\title{
Māoritanga model
}

In the mid-1970s and early 1980s the Department of Education ran 17 maraebased in-service courses on Education in a Multi-cultural Society (Department of Education, 1982). Those attending these hui (meetings) were made up of local marae members, inspectors of schools, principals of primary and secondary schools, numbers of administrators from various educational agencies, and several guest speakers. As a member of the Māori Advisory Services at the time I had the privilege of attending and at times contributing to some of these hui. At many of these hui, the Department used the services of a Tuhoe kaumātua (tribal elder), John Rangihau to talk about 'what it means to be a Māori', 'what it means to be Tuhoe', and 'what it means to be a citizen of Aotearoa New Zealand'. Rangihau was an eloquent speaker and orator in both English and Māori and he was an 
esteemed rangatira (leader) and kaumatua (elder). The purpose of his session, which often lasted for several hours, was to convey information about the complexity of te ao Māori (the Māori world). Rangihau's audiences, Māori and Pākehā, professional and lay, academic and vocational listened in awe and respect to the words of this tohunga (wise and knowledgeable person). Rangihau spoke to a conceptual model labelled Māoritanga (Fig. 2.1 at the end of this chapter). Concepts like aroha (respect), kawa (procedures), reo (language), kai (sustenance), manaakitanga (hospitality), wairua (spirituality) made up the content of his delivery as he defined each, related each to one another, spoke of personal experiences related to each, told a variety of stories related to each and generally outlined what can be referred to as a theory of Māoritanga. The structure of the model was a lineal design with arrows to show the connectedness and holistic nature of Māori thinking. At the four corners of the model was the concept Pākehatangā to signify, according to Rangihau, the comprehensive influence of Pākehā domination. In his terms, every part of Māoritanga has felt the impact of the dominant culture of the Pākehā. At one point I asked him why he spent all his time and energy talking about Māoritanga to mainly Pākehā audiences when nobody spoke about the comprehensive influence on Māori of Pākehātanga.

He agreed but said he did not think it was his place to do that. The problem, however, was that nobody thought it was their business to explain Pākehātanga. Perhaps this intervention, which is exactly what the Department of Education under the guidance of the highly respected Director of Māori and Island Education, Alan Smith was trying to do, that is, close the gap in ignorance between what the educational professionals know and do not know about te ao Mãori (the Mãori world). It assumes that when one group of people (Pākehā teachers for example) are better informed about another group of people (Māori for example) they are more likely to empathise with them and less likely to treat them as stereotypes. There are good reasons to suggest that the assumption stands up to empirical 
evidence. However, in educational circles the assumptions go a little further than simply empathy. It is assumed that when teachers (or policy makers, administrators, and managers) are exposed to the intricacies of Māoritanga, for example, they will be better informed about Māori students and their cultural backgrounds and as a consequence better able to teach them. The justification for this leap of faith is a little more spurious. To know something about the significance of te reo Māori to Māori people, tells us nothing about why it is in a threatened state, how it helps the student to learn at school, or why the teacher might want to encourage its use within the classroom. Ignorance was supported to a considerable degree because a cognitive 'gap' existed which made it easier for Pākehā to take for granted the context within which, in Pākehā hands, Māoritanga is both diminished and expanded; who is in charge, who has the power, and who is in control? Māori are indeed, members of an honourable and proud culture 'so long as they know their place within society'. Nobody ever says this but on the grounds of Pākehā being a dominant majority, this is the silent message that reverberates into every corner of society and into every aspect of everyday life. It is this aspect of not having to say those words that must be explored further but before we do, it is important to recognise that Rangihau's theory of Māoritanga is only one of several attempts by Māori scholars to represent a holistic Māori philosophy of education (Pere, 1985; Reedy \& Reedy, 1993; Marsden \& Henare, 1992; Te Rūnanga-nui o Ngā Kura Kaupapa Māori o Aotearoa, 1998).

Whether we are referring to the Māoritanga theory, Te Wheke², Te Whāriki, Kaitiakitanga or Te Aho Matua some things remain consistent. The world is considered value-bound (aroha, manaakitanga) we learn those values from the social world (whanaungatanga, tangihanga), we internalise them and they become part of us (whakapapa, reo). They cannot be set aside (mana, tapu). We come to know the social world as being essentially relativist and where multiple realities are the norm. Everyone has his/her own story to tell and variation is the reality

\footnotetext{
${ }^{2}$ See Pere (1999) 'Te reo me ōna tikanga' which is a kaupapa for Mãori language and practice.
} 
(tikanga). What counts as truth is dependent on an analysis of the text and the context of the narrative. A person's political identity is based on the premise that one's rights are equal to one's obligations (te mauritanga) whereas one's economic identity is bound up in the premise that giving is equal to receiving ${ }^{3}$ (koha, ohaoha). The holistic approach means that Māori culture is heavily oriented toward wanting to put things together, it is intolerant of disconnecting and atomising things within the social and natural worlds.

Despite approximately 200 years of the colonial experience, Mãori society remains, extraordinary as it seems, basically collectivistic and tribal-oriented in the midst of a twenty-first century, highly developed capitalist society. Two cultural elements could be seen to account for this phenomenon. The first is tūrangawaewae (a place where one can stand; a sense of belonging) and the second is the marae, the ancient institution brought by Māori from Hawaiki to these shores. So long as one has tūrangawaewae one has an attachment to the land (whenua) and so long as one has attachment to whenua one has mana (power and authority). And so long as one has a marae there will be kawa (sets of procedures for different activities) where the institution of hui (gatherings of all description) and celebration through kai (the partaking of food) and on special occasions, hakari (ritual feasting) will take place. The continuity of Māoritanga is ensured with these two phenomena because the life force (mauri) is intact and the soul or spirit (wairua) ensures that the connections (iho-matua) are firmly in place.

We can see that in terms of defining Māori education the Māoritanga theory of the 1970s played a critical role in preparing the ground for the radical progress that came with Te Kohanga Reo in 1982 and Kura Kaupapa Māori in 1985. It should be obvious that what is described in the above two paragraphs, is an analysis of the philosophical implications of the Māoritanga theory. The policies and practices pertaining to Māoritanga envisaged by mainstream professionals (eg. Taha Māori)

\footnotetext{
${ }^{3}$ I am grateful to Paul Green of Massey University for this insight as part of a lecture on 'the sacred and the secular' (1978).
} 
was always going to be some distance, cognitively, and practically from where most Māori would like and/or expect them to be.

\section{Liberal education model}

We turn now to a discussion of the Western epistemological tradition. The theory that most epitomises the Western tradition in education, is liberal theory. Much has been written on this topic both for and against. Dewey (1966) Where he is probably the father of liberalism in education, Strike $(1982,1989)$ is a contemporary educational and social justice advocate. Some of the critiques of liberalism captured international attention: Bowles and Gintis (1977) attacked liberalism from a political economy approach; radical historians like the American Karier (1976) saw the way in which education was basically about control rather than about progress; and the English educational historian Green (1990) examines, among other things, the relationship between liberal educational theory, state formation, and how these account for uneven educational development. I will focus firstly on Karier (1976) because of the social control argument he elaborates and then on Strike $(1982,1989)$ for the social justice orientation running through his works but before we do, a brief overview of liberal theory will be in order.

I will argue in this chapter that liberal education, despite the rhetoric of intent espoused by elites, is really a disguised effort to protect the privileged position liberalism holds in the social structure of this country. Māori (probably other ethnic minorities, and working class people as well) learn to think of themselves as being less capable and less motivated to succeed and that they have themselves to blame for it. The role that schools play in this form of social control is well documented in the work of the 'new sociology of education' international scholars, who were especially active in the 1970s (Bowles \& Gintis, 1977; Carnoy, 1974; Flude \& Ahier, 1976; Freire, 1977; Young, 1975). New Zealand educational sociologists were also very active throughout this period and I will discuss those 
works later.

For the purposes of this study, liberal theory can be characterised under four criteria: it favours evolutionary change through principles of gradualism, it is content to use education as a vehicle for proselytisation, it is secular oriented, and it prioritises nurture over nature which allows the principle of universal educability to be pursued.

Karier (1976) draws an important distinction between the nineteenth-century classical liberalism of J.S.Mill and the philosopher of twentieth-century liberalism, John Dewey. He was aware that both shared the principle that an enlightened society had to strive to achieve "the greater happiness of the greater number" (ibid. p.91) but there was disagreement about how this might be accomplished. Mill had a distrust of state power and as far as he was concerned the less government interference, the greater freedom for individuals with its philosophic justification for a competitive economy, private property and individualism. Dewey on the other hand saw individual freedom tied to a positive use of state power with its philosophic justification for a controlled economy, state planning and managed change. At the heart of Dewey's liberal educational philosophy is a strong 'social control' thesis that Karier identifies in Dewey's work and portrays in a summary of seven statements. I have selected some corresponding passages from the history of Māori education to show something of the parallel thinking that was going on in New Zealand education over a similar time span (see Table 2.1 earlier in this chapter).

We turn now to the American educational philosopher, Strike (1989) to explicate the relationship between liberal and social justice theory. He tells us that all societies have three issues to address in education. The first of these is to do with the sort of people it wants to produce. In the liberal view of education these people 
are described by Strike (ibid. p.30) as being autonomous and rational agents. The second issue the society must address is the role education will play in maintaining or altering the institutions of society. In line with his liberal theory of justice approach he argues that individuals will tend to support those institutions that treat them fairly. The role education will play in the distribution of the goods and services produced by the society is the third issue to be addressed. The liberal view of education is concerned with how, what is considered relevant and important for society, is fairly distributed. The meanings underlying the key concepts of autonomy, rationality and self-respect form a set of moral imperatives for liberal theory. Strike argues that rationality "is the capacity to choose and act on the basis of a warranted appraisal of relevant evidence" (p. 40). Māori have struggled for generations to succeed in the education system but in general terms, have not succeeded. Since 1982 and the beginnings of kohanga reo Māori have moved along a path which is creating a parallel system based on kaupapa Māori (a Māori philosophical and practice base). In Strike's terms, Māori are acting rationally.

Table 2.2 Liberal education and the social control thesis with relevance to Mãori education.

\begin{tabular}{|l|l|}
\hline $\begin{array}{l}\text { DEWEY'S LIBERAL EDUCATION } \\
\text { 'SOCIAL CONTROL' THESIS (following } \\
\text { Strike, 1989) }\end{array}$ & $\begin{array}{l}\text { THE 'SOCIAL CONTROL' THESIS IN } \\
\text { THE HISTORY OF MĀORI EDUCATION }\end{array}$ \\
\hline $\begin{array}{l}\text {-the individual would be 'scientifically' shaped } \\
\text { and controlled so as to fulfill the nation's } \\
\text { destiny (p. 91); }\end{array}$ & $\begin{array}{l}\text { The core of Māori educational policy in the } \\
\text { 1930's may be found in T.B.Strong's statement } \\
\text { that the type of schooling made available to } \\
\text { Māori children should lead the 'lad to be a good } \\
\text { farmer, and the Māori girl to be a good farmer's } \\
\text { wife'. During the 1940's this emphasis changed } \\
\text { to trade training for the boys; an emphasis that } \\
\text { lingered well into the '60s. (Harker in Codd et } \\
\text { al., 1990:33). }\end{array}$ \\
\hline $\begin{array}{l}\text { - a key concern for more effective and efficient } \\
\text { means of social control in order to eliminate } \\
\text { conflict and to establish the harmonious organic } \\
\text { community (p. 91); }\end{array}$ & $\begin{array}{l}\text { The system has worked well and has contributed } \\
\text { so much to the progress of the race that the } \\
\text { Māori people themselves have become proud of } \\
\text { their schools. But it is obvious that Māori } \\
\text { schools must be eventually absorbed into the } \\
\text { general system...It is possible to foresee the } \\
\text { time when the Māori will be on absolutely equal } \\
\text { terms with the European, receiving no special } \\
\text { treatment and requiring none. (Barrington \& } \\
\text { Beaglehole, 1974:250, quoting Beeby). }\end{array}$ \\
\hline
\end{tabular}




\begin{tabular}{|c|c|}
\hline $\begin{array}{l}\text { - ethnic and religious differences viewed as a } \\
\text { threat to the survival of the society and had to } \\
\text { be overcome through assimilation (p. 93); }\end{array}$ & $\begin{array}{l}\text { Steadily penetrating the fastnesses of Māoridom } \\
\text { the Native school teachers and their wives were } \\
\text { sent out as missionaries of a new social } \\
\text { order...In the school they were to be prepared } \\
\text { for successful contact with the foreign social } \\
\text { organization which was clearly destined in a } \\
\text { very large measure, if not wholly, to supplant } \\
\text { their own (Butcher, 1932:87). }\end{array}$ \\
\hline $\begin{array}{l}\text { - freedom meant rational control over future } \\
\text { possibilities - 'Control is the crux of our } \\
\text { freedom' (p. 94); }\end{array}$ & $\begin{array}{l}\text { When the National Advisory Committee on } \\
\text { Mãori Education met in } 1956 \text { there were five } \\
\text { Māori representatives and seven Pākehā...An } \\
\text { examination of the recommendations relating to } \\
\text { the handing over of the Māori Schools to the } \\
\text { education boards indicate that the Māori } \\
\text { representatives themselves were unaware of the } \\
\text { biases which shaped the negotiation process. } \\
\text { (Simon \& Smith, 2001:268) }\end{array}$ \\
\hline $\begin{array}{l}\text { - he favoured the idea that called for elites to } \\
\text { plan the new social order (p. 95); }\end{array}$ & $\begin{array}{l}\text { In the } 1930 \text { s...the assimilation policy was } \\
\text { replaced with a policy of 'cultural adaptation'. } \\
\text { Under this policy 'the best of Māori heritage } \\
\text { and custom' was to be incorporated into the } \\
\text { curriculum. It is important to note that it was the } \\
\text { Department of Education that decided what } \\
\text { represented 'the best of Māori heritage and } \\
\text { custom'. (Simon et al, 1998:73). }\end{array}$ \\
\hline $\begin{array}{l}\text { - the new social order will be planned by an } \\
\text { ideology-free social scientist (p. 95); }\end{array}$ & $\begin{array}{l}\text { The Treaty of Waitangi should be seen as a } \\
\text { basic document which is used to scan our } \\
\text { democratic procedures in the light of a } \\
\text { particular kind of equality - the equality of two } \\
\text { peoples who entered into a partnership in } 1840 \text {, } \\
\text { when the population ratio was very different } \\
\text { from now (100:1 in favour of Māori), and which } \\
\text { no one who genuinely believes in democracy } \\
\text { should now reinterpret in favour of the group } \\
\text { which has increased in number and advanced in } \\
\text { economic power. This must be what is meant by } \\
\text { bi-culturalism in Aotearoa-New Zealand. } \\
\text { (Snook, 1995:7). }\end{array}$ \\
\hline $\begin{array}{l}\text { - despite the equalitarian rhetoric, educational } \\
\text { liberals most often, in practice, supported an } \\
\text { education directed from the top down. } \\
\text { 'Enlightenment', for most, implied education } \\
\text { for social control (p. 95). }\end{array}$ & $\begin{array}{l}\text { I had the bright idea of putting secondary 'tops' } \\
\text { on three native schools....Apirana Ngata, for } \\
\text { reasons that I could not understand at the time } \\
\text { but can appreciate now, held himself aloof from } \\
\text { the project. I began to realize that I had } \\
\text { approached them in the European way- } \\
\text { presenting a ready-made scheme, supporting it } \\
\text { with the authority of my position and being } \\
\text { satisfied with something that looked like } \\
\text { majority approval. I hadn't allowed time for } \\
\text { them to work on the idea in their own way... } \\
\text { (Beeby, 1992:209-10). }\end{array}$ \\
\hline
\end{tabular}


Again, according to Strike (ibid. p.41), "one is autonomous when one's choices are not dictated or determined by external happenings, but are made according to one's own standards of judgement". The umbrella organisation of KKM (Te Rūnanga-nui o ngā Kura Kaupapa Māori o Aotearoa) moved to have their educational philosophy (Te Aho Matua) included in the Education Act 1989 because they had no control (they did not have autonomy) over which existing schools could be redesignated by the Ministry of Education as KKM, thus making it possible for their special character to be diminished and not being able to take action against it.

Self-respect as a moral imperative, "is an aspect of equal respect - it is the psychological requirement of an individual's capacity to secure his or her own rights and to respect those of others" (Strike, 1989:42). In Māori terms the self has a communitarian character that is not adequately embodied in psychological analysis. A Canadian law scholar (Johnston, 1989:22-23) writes about the notion of 'self-collection':

\begin{abstract}
In contrast to aggregates, collectivities are 'self-collecting' in the sense that the members engage in rule-following activity of a sort that constitutes the collectivity. The notion of 'self-collection' is intended as an analogue to 'self-reflection'. If self-reflection is basic to individual identity, self-collection is basic to collective identity.
\end{abstract}

There is a clear resonance between the notion of self-collection and the Māori concept of 'tuakiri' or identity. Mead (2003:273) defines tuakiri as follows: tua means on the farther side of something while kiri means skin, therefore, tuakiri

probably refers to the elements away from the body that help define the identity and personality of a person. That far side is probably the land, the mountains, rivers, lakes, the ocean front, the islands and the sea, all of which ground a personality to a place.

Following Strike's argument, the liberal view of Māori education would ask the question, 'If justice is to prevail in the education of Māori, what is it that needs to 
be distributed and how should that distribution be effected?' The application of liberal educational theory is not enough in itself to be able to answer the question.

\subsection{Native Schools as transition}

As indicated earlier, the Native Schools Act of 1867 established the Native and later Mãori schools system. According to Simon (1992:38), "it was intended that each Native School would be integrated into the public schools system as soon as the children in it were "Europeanised". Such a view about the transitory nature of Native Schools followed from the practice of not restricting the enrolment of Māori or Pākehā children on racial grounds from entering either system. The practice continued for the following 100 years but eventually numbers in the Māori Schools diminished and in 1969 Māori Schools shifted under Education Board control. By that time the idea of 'Europeanisation' was no longer a reason for closure but there can be no argument that the effect was true even though the rationale had shifted to expediency, efficiency, effectiveness, and improved education resourcing.

The increased visibility of Māori in mainstream education after 1969 did not have any ubiquitous effect on the system but there were some 'rumblings' and some of those rumblings can be attributed to the fact that "the Māori Schools are now gone, our land has gone, our language is dying, and the mana of the people is at a low ebb" ${ }^{\text {. }}$. The Department of Education/NACME (1970) produced an important report that made Māori language policy and implementation a central focus in Māori education that has remained through to 2000 .

Not for the first time but with ever increasing persistence Māori are insisting that the education system will deliver an education for Māori and not just about Māori. And within the education for Māori will be an education in Māori, that is, where the resources, the methodologies, and the delivery will be in the medium of Mãori.

\footnotetext{
${ }^{4}$ See Sharp (1997) especially chapter 1, pp. 3-12.
} 
In a report written for The Royal Commission on Social Policy, Penetito (1988:103-108) outlined, as sources of demand in education, what would count as educations in, about and for Māori. His conclusion, as it relates to the education system, is summarised as two inter-related concerns:

1. "how to facilitate Māori communities taking education decisions in their own best interests; and

2. the need to clarify the essence of an education which makes valid tangatawhenua knowledge, values and institutions in such ways that these become a central part of what it means to be educated in Aotearoa New Zealand" (Penetito, 1988:112).

Since the period of the Native/Māori Schools these two concerns have remained high on the Māori education agenda.

I have argued in this chapter that the social control thesis along with liberal education plays an integral role in shaping and transforming the nature of Maori society to fit that of the dominant Pākehā society. There is no suggestion that agency is neglected, only that the consequences remain consistent with transformation. One of the major ways it accomplishes that transformation is through the ideology of what has come to be called Māori education. To a considerable extent, and within the context of schooling (1867-2000), Māori have made huge gains in terms of enhancing their individual and collective cultural capital. One would be churlish to deny such enhancement. However, one would also need to be ignorant to deny that through processes of schooling Māori have also lost much of their valued traditions and customs (cultural capital) to the degree that in recent times Māori have been exploring the possibility of establishing an alternative system of education ${ }^{5}$ based on principles and practices

\footnotetext{
${ }^{5}$ Benton (1988) The Matawaia Declaration called for the establishment of an independent Māori education authority as a fully funded statutory authority. It was envisaged that the authority would
} 
which derive from a Maori world view or kaupapa Maori because they have, on the whole, been unable achieve the education they believe they are entitled to within existing philosophies, policies and practices.

\subsection{Systemic contributions to Mãori education pathology}

The thesis applies a sociological imagination to the study of the relationship between two educations in New Zealand, mainstream and Māori. It is difficult to avoid arguing a case in Māori education without reverting to what Bourdieu refers to as "those pairs of opposites beloved of scholastic thought" (2000:232) and yet Māori education as it has existed in New Zealand for more than a century is a product of mainstream education in a way that mainstream education has never envisaged being a part of Māori education. Some might argue with that assertion but this thesis will demonstrate how accurate that statement is. It is argued that mainstream education operates in the interests of the majority of the population whose cultural origins are mainly out of Britain and the Western world. These interests represent a political monopolisation of the educational agenda and have had a profoundly distorting effect on the cultural, educational and economic development within Māori society. The cost to Māori has been what the famous nineteenth century Black American scholar Du Bois called, "doubleconsciousness, a lack of true self-consciousness (that) only lets him see himself through the revelation of the other world" (Harris, 1995:2). The Māori education system of pre-European Aotearoa was a tribal system. In today's world the Māori education system is more akin to a virtual system.

The response of a significant proportion of the Māori population to the objectifying tendencies of the mainstream system has been to explore the possibility of establishing an alternative system of education based on

establish an alternative education system from pre-school to adult education based on kaupapa Māori principles. 
philosophies, principles and practices which derive from a Māori ideological position or kaupapa Māori. It is argued that the mainstream system has never offered or delivered an education that operates primarily in the interests of Māori, nor is it expected that it would. Mãori are, in relative terms, a disempowered minority group within a society structured in dominance. It is argued that the mainstream system cannot continue to offer piecemeal solutions to Māori educational disadvantage on the one hand, and on the other, prevent, discourage or even discriminate against Mãori acting to provide solutions to their own perceptions of what an education in their own interests might look like. Such opposition would be discriminatory, un-fair and un-democratic.

Governments in recent years have been following, and indeed promoting the principle of consumer choice defined simply as, 'voting with one's feet'. The principle is usually applied as justification, for example, for parents selecting the sort of school they want to send their children to. There is a growing proportion of Māori parents who are wanting to exercise their consumer choice in terms of the sort of education system they want for their children. The Waitangi Tribunal Finding Relating to Te Reo Mãori (1986:46) provides the sort of rationale behind this parental choice:

\footnotetext{
Judged by the system's own standards Mãori children are not being successfully taught, and for this reason alone, quite apart from the duty to protect the Māori language, the education system is being operated in breach of the Treaty.
}

Documentation of the system's failure to educate Māori is not simply a matter which can be laid to rest on teachers as the Waitangi Tribunal quite rightly pointed out. Evidence will show that systemic failure is comprehensive but the evidence does not seem to be sufficient in itself to persuade those who have the authority to make the changes to do something about it. After more than one hundred and thirty years of a state controlled, organised, operated, and managed education system the majority of Māori students continue to leave schools without receiving a basic 
education. On these grounds alone the system can be seen as a system geared for failure yet it continues to operate as though the main fault lies elsewhere, for example, among the Māori constituent. On these additional grounds there is a biased failure in the system and its continuation over time would suggest that the selective failure must be serving some interest.

What has the education system done to address the educational and cultural concerns of the Māori population over time? The answer is a great deal. The question then is, do the policies and practices advocated and implemented in the interests of Māori share some features in common, for example, what was the basis for the policies and practices? What role did Māori have in the decisions? Were the policies and practices fully implemented? Were those who were meant to carry out the practices capable of successfully implementing them? Were there sufficient resources to enable people to feel confident about what they were doing?

Many Māori parents are convinced that the education system, after such a long period of formal schooling, cannot provide the sort of education that they believe they are entitled to for their young people. The existing system is based around a regulatory framework which at best maintains Māori communities at the margins of society, and at worst converts Māori individuals into brown-skin Pākehā. Statistics like those in the following table can, and have been reproduced in a number of Māori education reports over generations, and show few signs of abating:

Table 2.3: Comparison of Māori and non-Māori Performance on four indicators

(Ministry of Education, July 2000)

\begin{tabular}{|l|c|c|}
\hline & Māori & Non-Māori \\
\hline 4 year old participation in ECE & $68 \%$ & $98 \%$ \\
\hline $\begin{array}{l}\text { Unspecified suspensions for males from school } \\
\text { (1998) - rate per 1,000 }\end{array}$ & 20.6 & 5.4 \\
\hline $\begin{array}{l}\text { Average mathematics score of standard 3 (year 5) } \\
\text { students (TIMMS Study, 1994) }\end{array}$ & 462 & 520 \\
\hline $\begin{array}{l}\% \text { of students leaving school without formal } \\
\text { qualifications (1998) }\end{array}$ & $38 \%$ & $12 \%$ \\
\hline
\end{tabular}


In spite of this statistical evidence, there remains a stubborn and at times petulant resistance to the idea that the system might indeed be wrong for Māori and that no amount of piecemeal intervention or 'tweaking' as the bureaucrats like to say will make the sort of difference that is spelled out in Māori aspirations. Māori scholars and professionals who know about schools, education, and the system do not support research conclusions like that of Chapple et al (1997) in spite of its scientific justification and scholarly origins. It is argued that either the science applied is misguided or the supporting arguments are flawed, or both. Chapple's conclusion on his review of the research literature asserts,

\section{There is no evidence.... to suggest that Māori children do badly at schools because their lived culture does not fit into, or is opposed to, the existing school system or of problems of cultural congruence.}

Chapple et al, 1997:99

The experience of a majority of Māori parents is that there is a direct relation between the lived culture of Māori children and a school culture that in some instances contains basic contradictions of Mãori culture. There is no 'valid' evidence for this conclusion because the only evidence that is made to count is 'research' evidence and the power brokers, so it seems, do not see the need for research which calls into question the validity and reliability of the system and its schools for Māori let alone any other disenfranchised groups. The education system, and by necessary association, the government of the day seem to find it preferable to pay out millions of dollars each year (according to the Ministry of Education's own estimates (1997:10), about $\$ 1$ billion from a total budget of approximately $\$ 6$ billion in 1997) to maintain the status quo in Māori education than solve the 'real' problem. What is the real problem? If we could answer these three questions we would be well on the way to answering the two concerns from Penetito (1988) referred to above. 
1. How is it that the same groups of people who uphold the values of freedom, justice through fairness, the right to speak and be heard, the wisdom to be gained through education, deliberately withhold the values that others hold dear? Pākehā have been doing such things to Māori for generations and continue to do so?

2. What is required for an education in New Zealand to be truly educative for all groups within the society and how can this be affected without penalising any group?

3. What are the 'ways of knowing' and validating Māori knowledge within the education system?

These are some of the questions resting uneasily below the surface of this study and are explored in some detail in the chapters indicated. Most of these questions will be viewed by those in positions of influence in education in a negative light, even if sympathetically, and as a result not given the attention required. That is unfortunate but the problems will persist until such time as due regard is given to the contribution Māori will make to this society and the world at large.

\section{The ideology of 'biased failure ${ }^{96}$}

Up to this point we have seen how the education system has generally failed to reduce Māori academic under-achievement and that this failure is, to a considerable degree, preventable. Even when Māori have recommended remedies to this problem (introduction of Māori language, closer relationships between schools and marae, formalised accountability between schools and hapū, increases in the input of Māori knowledge and custom into the everyday life of schools, and a more practically-oriented education utilising community expertise) the system has continually set out to address the problem of disparity between Māori and nonMāori academic performance rather than explain the marginalisation of Māori knowledge, history and custom within the system. What has been most damaging

\footnotetext{
${ }^{6}$ The analysis for this section borrows liberally from a parallel argument on who and what is served by the criminal justice system in America by Reiman. (1979) especially Ch.4.
} 
to Māori as a people has been the way in which the system's interpretation of the problem has not only worked to the advantage of mainstream but has actually contributed to the general public, viewing Māori education as a problem area, and Māori blaming themselves for their under-achievement, lack of motivation, absence of drive to achieve, and general deficiency in applicability and resilience. The advantages to mainstream lie in the ideological message conveyed by the education system's biased failure.

Some use ideology as though it meant 'world-view' (Royal, 2001), while others speak about it in terms of 'value-system'. The concept has a long pedigree dating back as far as 1796 (Williams, 1985:154) but made famous by Marx and Engels in The German ideology (1845-7). It is commonly used in two distinctive ways: "Sensible people rely on experience, or have a philosophy; silly people rely on ideology" (Williams, 1985:157). The latter is the pejorative sense and it is this interpretation that has most significance for my argument. This is not to say my preference is either silly or accepted uncritically. I have found the French Marxist scholar, Louis Althusser's four critiques of the way ideology has been used in theoretical debates (cited in Hirst, 1979:22-39) most useful for my purposes:

- ideology is not a distorted representation of reality, that is, of the real world;

- ideology is not ideal or spiritual - ideas are real and not 'ideal' because they are always inscribed in social practices and are expressed in objective social forms (language, ritual etc.);

- ideology has no history - the subject is related to the totality through an 'imaginary' relation (emphasis in original); and

- ideology is not false consciousness - it is not a representation of reality.

Given these provisos I think the definition of ideology from Reiman (1979:159) sits comfortably with my interpretation of the relationship between Māori 
education and the mainstream system.

When I speak of ideology, I mean the conscious or unconscious use of ideas (or images or other 'messages'), not for the purpose of conveying the truth, but falsely to justify (or legitimate) the prevailing distribution of power and wealth and thus to secure allegiances to (or undermine opposition to) the social order characterised by that distribution of power and wealth.

The argument for the success of biased failure can be summarised in four interrelated propositions:

1. Our education system has persistently failed a disproportionate number of Māori children to the extent that it can be considered (at least by Māori) to be a system 'designed for failure';

2. Those who are most vulnerable to educational failure are also those who are not in positions to make and implement change;

3. Those with the power to make the necessary changes in the system have not been persuaded to do any more than make minor piecemeal adjustments in order to maintain the illusion of transformation;

4. The ideological message made by the education system's biased failure is two-pronged:

(i) By focusing on the individual failure of Māori children, the education system diverts attention away from the contradictions and injustices of our social and economic institutions and most importantly, from itself; and

(ii) By focusing on the poor who fail, the education system diverts attention away from the middle-classes who most profit from our social, economic and educational institutions.

How is this abstract and theoretical argument interpreted in practice? 


\subsection{Education or socialisation - Reflection on experience}

It is unfortunate that in New Zealand we have an education which is commonly thought of as the norm, as what is provided through schooling for the mainstream population, and then we have Māori education which is either the term given for the schooling of Māori youngsters or else the knowledge and practices that derive from the Māori world that are made available for all children. It is unfortunate because, as I will argue, for any child to be educated in Aotearoa New Zealand, it should be required that $\mathrm{s} / \mathrm{he}$ is exposed to sufficient quantities and qualities of the two epistemological traditions to feel a real sense of belonging to the land as a New Zealander. It should not matter to the child whether its ethnic origins are found in England, China, Tokelau, or South Africa. As New Zealand citizens they will learn among much else in their lives what counts as knowledge from the West and what counts as knowledge from Māori perspectives.

When I trained to teach 40 years ago it was clear to me that I was prepared to go anywhere and to teach any child. My training as a primary school teacher equipped me to teach any primary school-age child in New Zealand and in most other Commonwealth countries. As it turned out, apart from one year in Essex, England as an Exchange Teacher all my teaching practice took place in this country. It is only on reflection that I realise that all the schools I taught in were significantly Māori in school population terms. The one school I chose to teach in because it was designated a Māori School was motivated by at least four factors that weighed heavily on me at the time: I had been teaching for seven and a half years in rural and urban schools and needed the challenge of running a school as its headmaster and being obliged to work with its community; I needed to get out of the city with my wife and daughter so that we could raise a family in a predominantly Māori environment; we needed to be able to live where we thought we could save money and travel (my wife is a Scot and had lived and trained in Edinburgh and all her family were in Scotland); and I desperately wanted my family to spend their early 
years close to Māori people where they could learn to relate to and develop sensitive understandings to the Māori world. I knew the pressures for familiarity with the Pākehā world would not hold the same difficulties for them were they to wait a few years until we moved back to urban settings and the different advantages that that brings. It is relatively easy for a Māori to fit into the Pākehā world because, paradoxically, most things in society are positioned to assist that transition. So why is there a problem with education? The prevailing belief among Pākehā is that deep down Māori really want to be like Pākehā. It is far more difficult choosing to be Māori even when you are Māori, but if you do not look as though you are Māori, for example, if you have fair skin, then choosing to be Māori has to be deliberately demonstrated publicly. So I had some very good reasons for choosing my first school that was significantly Māori.

Teaching Māori children in the urban metropolitan environment, like teaching most children in that environment was an extremely challenging task. I wanted to know why it was that children in my classes who came from Samoa or from the Cook Islands quite often performed better academically than Māori children in the same classes yet some of the Pacific children had parents who could hardly speak any English and the children were sometimes no more advanced linguistically than their parents in using everyday English. I wanted to know why Pacific parents always outnumbered Māori parents on official parents' evenings. The number of Māori students who were behaviour problems in and outside the classroom was completely frustrating; the most common problems being over-aggressiveness, swearing, challenging authority, or chronic withdrawal. I wanted to know what was behind these behaviours. My fear at the time was that there might be some inherent flaw in Mãori cultural development that left scars on the Māori psyche. I needed a rural community and I wanted a traditional Māori community where I could rejuvenate my own cultural batteries and where I had the time and the opportunity to explore some of the answers to these troubling questions. 
The school my wife and I chose and taught in for eight years was a Māori School that was originally established as a Native School in 1884. It served a traditional Māori community in the sense that it was located on a papakainga (kin-based land holding) with the whānau (families) situated around a marae (traditional gathering place), and where the residents were, apart from those who had married into the community, of the same hapu (sub-tribe) affiliation. Most of the members of the community belonged to the Ringatu religion (transformed Christian) and was practiced diligently by most of the community. Most of the adults had some facility in the Māori language although conversations with children were almost exclusively in English. Many of the kaumātua were bemused by our attempts as teachers to try and resurrect the use of te reo Māori (Māori language) among the children in the school by using the language in classes. "When we were at school the teacher used to growl us if we spoke our language and sometimes we even got strapped if we kōrero Māori, and now you want to teach our moko and our tamariki to kōrero Māori. But what if you teachers change your minds again? Koina te mate o te küware; kaore e mohio he aha te aha?" (That's the trouble when you don't know things; you don't know what's what). I did not have a satisfactory answer for the kaumātua then and the proper reply still eludes me. I am sure they were talking about us, the teachers, the inspectors, the policy makers, the government. Of course they were right and we knew it but being young teachers we were imbued with the same sort of zeal that the early missionaries must have brought to these communities. We wanted these children to know about their tribal history and the stories related to their marae. We thought the history of the Ringatu Church and its association with Te Kooti was particularly important and that these children had a right to that history. The more we learned about these people the more we wanted their children to know about themselves and their heritage. We knew that large sections of the tribal estate were confiscated by a nineteenth century racist government keen to confiscate Māori lands to appease 
land hungry settlers and we thought this was a history at least as important as knowing 'how the Māoris used to live before the whiteman came'. Our reading of the school logs revealed an intimate connection with another folk hero and villain to the Pākehā, Rua-the-Prophet was the name he was widely known by. We learned that he had several followers from this marae who lived with him in Maungapohatu. At the time we lived in the community, many decades after Rua's Maungapohatu was no longer, one of Rua's disciples, a tohunga returned home to his marae to die now that he was a very old man well into his nineties. We wanted the children of the school to know about the old man and about Rua. Fortunately, the school already ran a highly successful kapa haka (performing arts) programme and had done so for several years. What the programme lacked, unfortunately was an understanding of the waiata (song poetry), karakia (incantations) and haka (posture dances) that the children were intensively involved in learning. They could recite the words perfectly and produce the appropriate actions but $95 \%$ of them did not really understand what they were saying. They learned by rote and their tutor seemed content to leave it like that and nor did she appreciate anyone, including the teacher, trying to teach kapa haka any other way than what she had done for several years, successfully too, if one thinks about the enthusiasm engendered, the passion arising from the community every time the school kapa haka group was called on to perform, not to mention the awards the group won in inter-school competitions from time to time. I did not know the saying at the time but the adage that became very popular among those resistant to change during the educational reforms of the late $1980 \mathrm{~s}$, 'why fix it if it isn't broken' certainly seemed to apply to our school kapa haka group at that time. The years were 1967 to 1975 and they marked for me a conscious and deliberate beginning to a formalised enquiry into what Māori education was and what it could become. This same period was critical in that it established a foundation or a framework for the emergence of the most dynamic era in the development of Māori education as an entity in its own right; where Māori education was not only about what was to 
count as Māori but also what was to count as education. This study is a product of that enquiry.

It is considered bad manners among Māori to ask the question 'Ko wai koe-who are you?' 'It is suggested the association with the lack of manners comes from the idea that the basis of the question is more about 'putting a person in her place', that is, 'who do you think you are?' rather than an enquiry about identification. Ko wai koe is likely to invoke an irritated or even an angry response from Māori. 'He aha koe-what are you?' does not even count as a real question because he aha (what) is reserved for objects other than humans. It will be argued, 'he aha koe?' is the tacit question that is behind the current Māori struggle for an education in their own best interests. What we are as Mãori, in a very precise moment of history and the strategies employed by Māori to resist, what Foucault (1982:777) calls 'modes of objectification', is an important component of this study. This is the problem this thesis sets out to address - how does the mainstream education system through the processes of formal schooling transform Māori students into subjects? Foucault argues (ibid. p.781) that there are two meanings of the word subject: subject to someone else by control and dependence; and tied to his (sic) own identity by a conscience or self-knowledge. Both meanings, according to Foucault, suggest a form of power that subjugates and makes subject to. Both of these meanings are located in the practices found in mainstream and in kaupapa Māori education.

As someone who has worked all but a handful of years of his professional life in the field of Māori education, on reflection, they have been years tinged with frustration and exasperation at the seeming inability of the education system to provide an education that the majority of Mãori could feel good about. People feel good about an education if it satisfies at least two basic criteria: firstly, if it holds up a mirror to them and they can see themselves growing and developing in a way that is meaningful for them; and secondly, if it helps them to project themselves 
into the immediate world around them as well as into the world at large.

Why is it that so many intelligent researchers, thoughtful and competent administrators, as well as professional and caring teachers, who want the system to work effectively for all students continue to get it wrong for Māori young people generation after generation? My experience tells me that researchers genuinely seek to understand what happens with Māori students in classrooms. The instruments they use in their enquiries are, on the whole, scientifically designed, systematically administered, and sensitively adopted. I know that administrators and bureaucrats working in the field of Māori education are not part of some malevolent conspiracy plotting to keep Māori frustrated and on the defence, on the contrary, in my experience the administrative professionals in education I have worked with for more than 15 years have generally been without fault in trying to do what is best for Māori even if at times their policies and regulations have been difficult to justify in the eyes of those who have been the 'experts-on-the-ground'. I am equally confident the vast majority of teachers who work with Mãori students really do want them to succeed at school. Indeed, some of New Zealand's recognised finest teachers such as Sylvia Ashton Warner, Elwyn Richardson, Ruth Trevor and Gordon Tovey have found their inspiration and 'feel' for the educational enterprise in working with Māori students and Māori communities, quite often in the Native/Māori School system. But even the ordinary, everyday, local teacher who turns up Monday morning to teach a class of children, no matter what level of the education system, no matter what the decile rating of the institution, and no matter whether large, multi-ethnic, inner-city or small, composite, rural school, wants all children to do well. The teacher who sets out to make life difficult for any category of children, including those of Māori cultural persuasion, is non-existent. Of course there are teachers prejudiced against Māori and all of these are obnoxious but then teachers are human and share all human failures. Many are also incompetent and a few genuinely racist but $I$ have yet to 
meet teachers who did not want all the children they teach to be successful learners. So, if it is not incompetence, lack of fairness and intelligence, and conspiracies of belief that are operating against Mãori then how are we to account for the generally sad state of Māori education? Is the problem, so often heard from Māori, that of inadequate resourcing or institutional racism? Perhaps it is simply a matter of bad luck, misfortune or mischievous mis-labelling. In a universal and centralised education system such as exists in New Zealand not everyone can succeed or fulfil their aspirations through schooling. Perhaps nature (lack of intelligence) and nurture (an inadequate environment) are the major determinants of under-achievement as Jensen, Herrnstein, Eysenck and others have been claiming for decades. What is the reason for the sad state of Māori education? One thing I am sure of and that is reductionist explanations are no more helpful than are holistic explanations. "Holistic explanations", according to Rose et al (1984:280), "bear a sort of mirror image relationship to reductionism". Then what?

As with other indigenous peoples of the modern world (Australian Aboriginal, Native Americans, First Nations peoples of Canada, Inuit of Alaska) Māori share with them intensive problems, which in short-hand terms can be defined as problems of identity. The problems are seen to originate in acts of separation as a result of nineteenth century or earlier forms of colonisation. The separations are numerous, for example, from traditional lands, language, cosmologies, economies, sources of power and authority, knowledge and customs, food supplies and much more. Chapter 1 established a 'way of looking' at these problems (through a sociological and philosophical imagination) and investigating them. Chapter 3 will examine in some depth the issues surrounding 'Māori identity' with my own experiences as evidence. The questions addressed include: Is there a problem of identity among Māori? Are there 'modes of objectification'? What are they? How are Māori identities transformed? How are Māori students turned into subjects? 


\subsection{Māori agency and relative autonomy: a conclusion}

Throughout the duration of the writing of this thesis and indeed for the 40 years previous the thought has always been present, or at least close to the surface, as to whether Māori were neutered victims in a conspiracy to make them subordinate and to keep them there or whether they were active agents in their own demise. I'm not sure about a conspiracy of action but I think a conspiracy of belief has some real possibilities. The New Zealand historian, Sharp (1997:293) speaks about agency in the following way:

\footnotetext{
An agent is a person, either natural (a man or woman) or artificial (the Crown, a Government, an iwi, a Court of Appeal) who has the right to act; and the issues at stake were precisely as to who had the right to act, and in acting to wield authority and to dispose of resources, In te reo they were issues of rangatiratanga and mana
}

The simple binaries of coloniser/colonised, dominant/subordinate, and perhaps even Māori/Pākehā, are being called into question by those applying agency theory. For example, who is a Māori in today's world is highly problematic but the same is also true about who is a Pākehā. The question of whether Māori could have acted differently is not a neutral question. It depends on whether there was a choice, what the choices were, whether they were choices that were available through access, whether there were opportunities to make choices, whether they were the choices they wanted and so on. I think the very idea of agency (the ability to act independently) can be perceived as a kind of academic 'escape clause' to explain a manufactured and manipulated consensus. I see relative autonomy theory (Hargreaves, 1982:115) in a similar light because both theories remain reproduction-bound. More appealing to me, even with all its shortcomings is resistance theory Giroux, 1982:10-11). Whatever can be learned from agency theory one thing remains clear and that is that issues of rangatiratanga (the qualities of leadership, self-determination) and mana (authority, self-collection) are still to be achieved by the majority of the Māori population. 
Chapter 3 examines the effects of an education system in which education shapes the identity of Māori in such a way that 'being Māori' is substituted by 'being educated'. The penalty is disconnection from Māori culture and dislocation from the local community. Analysis is approached through the methodology of a sociobiography of the researcher. The research question addressed is, 'How does mainstream society and its education system influence Māori identity?' 
Fig. 2.1 Māoritanga Model - Rangihau (1977)

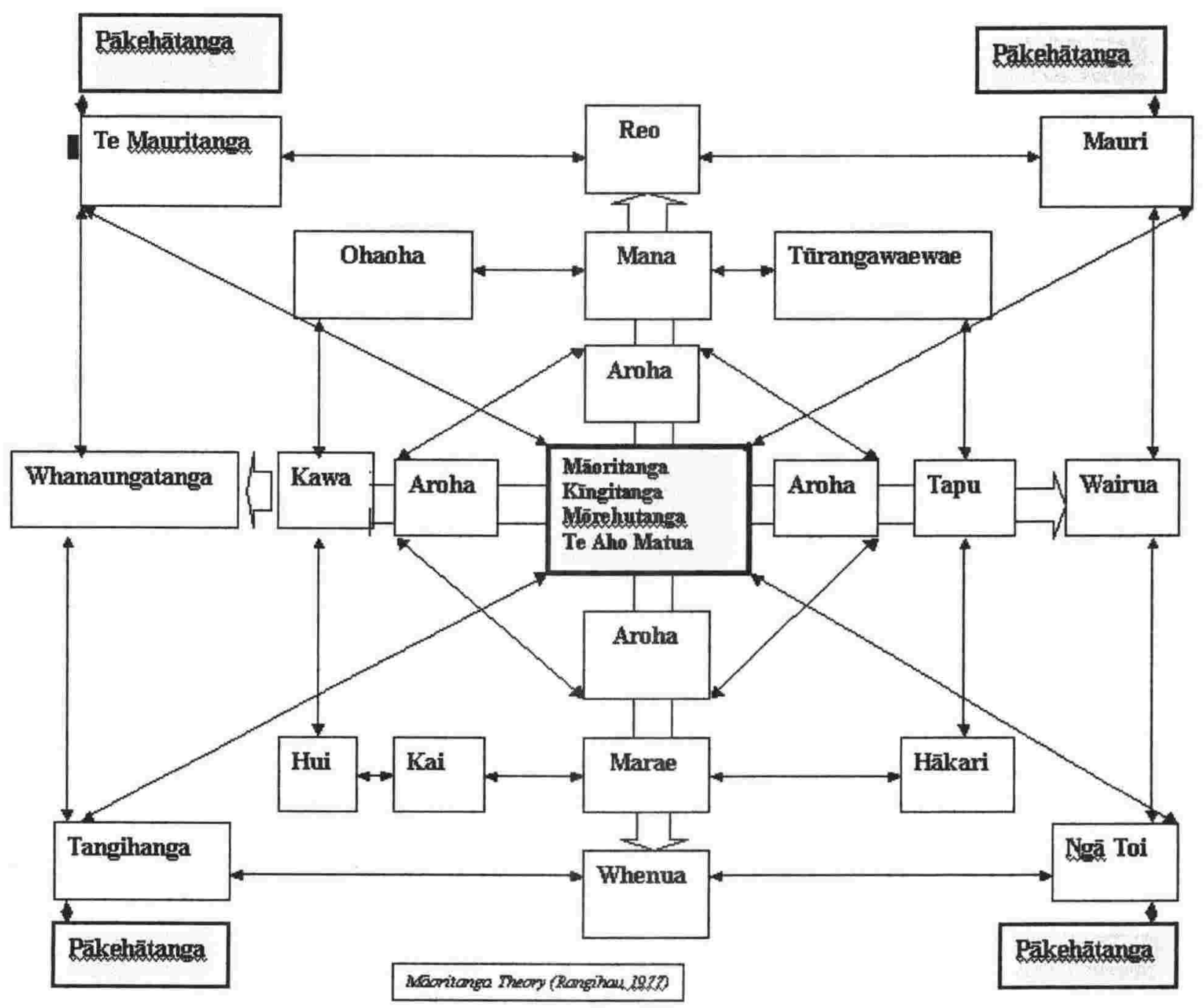




\section{Chapter 03}

\section{The socio-cultural construction of Māori identity}

\subsection{Introduction}

The British cultural studies academic, Hall (1997:134), tells the story of himself as a black migrant living in Britain. In answer to the often asked question 'why are you here?' he said he knew the reasons he was supposed to give: "for education, for the children's sake, for a better life, more opportunities, to enlarge the mind", and similar uplifting thoughts but the truth was, so he reiterated, he was there because it's where his family was not. He came to Britain to get away from his mother but spent his life finding other stories, other fictions to avoid telling a truth that would not be perceived as being authentic or acceptable.

Hall's story reminded me of an incident I observed when I was a young teacher in a rural Eastern Bay of Plenty Māori School. The community serving the school was in economic terms, relatively poor. The people of the community were $100 \%$ Māori and lived in a village or papakainga that was on their own land with their own marae located at the centre. They were in every sense spiritually Māori being practising ringatū (a Christian faith adopted by the warrior chief Te Kooti) with a strong sense of their own hapū (community) and iwi (tribal affiliation). There was no reason to question the Māori authenticity of the village residents. The nearest airport to the community was about a 40 minute drive away. One day I caught a plane from that airport to fly to Auckland. While on the plane I observed a man whom I thought was originally from the marae and was distantly familiar. I didn't take too much notice of it but from time to time I would glance his way and try to catch his attention. When people in unfamiliar surroundings catch each other's eyes they usually show some sign of recognition or not. He didn't seem to be avoiding my gaze and so I took that as a tentative confirmation that I must have been mistaken. When the plane landed in Auckland and we had to walk from the plane across the tarmac I quickly caught up to him, tapped him on the shoulder and asked if he was who I thought he was. I still had doubts but was prepared to 
apologise for my rudeness rather than separate with the question of his identity still in my mind. To my great relief and somewhat surprise, as soon as I touched his shoulder, he shrugged a quick look at me with a half smile on his face and I knew at that instant he was indeed Te Āhuapai (fictitious name). The thing was, $\mathrm{Te}$ Āhuapai looked nothing like he usually looked when I saw him around the marae. At home he looked more or less like every other 50 year old male: comfortable, worn but tidy, warm and relaxed, and conservative. Off the plane in Auckland the words that best describe his appearance are very modern and his demeanour, that of a 'city-slicker'. His grooming for the part was immaculate in detail from the trilby on his head to the beautiful leather boots on his feet. With a feigned look of surprise rather than rudeness I asked, "What happened to you?" He replied most matter-of-factly, "I've been living in the city for six months now. Do you know this is the first time in my life I've been anonymous. No one knows me when I walk down the street. For the first time in my life I can be the person I want to be, wear the clothes I want to wear, and look the way I want to look". Similar sentiments are echoed in the passage from the geographer, Harvey (1999:5) commenting on the development of postmodernism:

\footnotetext{
Raban (Soft city) appealed unabashedly to notions of subjective individualism which had so often been forced underground by the collectivistic rhetoric of the 1960 s social movements. For the city was also a place where people were relatively free to act as, and become what, they pleased. 'Personal identity had been rendered soft, fluid, endlessly open' to the exercise of the will and the imagination.'
}

A story like this could be interpreted as demonstrating the endemic problems attached to the parochialism of tribal existence. On the marae Te Āhuapai would continue to belong the way he and his ancestors had always belonged, proving their connections to each other, to the mountains, rivers, lands and skies the way they had always done, through whakapapa (genealogies) and (dialogue). In the city Te Âhuapai would have to learn how to belong. His new found freedoms might seem to him like discovering an identity which is not really him. Who was the 'real' Te Āhuapai? I felt ashamed of even having the thought but congratulated myself for at least having the good sense not to have asked the question out loud. It 
is a question filled with arrogance. It suggests a person can only be one thing, a 'marae' person or a 'cosmopolitan' person. In truth, Te Āhuapai is both, being rooted in both and as a result, belonging to both. One identity is imposed while the other chosen willingly. The irony is likely that the imposed marae identity would tend toward being more dominant because that is the characteristic of imposed collective identities, they are chauvinist in nature. By that I mean they tend to be overly ethnocentric, one either belongs or one does not belong. He seemed to have understood that identity is an invention formed, as Hall maintains (op.cit. p135), "at the unstable point where the 'unspeakable' stories of subjectivity meet the narratives of history, of a culture". The idea of identity as invention or construction is at the heart of this chapter. This is not to say that one can create one's identity as one pleases. In the same way there are incentives and possibilities there are also limitations and constraints. The politics involved in identity formation work in the same mysterious way as they do in the construction of the social formation.

This chapter attempts to take some of the mystery out of the process by the systematic exploration of the researcher's identity as a Māori, as an educationalist, as an academic, and as a New Zealander. This biographical approach is not without its own peculiarities. The problem is how to speak for oneself while purportedly also speaking for others without falling into the trap of essentialist and relativist accounts of situations. It is what Harvey (1993) calls the "vulgar conception" of individual biographies that I have tried to avoid in this chapter. He says,

I see, interpret, represent and understand the world in the way I do because of the particularities of my life history.....I proceeds as if none of us can throw off even some of the shackles of personal history or internalise what the condition of being 'the other' is all about and leads to an exclusionary politics..... And it is frequently used as a rhetorical device either to enhance the supposed authenticity and moral authority of one's own accounts of the world or to deny the veracity of other accounts (p.57).

Far from an exclusionary politics, the purpose of a chapter on Māori identity was to understand others as they understand themselves and from the desire to be understood as I understand myself. The selection of texts and the categories they 
are grouped into, establish an explanatory framework in order to understand and analyse contemporary changes occurring within the identity construction of Māori. What emerges is "a constellation of beliefs, values, techniques and so on, that is shared by a community" and what Kuhn called the "disciplinary matrix" (Bourdieu, 2000:100).

The key question this chapter addresses is 'How does mainstream society and its education system influence Māori identity?' Subsidiary questions are, 'How do Māori respond to systemic influences?' and 'What is the effect of this coconstruction?' It is hypothesised that the researcher's educational biography is more alike than unlike other Mãori educationalists of his generation: raised in a rural community; associated with a marae base; familiarised with extended whānau; experienced mainstream schooling as a Māori minority member; subjected to the indignities of selected health examinations; and exposed to the subtleties of personal prejudice and institutional racism. Attempts to understand this institutional career has taken the researcher down a complex path of discovery involving fields such as cultural politics, race relations, social justice and other fields that make up the content of the chapter.

This introduction is a description of the disciplinary matrix that begins with a postmodernist definition of the Māori politics of identity.

\subsection{Postmodernism and 'the politics of identity'}

It seems to be that I have been a critic of the education system from the time I entered my first classroom. My very first experience of school as a shy but energetic five year old remained on the fringes of my consciousness throughout the twelve long, mostly compulsory years of schooling. The best way now I can think of describing that first experience of school was that it was remote, detached, separated from reality, and institutionalised. When I look back at my old school photos, especially the earlier ones, it is clear that Māori made up about twenty 
percent of the classes; that is a little higher than the national average for those times. Those proportions changed dramatically the longer one stayed at school. By the time I was in the senior secondary school the academic stream was lucky if it had two or three Mãori students in a class. After all these years one had time to get accustomed to certain characteristics of schools, for example, it is wise to choose the teachers who like you and your chances of succeeding will be enhanced; you don't have to understand the content of what you are being taught, just learn it and give it back; and there is no point in being concerned about other bright Māori kids (brighter than you) who are not progressing with you - the message you get is that they made a choice to go into a non-academic stream because they wanted to stay together, or they wanted to leave school as soon as they could so they could get a job, or they wanted to be in a class with a lot of other Māori kids because it was more fun than without them.

The most frustrating part about schools for me was the relationship between oneself and the curriculum (perceived as what one was at school to learn). Apart from being taught to read, little else that we were force-fed was shown to be relevant. Primary schools were reasonable because virtually everything we learned was new. But at secondary school, we learned what our teachers taught us when the exchange worked. A lot of the time it didn't work because although all of the students were different what we got and the way we got it was aimed at some fictitious character sitting somewhere in the middle of the room and $s /$ he was never a Māori character. It was difficult to get excited about what one was taught when it was rarely clear why you were being taught it. Schooling seemed to be about a distant promise that Pākehā kids didn't seem to have difficulty perceiving and Māori kids always did. That is why I found schooling remote, detached, separated and institutionalised; they were places set up for Pākehā kids while Mãori waited around for their turn to come round.

Once I stepped into the university, criticalist intellectual thought almost became a pre-occupation. Few Māori sources were available outside the works of Ranginui 
Walker. Sociology led me inevitably to Marx but his social class analysis was always going to be an awkward bed-fellow for someone whose interests were closely associated with the subjective and the cultural. However, Marxist thought has been part of my repertoire ever since although it has never had a central role in my writing or practice. By the 1970 s I was reading everything I could find on the 'new' sociology of education. Specific influences are discussed in more detail under 'selection of categories and texts' later in the chapter.

We are told that Mäori have been coping with multiple identities for centuries (Ballara, 1998:335). We should not be surprised, therefore, that ongoing identity formation is part of the current mood of the times among Māori. As one might expect, this is not without its problems. Levine (1997) maintains that reconstructing ethnicity is a blend of primordialism (whakapapa), situationalism, invention (Spoonley's idea of a 'fictive Pākehā ethnicity'), the role of myths, and also a cognitive dimension (ie. systems of classification rather than practices). 'Identity formation' refers to the historical process by which modern Mäori has been constructed. This includes not only the construction of the cultural and institutional apparatus of Maoridom which constitute the private realm but also the formation of ideologies and collective beliefs which legitimate state power and underpin concepts of New Zealander and national character (typical Kiwi) in the public realm. The point I want to make about Māori identity is not to maintain that what we do as Māori is justification for who we are. That is an essentialist position that might account for some actions but it is not sufficient. The story of Te Āhuapai is a reminder that one can act otherwise than according to some mysterious inbuilt cultural memory. The multiple identities we have are influenced by a multiplicity of mediating entities. These relationships are represented in Figure 3.1. We all have individual identities (Ko au) as well as collective identities (Ko mātou). As New Zealanders, we also know ourselves in relation to the 'other' but, because of the nature of this latter relationship (minority/majority, subordinate/dominant, tangatawhenua/tauiwi), how we come to think about ourselves is no longer a simple matter of choice. We still have private and public 
personae but because the world we live in reflects a modern, Western, capitalist society, who we are as Māori and what we can become is deeply influenced by Pākehā mediating influences (Matthews \& Jenkins, 1999). The reciprocal experience on the part of Pākehā is very much a matter of choice.

Figure 3.1 Māori identity formation.

\begin{tabular}{|c|c|c|}
\hline & $\begin{array}{l}\text { Mediating } \\
\text { entities } \\
\text { (Pākehā) }\end{array}$ & \\
\hline $\begin{array}{l}\text { 'Public' } \\
\text { political } \\
\text { social } \\
\text { professional }\end{array}$ & & $\begin{array}{l}\text { 'Private' } \\
\text { pan-Māori } \\
\text { institutional } \\
\text { official }\end{array}$ \\
\hline
\end{tabular}

Individual

Identity

Collective

Identity

emotional

sexual

domestic

affiliation

tribal

'Private'

'Public'

\author{
Mediating \\ entities \\ (Māori)
}

\title{
3.3 Academic influences : scoping the literature (1970-2000)
}

I taught in schools throughout the country for 10 years before I studied for my first extra-mural university credit towards a bachelor degree. There is absolutely no doubt in my mind that those early years of teaching played a prominent role in my subsequent academic studies. Every course I pursued, every lecture I attended, every article and book I read that was related to study was in some way a reaction or a response to that first decade of classroom practice. I was never that interested in studying a subject like history or earth science in order that the focus of that discipline would be my area of teaching expertise. My interest was mainly around answering questions like how decisions are made about what will be taught in the curriculum; why some subjects seem to be more important than others, that is, 
whether they are compulsory or optional for example; why so many Māori children find schooling a negative experience; why the secondary school curriculum virtually ignores both the New Zealand and the Māori context and other similar questions. It is the underlying assumptions about why things are the way they are that have interested me, probably more than anything else although I have also had a strong desire to fix things up that I thought needed to be fixed.

Of course the earlier years of my life as a Māori male, brought up as the second eldest of a family of 11 , in the heart of the rural Waikato also had a significant role to play in shaping the sort of person who grew up wanting to be a teacher so as to influence young people's lives through education. Living in the midst of some of the most arable land to be found anywhere in the world, among relatively well-off Pākehā who owned the land that was once the domain of Ngāti Hauā, who were at that time and remain today, one of the most economically impoverished people in the country, was a reality that could never be simply set aside. What I thought was extraordinary and still do is the general level of ignorance of both Māori and Pākehā of the Ngãti Hauā territory of how the lands transferred from one set of owners to the other, and as a consequence, how one group of people became secure and forward thinking about the future and the other became pre-occupied with survival and entrenched into a dour existence. This grim picture is replicated in many other parts of New Zealand and in other parts of the world. One thing common to them all is the role education plays in maintaining the general level of ignorance about such matters. The system seems to prefer operating under the guise of finding solutions for the Ngāti Hauā problem, or the Māori problem, or the American Indian problem rather than on itself. As a result of this background knowledge, two critical social justice questions have always been part of my consciousness: if we are to live in a just society what is it that needs to be distributed (wealth, property, psychic gratification, mana...) and what are the principles upon which that distribution should be made; the second question relates to a breakdown or misrecognition in addressing the first question and directs our attention to questions of rectification and redress. 
Having completed a BA degree majoring in education and sociology the 'study bug' was so firmly entrenched that setting off on the next stage toward an MA in Māori education was like stepping into a comfortable pair of old shoes. Master's papers in the sociology of education, the management of educational change, Māori education, and multicultural education were consumed enthusiastically. My thesis was entitled 'Māori Language Teachers' Perceptions of Secondary Schools: The One-Year Trained Teachers'. I slogged away at this research for a year but was defeated in the end and had to give up. I learned two important lessons about Māori teachers from this exercise. Firstly, the level of conservativeness among Māori secondary school teachers at that time left me in a quandary. They refused to believe that a one-year teacher training course might have been inadequate preparation for a non-degree person to be holding down a full-time professional position in a modern secondary school. They believed, almost without exception, that because they were the experts in their field of study, that is, in te reo and tikanga Māori, that put them on an equal footing with other secondary school teachers who were experts in mathematics, science, geography etc. At one level that is undoubtedly true but at another level it is wishful thinking. There has always been a hierarchy of subjects in the curriculum and nowhere is that more obvious than in the secondary school system. Te reo Māori as a subject only just makes it onto the timetable but tikanga Māori, in the light of the system, is a figment of the imagination. The second lesson followed along similar lines; 14 of the 16 teachers interviewed believed that the reason so many Māori students failed to gain adequate qualifications at secondary school was because they did not work hard enough and/or because there was no support from their homes. They did not see that the attitudes they or their colleagues held about Māori students might actually contribute to the levels of achievement, motivation, desire to stay at school, resilience and so on that was reflected in the students' behaviours. Not completing the thesis also taught me an important lesson about myself; I didn't know how to organise large amounts of data and studying extra-murally did not help, especially when the thesis was also an extra-mural activity. I had not learned 
how to work in a team, under ongoing supervisory direction, where my thoughts and my work would be under constant review and critique. As an experienced teacher and an experienced extra-mural student I did everything, most of the time, by myself, usually late at night when the family had retired. Unfortunately, I am still trying to learn those most valuable scholarly skills without letting my ego interfere too much.

There are always important lessons to learn when one is engaged in higher education and they are not always the ones being pursued. The lessons I learned from studying for a master's degree proved to me the necessity of research as a systematic approach to understanding what is happening in schools and classrooms with Māori students and teachers. Keeping in mind the way in which familiar phenomena like hierarchy and routines are taken for granted is a much more difficult lesson to hold onto because of the complexity of life in schools and classrooms. The study of philosophy so often seems like an indulgence because of its esoteric nature but knowledge of philosophies soon reveal their pervasiveness in the everyday world of teaching and learning. Philosophical reality versus idealism seemed to be at least as common in usage as that between theory and practice. Becoming intimately engaged with colleagues at critical moments of the research project proved to be the one component of the thesis exercise that was most at risk.

These last comments about the MA thesis are those that are ex-post. The most difficult and frustrating time, however, was at the point of completing the analysis of the 16 extended interviews of fluent speakers of Māori, one-year trained, secondary school teachers. If it wasn't for the fact that I had had 10 years experience as a teacher in the system I might have been persuaded to re-examine my presuppositions but I knew with every fibre in my body that what I had elicited was not right on at least two scores. On the one hand, one-year trained Māori language teachers were inadequately prepared to teach in secondary schools, while on the other hand secondary schools were also ill-prepared to accommodate these 
teachers and the values and practices they would inevitably bring into the schools from the Māori communities. Secondly, that blaming the students and their families for their own short-comings in terms of cultural capital (dispositions, literacy levels, study skills...) was only a partial explanation at most of student performance at school. Concerns like school climate, policies encouraging student achievement, relevance of the curriculum, accountability of schools to Mãori communities, participation of Mãori in school governance, as well as the calibre of teachers (qualifications, professionalism, passion) all play important contributing roles in decisions over student performance. It is well to keep in mind that a degree of confidence in one's instincts born of long experience and 'gut-feelings' are not to be too readily discarded in the face of contrary evidence without that evidence being severely tested.

At the time my MA thesis came crashing down along with a bruised ego I won a fellowship for a year to the Institute of Education at the University of London. The education system in New Zealand at the time (1983) was promoting taha Māori and multicultural education. I went to London specifically to read in the fields of race relations, multicultural education, and anti-racist education and also to visit programmes and institutions that supported these three fields. I was exactly in the right place at the right time. The Inner London Education Authority and other Authorities close by were in the midst of an ideological battle in the year I was there and I had the benefit of scholarly debates on the topics, volatile teacher inservice courses, radical political proclamations, and extensive media coverage. My knowledge along with my personal library increased dramatically with texts in the fields of race relation, multi-cultural and anti-racist education during this time. There is no substitute I can think of for expanding one's knowledge and appreciation of the familiar than reflecting on it in an international context. Studying multicultural and anti-racist education and thinking about Māori education while in London made one issue crystal clear in my thinking. Māori education policies that addressed cultural elements (language, religion, customs...) 
to the detriment of structural elements (regulations, codes, accountabilities, power relations..) would be doomed to failure.

Where an influential sector of the Afro-Caribbean community in London were vigorously pursuing an anti-racist agenda in education an equally powerful lobby group of the Indian sub-continent communities were promoting a multicultural agenda in education. A proportion of the British white population (and the Black for that matter), at least in London, seemed to be split between the two agendas. The multiculturalists argued that modern society was a multicultural society and that unity through diversity was the best way to recognise the multi-ethnic population. The anti-racists argued that focusing on ethnicity could make a difference to most things except change power-relations. The problems they defined were about discrimination on the basis of race that over time became institutionalised. That discrimination, they argued could not be overcome by schools taking part in ethnic minority celebrations once or twice a year nor would learning a few phrases or greetings in the languages represented by the student population make the slightest inroads into either raising student achievement levels or in creating a more harmonious society. What was happening in London could not be generalised throughout England and Wales although there were pockets of this sort of ferment in several of the industrial centres like Manchester and Leeds. I was quite sure the radical nature of what was happening in London would not translate to the New Zealand context and nor should it. The history of our education system along with the history of race relations in New Zealand do not parallel that of Britain but on the other hand I was confident Mãori involved in education could learn from what was happening in London. The question for me was how to bring on board mainstream policy leaders, politicians, academics, and teachers who were looking for solutions that would satisfy the various interest groups like, Māori, iwi, Samoan, Tongan, Vietnamese, urban Pākehā, and so on as well as mainstream New Zealand. 


\section{Selection of categories and texts}

Seven categories of literature are reviewed. Justification of the categories is as problematic as the selection of literature under each category but going through the process of thinking what to include and what not is an important step in overall self-understanding as much as it is about knowing one's field. After 30 plus years of relatively disciplined reading on the topics and themes that interest me a large list of books, journal articles, conference papers and such like has accumulated. Some of these texts become favourites and are revisited frequently while others linger only briefly in the mind and get put away for later reference. It is the first of these that I am referring to as having an academic influence on my thinking. The question now is, what sort of influence and how has that influence been manifested in my thinking? I am referring strictly to the literature at this point although one would expect that after several decades of immersion in a field, individuals, practices and institutions would prove to be inspirational and that actually happens to be the case. I will refer where appropriate to these inspirational individuals, practices and institutions within the texts of each category.

Each category is scoped in terms of the influential sources on my thinking in Māori education (ME), that is, who said what when and why, how it was important to me (or not) and what I think could be done about it. The categories are those areas of academic study that I consider basic for an understanding of ME and what needs to be done to improve the field. The starting point for this analysis is based on the premise that the field of ME has been a problem for the education system since the establishment of the Native Schools System in 1867 and continues up to the present. The implications of this premise from the point of view of the system is that apart from sufficient knowledge within the system for Māori to feel they are part of a 'known and respected culture', it is important that they have an education that allows them to fit within the norms and practices of a modern industrialised state on the same basis as all other citizens. From the point of view of Māori society, it is being in control and managing an education in its own interests, in relation to the system that is the problem to be addressed. The system has long 
recognised its inability to meet either its own goal or that of Māori through formal education. The Currie Commission on Education (1962) was eloquent about this last point when it said, "In the Māori people lies the greatest reservoir of unused talent in the population. The benefit that could finally accrue in the field of race relations, if the Māori could play the important part in all areas of the community that his numbers warrant, needs no emphasising" (Department of Education, 1980:4).

\section{Māori education and cultural politics}

Starting with Māori education may seem obvious except that ME, since 1867 has been inextricably linked with mainstream education (MSE) (Simon, 1992, 1998; Simon \& Smith, 2001). ME like rural education, technical education, and special education are all sub-sets of the generic MSE. If there is an obvious starting point for a scoping of the literature it is probably MSE. I have avoided that choice not only because ME is my focus but I want to avoid seeing ME and MSE in comparative terms even though that is almost impossible to do because of the dominant dualist, if not quite interdependent way the systems have evolved. Paradoxically, a Māori system has evolved (at least in the heads of Māori) despite the fact that there is only one official system and that is the MSE system. Sub-sets of the system are part of the system. They are not separate or independent or autonomous.

It should not be surprising that despite the problematic nature of the field of Māori education, over the years, the field has spawned a significant number of innovative teachers whose practices have proven to be generative at national as well as international levels (Ashton-Warner, 1980; Richardson, 1964; Laughton in May, 1994). Many of these teachers became leaders in education at management and administrative levels as well as within academia. Another important point that should be noted is that these teachers have been both Māori and Pākehā. 
As a young teacher in the 1960 s and 70 s the writings of Walker in the New Zealand Listener and in Education were articles received and consumed with relish. He wrote on topics that were about education and about Māori, and about the relationship between Māori and Pākehā that put current events into cultural and historical contexts (Walker in Vaughn, 1972). By the mid-80s he was writing articles that had a much more forthright political edge (Walker, 1985, 1996). The books that eventually came out of this latter period were clearly congruent with creating space for a new cultural politics for education in New Zealand (Walker, 1987, 1990). Of course, Walker was not on his own in either of the two contexts just described. Some of the articles of the anthropologist, Schwimmer were like those of the earlier Walker period, that is, descriptive and explanatory, and apolitical (Schwimmer, 1964, 1973). I thought the 1967 monograph by Watson of the New Zealand Council for Educational Research on Horizons of unknown power-Some issues of Māori schooling was in advance of most of the thinking on Māori education at the time including that of Walker. By 1970 The National Advisory Committee on Māori Education (NACME) produced its first public report and then again, 10 years later, its second (Department of Education, 1970, 1980). By this time politicians, let alone officials had difficulty camouflaging a much more overt approach to addressing issues in Māori education. The fact that NACME had at least 50\% Māori representation was a radical move. The fact that of the Māori on NACME who were nominated by the Education Boards, most were also strong tribal representatives. This relatively simple recipe for representation on a national committee produced a mix that was dynamic. Concerns about the moribund state of te reo Māori, disproportionate drop-out rates, educational under-achievement, and the increasing visibility of brown faces in all areas of civil society could no longer be catered for using measures that might be consistent with systemic practice but not perceived by Māori as solving the problem or getting at the heart of the matter.

While at Massey University in the mid-1970s and early 1980s I was fortunate to be studying in an Education Department that had lecturers with particular strengths in 
the sociology of education and some in Māori education. Harker had both combined knowledge and research areas and they were exactly what I was in search of at that time. The book he published with McConnochie (1985) summarised much of what I had learned from him and others during this time. I was introduced to sociology, anthropology, philosophy, the sociology of education, and comparative education, but most importantly, guided toward an understanding of the relationship between these disciplines that are in themselves wealthy sources of knowledge. Even the connection to Aboriginal Studies acts as a catalyst to entering international indigenous scholarship. Harker and McConnochie (1985) is a study of cultural politics in education. Like all education systems, a specific cultural milieu or environment is being catered for. Seen in negative terms all education has a bias toward serving whichever is the powerful group within the society. The exercise of cultural politics sets out to make that bias overt. That is a central concern in my own thesis. The question is, will focusing on cultural politics be enough to reveal a bias. I suspect not. This is behind my exploration of race relations, social justice and other themes. The second concern is what to do having revealed a bias. As a practitioner and pragmatist at heart I feel compelled to complete this picture.

\section{Race relations and the 'politics of interpretation'}

The second category is race relations. The rationale for this choice is linked to the second to last sentence of the last paragraph. There is one official system (MSE) and one de facto system (ME); one operating under Pākehā philosophies and practices and the other under Māori philosophies and practices. Concentrating on race relations is not to deny that problems of racism exist in this society. The beginnings of the two systems are foundered on principles of race ideology. Tierney, Dickinson, Syer, Mullard, Gundara, Jones \& Kimberley (1982:24) argue that race ideology

\footnotetext{
..may be conceived as a belief system which provides a picture of the world in which individuals are classified as inferior/superior in terms of moral, intellectual or cultural worth, these being deterministically based on what are seen as racial origins.
} 
New Zealanders are not comfortable talking about race and nowhere is this more obvious than in official educational discourses. Discussions about ethnicity and culture are the preferred concepts for debate from official sources but this preference can be shown to be part of the ideological hegemony. Race, racism and race relations need to be confronted face-on. We have more than our share of takawaenga (go-betweens), karanga-rua (those perceived to have a double-calling), and what the British researcher, Bourne (1980) describes as new radicals in old clothes ("do-gooders, cheer-leaders, referees, ombudsman"). Among Māori voices, conceptual preference has historically been in favour of discussions about culture rather than ethnicity or race and it remains that way at present (King, 1978, 1992). Issues of race when they are debated in public tend to belong to academic discourse (Spoonley, 1987) and/or the subject of 'ginger' groups ${ }^{1}$. When issues arise related to race they are usually Māori making accusations against Pākehā racism, they are often highly-charged emotive issues, and most of the discussion, when it occurs, is in the media ${ }^{2}$. It is probably too much to call these exchanges debates even when they are highly organised and closely managed. One wellknown exception among Māori that does confront the question of racism directly is the work of a committee chaired by a highly respected Tuhoe kaumatua, Rangihau ${ }^{3}$. The report is a bold departure from the products of most Ministerial Advisory Committees in that it does discuss topics that usually would be edited out or thinned out well before being made public. The report includes discussions around topics such as the issue of racism, the faces of racism, the roots of dependency, and beastly communism. However, in my view, the report still has culture/biculture and the Māori perspective as the critical component rather than problems of reductionism, biological determinism, discrimination, and unequal power relations. The concept of culture as used by Māori tends toward being

\footnotetext{
${ }^{1}$ An Auckland based group called 'Programme on Racism' as part of the Confederation of Churches in Aotearoa New Zealand disseminated a regular newsletter through the 1980s and provided a lot of information on race issues from current events.

${ }^{2}$ There is at least one major race-based agenda item in the print media every year and quite often several more but at least one will often run regularly for several months. One such item ran at boiling point for much of 1995 having appeared in the press initially in 1993.

${ }^{3}$ Ministerial Advisory Committee on a Māori Perspective for the Department of Social Welfare, (1986).
} 
treated as a biological, genetic, inherited term, equivalent to race. The application of genealogy or whakapapa as evidence of identity would seem to support a determinist interpretation of the concept of culture. When Māori talk about Māori culture they usually mean all those customs, knowledges, stories that are handed down from ancestors. They might be in use today but they nevertheless are tāonga tuku iho a ngā tūpuna (treasures handed down from the ancestors). Where we can talk about a commonly accepted definition of culture we understand that it is something we, as humans learn like the language we speak, the religions we practise, the foods we eat and so on. None of these characteristics of human beings are inherent except as capacity. We must learn from others, usually those closest in proximity to us, to speak a language or languages, to eat with our hands or with utensils, how to greet and farewell strangers etc. In the earlier scenario where one assumes a biological interpretation of culture, there are reasonable grounds to believe that like the biological concept of race it can be proved to be a nonsense.

I think the avoidance of education on race relations coupled with the relative absence of New Zealand history in the school curriculum has much to do with the dearth of informed and reasoned argument on the topic. New Zealand children leave school after 14 years basically ignorant about race relations and New Zealand history let alone being informed about racism and its multiple manifestations. Where students might be exposed at the community level to these topics in a place-based approach to education the best that can be expected is an intensive surface level investigation of some local community (often someone else's) as a sort of bonus for working hard in the classroom all year. It is supposed, 'real' education occurs in the classroom, is mainly teacher-directed, print textoriented, and oracy-literacy dependent. The origins of this cognito-centric approach to education, I will argue, has its roots in Pākehā ethnocentrism and in an education system foundered with racism at the centre. 


\section{Social justice and the 'best of both worlds'}

Long before one ever learns the appropriate language for talking about what it is to know about the world and to know one's place in it, issues of social justice, usually framed in the context of fair or not fair, equality or inequality, rights, entitlements, sameness and difference, wants and needs, haves and have nots, wealth and poverty, come into our consciousness as reality experienced through being in the world. This reality is to the forefront of most Māori adults perceptions of the world. It is interpreted in rural communities through discussions on the Treaty of Waitangi, land confiscations (raupatu) following the New Zealand Wars of the nineteenth century, and Māori rural underdevelopment. In the urban situation, the context for interpretation of social justice/injustice among Māori is related to the separation of whānau from the traditional well-spring of Māori custom and belief (the marae), forced associations with non-Māori people (earlier policies of 'pepper-potting'), mainstream institutions and practices (the monocultural society), and institutionalised forms of racism (evidenced in the jobmarket, accommodation and housing, and the inadequacy of accountability in the delivery of social services).

From the Treaty of Waitangi of 1840 to the present, Pākehā have sought ways to absorb the Mãori population. Different universal policies have become known as racial amalgamation, assimilation, integration, and multi-culturalism. Evidence suggests Māori have never wanted to be culturally absorbed by Pākehā but instead have struggled to create some measure of political independence, examples include Kiingitanga (the King Movement), kauhanganui (convention of chiefs), and Paremata Māori (Māori parliament) (see Cox, 1993:58-63). The problem as Sinclair points out is that "those aims were incompatible with New Zealand nationalism as envisaged by Pākehā" (1986:208). It is important to recognise the work that power-relations plays in this scenario but the drama of social justice is played out on a platform much more subtle than that which relies on the exercise of coercion, force or even regulation. One of the world's current truly international academic giants, Chomsky (2003:31), said in an interview, 
It's extremely easy to be sucked into the dominant culture, it can be very appealing. There are a lot of rewards. And what's more, the people you meet don't look like bad people - you don't want to sit there and insult them. Maybe they're perfectly nice people. So you try to be friends, maybe you even are friends. Well, you begin to conform, you begin to adapt, you begin to smooth off the harsher edges - and pretty soon it's just happened, it kind of seeps in.

Of the approximately half a million people who claim to have Māori ancestry, there will be very few if any who have not experienced the 'sucking effect' of the dominant culture. It is daily in one's face. It is ubiquitous, comprehensive, compelling. It will not go away and it will not be ignored. What is more, most Māori by far, want to be a part of this world but where it becomes unstuck is where this world is intolerant of Māori wanting to retain a Māori world. The dominant world says out loud, 'You have to choose Māori. You can't have both. We don't want both and so neither can you!' On the surface that sounds reasonable enough except that Māori did not have a choice, they were to be Europeanised or they would cease to exist. Māori have become Europeanised to a substantial degree but a significant proportion choose to remain culturally Māori. The Pākehā population, on the other hand, choose to remain mainly ignorant about anything Māori much to the chagrin of the tangatawhenua (the indigenous Māori) of this land. The Mäori politics of self-determination are as alive and well today as they were at the time of the Land Wars, the Kiingitanga, kauhanganui, Paremata Māori, and other kotahitanga movements of the last two centuries. The work of the Waitangi Tribunal investigating past injustices against Māori and recommending redress where injustices have occurred has placed issues of social justice in a position that can no longer be ignored or played down.

Like colonised indigenous peoples everywhere, Māori are torn between two competing versions of social justice: they want to be a part of the society to which they belong and they want to belong to the society they are part of, that is, they choose, on the whole, to be Māori New Zealanders. Māori constantly find themselves in situations that are contradictory, where they are confronted with ambivalence, where alienation and anomie are frequent bed-fellows; Māori often 
experience the double-bind situation. It is no surprise that Māori are seen by the public at large as being never satisfied with their lot. Survival in itself is not social justice. Rectifying past injustices is necessary but not sufficient in itself. As the multi-ethnic, anti-racist British academic, Gundara has argued, "people are disadvantaged because of present forms of racism, present forms of structural inequalities, and present barriers to choice. While older forms of inequality might be removed, new forms of inequality are continually being instituted" (1982:112).

\section{Philosophy of education and the 'logic of sameness'}

Every culture is interested in reproducing itself. Education plays an important role in cultural reproduction. If we think about the different 'forms of life', social/cultural activities, or practices that derive from the Māori world, they are likely to be expressed in a number of ways: as metaphor (the early childhood adoption of whāriki or woven mat for example); as ritual (such as karakia/ incantation, and tangihanga/ mourning ceremony); in terms of process (such as powhiri/ welcoming ceremony); or in terms of methodology (such as whakapapa/ genealogy). Forms of life such as these we can think of as being indigenous knowledge, community knowledge, or collective knowledge. Each form is constructed within a social context, that is, knowledge premised on some idea of a culture or a society.

In Māori terms, what is known is inseparable from how it is learned, that is, knowledge takes its meaning from the forms of life within which it is located. According to Young ${ }^{4}(2000$ : 531), the process of grounding or embedding, or giving meaning to knowledge is subtle and difficult to describe concretely. Enquiries need to start from specific cases of actual communities. The way one thinks about any specific form of life is critical. If one form of life is treated as though it arose in traditional times and remains there, the stance taken is called philosophical idealism (the world of ideas, of mind as reality - to exist, something must be perceived by the mind - it looks inward). However, if the specific form of

\footnotetext{
${ }^{4}$ I have borrowed liberally from Young's thinking in this section. See Young (2000).
} 
life is treated as though it originated in traditional times but has been modified, reconstructed, reconstituted, and reinvented to give it contemporary relevance then the philosophical stance considered is more likely to reflect a philosophical realism (realism looks outward to the physical world where one uses one's senses to discover and affirm truth). There is a third position which takes a specific form of life as being a social/cultural invention created by members of a group to maintain their identity as a group and to address present circumstances. This third philosophical position could be described as existentialism (immediate subjective understandings of events are the source of reality. Each person exercises his/her freedom of choice to discover the truth.)

We can conclude that knowledge has both a social/cultural base (even the most basic categories of thought such as causation and time were social in origin) and an epistemological base (concerned with finding the truth or the meaning of the idea of truth) and can therefore be termed social/cultural epistemology, that is, that knowledge is premised on some idea of culture or society. If Mãori education was conducted within an education system that operated according to its philosophical beliefs and practices it is likely the pathologies they have historically had to struggle against, mainly to do with the survival of their distinctive culture, would not be a problem. Their concerns, like those of mainstream New Zealand, would be about how to continue to improve their quality of life through the process of education. This has not been the case. Instead, Māori have had to combat what the French philosopher and psychoanalyst, Irigaray describes as the "logic of sameness' (Gilbert, 2001:298). Gilbert and Irigaray are theorising representations of sex/sexual differences within a system that,

\footnotetext{
is not a system of difference, but, instead, is a 'logic of the same': that is, within this system, there is one sex, one sexuality, one form of subjectivity and so on. The effect of this is that it is impossible to think of femininity as something selfdetermining, separate from and independent of masculinity, and it is impossible to be a woman and, simultaneously, the authoritative author of knowledge.... For Irigaray, the problem with developing a separate category for women and a genuinely female subjectivity is that, at the very deepest level, and from the very earliest stages, our psyche and our thinking are entirely structured by the masculine symbolic order.
} 
Translating this text by substituting gender-related concepts to ones representing Māori and Pākehā relations, can be seen as being more or less equivalent. The only part I might re-phrase would be the last part of the last sentence. Māori thinking is not, in most cases, entirely structured by the Pākehā symbolic order; there is an underlying deep Mãori consciousness of place. This is what I understand O'Sullivan (1999:181) is talking about as the cosmological context. He says, "the universe in its full extension in space and its sequence of transformations in time, is best understood as 'story', in the depth of origin (his emphasis). We bear the universe in our being as the universe bears us in its being". As the people of Wanganui say,

\footnotetext{
I rere kau mai te awa nui, mai te kähui maunga ki Tangaroa. Ko au te awa, ko te awa ko au (The river flows from the mountains to the sea - I am the river, and the river is me).
}

Such a statement represents a profound sense of the relational quality of the unfolding process of evolution. One cannot perceive of Māori education outside the prioritising effect of relational philosophies. There can be no accepting of 'sameness' ('He iwi tahi tātou', to quote Governor Hobson at the signing of the Treaty of Waitangi in 1840) without there being an affirmation of difference.

\section{Sociology of education/knowledge and 'socially constructed reality'}

From the moment I began reading sociology and especially the sociology of education the effect on my thinking was dramatic. Studies in educational psychology left me absolutely frustrated. Its definition of the problem in Māori education seemed to be always something in the make-up of the Māori individual, her family, and her culture. Psychological accounts of Māori under-achievement, in fact, explanations of a host of negative outcomes (learning difficulties, nonstandard English, truancy etc.) were just too neat and tidy for my liking. The sociology of education turned psychology on its head as far as I was concerned. Its focus was on educational inequality ${ }^{5}$ and although Marxist analysis was very much

\footnotetext{
${ }^{5}$ Harvard Educational Review (1973) was a watershed for my newly acquired interest in critical scholarship.
} 
to the forefront ${ }^{6}$, it was really the inspiration of Durkheim ${ }^{7}$ and Weber ${ }^{8}$ that the 'new' sociology of education really began to flourish. The sociology of knowledge (Berger \& Luckmann, 1967) I found particularly intriguing with its focus on the social (cultural) location of ideas (Keddie, 1973) and its analysis of the way in which ideology functions to serve vested interests (Carr \& Kemmis, 1986). Analysis in Mãori education could surely benefit from the sociology of education perspective (Nash, 1983; Harker, 1990) but if there was a problem, it did not take too long to surface and that was the emergence of new types of analysis with new insights but still with one glaring omission - what needs to be done? How do we move from analysis to change? Shifting the blame from individuals to systems, shifting the analysis from structural-functionalist to criticalist, and shifting the focus from an examination of children's failure to questioning the status of school knowledge did little to transform the state of Māori education. Marx was right when he argued that, 'the philosophers [and educators - my inclusion] have only interpreted the world, in various ways; the point is to change it'. The 'new' sociology of education was unquestionably an exciting and challenging discipline for those 'left-leaning' New Zealand academics that researched in the field of education such as Bates (1978), Middleton (1993), and Nash (1993). These texts and many others mainly from New Zealand, Australia, Britain and the United States of America, I found greatly appealing. When I ask myself why that is, the question is a little more difficult to put one's finger on. As a teacher, psychology is the paramount supportive discipline. I have already expressed my disappointment about psychology's contribution to Māori education. Looking back on 30 years of the sociology of education there is no question that texts now available in this field have multiplied several-fold but it cannot be said that improvements in Māori education have little or anything to do with research and scholarship that has emerged under the rubric of the sociology of education. It remains to be seen whether Māori researchers and scholars who studied in the sociology of education

\footnotetext{
${ }^{6}$ Probably the best book I have read on Marx and education is that by Sharp (1980)

${ }^{7}$ The massive contributions from Bernstein (1977) as an example, and Bourdieu (1975) as an example owe much to Durkheimian theories.

${ }^{8}$ Weberian comparative and interpretive sociology appeared in the works of Young (1975) and Freire (1985).
} 
whilst at universities can apply that discipline to transform the status of Māori education. Some of the books (Bishop \& Glynn, 1999), research (Bishop, Berryman \& Richardson, 2001), and review of policies (Irwin, in Hatton, 1994) appearing in recent years are indicative of new possibilities arising out of the new sociology of education. They all use concepts borrowed from the sociological perspective, such as, ideology, power relations, society, social construction etc.; most use secondary sources (New Zealand academic interpretations of overseas literature); and all integrate theoretical perspectives borrowed from anthropology, human development, race relations, and political economy with specific Māori orientations. Theorising tends to be neither eclectic nor what Barnes decribes as 'ersatz' (1995:1). It might take another decade for a clear perspective to emerge but unlike European/Pākehā scholarship which only requires collaboration among a significant proportion of those in a field, for a perspective, such as the 'new' sociology of education to be accepted, Māori must not only satisfy a similar criterion among its colleagues, but it must also be acceptable to Māori in the community. Because many Māori academics tend to also work with community groups it is likely the synthesis of theory with practice is already relatively well developed.

\section{School/classroom and 'community-based action'}

The inner life of the classroom and the school, once reflexively experienced and internalised can never be considered as anything else except as being at the heart of the educational process. At the centre of that process is what the Welsh educational sociologist, Davies describes, in relation to Bernstein's project, as "the utter necessity of penetrating pedagogy" (1994:11). Having taught several hundred children over a number of years the dynamics of classroom life remain forever a deeply challenging phenomenon to describe, analyse and evaluate with any degree of accuracy no matter how long the periods between visits. Yet, teachers, children and their parents or care-givers, know virtually instinctively that those things that coalesce around the teacher-student relationship have the most profound effect on the quality of education students will leave school with. Generally, the effect arises 
from the teachers who work with the child over the period of the child's institutional history, however, it is also not unusual for just one teacher throughout the child's institutional history to make the difference to the child's disposition.

As an under-graduate education extra-mural student in $1971 \mathrm{I}$ read everything I could get my hands on that put education, schooling, curriculum, and pedagogy under the microscope. These included Goodman (1971), and Henry (1971) on education; Reimer (1971) and Holt (1971) on schooling; Apple (1979) and Bernstein (1977) on curriculum; and Kohl (1967) and Postman \& Weingartner (1971) on pedagogy. Perhaps it was because I was still a practising classroom teacher, but the most moving account of life in classrooms and schools for me was the book written by the students called 'Letter to a Teacher' by the School of Barbiana. These and other low priced similar texts - published mainly by Penguin Education Specials - written in accord with a more socially critical perspective, not only impressed me with the sheer power of their respective arguments but I found I could professionally relate much of what they were discussing to what I was experiencing in Māori education. They were in a sense, kindred spirits, sharing a community of thought and action. Some of the more prominent works in this genre include Illich (1974), Freire (1972), Bowles and Gintis (1977), Carnoy (1974), Sharp and Green (1976) and Willis (1981). Each one of these books I found totally absorbing and enveloping. These scholars provided a comprehensive theorising of what goes on in schools and in education in the respective parts of the world they came from. The problem seems to have been a breakdown in communication between the researchers, the writers, the policy analysts, the teachers, parents and their children. The dynamics and complexity of life in classrooms remains a virtual mystery.

\section{Summary of influences}

An overview of the categories and the themes derived from the literature are comparatively consistent with other recent doctoral research in ME (Simon, 1990; Smith, G., 1997; Johnston, 1998; Balcolmbe, 2000; Smith, C, 2002). They are 
essentially critical of the prevailing dominant/subordinate relationship between Pākehā and Māori, they are accepting of Māori playing a more prominent role in the formal education of their own children (mainly through Kaupapa Māori approaches), and they all lean heavily on international literature/scholarship/theories to argue their cases. This research shares those characteristics although, as the title of the thesis suggests, the sociological orientation is more obvious here than those listed in the footnotes. A basic breakdown of the literature used in this chapter that has impacted on my thinking over the years shows that $35 \%$ of the works cited have New Zealand authorship and of those only $8 \%$ can be attributed to Māori writers. The remainder of the articles or books are from overseas sources with most coming from Britain (24\%), America (14\%) and the rest from France, Australia, Canada and Brazil. Walker (5) was the most referenced Māori academic in this chapter, with the French sociologist Bourdieu next (4), and Simon (3) as a Pākehā educationist and anthropologist along with the Brazilian theologian, educationist and scholar Freire (3). Most of the texts are from the periods 1970-79 (57\%), 1980-89 (28\%), and $1990-1999$ (25\%).

A question in some minds would likely be, "Why is there such a heavy influence from Pākehā and overseas scholars on someone who describes himself as a Māori educationist?' It is a good question and one that deserves serious consideration. When I ask myself what is my purpose in what I do, the answer has always been to contribute to making a difference in the education of the Māori student. The way to do that is to ensure the context within which an education can take place is congruent with a set of key indicators that operate in her/his best interests. The problem is that the dominant context has effectively demanded that the Mãori student needs to adjust to those demands if $s /$ he wants an education. That is my rationale for focusing on the mainstream, on mainly Pākehā researchers because up to now they are the ones who do most of the research and produce most of the literature. Finding gaps in what they explore, issues with regard to methodologies employed, and conclusions based on unsound inferences are critical parts of the 
research endeavour. Of course, Māori researchers can get these things wrong just as easily as non-Māori can but until such time as there is a critical mass of Māori researchers it is the non-Māori variety and the research they do that needs to be kept under critical scrutiny.

Those Māori who are researching in education have already made an impact through the developing methodology of kaupapa Māori research. Such pioneers include Bishop, Jenkins, and Nepe. Kaupapa Māori research sets out to encompass a Māori philosophical base as well as Māori ways of framing the research endeavour. The message these researchers convey is that the approach to research is more than a matter of preference that has with it the underlying notions of liberal, private, consumer choice. Kaupapa Māori research is an orientation suggesting something enduring, and embodying innate facets of what it means to be Māori. That is the key to Māori participation in research, in education, in politics, in business as in anything else.

Looking to overseas research and scholarship is important for me because there are some areas of study and research that Māori and Pākehā New Zealanders and the research brokers have not been interested in pursuing. Most of the overseas literature that I find useful, takes a criticalist ${ }^{9}$ stance on the way education systems deliver to ethnic minorities, women and girls, colonised populations, indigenous peoples, and/or working-class peoples. There are clear parallels between the concerns coming out of these five areas and those of Māori.

\footnotetext{
${ }^{9}$ For a discussion on a 'criticalist approach' to research see Kincheloe \& Mclaren in Denzin \& Lincoln (eds.)(1994), p.139-140. We are defining a criticalist as a researcher or theorist who attempts to use her or his work as a form of social or cultural criticism and who accepts certain basic assumptions (here are two):

- that all thought is fundamentally mediated by power relations that are social and historically constituted;

- that certain groups in any society are privileged over others and, although the reasons for this privileging may vary widely, the oppression that characterises contemporary societies is most forcefully reproduced when subordinates accept their social status is natural, necessary, or inevitable;
} 


\subsection{Who is a Mãori - the quarrel with 'essentialism'}

Who is a Māori has become an increasingly contested definition, however, I will argue that so long as those who self-define as Māori and can find the spark of life (the mauri ora) ${ }^{10}$ within them ${ }^{11}$, then Māori exist. I am not referring to finding the 'spark of life' as though it was misplaced, lost or forgotten. It is a quality that one sets out to acquire. It is a quality that one sees in others, admires it, and decides to acquire it for oneself like patience, humility, passion and openness, for example. It might also include traditional knowledge and practices such as whakapapa (genealogy) and whaikōrero (formal oratory). The quarrel with an essentialist position is about a struggle against those fundamentalists who have either given up on the virtues of compromise and mediation, or lost their nerve in the battle for concessions and decided that the only way to survive as Māori is to operate as though the world was exclusively Māori. An equally essentialist stance is one which argues that there is no longer any category that could be legitimately labeled Māori because (a) the frequency of inter-marriage over almost 200 years has dispersed whatever characterised Māori, and (b) those who have chosen later in life to become socialised into the dual heritages of Māori and Pākehā lack the conviction and commitment to either group placing them in the difficult context of the double-bind.

The problems related to essentialist positions and the consequence of the doublebind hypothesis is one of the more difficult arguments in the thesis. The problem is illustrated by way of the so-called crisis of Māori identity and addressed by way of an educational philosophy (tuakiri tangata) introduced in this chapter, illustrated in Chapter 8 and contextualised in Chapter 9

\footnotetext{
${ }^{10}$ Within Mãori metaphysics the mauri is within everything and only when an object dies does the mauri no longer exist As one of my colleagues expresses it, 'I breathe, therefore I am' (Rawiri Toia). This definition is clearly primordial and if foisted on others, fundamentalist. But Māori do not foist such explanations on others. What they expect from others who want to redefine such explanations is dialogue and not propaganda, for a one-world view.

${ }^{11}$ This is not to deny the problems inherent in self-identification. See Stewart-Harawira $(1993: 29)$ who suggests that self-identification may be as problematic as legal definitions.
} 


\begin{abstract}
A Māori identity crisis? ${ }^{12}$
Those adults in New Zealand society who strongly identify as Māori puff themselves up with pride when they see Māori of a younger generation indulging in acts which symbolise their generation such as speaking te reo Māori, showing respect to elders, attending hui, helping out without being told, sharing those things valued, spontaneously expressing emotion, standing up for their whānau, singing waiata, being humble but never bowing their head to another, and eating kai Māori. Little more than half a century ago, the legitimate authority among Māori for upholding these values, what Durkheim (1960) referred to as the conscience collective, rested with kaumātua and their upholding of tikanga. Today, kaumātua struggle to maintain their own authority and in many cases tikanga has become a blueprint for behaviour rather than a framework for acting in the interests of all parties.
\end{abstract}

The individual and the social are inextricably linked. Among Māori and other indigenous peoples, this truism is located in a number of important sites such as the link to whenua/land (Arohia Durie, 1997:142 and 151). The familiar link to land is equally true for Australian Aborigines (Munn, 1996:465) and Native Alaskans (Kawagley and Barnhardt, 1999). Pepeha/proverbs, as in the following saying from Tainui, maps out the legitimate tribal territory of those descended from that waka/canoe. Such pepeha (sayings) were critical for political reasons (this is our space), economic reasons (these are our resources) and for spatio-temporal reasons (we are the land).

\title{
Mokau ki runga, Tamaki ki raro. \\ Ko Pare Hauraki, ko Pare Waikato, \\ Ko te kaokaoroa o Patetere.
}

To emphasise one's attachment to one's tribal ancestors, language is a critical site for the confirmation of one's individual and social identity. This is dramatically represented in the assertion which goes, 'without the people you are nobody, you have no stance':

\footnotetext{
${ }^{12}$ This section is taken from Penetito (pp.52-65) in Bird \& Drewery (2000).
} 
Ki te kore te iwi, kiia, e kore koe e karangatia - he tangata.

Is the prioritising of identity through ritual pepeha (sayings), whakataukī (proverbs), whakapapa (genealogy) like those above, an impediment to clear thinking about who and what one is and therefore, about who and what one can become? The ongoing debate about whether urban Māori and iwi Māori have legitimate claims to authenticity seems to be calling the tradition into question. The inclination to glorify and romanticise traditional Māoritanga can lead to an unanalytical approach in trying to locate oneself in space and time. In a seminal article by van Meijl (1996) he argued that the concept of Mãoritanga was based on "an objectified and essentialised conception of Māori traditional customs" (this is the notion of reification) and is critical of the idea that Māoritanga can be lost and recovered, be treasured and manipulated. In my experience, and many others like me, this is precisely our experience. I maintain that Māori, as a people, have never stopped being Māori but what counts as being Māori has always been problematic. Isn't that true for everybody?

It is probably not an accident that more and more Māori (and other indigenous) authors, whether as academics or as fiction writers are claiming their tribal links on everything they produce. The copyright mark says this is your intellectual property and the iwi affiliation says this is your cultural property. But Māori identity, at least post-European, and probably earlier has never been that constrained. As Ballara has argued, "Māori have been coping with multiple identities for centuries" (1998:335); however Hall (1997:4) claims, "Identities are never unified and, in late modern times, increasingly fragmented and fractured, never singular but multiply constructed across different, often intersecting and antagonistic discourses, practices and positions". And in the new language of postmodernism, "We are told that we are living now in a world of multiple identities, of hybridity, of decentredness and fragmentation" (Dyer, 1997:3). 
If the link between the individual and the collective is so formally embodied in Māori tradition, thinking, belief and behaviour how is it that an identity crisis figures so prominently in writings both of, and about Māori? Explanations about Māori educational underachievement, unemployment, ill-health, social dislocation, suicide, imprisonment and even cot deaths are attributed to crises of identity. Are we to assume this crisis of identity has its beginnings in the acts of separation between Māori and their land, Māori and their language, Māori and their religion, Māori and their customs, in other words, the legacy of colonialism? How far can these acts of separation go, given the ancient traditions of Māori culture, or is cultural imperialism through colonisation a totalising experience which is some kind of justification for its continuation? Brock and Tulasiewicz (1985:6) argue that cultural imperialism is:

\begin{abstract}
The imposition of a uniform, technologically/economically efficient culture upon a weaker, traditional folkloristic one which in due course it would destroy. In this process it is not the working pattern of lived culture which is being destroyed, new values, religion or even languages being imposed - but the pattern for culture, the very code itself which is being changed. This might be accomplished by friendly missionaries as much as by foreign aggressors or persuasive educationists introducing new ideologies resulting in new patterns for behaviour whicb in turn produce actual new attitudes and values.
\end{abstract}

I have tried to 'get under the skin' so to speak, to investigate the subtleties surrounding Māori identity change. It is not new to hear about the confusion, conflict and even crisis of Māori identity (Schwimmer, 1973; Vaughan, 1964) yet Māori are numerically stronger than ever before and self-identifying at least as convincingly as earlier generations.

What keeps the Māori agenda alive is its profound belief in its capacity to contribute to inclusive communities, to share a collective power in the pursuit of common values, and to transform a society without turning it inside out as in the new world order of market individualism. It is easy to argue this is mere rhetoric but out of the millenarian movements (Webster, 1979), the kōtahitanga movements (Cox, 1993), and the Māori activism of the nineteenth and twentieth centuries (Walker, 1984), valuable lessons have been learned about combating Pākehā 
power, Western ideology, and the worst excesses of modern capitalism. The whole idea of a crisis of Māori identity is an oxymoron - an inherently flawed and internally contradictory notion. But having said that, I do not claim that Māori are being all that they can be - this is clearly far from being the case. Both Māori and the state, agency and structure, have important roles to play.

Māori like to do things together, to acclaim their Māoriness to one another, to meet and strengthen their social bonds for each other, to participate in games that challenge and unite, to share food, stories, and histories, and to remember those no longer in the world of light. Michaels (1992:673) puts this simply: "What this involves is the representation of your culture not as the things you love to do but as the things you love to do because they are your culture". Michaels stands firmly by the view that, "we need to cease to explain what people do or should do by reference to who they are and/or what culture they belong to" (ibid. p.684, footnote 39). These ideas are what are defined as an essentialist assertion of identity. Civilisations have come and gone but it is most unlikely those that became extinct did so as the result of any essentialist assertion of identity. Identity is a construction, a process never completed, never a proper fit, a totality. I think Achebe quoted by Appiah (1995:108) summarises the tentativeness of identity very well without diminishing its political potential for intellectual debate.

The duration of awareness, of consciousness of an identity, has really very little to do with how deep it is. You can suddenly become aware of an identity which you have been suffering from for a long time without knowing.

\subsection{Tuakiri tangata: identity and the evolution of consciousness}

In Spaces of Hope (2000) a prominent Marxist geographer, Harvey, entitles his last chapter 'The insurgent architect at work' (pages 233-255). The architect he describes is seen :

- embedded in a physical and social world full of manifest constraints and limitations; 
- as someone striving to change the world through thinking strategically and tactically about what to change and where, about how to change what and with what tools; and

- as a person who even when trying to change the world must somehow continue to live in the world which is full of contradictions and highly contested meanings and aspirations.

The idea of an 'insurgent architect' appeals as exactly the sort of change agent needed to progress the defining characteristics of an education for Māori rather than the accustomed schooling or socialisation of Māori discussed in Chapter 2, with the limitations imposed by the 'mediating structures' outlined in Chapter 4 and described and analysed in Chapters 5-8 of Part 2. Harvey (ibid. p.245) warns that,

\footnotetext{
As real architects of our future we cannot engage in endless problematisation and never-ending conversations. Firm recommendations must be advanced and decisions taken in the clear knowledge of all the limitations and potentiality for unintended consequences (both good and bad). We need to move step by step towards more common understandings.
}

I could not agree more. There has never been a time when so much interest was shown and so many resources directed toward the fulfilment of Māori aspirations in Māori education. A review of Ministry of Education Annual Reports on Māori Education from 1992-2000 reveal a most impressive range of policies, initiatives and resources devoted to improving the education of Māori students from early childhood to tertiary. From the Ministry of Education's point of view no area of focus has been better served throughout these years than that related to the revitalisation of Māori language. But therein lies a paradox. The time of the greatest official support for te reo me ngā tikanga Māori (language and custom) coincides with the moment in history when Māori have the least direct control over their traditional knowledge in everyday life; it is either dormant, lost, or seen as less relevant in a modern world. The so-called Māori renaissance has attempted to recreate a vibrant communally-oriented culture within a socio-political context that 
is individualistic, consumption-driven and not overly enthusiastic to what it perceives as a utopian, holding onto the past.

For an insurgent architect to do her work, the first step is to ensure the context is right. This is the briefest outline of a context for Māori education. It takes the idea that learning or education is the evolution of consciousness and that organisations are learning communities that foster that evolution ${ }^{13}$. In a phrase, Owen argues, "Learning, at its root, is nothing more nor less than the evolution of consciousness", and that, "context is the state or level of consciousness achieved by the organisation and the individuals involved" (1991:17). There is nothing particularly revolutionary about this. The stages of consciousness in learning could be described as E, D, C, B, A, where E represents the lowest level of consciousness and A the highest. These could then be matched against a reciprocal set of levels of organisational consciousness, for example, Z, Y, X, W, V, where Z represents the lowest level of consciousness and V the highest. We could match one set against the other to assess likelihood of fit-for-purpose of level of consciousness in learning with level of organisational consciousness.

Before we translate this idea into practical terms Owens comes up with a surprise. At the highest level of consciousness of learning he places spirit (A), which he defines as inspiration or everything we can be. At the lowest end is body (E) that he takes to be the elemental level at which spirit operates, it is about basic needs at this level. In terms of organisational consciousness, Owens places inspired at the highest level (V) and is where an organisation's performance exceeds the technical capacity of its members. At the lowest level is re-active $(Z)$ which defines the world of the entrepreneur where things are basic and primal. In between the lowest and the highest levels of learning and organisational consciousness are a further three levels. The full set is set out as follows:

\footnotetext{
${ }^{13} \mathrm{I}$ am indebted to a paper by Owen (1991) for providing the inspiration behind this idea. [http://www.context.org/ICLIB/IC27/Owen.htm].
} 
Figure 3.2 Matching levels of consciousness between learning and organisation

\section{Levels of Consciousness}

Learning

Organisation
A. Spirit
B. Soul
C. Intellect
D. Mind
E. Body
V. Inspired
W.Inter-active
X. Pro-active
Y. Responsive
Z. Re-active

If there is an inherent problem in the New Zealand education system as it affects Māori it is one of context. As it stands in history, the system has rarely been as bold as it was in establishing the Native Schools system in 1867. From time to time it has seriously attempted to incorporate elements of Māori knowledge, custom, arts and crafts, history/social studies and language into the system but never at the expense of sacrificing any of the major components of Pākehā consciousness and definitions of reality. But for Māori, there is no concept of being which excludes notions of spirit.

The introduction to a model called 'The evolution of consciousness' described above will be interpreted in both English and Māori (as tuakiri tangata) and as stated earlier, grounded in Chapter 8 and contextualized in Chapter 9.

\subsection{Agency and culture: summary}

Māori are tangatawhenua, New Zealanders, Kiwis and the indigenous people of Aotearoa New Zealand. Pākehā are New Zealanders and Kiwis but cannot be Māori, tangatawhenua or indigenous to Aotearoa New Zealand. It is not enough to argue that all were 'travellers' who arrived on these shores at different times even though that is true. Pākehā society has set itself up as the dominant society. As far as they are concerned this land did not even have a name before they named it; all events that took place here before their arrival were pre-history, that is, before history; and what really matters is who is in charge rather than who was here first. 
In Māori terms not only were they here before Pākehā, not only did they name the land and every part of it, and not only did they have a comprehensive articulated history of their association with the land recorded in whakairo/carvings, moteatea/verse poetry, and whakapapa/genealogies, they practised their history religiously on a day-to-day basis. Māori could have acted otherwise, that is, they could have decided that 'might is right' and allowed themselves to be gobbled up by the ever-intrusive Western mechanisms of hegemony but they have not. Despite the internal hegemony of cultural chauvinism, agency, exercised through the power of rangatiratanga/self-determination and mana motuhake/an independent spirit, has remained an important component of the relationship equation. It is a stubbornness without the negative connotation, it is a belief in the notion that Māori have a quality that is worth perpetuating, it is a confidence in the view that Pākehā will seek out this valuable relational quality that differentiates and distinguishes Māori from Pākehā. This quality is a heritage passed on through the millennia that embodies what it means to be Māori/tangatawhenua/indigenous to this land. 


\section{Chapter 04}

\section{A theory of mediating structures in Māori education}

\subsection{Introduction}

There are two elements that are central to the overall coherency of this project, firstly, the concept of mediating structures, and secondly, the nature of New Zealand society and the education system which derives from it. As was stated in the introductory chapter, a basic theme of this study is the integral role that education plays in moulding, shaping and reflecting the nature of Māori society to fit that of mainstream society. As discussed in Chapter 2, the major way mainstream education accomplishes that integration is through the ideology of Māori education. This is a study of the relationship between two educations and the way in which the mainstream variety has had a distorting effect on the developments within the latter, Mãori variation, to the degree that the establishment of separate systems is seen by advocates of kaupapa Māori schooling as a logical development. Not all Māori are advocates of kaupapa Māori schooling but that is not to say that those who are not advocates are opponents. Where a dilemma exists it is in the minds of mainstreamers who by definition are not comfortable with alternatives especially when the alternative is visibly minority-driven, for example, by Māori. Māori in mainstream education (MSE) as well as Māori in Māori medium education (MME) are described in Chapter 3 as belonging to a culture of those who are "multiply constructed across different, often intersecting and antagonistic discourses, practices and positions". The cultural capital which nurtures and sustains each cohort of the Māori population borrows liberally from at least two fundamental sources: one Pacific in origin embodied in what O'Sullivan (1999:225) refers to as the "primary matrix" and Royal (2003:xiii) as "te kahu o te rangi" (the fabric of the universe); and the second, in Western European values. These rich heritages have spawned a new Māori with one foot inside and the other outside the mainstream system. To the new Māori, an education that sets limitations on what it means to be Māori is 
inadequate in either the mainstream or Māori worlds and, therefore, is not acceptable; an education which promotes one sort of Māori to the detriment of the other is considered biased and, therefore, rejected; an education which prioritises either one, is seen as taking the choice away from where it ought to lie, that is, with the learner. Learners will choose from the moment that making a choice has meaning to him or her, where adequacy and priority will lie. This is the case argued in Chapter 3.

Chapter 4 is an attempt to account for the dominance of mainstream society/education on Māori society/education. It is maintained that educational dominance is the manifestation of processes established through what are called 'mediating structures'. It is postulated that the basic reasons mediating structures are central to Māori/Pākehā relations, derives from the socio-political and cultural backgrounds of the two societies. The Māori heritage is Pacific and indigenous to Aotearoa in origin and is profoundly collectivistic in nature; the Pākehā heritage is European and colonialist in origin and profoundly individualistic in nature. Both heritages have positive and negative impacts on each other but the nature and degree of impact each has on the other is determined by the political power specific to each body and the differentiated socio-cultural power shared by both bodies. In concrete terms, Māori culture has been severely damaged by a colonial force that deliberately set out to dismantle its 'beastly communism' (we can read into this its tribalism and its collectivism). In response, Māori have been in a constant struggle with the education system, to transform it so that it reflects its image of reality and to enable its aspirations to be realised. On the other hand, Pākehā society has seen how Europe emerged out of several defining revolutions (the Renaissance, the Protestant Reformation, and the Enlightenment) over several hundred years in which collectivism was virtually replaced by individualism. Pākehā society were not about to sanction a turning back of the cultural clock and certainly not to satisfy a disgruntled minority, not even when it could be shown that they had sound reasons for being disgruntled. It has always been in the interests of Pākehā decision makers to ensure that they maintained control of the 
education system. The coercive way to do that is through the mechanisms or processes of control and regulation but more importantly, for a modern, capitalist, and democratic society are those mechanisms that derive their power and authority through consensual and symbolic means. This is the role of mediating structures.

One further point needs to be clarified in this context. As implied by the colonial label placed on Pākehā society there is a necessary asymmetrical power relationship between the coloniser and the colonised. This does not alter the fact that some elements of both cultures are seen as worthy to be shared and others not. Some elements of the Pākehā materialist culture (clothing technology for example) and some elements of the Māori expressive culture (arts and crafts for example) constitute what I have called an imbricated cultural capital. Over time this overlapping rather than integrating or assimilating process has seen a gradual increase in the social category that shares an imbricated cultural capital.

The chapter begins with a general exploration of the concept of mediating structures as discussed in the sociological literature. The purpose is to elicit propositions around the third research question (RQ3), namely, 'How does the mainstream education system, through the mechanism of compulsory formal schooling, go about its business of transforming Māori students into subjects from one generation to the next?' The creation of a construct labeled Māori education is a partial answer to the question but the discussion becomes dangerously tautological. Examples of mediating structures that have operated in the broader context of Māori-Pākehā relations are introduced in an attempt to generalise the argument before explaining the selection of the four educational mediating structures that make up the data base of this study. The last part of the chapter sets out to provide a way of looking at each of these mediating structures. The first way of looking is through the perspective of sociology as seen through the lenses of functionalism, interpretivism, humanism and structuralism. These perspectives, or paradigms as Burrell and Morgan (1979) prefer to call them, are reasonably 
consistent with most other theorists of sociology. ${ }^{1}$ The second way of looking is through various mechanisms that are seen to regulate and/or control levels of inclusiveness and therefore participation of Māori in the system. The final way of looking reflects on the creation and reproduction of different cultural capitals that are seen as the result of the different modes of socio-cultural regulation and controlling processes within education. The chapter concludes with a set of propositions derived from the above argument.

\subsection{Mediating Structures}

According to Peter Berger (1979:169),

Mediating structures are those institutions which stand between the individual in his private sphere and the large institutions of the public sphere.

In the text where this concept is explored by a variety of authors (Mediating Structures and the Dilemmas of the Welfare State), Berger and his co-author, Richard John Neuhaus (1996) give four examples of mediating structures: neighbourhood, family, church, and voluntary associations. They say these institutions provide mediation by "constituting a vehicle by which personal beliefs and values could be transmitted into the mega-institutions". The mega-structures identified include,

the large economic conglomerates of capitalist enterprise, big labour, and the growing bureaucracies that administer wide sectors of the society (ibid.p.158).

Megastructures are described as "typically alienating" in that "they were not helpful in providing meaning and identity for individual existence" (ibid. p.159). Because mediating structures mediate by constituting a vehicle by which personal

\footnotetext{
${ }^{1}$ Some outline what they see as the major sociological paradigms. Kinloch, for example discusses organic-structure functional, conflict-radical, and social behaviourist-social psychological (1977: 294). Others focus on classical sociological theorists such as Marx, Durkheim and Weber (Aron, 1976) while a third approach fixes on some of the key ideas that sociology addresses such as community, authority, status, the sacred, and alienation (Nisbet, 1973). A fourth approach puts each of the above three approaches within broad themes. Zeitlin (1968) for example, organises his thoughts around the themes of the Enlightenment, post-revolutionary thought, the Marxian watershed, and the debate with Marx's ghost.
} 
beliefs and values could be transmitted into the mega-institutions, they were therefore, Janus-faced institutions, facing both upward and downward.

Their mediations were then of benefit to both levels of social life: the individual was protected from the alienations and 'anomie of modern life, while the large institutions, including the state, gained legitimacy by being related to values that governed the actual lives of ordinary people (p.148).

Berger and Neuhaus argue, "that an institution should be considered a mediating structure if indeed it fulfilled a mediating role" (ibid. p.149). Further on they caution that their definition allows some forms of mediating structures that may indeed play nefarious roles in society. In the New Zealand context organisations such as gangs and political neo-fascist groups and petty bourgeois extremist groups (Spoonley, 1987) are examples. As a safeguard Berger and Neuhaus suggest,

there are (to put it plainly) both good and bad mediating structures and that social policy will have to make this differentiation in terms of the values being mediated. (ibid. p.150)

Following this elaboration it is clear other institutions are possible, for example, the school and in the Māori context, the marae. It is equally clear that Berger and Neuhaus (1996) view mediating structures in a positive light, as mechanisms that ought to be utilised and recommended as a precaution against what they see as the "fatal embrace of regulation" (ibid. p.150). Mediating structures, they assert, despite the critics who see them as manifestations of eighteenth century tribalism and parochialism, are in fact empowering because of these characteristics. They see the resistance to massification, as well as opposition to the management mindset of modernisation, rationalisation and bureaucratisation, as being a critical component of the democratic process and an important development in the emergence of a paradigm of pluralism.

\footnotetext{
${ }^{2}$ Anomie is used mainly in sociological theories to mean a state of mind where there is a breakdown of common bonds, where normlessness occurs (not aware of what the norms of behaviour are).
} 


\section{Why mediating structures?}

The concept of mediating structures is not new and as Berger (1979:169) reminds us could be one of the central themes of the sociological tradition. The French philosopher and sociologist Emile Durkheim wrote in 1925:

(W)ith the exception of the school, there is no longer in this country any society intermediate between the family and the state (Durkheim, 1961:232).

Durkheim was so upset by the 'marked inclination toward a fierce individualism' that had developed in France that he envisaged the growth of new groupings so as 'to breathe life into the spirit of association'. He saw the school as being an important intermediate association. The weakening of the inclination toward collective life, according to Durkheim, can be rectified by the socialising functions of the school; to imbue in children the habit of expressing his interests and activities in various groups that will counterbalance the fierce individualism of French life.

Durkheim believed that intermediate associations such as the school had a moral imperative:

\footnotetext{
For morality to have a sound basis, the citizen must have an inclination toward collective life. It is only on this condition that he can become attached, as he should, to collective aims that are moral aims par excellence. This does not happen automatically: above all, this inclination toward collective life can only become strong enough to shape behaviour by the most continuous practice (ibid. p.233).
}

None of this, however, really answers the question of why mediating structures emerge, why they continue, or how useful they really are in relation to their espoused value.

Durkheim tells us they are a function of an overly zealous French individualism. Whereas from Berger we can infer that mediating structures are a kind of 'buffer' between what an individual can do in her private capacity and what she might be able to do if she knew how the mega-institutions of the public sphere worked; the mediating structures would assist her in some way to conduct her business in a 
way satisfactory to her. But why have they become necessary, assuming they have? Durkheim's life work was spent exploring what Giddens (1977:41) describes as his, "preoccupation above all with the confrontation between the dissolving 'traditional' society and the emergent 'modern' type".

Modernity then, according to Durkheim, is one of the reasons for the establishment of mediating structures. The concept of modernity, the processes of modernisation, and the phenomenon of modernism are deeply embedded representations of Western culture on the Māori psyche. With nineteenth century colonisation came modernity; with modernity, Christianity and capitalism; with Christianity and capitalism came the highest ideals of individualism, right to private property, and sovereignty of the people; and with these ideals followed the procedural standards located in impersonal bureaucratic administration, regulatory frameworks, and the separation of the public from the private spheres through the application of the scientific norm of objectivity. The three highlighted procedural standards play a prominent role in the critique of mediating structures as they are seen to operate in Māori education, while the way forward is via, what Furlong (in Davies, 1994:13) describes as "a sociology of emotion focusing upon hidden injury. Progress begins", he maintains, "when we see that educational structure is used not just to impose certain sorts of behaviour, but to construct young people in particular ways (which we insist) that they come to see themselves" (ibid. 1994:13, emphasis in original).

There is a sense in which a sociology of emotion does figure in this argument but more importantly is emphasised the need for a sociology of transformation and the search for what the Marxist geographers, Soja and Hooper (1993:198) refer to as "a 'thirdspace' of political choice - different but not detached entirely from the geographies defined by the original binary oppositions", for example, objectivesubjective, concrete-abstract, real-imagined, structure-agency, body-mind. 


\section{Types of mediating structures internal characteristics and processes}

From the very earliest associations with the outside world to today, Māori have welcomed strangers with what the French postmodern philosopher Derrida calls the "unconditional law of hospitality". He describes this as "a law which tells or invites us, or gives us the order or injunction to welcome anyone, any other one, without checking at the border who he or she is, what his or her nationality is, it's a way of being open to whoever comes" (Simmons \& Worth, 2001:27). In the same chapter, and as though to illustrate the point, Simmons and Worth describe the first Frenchmen to arrive on these shores in 1769 on board the Saint JeanBaptiste,

\footnotetext{
The fears which the French had entertained as they sailed toward New Zealand (17 December 1769) proved to be groundless. 'It is easy to imagine,' one of the officers wrote, 'the joy felt by our unhappy crew at finding themselves among people who had already treated us with humanity' (op. cit. p.11).
}

The point of this brief narrative is to emphasise the Māori culturally generated predisposition for establishing courteous relationships with others. Another cultural trait that has not deserted the Māori people, despite the gravest threats to their mana (self belief) and mauri (life force) as a result of the colonial condition, is that of patience. Yet those in positions of power have felt compelled to maintain a high level of challenge, boundary marking, and exclusivity against a Māori openness to working together and taking time to get the relationship right. This is where dominant hegemonic constructions such as is found in mediating structures play a role. Mediating structures bring parties together with the view to creating consensual relationships (much the same way that the role of powhiri (welcome ceremony) plays in bringing manuhiri (visitors) and tangatawhenua (locals) together). The difference is often a matter of purpose: why consensual relationships? If one party knew in advance that it stood in a position of advantage vis-à-vis another party why would it set out to negotiate or mediate consensual relations? The powhiri accepts as its baseline principle that the parties involved, given everyday circumstances, have equal mana and the ritual of coming together is to protect each other's mana and the mauri of each individual. The 
"unconditional law of hospitality" (ibid. p.27) is that koutou (you, the collective identity of manuhiri/visitors) and mātou (us, the collective identity of tangatawhenua/hosts), along with rātou (those, the collective identity of those connected to us who could not be present) are brought together symbolically and materially for this occasion as tātou (us combined, that is, the collective identity, koutou + mātou + rātou $=$ tātou).

Social formations that are created as a result of the colonial condition are in every case foundered on relations of dominant hegemonic construction. Attempts to appease the subordinate group by involving them in early discussions (review/advisory committees), committing them to face-to-face dialogue (consultation), appropriating their institutions (marae), and supporting the grounding of their cultural practices within new institutional forms (kaupapa Māori schooling) go some distance to share power and authority but Māori are never left in doubt that they are getting the 'best deal' they can expect at this time. First there is a mātou who is in charge. Then there is a koutou who mātou is prepared to allow some concession because (a) koutou were here before mātou, and (b) koutou and mātou were signatories to an historical treaty. Rātou are part of the historical legacy and will remain there while tātou, in its modified form, is part only of the national mythology to be brought out whenever appropriate to honour the Kiwi New Zealander.

\section{Sources of conservatism or agents of change?}

On the jacket of their recently republished book, To Empower People - From State to Civil Society, the authors, Berger and Neuhaus (1996) state,

\footnotetext{
that, unlike some aspects of today's political culture, the mediating structures proposal is not anti-government... The idea is that persons and persons in community are best situated to answer what Aristotle said is the (emphasis in original) political question: How ought we to order our political life together? In this sense, people do need to govern themselves. The 'state' does not instruct the people; the people instruct the 'state'.
}

They continue, 
The political question is also a moral question, and the mediating structures proposal will not go very far unless it engages the intellectual and moral energies of the next generation.

Berger and Neuhaus take a positive and conservative approach to mediating structures; they see them as good, worthwhile, and useful which is not surprising given the predisposition of both authors to an interpretive and religious orientation to sociological theorising. If anything, their approach to the workings of society sit more comfortably with Māori ways of thinking than the harder, more positivist and secular orientations of sociologists with a structural-functionalist inclination. This does create something of a dilemma for one who is trying to apply a more scientific and realist approach to an analysis of Māori education. Once again, the application of a sociological imagination provides some insights for perceiving mediating structures that can be both sources of conservativism and simultaneously, agents of change.

The purpose behind the creation of a mediating structure might be to control but it can also be used as leverage to undermine that control. The Treaty of Waitangi, the Native Schools, and the Māori Land Court are examples of this duality of purpose in practice. These are quite distinct from other structures that resulted from nineteenth century political and prophetic movements such as Kingitanga, Kotahitanga, Kauhanganui and the Repudiation Movement ${ }^{3}$. Where the former structures originated from the actions of Europeans to gain advantage over the land as well as the hearts and minds of the indigenous population, the latter movements had their beginnings in the actions of Māori with the object of holding onto tribal rangatiratanga in opposition to Pākehā impositions of individualisation, governance, confiscations and alienation. One set of structures sets out to separate, the other to hold on; one has the force of government behind it, the other attempting to simulate a parallel authority; but only the European-originated structures can be considered mediating structures as defined because they are an artifact of an asymmetrical power relationship, that is, they are created to force

\footnotetext{
${ }^{3}$ See Williams (1999) especially Chapter 4, The Land Tenure Revolution
} 
association. In effect, you will sign the Treaty so that we can become one people ("He iwi tahi tâtou" in the words of Hobson); there will be a Native Schools system so that you can become civilised like us ("...to bring an untutored but intelligent and high-spirited people into line with our civilisation," according to James Pope) (Simon, 1992:9); and there will be a Māori Land Court so that you will learn about the absolute priority of the individual ("In this context the transformation of customary tenure, a communal title often labeled 'beastly communism', into individual property rights that could be defined became an important element in the process of colonisation and civilisation", explains Stokes, 2002:2). The political and prophetic movements among the Māori population, however potentially transformative and successful each was during its time, only Kingitanga survives into the present. Where each had the potential to play a real mediating role between tribal communities and the Crown, a two-way exchange of equals was not in the interests of the Crown, successive governments, or the early settlers.

Van Til (1984:318) cites two American economists, Wilber and Jameson who describe what they see as the revitalising potential in mediating structures for the future of citizen participation:

\footnotetext{
Our modern political philosophies - liberalism, conservatism, socialism - have failed precisely because they have not understood the importance of mediating institutions. Liberalism has constantly turned to the state for solutions to social problems while conservatism sought the same in the corporate sector. Neither recognised the destructiveness to the social fabric caused by reliance on megainstitutions. Socialism suffers from this same myopia. Even though it places its faith in renewed community, it fails to see that socialist mega-institutions are just as destructive as capitalist ones.
}

The problem of getting Māori to participate fully and voluntarily within society has been a concern of all governments, of the corporate sector, of labour unions, and of state institutions for at least a century. There has always been Māori participation within mainstream society but always disproportionate. The reason relates to the illegitimate and/or unjust exercise of power, that is, "that tyranny is both a real and a potential consequence of participatory development, counterintuitive and contrary to its rhetoric of empowerment" (Cooke \& Kothari, (eds.) 
2001:3). Māori have learned like recruits in the army, that participation is not something one volunteers for. The penalty is too high unless the mediating structures available to you, operate in your interests as well as in the interests of others. The questions now are, in terms of Māori-Pākehā relations, which mediating structures are considered most appropriate and on what basis should that decision rest. We need to turn to the broad context of New Zealand society and consider the sort of education system it is trying to develop.

\subsection{The nature of New Zealand society and its education system}

The tenor of the discussion thus far treats mediating structures as a slippery concept, difficult to grasp and pin down to a finite definition. This can be seen as both a plus and a minus. Mediating structures as applied in this thesis, is consistent with the Italian scholar, Gramsci's concept of hegemony, especially as it relates to his discussion of consent and of coercion.

\footnotetext{
Gramsci uses the concept of hegemony in two ways. First, hegemony has the meaning of an exercise of control through moral and intellectual leadership by a dominant class over other classes.....The second meaning of hegemony refers to how the dominated and dominant classes relate to each other. By the use of both coercion and consent, but mainly the latter, the dominant classes uses its economic, social and intellectual leadership to present a universal and immutable view of the world' (Watkins, 1992:52,55).
}

The notion of class is substituted by culture or ethnicity within the New Zealand context but it is difficult to comprehend the difference. At the signing of the Treaty of Waitangi in 1840, Governor Hobson was recorded as greeting each of the Mãori rangatira who signed with, "He iwi tahi tătou" (we are now one people). This egalitarian gesture lives on in the New Zealand psyche from then to now as an assumed unchallenged, and rarely tested truism. Egalitarianism, so it seems, is so obviously just, as to require no justification. This is the point at which consent is made to do its work. Reliance on ideological constructions such as education, religion, and the media appeal to the everyday persons sense of justice, fairness, goodwill and commonsense in order to conform to the dictates of the dominant majority. Where consent breaks down, then the disciplinary mechanisms of 
coercion manifest in policies and regulatory frameworks, including legislation, are brought into play. Consent is highly dependent on the choice of mediating structures and the way in which they go about gaining consent. These structures are examined in some detail in Part 2 of the thesis.

This study of ME examines two major dimensions underlying the development in New Zealand of the society itself and of the education that it has nurtured. ME is a microcosm of these developments both affecting and being affected by them but in the final analysis not side-stepping the fact that in a modern democratic, capitalist society, education (Carnoy, 1974; Archer, 1984), like law (Sheleff, 1997) and most other ideological state apparatuses deal with social control. The key question then becomes, as we are reminded by Sheleff (p. 310), "whether social control is to be extensively imposed and rigidly enforced, or whether it is to be no more than a flexible guideline for action".

We begin with a sociological explanation of regulation and control versus transformation and change. Following Burrell and Morgan (1979) the sociology of regulation is concerned with maintaining six imperatives: the status quo, social order, consensus (voluntary and spontaneous agreement of opinion), social integration and cohesion, solidarity, and need satisfaction (individual or system needs can be satisfied within the context of existing social systems). The sociology of regulation follows a conservative politics. As to the sociology of transformation and change, its concerns are built around radical change, structural conflict, modes of domination, contradiction, emancipation, and deprivation.

As is true in all societies throughout history, the key problems to be addressed are those of how to survive, how to maintain order and how achieve sufficient unity to ensure continuity and stability in everyday life. Taking into consideration the values of regulation and change it is reasonable to assume that both will be called on in any society wishing to address these three problems. The mix will depend on societal orientation so that, for example, sacred-oriented societies will likely want 
to maximise unity, working together, being co-operative, gaining consensus, and building solidarity whereas, secular-oriented societies would likely be more concerned with gaining and keeping control, using adversarial approaches, and pushing all the time for progress. The first (sacred-oriented) prioritises regulation and equilibrium. Culture, especially, plays a prominent role in maintaining order, survival and unity. The second (secular-oriented) puts the emphasis on transformation and change. The creation of stable structures and people's understandings or consciousness of what counts as desirable changes is critical for the stability of the secular and conflict-oriented society. It is important to recognise the creative tension between change and equilibrium oriented societies. They exist in a dynamic dialectical power relationship between the sacred and the secular, traditional and modern, Māori and Pākehā.

There is a further complicating factor in this regulation/transformation model and that has to do with New Zealand's history as a colonising nation. The colonisers are the European ancestors of Pākehā, and those colonised, are the Māori ancestors of modern Māori. The dialectical power relationship between a somewhat sacredoriented Māori society and a secular-oriented Pākehā society is almost prioritising the suggested norms in reverse order, that is, Māori are constantly seeking change in the system while Pākehā continue to regulate to maintain control. As though that was not complicated enough, the point is also made in this thesis (Chapter 8) that an important consequence of the kaupapa Mãori agenda, at least as espoused by some in the field, is its fundamentalist leanings, conservative orientation, and utopian vision of a reincarnate warrior tradition. Transformation is then seen as the means toward a regulatory goal. Self-exploitation is still exploitation.

The second key component relating to methodology explores the assumptions about the nature of education in New Zealand with special reference to the objective versus subjective split that is a significant marker differentiating Māori education (ME) from mainstream education (MSE). To conflate the two concepts and treat them as variations on a single theme is to ignore or at least to underplay 
the fundamental differences that exist between them. Those who view the social world in objective terms see it as hard and tangible, with empirical entities that are prior to existence and consciousness. In those terms it is described as being realist. Compare this orientation with those who see the social world as mainly created or constructed by people for the benefit of people. This is the subjective view of the world that is value-bound and if we want to know how that world works, for example in education, then we need to elicit the points of view of educationalists and students. The problem about focusing on participants is that it is essentially relativist.

As in the previous discussion about transformation and change, again we have a creative tension between objective and subjective societal orientations. Nothing is ever all one, or the other, however, it is possible to ascertain an orientation to one or the other as they relate to societies or institutions. Pākehā society tends toward an objective orientation while Māori society is basically subjective-oriented. Again, the dialectical power relationship between the objective and subjective nature of the social world corresponds with the regulation-transformation dialectical power relationship of the dominant Pākehā and subordinate Māori social worlds. The theory of correspondence is only indicative but the experience of correspondence is much closer when society and its education system is viewed through a Māori lens.

The most significant values that define this society are those based on the aspirations of dominant mainstream society, that is, middle-class Pākehā New Zealand. Regulation/equilibrium based on objective analysis has priority but controlled evolutionary change defined as 'progress' is also seen as essential in an ever-changing world. There is, and always has been, an internalised incentive to maintain an umbilical-like attachment to the ongoing development of Māori society through education. An array of institutions and structures has emerged over the last 140 years to mediate the relationship between Māori and Pākehā in tune with the values espoused in Table 4.2 at the end of this chapter. 


\subsection{Mediating structures - function in Mãori-Pākehā relations}

For as long as I can remember, and a long time before that, Māori and Pākehā relations in virtually every walk of life within Aotearoa-New Zealand have been via some kind of moderating influence. At the time of the early settlers, the courts and the law played an important role in helping the settler to separate the land from the Mãori. And even before that, the treaty signed at Waitangi helped to divide Hapū tino rangatiratanga (Māori absolute authority) from Crown kawanatanga (Pākehā governance) and ultimate sovereignty. It is important to recognise, that neither the politicians of the day nor the settlers saw separation or division as important strategies in order to accomplish what they wanted. What they wanted was the opportunity to gain access to land and to settle it as peaceably as possible. Māori were not averse to this happening, indeed, the earliest associations between Europeans and local Māori were generally harmonious, albeit, heavy with curiosity. This curiosity was facilitated by three facts: that contact was mainly at the surface level and infrequent; that Māori and European were immediately open to material exchanges, and Māori clearly outnumbered Europeans.

Two of the earliest formal and political exchanges revolve around the Treaty of Waitangi and the establishment of the Native Schools system. Ideas about fairness come through in the literature about these two bold ventures to the degree that they can be seen to represent positive interpretations of mediating structures. The same cannot be said, for example, about the Native Land Court. The apparent unity of Pākehā settler society was juxtaposed with the apparent disunity among Māori village society yet there was no perceived need to influence that state of affairs, and indeed, the development of the colony was dependent on maintaining the condition of uneven development for as long as possible, or at least until such time as Pākehā society outnumbered Māori society ${ }^{4}$. Where the show of force could lead to conquest and therefore confiscation or raupatu there would be no necessity

\footnotetext{
${ }^{4}$ See Simon (1992:41) "At the time of the Treaty of Waitangi it is estimated Māori outnumbered Pākehā by $40: 1$. By the end of the 1850 s the two populations were almost the same".
} 
for mediating structures, which was the case in the Waikato. Raupatu, however, was not seen in the same light everywhere:

Taranaki Māori, unlike Mãori of other places, do not use 'raupatu', or conquest, to describe confiscations resulting from war. They use 'raupatu' for their marginalisation by the organs of the State, for on this view, they were never conquered by the sword but were taken by the pen (Williams, 1999:229).

Whereas these first three mediating structures serve to provide some historical perspective to this section the last three examples (NZEI-Te Miro Māori; Te Ohu Whakatupu, and 'The Tū tangata Way') are contemporary. What follows is a brief background on these six mediating structures.

\section{Treaty of Waitangi}

The Treaty of Waitangi, in its English form, is perceived by many as being a straight-forward agreement in that Māori ceded or transferred sovereignty and gave the Crown sole rights of pre-emption. In return, the Crown guaranteed Māori full exclusive and undisturbed possession of their lands, estates, forests and fisheries and other possessions, promised Crown protection and granted Māori the rights of British subjects.... The Māori text of the Treaty required that Māori cede kawanatanga (governance) over their land to the Crown, kawanatanga being the authority to govern their own people in the colony.

From the Māori text it is conceivable that they might have drawn the conclusion that they were being asked to share some of their authority with the British in a protectorate type relationship. The Ngāti Hauā chief Tarapipipi Te Waharoa echoed this interpretation about the Kingitanga movement, that is, that the Kīngitanga will help to govern Māori. Nevertheless, it seems inconceivable that a warrior race, numerically a majority of at least forty to one, could sign away their absolute authority. I am reminded of the words of the famous black Algerian psychologist, Fanon (1970:65):

The colonial, even when he is 'in the minority', does not feel that this makes him feel inferior. In Martinique there are two hundred whites who consider themselves superior to 300,000 people of colour. In South Africa there are two million whites 
against almost 13 million native people, and it has never occurred to a single black to consider himself superior to a member of the white minority.

Like colonised indigenous peoples everywhere, Māori are torn between two competing versions of social justice. They want to be a part of the society to which they belong and they want to be belong to the society that they are part of, that is, they choose, on the whole, to be Māori New Zealanders. Māori constantly find themselves in situations that are contradictory, where they are confronted with ambivalence, where alienation and anomie are frequent bed-fellows; Māori often experience the double-bind situation, a sort of heads you win; tails I lose dilemma. It is no surprise that Māori are seen by the public at large as being never satisfied with their lot. Survival in itself is not social justice. Rectifying past injustices is necessary but not sufficient in itself.

It is the context that has to be addressed. At the political level Treaty issues need to be constitutional issues. At the level of the education system, the relationship between the Crown and Māori is one that began with Māori (the Native Schools system, 1867-1969) as a separate system from the mainstream (the Education Act, 1877). Over time, the relationship in education between the Crown and Māori has developed into a 'fiduciary' obligation on the part of the Crown (Finn in Wardill, 2001):

A person will be a fiduciary in his relationship with another when and in as far as that other person is entitled to expect that he will act in another's interests or (as in a partnership) in their joint interests, to the exclusion of his own several interests.

Social justice as fairness, linked to a liberal interpretation of it as described by Strike (1989:30-31), has its foundations in values like the absolute priority of the individual, who will learn to become an autonomous and rational moral agent, and who will be free to choose his/her own conception of their own good. In traditional Māori terms, the liberal values espoused by Strike are almost the antithesis of Māori values. What chance then for a Māori interpretation of fairness? A Native Schools inspector reported in 1922 (Simon \& Smith, 2001:254): 
The Mäori race, notwithstanding the doctrine of the survival of the fittest, has a place in the economic scheme of things. 'The people are entitled to their place in the sun, and it is the bounden duty of the dominant race to lead them to it, gently if possible, firmly if necessary, but at all times patiently.

Although patronising, social Darwinist and racist, a generous interpretation would still find scope within statements like this for a positive 'spin' on fairness and therefore a chance for Māori and Pākehā to come to some agreed and socially just arrangement in the future. The Waitangi Tribunal is a mediating structure, created by the Crown to work in the interests of both parties to the Treaty to redress past injustices back to 1840 .

\section{Native/Māori Land Court}

Many of the early settlers left Britain for New Zealand with the specific intention of acquiring land which they were led to believe was reasonably priced and readily available to purchase, as well as being of high quality for production purposes. One of the early stumbling blocks they encountered was to do with the problem of title. As Kawharu writes in the foreword to Williams (1999: xvi),

\footnotetext{
Settlers had come to learn, their demand for tribal land could not be satisfactorily met unless the land was clothed with valid title.
}

Thus was created the Native Land Court later to become the Māori Land Court. The 1865 Native Lands Act established the Native Land Court that was required to individualise Māori land tenure before individuals sold land, thus accommodating colonisation and fostering detribalisation. The effect was to force assimilation. Nowhere is this point made more dramatically than those expressed in the words of the historian Ward (in Williams, op.cit. p.18),

\footnotetext{
the real problems and the real short-changing of the Māori, began precisely when they looked like becoming too effective in their mastery of the techniques of government and administration and would use their skills to close the land to settlement. For the settlers wanted the land, and the law was continually framed to deny Māori more than a minor share in state power and control of resources. That most precious institution of British culture, the rule of law, was prostituted to the land grab, and brought into the contempt in which many Mãori today regrettably still hold it.
} 
Apart from the unscrupulous separation of Māori from their traditional lands ${ }^{5}$, the Native/Māori Land Courts played a significant role in diminishing the collective tribal orientation of Māoridom in favour of individualisation (Stokes, 2002), and contributed as well to the destruction of traditional leadership hierarchies by establishing a new and powerful class of Māori interpreters who were not necessarily rangatira or tohunga but had the good fortune of being associated with the settlers and could speak English and were therefore called on to translate for the Minutes of the Māori Land Court. It is a mendacious use of language to suggest that the Māori Land Court was set up to work in the interests of Māori. On the contrary, it was as Māori quite correctly labeled it, 'te kooti tango whenua', the land-eating court and documented graphically in maps of the North and South Islands of New Zealand showing the disappearance of lands owned by Māori in 1860, 1890, 1910 and 1939 (Ward, 1999:162-166).

There can be no mistaking the advantages to the colonising government and settlers of the nineteenth century, and later their descendents also gained by the creation and work of the Native/Māori Land Court. As a mediating structure, the Māori Land Court has been a total failure. As a hegemonic tool for the destruction of a society's political, spiritual and economic base, it would be difficult to say what instrument could have been more successful.

\section{Native/Māori Schools}

(The Native Schools) system had been established in accordance with the 'civilising' agenda of the nineteenth-century state, specifically to facilitate the 'Europeanising' of Māori. The Native School was thus intended as a structural interface between Māori culture and European culture - a site where the two cultures would be brought into an organised collision, as it were - with one culture being confronted by the other in a systematic way (Simon and Smith, 2001:3).

The idea of a structural interface is the equivalent mediating structure of this study. Not much else needs to be said about the Native/Māori Schools system at this point given coverage in Chapter 2 and again in Chapter 8 . The volume of studies

\footnotetext{
${ }^{5}$ Documented in a host of Waitangi Tribunal Reports dating from 1978 to the most recent Te
} 
done on the Māori Schools suggest that on the whole these were the nearest institutions of those created by a central government to operate as mediating structures as defined above. At worse, those officials closest to them were patronising and paternalistic but the schools lasted a hundred years because not only did Māori come to 'own' them in a psychological sense, but they also captured the attention of many Pākehā professional educators who believed in what they were doing in helping to integrate two different but intelligent peoples.

\section{NZEI-Te Miro Māori}

The New Zealand Educational Institute is the Early Childhood and Primary School Teacher Union. Te Miro Māori came into existence in 1992 having been earlier recommended in the 1990 report to the annual meeting:

The Institute shall give honour and effect to the Treaty of Waitangi with Māori and Tauiwi being equal parties in Institute operations (Hamilton, 1992:124).

Te Miro Māori was not a centre or a unit but a structure that more or less paralleled the mainstream, or more accurately, the 'Tauiwi' strand. Hamilton spells out the purpose and role of Te Miro Māori in seven statements (1992:124):

(a) represent Māori issues and Māori members in Institute operations;

(b) make decisions about Māori issues;

(c) mobilise Māori member involvement in Institute operations;

(d) select those who will represent Māoridom on Institute business;

(e) promote understanding of Māori needs and aspirations;

(f) be one of the parties that will aid the development of a bicultural Institute and education system; and

(g) take responsibility for the development and mobilisation of NZEI Māori education policy.

The priorities for 1992 onwards will be to develop and establish links between existing structures and the Miro Māori, and redistribute resources so that both parties in the partnership can be effective. 
It is clear that from 1992 Te Miro Māori has operated within NZEI as a mediating structure whose role is to be an agent of change in transforming the education system from within. The development of the structure has made it possible "to empower Māori (teachers) to make decisions" while "requiring the NZEI to provide sufficient resources and energy to implement and support the decisions" (Hamilton, 1992:132).

\section{Te Ohu Whakatupu}

As the senior Māori policy analyst in the Ministry of Women's Affairs, Tahi asks, "How can we, as Māori women, effectively impact on the development of policy where government is overwhelmingly dominated by policy makers and politicians who are white and male?" (1995:65). In the Ministry of Women's Affairs, Te Ohu Whakatupu, as the Māori Policy Unit, was at least part of the answer to that question. Tahi was initially an analyst and later its manager during the very important 'bedding-in' phase of the economic reforms of the Fourth Labour Government. According to Tahi, it was important that in giving policy advice to the government, Te Ohu Whakatupu was not about "accepting conventions at the outset" and that it was critical that they "questioned assumptions and pushed boundaries" (p. 73). In her view, the motivation within their unit was "to optimize opportunities for Māori in a Pākehā dominated society" (p. 62). At this time (1980s-90s), ideas about a bicultural New Zealand society, the promotion of equity principles to promote the interests of women, and rectification of past injustices against Māori through the workings of the Waitangi Tribunal figured prominently in the work of all government departments. One of the structural manifestations of this period was the establishment of specific Māori units or centres within government departments to provide a focus for their responsiveness to Māori. Te Ohu Whakatupu was such a unit (the Ministry of Education had Te Wahanga Māori; the Education Review Office had Te Uepu; the New Zealand Qualifications Authority had Te Whānau, and so on). 
As a mediating structure, Te Ohu Whakatupu under the leadership of Tahi, clearly operated as a catalyst for change even as it set out to accomplish the more liberal goals of the government of the day. Te Ohu Whakatupu was challenging its own department, government and society itself "to move beyond biculturalism as theory and policy and apply it practically, as good business practice" (p. 61).

\section{The 'Tū Tangata Way'}

Tu Tangata Way, in the words of its own publicity brochure, is about "bringing our places of learning into the daily lives of our children" (frame 12$)^{6}$. It does this by "positioning the community on site with their children everyday" (frame 13) to produce safe schools, better motivated and more positive students, academic and social enhancement, substantial increases in learning time in classrooms, reduction in truancy, drug use and suspensions, and teachers who are more successful as teachers (frame 14). How does it do this?

The Tu Tangata Way has a paid community workforce in the classrooms everyday.

The community workers have specific job tasks everyday that they are required to complete. The relationship between teachers, community workers, and the students are expected to be new and unique. Because of the additional support available the

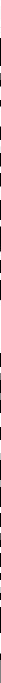


The six mediating structures reviewed represent at least three that are well known by the New Zealand public and three that are known mainly by specific interest groups. All of them are politically conservative in the sense that they mainly serve advocacy roles and recommend to higher order decision-making bodies. In studying mediating structures such as these, one is often left with a taste in the mouth that the appetite has been whetted but the main course has yet to be served. The mediating structures that make up the data base for this research are discussed below as a moderately expanded interpretation of Table 1.1 in Chapter 1 .

\subsection{Mediating structures in Māori education}

Orthodox sociological models (Burrell \& Morgan, 1979) are applied to an analysis of a selection of four mediating structures used extensively in ME over the period $1960-2000^{7}$. The sociological paradigms referred to in Burrell and Morgan's text (functionalism, interpretivism, humanism, and structuralism), will be modified and reframed in this discussion as 'sociological orientations' to avoid the boundedness of a purely sociological perspective. In theoretical terms the orientations are seen as mutually exclusive. The exclusivity of each orientation is deliberately constructed to assist analysis although in reality there may well be more continuity between the models than is shown in this study. The orientations are meant to describe distinctive ways of looking at the world, whether Māori or Pākehā, ME or MSE. They represent ways of seeing and therefore provide alternative views of social and educational reality.

In the selected mediating structures they are treated like 'terms of reference'. This is a more precise definition and, more importantly, suggests a way to proceed, or

\footnotetext{
${ }^{7}$ It is important to note that the thesis is not primarily about particular sociologists, specific sociological theories, or sociological paradigms but I am indebted to some sociological studies for the insights they bring to an analysis of Mãori education. Burrell \& Morgan's (1979) macro analysis of sociological paradigms is clearer than most I have read; Mills' (1977) sociological imagination appeals to my inclination to mix categories and stride across different perspectives; while Barnes' (1995) social theorising is exactly the sort of discussion needed for this chapter on mediating structures in Māori education.
} 
sets guidelines for action in relation to some specified problem The term paradigm, at least as envisaged by Kuhn (1962), came about as a description after the event of some practice of 'normal science' was interrupted by brief periods of 'revolutionary science'. The brief period that each mediating structure is explored, hardly justifies more than what is generally understood when talking about a 'terms of reference'. Orientation, on the other hand, has the opposite effect from terms of reference; it is less precise, more generic. The four sociological orientations outlined, are not clearly demarcated one from the other. Each sociological orientation is, in effect, associated with at least two other adjoining orientations. The sociological orientations represent fundamentally different frames of reference. They present themselves, therefore, as alternative models for the analysis of social processes. A brief outline of the four sociological orientations and the reasons for the selection of the corresponding four mediating structures follows.

\section{Functionalism - reports on Māori education}

Writing about educational planning in New Zealand, one of education's senior officials writes,
In the last analysis 'educational policy and planning' cannot really be separated from 'national development planning' in its broadest sense. The aims and policies of the education system need to be in essential harmony with the goals of the type of society we are trying to create, the nature of the economy we are seeking to build up, and the maintenance of general social, cultural, and environmental viability in New Zealand (Preston in Renwick \& Ingham, 1974:81).

These words contain the main ingredients for a functionalist approach to education. They pre-suppose the rationality of planning for unknown futures; they assume a coherence between the aims of the system of education and the goals of society at large; they accept that education has a contribution to make to the economy and New Zealand culture in general; while the use of the abstract 'we' implies those situated in the culture of policy making are involved in a normative exercise which includes the ability to win and shape consent. Functionalism is concerned with providing explanations of the status quo, maintaining social order, 
gaining consensus, and meeting people's needs. It has a strong individualist orientation, with a mainly objectivist appreciation of the nature of the social world. Functionalism tends toward a realist ontology.

With regard to the chapters on mediating structures (Chapters 5 to 8 ) we will explore each in terms of answering two questions: (a) what are the critical forces that shape Māori participation; and (b) what are the processes for controlling, or the modes of regulation, that are incorporated to gain consensus?

\section{Interpretivism - processes of consultation}

The interpretive orientation to sociology sees as its primary concern, the issue of how to explain the world, as it is perceived through the eyes of the participants. There are several substitute names for interpretivism, for example, hermeneutics and phenomenology and they are all troublesome to explain especially to functionalists who perceive interpretivism as idealist and strongly oriented to a collectivistic orientation. Interpretation plays an important role when trying to determine the meaning of things. Wilber argues that,

no amount of analytic-empirical-scientific data, no matter how complete, can
totally establish meaning.... Rather, meaning is established, not by sensory data,
but by unrestrained communicative inquiry and interpretation (1981:32).

Two questions critical to an understanding of the interpretivist orientation, as this applies to the world of education, are (a) what counts as knowledge; and (b) who said? These questions belong to the specialist field of the sociology of knowledge. One of its leading proponents is the American sociologist Berger (1971:128). He describes the field in these terms:

It concerns itself with the social location of ideas. It rejects the pretence that thought occurs in isolation from the social context within which particular people think about particular things. Ideology enters the picture when a certain idea serves a vested interest in society, or when an interpretation of social reality is needed so that justification is made plausible. Ideology is a kind of self-deception but it is not lying; the liar knows he is lying; the ideologist does not. 
The processes of consultation in Māori education are explored under an interpretivist orientation because interpretation and translation are always the key determining factors whenever consultation occurs.

\section{Humanism - institutional marae}

The primary commitment of a humanistic orientation is to change consciousness through critique. As with the interpretivist orientation, humanism also tends toward a collectivist and sometimes, even anarchist individualistic approach. The French sociologist, Althusser (in Coward \& Ellis, 1979:87) writes, "humanism seeks to explain society and history by taking as its starting point human essence, the free human subject of needs, of work, the subject of moral and political action". As might be expected, given the pastoral-like historical relationship between education interpreted as schools, teachers and students, there is a strong humanistic tradition in education. Combs (1981) describes the humanist orientation to education as,

a commitment to educational practice in which all facets of the teaching/learning process give major emphasis to the freedom, value, worth, dignity, and integrity of persons. More specifically, humanistic education:

- accepts the learners' needs and purposes and develops experiences and programmes around the unique potential of the learner;

- recognises the primacy of human feelings and uses personal values and perceptions as integral factors in educational processes;

- develops a learning climate that nurtures learning environments perceived by involved individuals as challenging, understanding. supportive, exciting and free from threat; and

- develops in learners gemuine concern and respect for the worth of others and skill in conflict resolution.

The mediating structure of institutional marae is investigated under a humanist orientation because it is probably the only Māori structure that exists within education, it is a traditional institution that dates back more than a thousand years, and it is supposedly positioned within mainstream institutions to serve the cultural interests of Māori students as well as being present in concrete form to influence the consciousness of non-Māori students. 


\section{Structuralism - Māori medium schooling}

My argument is that the real commitment ought to be a 'radical structuralism' rather than a radical humanism although they need not be mutually exclusive. Perhaps radical humanism is a necessary pre-requisite to radical structuralism. Radical structuralism calls for a change to the social order by changing structures and/or modes of domination. The Māori medium Education (MME) movement, at its most transformative edge, includes te kōhanga reo, kura kaupapa Māori, wharekura, wānanga, Te Ataarangi and the notion of a Māori education authority and is an attempt to create an alternative structure for the delivery of education. In terms of mainstream, an MMP parliament is a structural creation designed to promote a fairer representation of New Zealand's population at the level of government and as a result there are more Māori in parliament since MMP than ever before. A Māori network of regional radio stations and a national television channel is an alternative communicative network and has had a profound effect on Māori self-perception because now there is a 'Māori voice' or more accurately, 'Māori voices' being heard nationally as well as locally. These structural creations are all important contributions toward the establishment of a socially just society.

The question of whether education merely reflects society or whether it has a role in changing society takes us into the binary trap again of choosing one over the other rather than both in a relational dialectic. Bourdieu and Passeron (in Giroux, 1982),

postulate that the content of a given group's culture is an arbitrary selection, and, furthermore, that cultural systems characteristic of social groups are assigned positions in a 'dominance-subordination' hierarchy. They argue that the 'system of education' then reproduces the culture of the dominant groups so that power relations between groups are socially reproduced in such a way as to ensure the continuance of dominant group hegemony..... They define 'symbolic violence' as the power of the school to impose and inculcate children with a culture which reproduces social conditions and relations which are supportive of the dominant group.

Research on the implementation of kaupapa Māori into the education system, even though little more than two decades old, already has a lively literature that 
underlines the systemic resistance and symbolic violence brought to bear against those who would challenge existing structures (Smith, G.H., 1997; Rata, 1991).

The rise of Māori medium schooling is the fourth and final mediating structure explored in this study.

Table 4.1 The primary concerns of four sociological orientations

THE SOCIOLOGY OF CHANGE/TRANSFORMATION

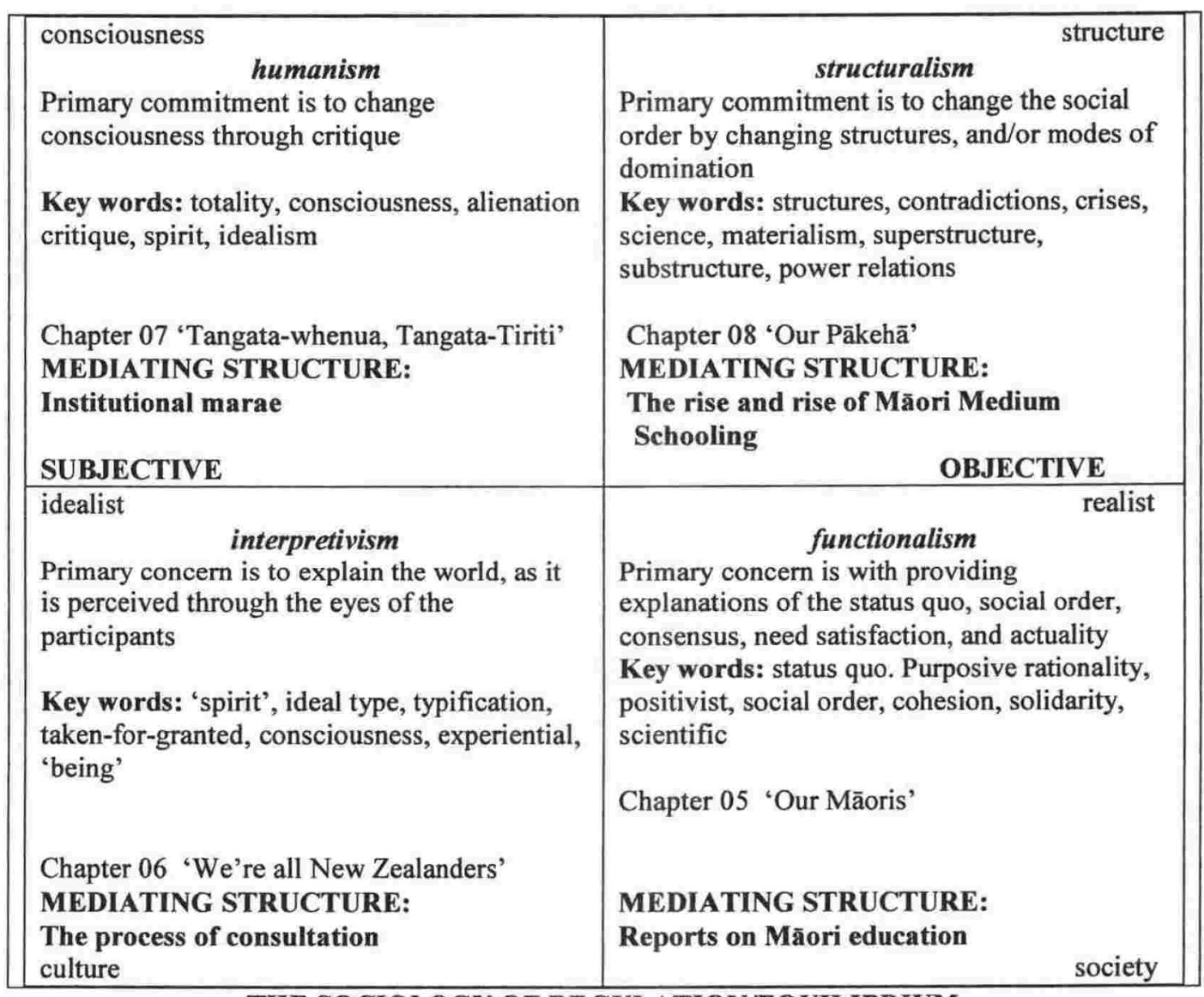

THE SOCIOLOGY OF REGULATION/EQUILIBRIUM

Adopted from Burrell \& Morgan (1985)

\subsection{Propositions for a theory of mediating structures}

The overview discussion on mediating structures, and the four foci specifically selected to illustrate the role mediating structures play in reproducing the policies 
and practices that constitute Māori education, can now be restated as propositions for investigation. Reports on Māori education (Chapter 5) and the processes of consultation (Chapter 6) are, and have been official practice for several decades. They are analytic-oriented mediating structures with value-generating and valuemaintaining agendas. The second two, institutional marae (Chapter 7) and Māori medium schooling (Chapter 8) are programmatic-oriented mediating structures that draw Māori in and away from official definitions of what Māori want (how they get their meaning, identity, fulfilment). Where the first two are seen as disempowering the second two are seen as containing possibilities for transformation.

A first proposition is that mediating structures in education operate to distort what Māori want from schooling, namely, meaning, cultural identity and personal fulfilment, that is, the same as what everyone else wants from education. One prominent form in which this distortion is manifest is in the area of Māori academic under-achievement (Chapter 2).

A second proposition is that if the first two mediating structures dealing with reports on ME and processes of consultation - (Chapters 5 and 6) could be more like the second two on institutional marae and Māori medium schooling (Chapters 7 and 8), the political order for Māori would be more meaningful. Mediation processes between institutional life and the values and realities of individual life for Māori would be more familiar, hence Māori would feel 'more in control of their own destiny'.

A third proposition stems from a busy area of study called the 'identity politics of place - who am I' and a 'spatialised politics of identity - where am I?' which was introduced in Chapter 3 and the major component of Part III of this research. Resistance to disempowering mediating structures as they exist in ME is about commitment to challenging the hegemonic constructions of place, of politics, and of identity. On the other hand, institutional marae (Chapter 7) and Māori medium 
schooling (Chapter 8) provide a platform for dissecting and critiquing essentialist uses of concepts like culture, ethnicity and race. To be caught up in the traditional binary of Māoritanga (cultural capital 1) and Pākehātanga (cultural capital 2) constrains us from recognising what the American professor of English and humanities, Michaels (1992:680) warns as not being able to account for the discovery of 'new ways to be different' as he describes reinvented culture (cultural capital 3). This is my reference in Table 4.2 below to an hypothesised imbricated education system and is the central recommendation of this thesis. It can be likened to the political 'third way' (Giddens, 2000) or 'thirdspace of political choice' according to Soja and Hooper referred to earlier in this chapter.

The research set out to provide a rigorous examination of the mediating structures, particularly reports on Māori education and the processes of consultation because they are the officially initiated practices that need to be minimalised because of their negative effects on Māori. The second two, institutional marae and kaupapa Māori schooling beg the question of whether they can or should be utilised further in the interests of ME.

Table 4.2 is structured to illustrate the way in which mediating structures produce and reproduce both Māori and Pākehā cultural identities. In a very general sense it assumes a generic Māori cultural capital exists (the characteristics down the left side of the table), and a generic Pākehā cultural capital also exists (the characteristics down the right side of the table). It is assumed further that in an education system dominated by one cultural group (Pākehā) the other cultural group (Māori) will be consistently disadvantaged for no other reason than it is a minority as well as being culturally subordinate. A third assumption is that pressures to assimilate the minority into the Western philosophical world is a constant feature of an education system designed in the interests of the majority. Matching this assumption is an ongoing struggle from Māori to retain its authentic identity by appealing for the inclusion in the system of increased elements of the kaupapa Māori agenda. It is hypothesised that there already exists within New 
Zealand society a growing number of New Zealanders (predominantly Māori) who already know how 'to walk in both worlds' and many more (all other New Zealanders) who want to know how to. It is suggested that the greatest scope for creating a more just and ethical society depends on the overlap of the two main cultural capitals but the acceptance of mediating structures needs to be called into question.

Table 4.2 The emergence of different cultural capitals

A Theory of Mediating Structures in Māori Education The Social and Cultural Reproduction of Māori Identity

\begin{tabular}{|c|c|c|}
\hline $\begin{array}{l}\quad \text { Kaupapa Māori } \\
\text { (Māori cultural capital) } \\
\\
\text { - sacred oriented } \\
\text { - ontologically subjectivist } \\
\text { - epistemologically } \\
\text { relativist } \\
\text { - human nature - determinist }\end{array}$ & $\begin{array}{l}\text { Māori-Pākehā imbricated } \\
\text { cultural capital } \\
\text { Ch.2 The Ideology of Māori } \\
\text { Education } \\
\text { Ch.3 Māori Identity } \\
\text { Pākehā dominant/Māori } \\
\text { subordinate education system: }\end{array}$ & $\begin{array}{l}\text { Western Philosophy } \\
\text { (Pākehā cultural capital) } \\
\text { - secular oriented } \\
\text { - ontologically objectivist } \\
\text { - epistemologically positivist } \\
\text { - human nature - voluntarist }\end{array}$ \\
\hline \multicolumn{3}{|c|}{ Thesis Methodological Mode } \\
\hline - mainly ideographic & $\begin{array}{l}\text { Ch. } 4 \text { 'mediating structures' } \\
\text { \& 'controlling processes' }\end{array}$ & - mainly nomothetic \\
\hline \multicolumn{3}{|c|}{ Modes of Socio-Cultural Regulation } \\
\hline $\begin{array}{l}\text { - priority of the collective } \\
\text { - role of tikanga }\end{array}$ & $\begin{array}{l}\text { dividing practices/manipulated } \\
\quad \text { consensus } \\
\text { Ch.5 'Māori Education Reports' } \\
\text { modes of inquiry/constructive } \\
\text { dialogue } \\
\text { Ch. 6'Role of Consultation' } \\
\text { self- } \\
\text { subjectification/culturalcontrol } \\
\text { Ch.7 'Institutional Marae' }\end{array}$ & $\begin{array}{l}\text {-priority of the individual } \\
\text { - role of the law/regulation }\end{array}$ \\
\hline
\end{tabular}

Modes of Cultural-Educational Transformation

\begin{tabular}{|c|c|c|}
\hline $\begin{array}{l}\text { - manaaki tangata } \\
\text { - tātou tātou } \\
\text { - tino rangatiratanga } \\
\text { - whakawhitiwhiti kōrero } \\
\text { - contribution through } \\
\text { participation }\end{array}$ & $\begin{array}{l}\text { A theory of Māori schooling } \\
\text { self-subjectification/cultural } \\
\text { control } \\
\text { Ch.8 Māori medium } \\
\text { schooling/immanent } \\
\text { transformation }\end{array}$ & $\begin{array}{l}\text { - hierarchy } \\
\text { - bureaucracy } \\
\text { piecemeal intervention } \\
\text { - authority and control } \\
\text { - purposive rationality }\end{array}$ \\
\hline
\end{tabular}

Hypothesised Imbricated Education System

\begin{tabular}{|l|l|l|}
\hline - Mãori medium education & $\begin{array}{l}\text { Ch. 9 'What it means to be an } \\
\text { educated citizen of } \\
\text { Aotearoa/New Zealand'. }\end{array}$ & - bicultural education \\
\hline
\end{tabular}




\section{PART II Mediating structures in the development of Māori education}

\section{Introduction to Part II - The Data}

One of the most consistent messages conveyed throughout the history of Māori education has been that which has called for more and more participation of Māori within the education system. Slogans like, 'We need more Māori teachers', 'Teachers can't do it alone', 'Māori parents must work in partnership with educationalists', 'Māori leaders must encourage their students to stay at school longer', and 'Māori parents are needed on boards of trustees' have been in the public domain for many years. What is the problem of participation? How has it been addressed? What has been the effect of attempts to close the participation disparity? Even the Native/Māori Schools, it was argued in Chapter 2, were intended only as a transition in the development towards an inclusive mainstream system of schools and educational facilities. What were the critical forces that would shape Māori participation within the education system throughout this history, especially those of the period 1960-2000? What were the elements of development that formed part of the struggle between mainstream and Māori for control of the educational agenda which, as is well recognised, is synonymous with the control of the hearts and minds of young people as well as the development of their intellect? What has been the effect on Māori?

Chapters 5-8 contain the data chapters on mediating structures. The key research question being investigated is, 'How does the mainstream education system, through the mechanism of compulsory formal schooling, go about its business of transforming Māori students into 'subjects' from one generation to the next?' (Research Question 3). The question is informed by what Foucault (1982:777-778) calls 'modes of objectification', namely, dividing practices, modes of inquiry, and self-subjectification. Nader et al (1997:1) gives us an alternative set of 'controlling processes', namely, manipulated consensus, constructive dialogue and cultural control which are seen to operate in a manner similar to Foucault's 'modes of 
objectification'. The answer to RQ3 is through the work of mediating structures, specifically, the four that make up the data base of Part II.

Education reports (Chapter 5) and face-to-face consultations (Chapter 6) have been the mainstays for many years for communicating the system's intentions, and at the same time, for evaluating the level of agreement among communities of policy directions recommended. The institutional marae (Chapter 7) is a different proposition in that like Māori medium schooling they arose out of Māori communities choosing to participate in a manner familiar to them. Severe criticisms of education reports and consultations from Māori often would draw heavy flak from mainstream education, while similar criticisms of institutional marae and Māori medium schooling (Chapter 8) would likely draw an equally embittered response from Māori educational sources. I accept that those criticisms of my research might be forthcoming. My concern is less about the backlash my work might attract than the comprehensiveness and cohesiveness of my analysis of the four mediating structures. As a precaution the selected mediating structures have been subjected to a composite set of analytical tools borrowed from Foucault (1982), Nader et al (1997), and Van Til (1984) and others. An introduction to the contributions from Foucault and Nader appears in Chapter 1 under RQ3 and again under Proposition 2.

In an article on policy studies Van Til (1984) writes about three important megatrends in citizen participation: the shift from centralisation to decentralisation, from representative democracy to participatory democracy, and from a focus on hierarchies to networking. These trends are also evident within educational developments in New Zealand and make up an important component of the discussions on mediating structures set out in Chapter 4 of this research. There is, however, one further megatrend, if it can be called that, which persists and that is the one of maintenance of the status quo, of continuity with the way things are. This is a state that doesn't happen automatically; it continues because some people in positions of influence want the status quo to remain. When these 
four megatrends are viewed in the light of some of the critical forces that have, and continue to shape the participation of Māori in education, we begin to fill in the development gaps that have made Māori education the unique configuration that exists today. The four critical elements of development identified by Val Til (ibid.) are appropriate for this study. They are social justice, communications, lifestyles/life chances, and cultural mobilisation.

Where participation relates to social justice, we are reminded that rewards within a society are not equally shared whether they are economic, educational or otherwise. However, it is important for the system that those disadvantaged feel that they are deserving of what they receive, as somehow being inevitable and right, because they are a minority. Co-option plays an important role in this charade in order to achieve consensus, even of the manufactured variety made infamous by Chomsky ${ }^{1}$. Participation patterns vary in education depending on the level of relevance of the education offered because people need to feel that the education they receive they must accept compulsorily as being in their interests. Access and opportunity are critical but they are not sufficient in themselves. The element of social justice is explored in Chapter 5 in an analysis of reports on Māori education. These reports constitute the initial mediating structure of this research.

The second critical force shaping participation is what Van Til identifies as communication (1984:313). According to him, "communications affect participation because persons must interact to advance personal and economic interests" (and, we will argue, educational, and race relations interests). In Māori terms, kanohi-ki-te-kanohi, as in face-to-face interactions, has priority over all other forms of communication but in terms of Māori custom, the primary interaction is where the relationship is negotiated and agreed. It is not a tacit affirmation in advance of negotiation if the dialogue that follows is to be a

\footnotetext{
${ }^{1}$ Noam Chomsky (undated) Manufacturing Consent - A feature documentary by Mark Achbar \& Peter Wintonick. Video Education Australasia Pty. Ltd, Bendigo, Victoria, Australia.
} 
constructive one. The element of communication is explored further in Chapter 6 in our discussion of consultation as a mediating structure.

Life-style/life-chance is the third factor affecting participation. In the midst of a consumer-oriented society where individualism, privatisation and competition triumph, Māori continue to hold firmly to collective concerns like whānau, hapū and iwi (family and tribe) as well as the ecological rootedness of whakapapa (genealogical links to place). There is a problem where life-style becomes a priority and that is when it becomes an end in itself. As an example, institutional marae are not created with the view of replacing traditional marae or to increase the number of marae facilities in any specified area. They will never service a kinbased community for any extended and continuous period of time. In a legal sense, they are the property of the institution where they are located. Focussing on lifestyles to the detriment of life-chances is to elicit accusations of 'culturalism' (Rata, 2000:24). The problem relates to the vulnerability of self-subjectification where the critical forces doing the shaping are one's own. Instead of being exploited by outsiders one is exploited by insiders. The problem is not about who is doing the exploiting as the fact that exploitation occurs at all. The element of life-style/lifechance affecting participation is elaborated in a discussion of the institutional marae as the third mediating structure of the thesis and is the content of Chapter 7.

Cultural mobilisation is the fourth factor affecting participation. The political shift from a highly centralised education system to a more decentralised one made possible in the educational reforms of the late 1980s and early 1990 s helped facilitate the Māori medium schooling (MMS) movement. There is a close affinity between the manner in which institutional marae operates and the development of Māori medium schooling. Both depend on modes of cultural regulation that make self-subjectification an important mechanism for asserting difference; both rely heavily on cultural control mechanisms that are fundamentalist and essentialist in nature; and both emerged out of Māori discontent in education and a powerful 
desire to take control over their own educational future. The mediating structure of Mâori medium schooling is explored in Chapter 8.

These four critical forces have shaped Māori participation in education and will be discussed in more detail in the appropriate chapters of Part II.

The megatrends and the forces shaping participation suggest a number of participatory futures that will be call scenarios. The first of these refers to the notion of status quo and is therefore hierarchical. At the other end of the participatory spectrum the scenario is transformation. A liberal extension of the continuity and hierarchical scenario is the scenario that promotes networking and conventional imaging while the conservative variation opts for participatory democracy.

In summary, the combination of (a) four megatrends in participation (status quo, representative to participatory democracy, a focus on hierarchies to a focus on networking, and centralisation to decentralisation), along with (b) the four critical forces shaping participation (continuity, communication, life-style/life-chances, and cultural mobilisation), plus (c) the four scenarios that form the likely futures for participation (hierarchical, participatory democracy, conventional imaging, and transformation) and we are in a position to locate those mediating structures that best match the patterns of participation in the development of Māori education 1960-2000. The third column on the modes of regulation/controlling processes is set out as an extension of Table 1.4. 
Outline of the structure of Part II-An extension of Table 1.4

\begin{tabular}{|c|c|c|c|c|c|}
\hline Megatrends & $\begin{array}{l}\text { Critical forces } \\
\text { shaping } \\
\text { participation }\end{array}$ & $\begin{array}{l}\text { Mode of } \\
\text { regulation- } \\
\text { Controlling } \\
\text { processes }\end{array}$ & Scenario & $\begin{array}{l}\text { Mediating } \\
\text { structure }\end{array}$ & Chapters \\
\hline Status quo & $\begin{array}{l}\text { - continuity } \\
\text { - democracy }\end{array}$ & $\begin{array}{l}\text { - dividing } \\
\text { practices } \\
\text { - manipulated } \\
\text { consensus }\end{array}$ & hierarchical & $\begin{array}{l}\text { Reports in } \\
\text { Māori } \\
\text { Education }\end{array}$ & $\begin{array}{l}\text { Ch 05 'Our } \\
\text { Māoris' }\end{array}$ \\
\hline $\begin{array}{l}\text { Representative } \\
\text { democracy to } \\
\text { participatory } \\
\text { democracy }\end{array}$ & $\begin{array}{l}\text { - authoritarian } \\
\text { - } \\
\text { communication }\end{array}$ & $\begin{array}{l}\text { - modes of } \\
\text { inquiry } \\
\text { - constructive } \\
\text { dialogue }\end{array}$ & $\begin{array}{l}\text {-pseudo- } \\
\text { democratic } \\
\text {-participatory } \\
\text { democracy }\end{array}$ & $\begin{array}{l}\text { Consultation } \\
\text { in Māori } \\
\text { Education }\end{array}$ & $\begin{array}{l}\text { Ch.06 'We're } \\
\text { all NZers' }\end{array}$ \\
\hline $\begin{array}{l}\text { Focus on } \\
\text { hierarchies to } \\
\text { focus on } \\
\text { networking }\end{array}$ & $\begin{array}{l}\text { - life } \\
\text { styles/chances }\end{array}$ & $\begin{array}{l}\text { - self } \\
\text { subjectification } \\
\text { - cultural } \\
\text { control }\end{array}$ & $\begin{array}{l}\text { - conventional } \\
\text { imaging } \\
\text { - networking }\end{array}$ & $\begin{array}{l}\text { Institutional } \\
\text { Marae }\end{array}$ & $\begin{array}{l}\text { Ch.07 } \\
\text { 'Tangata- } \\
\text { whenua- } \\
\text { Tangata-tiriti' }\end{array}$ \\
\hline $\begin{array}{l}\text { Centralisation to } \\
\text { decentralisation }\end{array}$ & $\begin{array}{l}\text { - cultural } \\
\text { mobilisation }\end{array}$ & $\begin{array}{l}\text { - self } \\
\text { subjectification } \\
\text { - cultural } \\
\text { control }\end{array}$ & $\begin{array}{l}\text { - transform- } \\
\text { ational } \\
\text { - decentralis- } \\
\text { ation }\end{array}$ & $\begin{array}{l}\text { Māori } \\
\text { Medium } \\
\text { Schooling }\end{array}$ & $\begin{array}{l}\text { Ch.08 'Our } \\
\text { Pākehās' }\end{array}$ \\
\hline
\end{tabular}




\title{
Chapter 05
}

\section{'Our Māoris': reports on Māori education (1960-2000)}

\subsection{Introduction}

How politicians decide what direction an education system will take depends much of the time on the political philosophy of those who have command of the treasury benches. A political philosophy is an ideology in terms of which certain institutions and practices are justified and others attacked; it is an articulation of ideals as goals and guidelines for aspirations and policies; it contains strategies and programmes that embody both ends and means, and, as Mills (1977a:14) states:

\begin{abstract}
[they] contain theories of man, society and history, or at least assumptions about how society is made up and how it works; about what are held to be its most important elements and how these elements are typically related; its major points of conflict and how these conflicts are resolved. It suggests the methods of study appropriate to its theories. From these theories and with these methods, expectations are derived. A political philosophy tells us how to find out where we stand and where we may be going; it gives us some answers to these questions; it prepares us for possible futures.
\end{abstract}

This chapter sets out to identify the ideologies, ideals, strategies and theories that are embedded in the reports on Māori education and then evaluate what has been elicited in the light of earlier descriptions of mediating structures and the impact of these on developments in Māori education.

A total of 32 reports were selected for the original analysis (these are listed in the appendix) but were reduced to 10 of the more generative of them, that is, those that were the boldest in trying to shift away from their anticipated conservatism and set out to make space for Māori values, knowledge, and practices. These are the Focus Reports and are listed below. The reports are discussed in two separate but interrelated periods: Part 1 looks at the period 1960 to 1977 and Part 2 the period 1978 to 2000 . These two periods are viewed as the most potentially transformative in the history of post-colonial Māori education developments. The first, 1960-77, signals an awakening of mainstream New Zealand to the potential within both the 
education system and within Māori society to contribute to the development of the nation. The second, 1978-2000 is marked by a major surge forward by Māori in promoting and revitalising the essence of what it means to be Māori in their own terms. All these reports are public documents and at the time of their publication, freely available to educationists at all levels.

The sociological perspective by which these reports is analysed is primarily described as 'functionalist' because educational reports, it is argued, are concerned with providing explanations of the status quo, of the 'way things are', or more precisely, of the 'way things ought to be'. This is the moral imperative of an education system embedded in liberal perceptions of social justice. Despite the remark from the $18^{\text {th }}$ century Scottish philosopher David Hume that 'ought' is not implied by 'is', that there can be no deductive steps from saying how things are to saying how they ought to be (Ayer, 1969:30), there would be little point to recommendations otherwise. Functionalism places a high priority on the maintenance of stability, of integration and of consensus. A sociology of regulation or control rather than transformation or change is taken as imperative while there needs always to be the incentive to be seen to be improving the system by establishing processes that are more inclusive, more participatory, and therefore more democratic.

The writers of each report are also charged with the responsibility of bringing a minority Māori perspective to the discussions which means Māori participants were involved in the various reports to inject Māori understandings, views, and perceptions into the deliberations of the group, and indeed, to the final report. This endeavour to elicit alternative explanations of the educational world through legitimating perceptions as seen through the eyes of Māori participants has meant that an interpretive sociological perspective has to be considered as well when analysing the reports. It will be argued that the minority status of Mãori compared with non-Māori is in accord with the minimal influence of interpretive sociology vis-à-vis functionalist sociology in the reports, even when the reports in their 
totality were written to address Māori education. This is a basic contradiction that lurks in the shadows of most/all reports that deal with education and have something to say about Māori education. Sadly, the contradiction or what others might refer to as the 'double-bind' (Sampson, 1976:234), also comes through in reports that are dedicated to focus specifically on Māori education. Māori in particular are placed in a paradoxical situation in which there is ambiguity about which way to respond. There is ample research evidence to suggest that historically, Māori saw benefits in acquiring literacy, speaking English, and accepting the advanced technology of Pākehā society, but it is equally true that they did not believe that Pākehā wisdom was in any way superior to their own indigenous wisdom; the same is true today as it was 200 years ago. It is this 'damned if you do' and 'damned if you don't' quality of reports on Mãori education that gives them the characteristic of a 'mediating structure'. The pathologies surrounding Māori schooling, as an example, are taken as no longer tenable once the recommendations are reconfigured as policy, resourced by government, and implemented by teachers. This is the process discussed in Chapter 1 under sociology of regulation. It is in this area that the mode of objectification Foucault calls dividing practices (1982:777) is located. Dividing practices are forms of co-option. Co-option occurs every time Māori subjects are brought into decision-making bodies or pseudo-scientific groups to discuss Māori education matters where they are placed in a position where they are either divided inside themselves or divided from others. If they are to operate as Māori they must first of all either educate the non-Māori group members about things Māori or be prepared to 'turn-the-other-cheek' in order not to be challenging every transgression against Māori ways of thinking and acting. If the group meets for more than a day or two they will likely both educate and ignore their colleagues frequently. The balance between the two extremes gives the Māori member some sense of either the worthwhileness or futility of the project.

The micro-processes for resocialisation involved in those working intimately on reports provide many opportunities for members to debate issues, for conciliation 
and compromise, and to 'get under the skin' of what the American sociologist Mills distinguishes as the 'personal troubles of milieu' versus 'public issues of social structure' (1977:14). When those in positions of power want to do what is right but confuse or distort the personal over the structural in matters of Māori/Pākehā relations, the oxymoron of coercive harmony or manipulated consensus seem like a pragmatic solution to a problem really intended for the "too hard basket'.

\subsection{Methodology and argument}

It is argued in Part 1 of this chapter that 'the outward embrace' was the focus in Māori education for the period 1960 - 1977. The education system set about strengthening Māori participation in all its sectors throughout this period by including Māori leadership more centrally in decision-making roles highlighted by the National Advisory Committee on Māori Education (NACME) that came into existence in 1955 and produced its first major report in 1970. Watson recognised this development in his statement, "For thirty years a deliberate attempt has been made to foster Māori history, arts and crafts, in schools attended by Māori children, and now more generally" (1967:40).

The full aphorism of the sub-title to Part One is, Ka awhi noa i waho, kare e uru ki roto (We are outwardly embraced, but never get inside). The reports are subjected to three forms of analysis. The initial area of analysis of these reports is to assess and evaluate whether the purpose of each report (judged in the light of its Māori membership and the specific issues to be addressed) facilitate Māori education remaining a peripheral activity in education or whether it envisages it penetrating the dominant system in some fashion. Put another way, the question asked of each report is whether what the committee has set out to address is merely to provide an outward embrace or whether it could effect or contribute to cultural and educational transformation. Of course, one cannot know for sure the purposes for which some activity is undertaken since it is an end-view that involves foresight of 
the consequences that will result from the actions, and even if it was possible to interview those involved, and many are now no longer available, it is unlikely interpretations will be the same now as they were at the time of the report. At face value, we learn from Dewey (1974:69) that the formation of purposes involves:

- observation of surrounding conditions;

- knowledge of what has happened in similar situations in the past (through recollection, information, advice, and warning of those who have had a wider experience); and

- judgement which puts together what is observed and what is recalled to see what they signify.

The concepts of cultural and educational transformations were discussed more fully in Chapter 3 but this quote from Lewis et al (undated) is suggestive of those areas of reports to be considered:

Transformations.... are reorganisations of previous categories of knowledge.
(They) provide new insights and impetus to explore the environment in a new
way. In this sense transformations are not static... achievements, but powerful
combinations of the old and the new that can be used to foster and direct
additional learning

Further analysis of the reports focuses on an assessment and evaluation of the various discourses within each report. From a postmodernist and critical perspective Best \& Kellner (1991:32) suggest an approach for analysing how writers [of a report]:

- characterise and criticise education and its discourses;

- postulate a break with prevailing educational theory;

- produce alternative transformative theories, positions or perspectives; create, or fail to create, a theory of transformative education; and

- provide or fail to develop, a new transformative politics adequate in the supposed future situation. 
In Part One a selection has been made of five of the 13 reports (the focus reports) for an in-depth analysis of the purpose statements. Part Two follows the same pattern of five Focus Reports selected for in-depth analysis from the 19 reports reviewed. The tables below summarise four categories with two questions in each in order to clarify the purpose of each report as well as the various supporting discursive statements. In most cases the questions are artificially posed in dichotomous terms to help make clear analytical/theoretical distinctions. They are posed this way to reflect the asymmetrical power relationship that exists between Māori and non-Māori within the education system.

(i) ideology Q1. What are the main problems the writers of the report set out to address? Q2. Whose interests do the writers of the report think or believe they are catering for?

(ii) ideals Q3. Does the report view the long term goal as being about unity, conformity and sameness? Q4. Does the report view the long term goal as being about difference and diversity?

(iii) strategies Q5. Is there consensus about the need for change? Q6. Is the unit for change basically targeting the collective /group or the individual?

(iv) theories Q7. Is there a theory of cultural change? What is said about it? Q8. Is there a theory of structural change? What is said about it?

An overview of New Zealand society might be helpful at this point. Reduced to its most basic form, New Zealand society comprises two cultures, one Polynesian in origin (Māori) and the other Western European (Pākehā). Because of its colonial history these two cultures are constructed in a dominant-subordinate relationship. Because of their history of more than 150 years of capitalist exploitation these two cultures have experienced uneven development where the former Māori culture is disadvantaged economically in relation to those who belong to the Pākehā culture. Along with the political effects of colonialism and the economic effects of capitalism is the third side of the holy trinity of the domination of a people and 
that is Christianity-oriented education that first undermined and disrupted, and then distorted and replaced a Māori cosmology that dated back to the beginning of time. In New Zealand today, political, economic and educational institutions struggle to redress the imbalance that history has shaped in Māori/Pākehā relations. This study, through the analysis of mediating structures (Māori education reports in this case) is a small attempt to throw light on the contribution education might make to rectifying existing inequalities.

\subsection{The functionalist terms of reference}

Functionalism sets out to provide essentially rational explanations of social affairs. The vocabulary of functionalism is located in concepts like, status quo, social order, consensus, social integration, solidarity, and need satisfaction. Its approaches are considered realist, pragmatic, problem-oriented, and practical while regulatory solutions are often seen as necessary outcomes.

The motivation in providing re-interpretations of the reports is not to discredit them but to throw new insights on them. I think Foucault's concept of 'procedures of rarefaction' have distinct possibilities in any re-appraisal of works such as those found in Māori education reports. With reference to Foucault, Tomlinson (1997:9) "refers to the regulation of discourse, as it were, from within (emphasis in original) - not prohibiting discourse, but keeping it in check by trying to contain regulative principles. Rarefaction is a complex term," we are told, "but it has the general meaning of becoming less dense thus of refinement or purification, but also of 'thinning out' of the dense mass of what is said about a subject". Māori are a minority within New Zealand and in the majority of reports on Māori education, remain minority members of these committees. Māori on Pākehã committees are typically less vocal and commonly are asked to play the role of educating their Pākehā peers about the Māori world. What ends up in the report from the Māori contributions is highly problematic. To say that all members of committees have to 'sign-up' to what appears in the final report is a safeguard against false reporting, or mis-communication or some such distorting effect is to mis-recognise the 
compelling procedures of rarefaction. "These so-called 'voices from the margin' may not be more authentic, less corrupt and therefore more revolutionary" to quote from Harvey (1996:100), but they are certainly outside of the systems of determination, they do not have the final say.

The work of committees, such as are discussed below, are primarily conducted in dialogue between the members. This dialogue is the primary condition of discourse but of course reports are not dialogue written down but are rather interpretations made by one or two people (part of a secretariat quite often) of the many dialogues conducted by members of the committee. This is why the exercise of hermeneutics, of critique, and of discourse analysis is so important to get at the underlying meaning. In her book on Theories of discourse (1986), Macdonell tells us that "discourse is social. The statement made, the words used and the meanings of the words used, depends on where and against what the statement is made" (p.1). She goes on to illustrate, "In my institution, there is a distribution and a hierarchy of discourses. Where a pregnant woman wants her childbirth to be natural, her statements and the concepts in which she thinks may conflict with those of the doctor - not all the statements about the woman's pregnancy may be accepted as 'knowledge': the woman may find her words carry little weight" (p. 2).

\subsection{Characteristics of reports}

The reading and analysis of reports is different in nature than the reading and analysis of most other kinds of written material. Firstly, in a centralised system such as exists in New Zealand, reports are written by a committee the members of which are selected by government. The committee has a chairperson who is also selected by government especially for that position. He or she is almost always a very experienced and highly regarded member of the public with some affinity to the area under inquiry. The sort of affinity, will depend on government and might include proven expertise, political allegiance, reputation in dealing reasonably 
quickly given difficult time lines, fairness, in-depth experience in the field and any number of other criteria. Thirdly, the government prepares the terms of reference that the committee is expected to work within. These terms of reference are very carefully prepared because they constitute what Parekh (1989: 228) says is "its source of legitimacy, its birth certificate as it were". Fourthly, committees of inquiry often have the luxury of not having to concern itself, at least overly, with originality or scholarship although those committees that ignore a sense of history or wish to argue contrary to the conventional wisdom of their field are likely to invite unnecessary critique and invective. Finally, once committees submit their reports to government they usually have no further role except perhaps to communicate and explain their recommendations to the public. What the government does with the report will most likely depend on how close the report's recommendations are to government's expectations.

\subsection{Selection of reports}

(a) The reports and the recommendations have been selected with three criteria in mind: first, they were released between the years 1960-2000; second, in the view of the writer ${ }^{1}$ they made a positive impact among Māori audiences; and third, they were again, in the opinion of the writer, important for the effect they had in their time as well as incrementally in raising and reinforcing a kaupapa Māori discourse, that is, one that reinforces a Māori philosophical position.

The focus reports are as follows:

Part One 1960-1977

Report 2: The Report of the Commission on Education in New Zealand (Currie Report, 1962)

\footnotetext{
${ }^{1}$ The writer has been a professional participant in the education system from 1960-2000 and reserves the right to comment as an informed insider.
} 
Report 4: Report of The National Advisory Committee on Māori Education (NACME, 1970)

Report 5: $\quad$ Māori Children and the Teacher (1971)

Report 9: Report of the Committee on Communication Between Schools and Parents: Parent-School Communication (1973)

Report 11: Report of the Committee on Secondary Education, 'Towards Partnership' (McCombs Report, 1976)

Part Two (1978-2000)

Report 15 Report of the National Advisory Committee on Māori Education (NACME, 1980)

Report 20: Review of the Core Curriculum for Schools (1984)

Report 27 Report of the Taskforce to Review Education Administration (Picot Report, 1987)

Report 31 Māori Participation and Performance in Education - A Literature Review and Research Programme (1997)

Report 32 Māori Commission Reports (1998/99)

\subsection{Committee membership}

The chairperson in all of the reports as well as the Māori members of the committees are named where this is known. This is done for two main reasons: since reports are written by committees under the guidance of the chair it is obvious that each member has his or her own contribution to make to the inquiry and a consensus will likely not exist among the members until these can be negotiated over the duration of the committee's work. The chairperson's authority in the area of inquiry as well as in the leadership role will contribute significantly to the speed and durability with which negotiated compromises will be met. Second, Māori members of the committees have been named in the descriptions of the committees because, in Māori terms, names rather than numbers serve the same purpose as naming the chairperson: Māori audiences can judge credibility, 
expertise, loyalty, authenticity, and trustworthiness, that is, a notion of groundedness of the Māori members in matters related to the Māori world. This is not suggesting there is a single Māori essence walking around 'out there' but in the everyday sense it is possible to differentiate Māori leadership in the same way Pākehā leadership (chairpersons) can be selected.

Who the Māori representation is can go some way to understanding the nature of the contribution the report makes in regard to one which 'speaks to Māori' or one that does not. The Ministerial Advisory Committee Report for the Department of Social Welfare chaired by Rangihau (Puao-Te-Ata-Tu, 1986) is an example of this last point. Rangihau was a deeply respected public servant and a rangatira (traditional leader) among Māori everywhere. As far as advisory committee reports go, Puao-Te-Ata-Tu has been highly regarded among Māori for its critical analysis of New Zealand society, the role of the Social Welfare Department, and their relationships with Māori. Rangihau's leadership had much to do with this report's acceptance from government and credibility among Māori. A subsidiary reason is that reports are often named after whoever chaired them whereas Māori members of committees, like the other members are often either not known or quickly forgotten. Since the reports I have chosen to comment on are ones that have generally been favourably received by Māori communities, it is a legitimate opportunity to at least honour the chair and the Māori members of these reports.

\subsection{Focus on purposes and discourses}

The purposes of a selection of Māori education reports (1960-2000) are set out as Parts 1 and 2 below. The recommendations have not been a formal part of the analyses except for specific instances or examples that are atypical in the context of the report. Recommendations are typically perceived, in commonsense terms, as being the key to the changes the committee would like in the system. They signal to government and its bureaucrats the need for new policy, adjustment in policy, and/or the withdrawing of earlier policy in some specific area(s). In this way the 
implementation of major recommendations is often taken as a de facto measure of the effectiveness of the committee's work as represented in its report. In the experience of the researcher this is a misguided notion of the work of committees taking part in national level projects. In reality officials are frequent visitors in the on-going work of committees and they can have a profound effect on what gets into a report and what does not. Committee members assume that with recommended new policy also comes resourcing to enable the policy to be implemented. Of course, commissions like committees can 'get it wrong' while governments can decide to 'file' those reports it considers either outside the boundaries of its own governing policies or what it perceives to be outside the public interest (consider the idea of political philosophy discussed at the beginning of this chapter). However, any government that ignores those recommendations that the public perceive as being critical for implementation can find itself in difficulty in terms of public and democratic accountability. Recommendations can be and frequently are powerful catalysts for change but other things are necessary ingredients for the success or otherwise of any report. The acceptability of members of the committee to those they represent is one of these key elements.

\section{THE REPORTS - PART ONE (1960-1977): Ka awhi noa i waho}

\subsection{Background}

The reports released over this 17 year period mark significant progress in the field of Māori education if for no other reason than the realisation that Māori do have something to offer in education for this society and that the system owes it to Māori to do something active about that contribution. It should be noted, however, that changes in Māori education are almost always seen against a background of other changes occurring within society itself, for example, the introduction to the Currie Report (1962:3) reminds us that at that time, "a new urgency regarding education" was brooding in all countries throughout the world. The Commission felt strongly enough to express its beliefs with regard to this new urgency in the words, 
that New Zealand is not only willing but anxious to give the best education possible to all the children in its State-supported schools and to provide for all children from homes rich or poor the equality of educational opportunity in which it profoundly believes (1962:6).

From a Māori point of view, the establishment of a Native Schools system (18671969 ) operating in conjunction with a mainstream system (1877 to the present) often felt like Pākehā were trying to embrace Māori differences but never quite had the courage, vision or wit to encourage the full range of Māori social, cultural, economic or educational development in a way of their choosing, hence the subtitle to Part 1 reports, 'ka awhi noa i waho' (the outward embrace).

\subsection{The Reports}

There are 13 works summarised in Part 1 (1960-1977) eight are reports, three are more in the nature of monographs rather than reports, while two are official handbooks. These works need to be read along side a second cluster of reports on Māori education that date from 1980 to 2000 . The purpose of each report and a comment on each is discussed. An analysis of the recommendations follow at the end of each Part with a concluding statement at the end of the chapter about the role of Māori education reports as mediating structures.

Only the analyses of the Focus Reports are included below. The remainder (Reports 1,3,6,7,8,10,12,13) are listed in the Appendix.

\section{REPORT 2 -Report of the Commission on Education in New Zealand (1962)}

[The Currie Report] 886 pages

Chair: Sir George Currie

Māori members: Nil out of 11 members

Certainly by today's standards it seems extraordinary that there were no Māori on the Commission. In 1955, the Department of Education established a National Advisory Committee on Māori Education (NACME) and in that same year decided 
to abolish the Māori Schools (Hunn, 1960:25). Hunn also asserted the importance of education for an integrated race relations policy as well being able to do the most for the cause of Māori advancement (ibid. p.22). We know from the records that the Commission did canvas Māori opinion through the usual channels of submissions (appendix A of the report), interviewing key people, and making visits to a host of institutions including a significant number of Māori Schools (34), and a Māori Girls' College (appendix B of the report). Nevertheless, this was a far from satisfactory initiative from a Commission that affirmed

the Mãori pupil has the same body of learning to master as the non.-Māori. But such elements of his Mäori background must be included in his schooling as will give him still the sense of belonging to a race of known and respected culture, (Currie, 1962:415-416).

The Commission spent one week divided into four groups to visit separate areas where there were "substantial numbers of Māori pupils and Māori schools to see at first hand some of the special problems of Māori children" (p.3). The chapter on Mãori Education (Ch.8 (pp.401-437) has a total of 23 recommendations. In underlining the unanimity of the Commission, its secretary, Renwick (1964:1-2) pointed out the diversity of the group as follows:

\footnotetext{
Five were professionals: they brought with them an intimate knowledge of public education in one of its main branches - teacher education, post-primary education, technical education, or education as a university study. Five were laymen: a housewife, a farmer, a businessman, a chemist and a retired public servant of the administration of education...The chairman confessed himself to be a complete layman.
}

The main external influences on the terms of reference are spelled out as issues in the first chapter. They are (a) equality of educational opportunity, (b) the function of schools, and (c) the role of the education system in relation to the national economy.

\section{purpose:}

The Commission was asked to consider the publicly-controlled system of primary, post-primary, and technical education in relation to the present and future needs of the country. Within the broad scope of this reference, the Commission was asked to "inquire into nine separate entities which made up the terms of reference". 
Māori education was not one of the problem areas the Commission was set down to investigate, however, "it steadily emerged throughout its deliberations as one that did require very special attention in itself" (p.401).

Table 5.1 discourse analysis

Commission on education in New Zealand (1962)

\begin{tabular}{|c|c|}
\hline $\begin{array}{l}\text { Q1. What are the main problems the writers of } \\
\text { the report set out to address? }\end{array}$ & $\begin{array}{l}\text { Q2 Whose interests do the writers of the } \\
\text { report think or believe they are catering } \\
\text { for? }\end{array}$ \\
\hline $\begin{array}{l}\text { p. } 7 \text { special measures (that) should be taken to } \\
\text { encourage the education of Māori children } \\
\text { p. } 418 \text {...Māori education as an area of special } \\
\text { need, requiring special measures and, inevitably, } \\
\text { increased expenditure. }\end{array}$ & $\begin{array}{l}\text { p. } 414 \text { the nation cannot afford to waste any } \\
\text { unused talent in the population } \\
\text { p. } 426-7 \text { Mãori cultural identity and the security } \\
\text { that such feelings of identity confer. }\end{array}$ \\
\hline $\begin{array}{l}\text { Q3 Does the report view the long term goal as } \\
\text { being about unity, conformity and sameness? }\end{array}$ & $\begin{array}{l}\text { Q4. Does the report view the long term goal } \\
\text { as being about difference and diversity? }\end{array}$ \\
\hline $\begin{array}{l}\text { p.434 ...indisputably, the aim must be to abolish } \\
\text { all special provisions and all emergency measures } \\
\text { as soon as the need for them passes. }\end{array}$ & $\begin{array}{l}\text { p. } 7 \text { No. The Mãori people have in law the same } \\
\text { opportunities in education as the European. }\end{array}$ \\
\hline $\begin{array}{l}\text { Q5 Is there consensus about the need for } \\
\text { change? }\end{array}$ & $\begin{array}{l}\text { Q6. Is the unit for change basically targeting } \\
\text { the collective / group or the individual? }\end{array}$ \\
\hline $\begin{array}{l}\text { p.15 In providing true equality of educational } \\
\text { opportunity for the Māori people of New Zealand, } \\
\text { in aiding them by this means in their effort to } \\
\text { reach equality of status in this community, we } \\
\text { have before us a task of imperative priority. }\end{array}$ & $\begin{array}{l}\text { p.15 No group in the community has given the } \\
\text { Commission greater cause for thought and } \\
\text { discussion than the Māori people. }\end{array}$ \\
\hline $\begin{array}{l}\text { Q7. Is there a theory of cultural change? } \\
\text { What is said about it? }\end{array}$ & $\begin{array}{l}\text { Q8. Is there a theory of structural change ?. } \\
\text { What is said about it? }\end{array}$ \\
\hline $\begin{array}{l}\text { p. } 420 \text { the policy of gradual change with consent } \\
\text { of parents; need for pace of change to be greater. } \\
\text { p. } 415 \text { The school's main task is undoubtedly to } \\
\text { provide...the educational equipment to enable the } \\
\text { Mãori child to play his part in the modern world. }\end{array}$ & $\begin{array}{l}\text { p. } 415 \text { Two educational problems are posed: to } \\
\text { determine how far the education offered the } \\
\text { Māori is in fact the most suitable for his } \\
\text { needs; how best to enable the Māori to take } \\
\text { advantage of the education that is offered, to } \\
\text { the extent that this lies within the control of the } \\
\text { education system. }\end{array}$ \\
\hline
\end{tabular}

\section{comment:}

The familiar Fraser policy statement of 1939, was in the eyes of the Commission "essentially a statement of social aspiration" ( Beeby, 1986:xxxv). It is worth quoting again as a sort of foundation statement of both New Zealand's egalitarian philosophy as well as its practice of equality of educational opportunity. Beeby refers to this philosophy and practice as an 'educational myth' (ibid.xv) or what others might call a model in that it is not true or false; it is useful and adequate to 
varying degrees; and it remains open to question even when it is working. The quote reads,

The Government's objective, broadly expressed, is that every person, whatever his level of academic ability, whether he be rich or poor, whether he live in town or country, has a right, as a citizen, to a free education of the kind for which he is best fitted and to the fullest extent of his power. (Renwick, 1986:16).

REPORT 4 -Report of the National Advisory Committee on Mãori Education (1970).

19 pages.

Chair: J.L.Hunter (Assistant Director-General of Education)

Māori members: Out of the 24 members of the working party 10 were Mãori.

Four members of the working party were members of the NACME having been nominated by Education Boards to represent the Māori people who lived within the specific Board boundaries (these are shown as the place in parenthesis after each name). As members of the working party they were also nominated to represent their respective iwi (the second designation after place): M.D.T.Walters (Dargaville/Ngāti Whātua), M.R.Jones (Otorohanga/Ngāti Maniapoto), Mrs M.Penfold (Pakuranga/Te Aupouri), J.Bennett (Havelock North/Te Arawa).

Six other Māori were selected for the working party because of their wide experience in some field of Māori education but once again, it was their respective tribal affiliations that were noted in the report: Mrs E.R Tawhiwhirangi (Ngāti Porou), Mr M. Te Hau (Whakatohea), Mr B. Puriri (Ngāpuhi), Mr G. Marsden (Te Aupouri), Mr T.K.Royal (Ngāti Raukawa), and Mrs M.Pewhairangi (Ngāti Porou).

The Māori/iwi/Board representation on the working party is a formidable combination with close affinities to Māori communities, broad experiences across all educational sectors, insider knowledge of the public sector and the workings of government. If there was a weakness it was probably related to knowledge of research in the broader context of education. To speak of weaknesses or gaps in the representation is to be 'nit-picky', however, significant tribal groupings such as Wanganui, Taranaki, Kahungunu, Tuwharetoa and Ngai Tahu might think 
otherwise. It was not common for official documents of this time to list tribal affiliations of Māori. Today it is almost uncommon for tribal affiliation of Māori leadership to be left off in any document.

There are 46 recommendations in the report 13 of which are designated priority. The recommendations are not organised around themes or categories although the report is.

The NACME set up a working party to prepare this report. It includes some members of the NACME and others with a wide experience of Māori education. Of the 14 Pākehā members of the working party, 6 were also members of the NACME representing various interest group organizations: Mr J.L.Hunter (Assistant Director-General of Education and chairman of NACME as well as the working party), Mr J.McEwan (Secretary of Māori and Island Affairs), E.F.Hamill (President, New Zealand Post Primary Teachers' Association), H.M.Hunter (New Zealand Educational Institute), H.B.Holst (Officer for Māori and Island Education, Department of Education), Mrs G. McDonald (nominated by Minister of Education).

The remaining 8 Pākehā members of the working party, selected specifically for the contribution they had made in the past, or the organisation they represented could make to Māori education in the future, are no less formidable and include: Miss L.Shaw (Māori Education Foundation), Mr J.Osborne (North Shore Teachers' College), Mr B.A.Gummer (Department of Labour), Mr F.W.Shortcliffe (Auckland Technical Institute), Mr J.F.Hughes (Post Primary Teachers' Association), Mr N.Irwin (New Zealand Educational Institute), Mr C.C.Watt, Mr R.F.McFarland and Mr B.A.Kings (Department of Education).

Membership of the NACME in 1970 was evenly split ethnically (8 Mãori and 8 Pākehā) with a senior Pākehā administrator as chairman. 
This relatively detailed discussion around membership, representation and ethnicity is an important part of the analysis of all the reports reviewed in this research. Membership, representation and ethnicity contribute to the problematic of reports on Māori education; in this case, the purposes underlying each report. The French sociologists, Althusser and Balibar tell us that

a word or concept cannot be considered in isolation; it only exists in the theoretical or ideological framework in which it is used: its problematic. (1983:316)

To provide an example of something of this problematic we know that NACME was established in 1955 to advise the Minister of Education on all aspects of Māori education (NACME, 1980:3). On the same page we are told that in 1969 the committee was reorganised to include wider representation of Māori interests and to ensure that the majority of members were Māori. Between 1955 and 1969 we can assume that Māori were not a majority on the NACME yet Watson writes (1967:36) that "NACME was set up in 1955 with the express purpose of enlisting the advice of a majority (my emphasis) of Māori representatives who are recognized leaders in their own districts". Are we to understand that they need not be a majority on the committee (to advise on Māori education) so long as the majority of them who were on the committee were recognised leaders in their own districts? This is a part of the dilemma of asymmetrical power relations between Māori and non-Māori; the powerful get to define the context. Butterworth (1993:40) describes the period from 1950-75 as "the years of prosperity". For Māori, Hunn (1960) was a reminder that they were a minority, albeit one worthy of surviving so long as the goal of integration was pursued with vigour. The Currie Report (1962) established Māori education as an area of 'special need' "so that equality of opportunity becomes in every sense a reality for both races" (p.7). Watson's conference paper of 1967 was at least encouraging and hopeful that teachers, once they grasped the relevance of Māori values or social structure, could make a difference. In a historical sense, the most profound change through the 1960s was the phasing out of the Māori school system after more than a century. 


\section{purpose:}

As mentioned earlier, the NACME was established to advise the Minister of Education on all aspects of Māori education. In this report, the NACME contextualise their advice within two philosophical premises:

- The need to equip Māori children to realise their full potential; and

- To achieve this goal through principles of social justice, for example, (a) equals should be treated equally (equality of opportunity principle), and (b) unequals should be treated unequally (the equity principle or what has become known as affirmative action). The report says that in order for "Māori children to realise their full potential....it is often necessary to take measures that are vastly unequal" (p.3).

Emerging from surface of these two very important premises is a third, more contentious premise, that which links causally, not knowing one's Māoritanga (what it means to be Māori), to possessing a damaged self image (low selfesteem), which is why, it is asserted, so many Māori children under-achieve (not realise potential) at school. The solution, that follows, is to teach them their Māoritanga, so that they can repair their own self-concept, and as a result succeed at school. I know of no research at that time to substantiate such a claim but it was a view shared by many Māori who observed the rapid urbanisation-effect on Māori youth and the economic and cultural forces at work destabilising and marginalising those who tried to hold onto their Māoritanga in the midst of an unsympathetic urban Pākehātanga.

The recommendations of the report are directed toward equipping Māori children to fulfil their potential by focusing on the key transitional points in a pupil's progress through the educational system: from early childhood to the infant school, from primary to secondary, and from secondary school to the job market. 
Table 5.2 discourse analysis

National Advisory Committee on Māori Education (1970)

\begin{tabular}{|c|c|}
\hline $\begin{array}{l}\text { Q1. What are the main problems the writers of } \\
\text { the report set out to address? }\end{array}$ & $\begin{array}{l}\text { Q2 Whose interests do the writers of the } \\
\text { report think or believe they are catering } \\
\text { for? }\end{array}$ \\
\hline $\begin{array}{l}\text { p.3 self-image ---Mãoritanga; unequal measures } \\
\text { to achieve equality of opportunity } \\
\text { - lack of confidence (p.7) } \\
\text { - Māori population growth rate } \\
\text { - migration form rural to urban } \\
\text { - increased contact between Māori and non-Māori } \\
\text { - progress of Māori students in learning English } \\
\text { (p.7) }\end{array}$ & $\begin{array}{l}\text { p.3 Māori children's potential; equality of } \\
\text { opportunity } \\
\text { p.4 local community }\end{array}$ \\
\hline $\begin{array}{l}\text { Q3 Does the report view the long term goal as } \\
\text { being about unity, conformity and sameness? }\end{array}$ & $\begin{array}{l}\text { Q4. Does the report view the long term goal } \\
\text { as being about difference and diversity? }\end{array}$ \\
\hline $\begin{array}{l}\text { p.7 teaching of English to Māori and Polynesian } \\
\text { pupils; improvements in staffing to allow greater } \\
\text { flexibility in school organisation and enable } \\
\text { closer links to be established between home and } \\
\text { school. }\end{array}$ & $\begin{array}{l}\text { p. } 7 \text { Māori language and Māori studies to all } \\
\text { pupils; Māori language as a basis for further } \\
\text { understanding both by schools and parents as a } \\
\text { pre-requisite for better race relations }\end{array}$ \\
\hline $\begin{array}{l}\text { Q5 Is there consensus about the need for } \\
\text { change? }\end{array}$ & $\begin{array}{l}\text { Q6. Is the unit for change basically targeting } \\
\text { the collective / group or the individual? }\end{array}$ \\
\hline $\begin{array}{l}\text { p. } 6 \text { developments in pre-school education be } \\
\text { given high priority; programmes (in F1-4) need } \\
\text { to be graded more closely to the needs, interests } \\
\text { and experiences of Māori pupils in both content } \\
\text { and method. }\end{array}$ & $\begin{array}{l}\text { p.5 educating Pākehā } \\
\text { p. } 6 \text { School organisation should be based on } \\
\text { heterogeneous grouping rather than on } \\
\text { streaming; opportunity should exist for the } \\
\text { development of the individual child's potential }\end{array}$ \\
\hline $\begin{array}{l}\text { Q7. Is there a theory of cultural change? } \\
\text { What is said about it? }\end{array}$ & $\begin{array}{l}\text { Q8. Is there a theory of structural change?. } \\
\text { What is said about it? }\end{array}$ \\
\hline $\begin{array}{l}\text { p.8,9 teachers to have a sound working } \\
\text { knowledge of the cultural background of Māori } \\
\text { children } \\
\text { p. } 5 \text { The Committee hopes to see the development } \\
\text { of Māori-Pākehā groups but it accepts the fact } \\
\text { that some Māori groups wish to work alone, at } \\
\text { least in the beginning stages. }\end{array}$ & $\begin{array}{l}\text { p. } 7 \text { provision of five-day hostels; homework } \\
\text { classes } \\
\text { p. } 8 \text { trade training schemes to include girls } \\
\text { p. } 10 \text { appointment of advisers on special aspects } \\
\text { of Māori education; existing Māori } \\
\text { organisations extended to include adult } \\
\text { education }\end{array}$ \\
\hline
\end{tabular}

\section{comment:}

The National Advisory Committee on Māori Education produced a report that demonstrated a courage and commitment that those in the field were not used to seeing at this level of the system. Although worded in simple and general terms there was no disguising the resolve of the Committee wanting to make a real difference in Māori education in those matters that Māori felt most threatened 
about if they were not supported, namely values, language, knowledge, institutions and relationships. The recommendations were particularly encouraging.

\section{REPORT 5-Department of Education. (1971a). Mãori Children and the} Teacher. Wellington: Government Printer.

\section{6 pages}

Numbers in parentheses are page numbers from the Handbook.

There are references and a bibliography.

Author: Miss Myrtle Simpson

Māori contributors: Mrs M.M Isaacs, Mr F.H. Leonard, Dr S.M.Mead

Each of these Māori contributors is a recognised expert in some field of education. Mrs Isaacs was a well known infant classroom teacher in her time; Mr Leonard was a respected principal of primary schools; Dr Mead was an ex-Māori School headmaster, an adviser in Māori arts and crafts as well as a respected academic with degrees in anthropology and Māori.

The Preface underlines the need for such a publication (see table in Q1 below). It was a sign of the times that even with the Māori educational, academic, and administrative expertise available, the Department of Education still saw it necessary to employ the services of a non-Māori person to prepare this handbook. This is no mere 'throw-away' judgement. At the time, that is, in 1971 I vividly remember commenting to other teachers about the fact that the Department of Education, more than a century after the establishment of the Native Schools, still had to ask a non-Māori person to research and write a book for teachers' college students and teachers, about traditional Māori culture, Māori children at home and at school. This is not to disparage Miss Simpson since it is clear from what we are told about her (editor of infant readers, senior inspector of schools, and obviously a highly successful teacher in order to become an inspector) that she could do the job and do it very well which in fact was the case. It is the blatant paternalism and the message conveyed to Māori that one wonders about such decisions. It smacks of a 'do what we say and not what we do' message to teachers. 


\section{purpose:}

The Handbook is divided into three broad areas: The Influence of Tradition; Māori Children at Home; and Māori Children at School. There are references and a bibliography.

- This Handbook has been published primarily for the use of those directly concerned in teaching Māori children and teachers' college students. It is an attempt to give information and direct the attention of teachers in a way which will help them to understand the background of Māori pupils who come into their care (v).

- This booklet is based on material written by Miss Myrtle Simpson, previously Senior Inspector of Primary Schools in Christchurch, and editor of the Department's series of Infant Readers, Ready to Read (vi).

- Three Māori people were involved to provide criticism and suggestions of the project: Mrs Maud Isaacs (supervisor of junior classes), Fred Leonard (head teacher), and Dr Hirini Mead (academic) (vi-vii).

Table 5.3 discourse analysis

\section{Māori children and the teacher (1971a)}

\begin{tabular}{|l|l|}
\hline $\begin{array}{l}\text { Q1. What are the main problems the writers of } \\
\text { the report set out to address? }\end{array}$ & $\begin{array}{l}\text { Q2 Whose interests do the writers of the } \\
\text { report think or believe they are catering } \\
\text { for? }\end{array}$ \\
\hline $\begin{array}{l}\text { [visibility of Māori children in schools] } \\
\text { p.v Māori student separation from 'centres of } \\
\text { traditional life' (shift from rural to urban) } \\
\text { p.v Change of status from rural majority to urban } \\
\text { minority } \\
\text { p.v Direct responsibility due to transfer of Māori }\end{array}$ & $\begin{array}{l}\text { p.v Those directly concerned in teaching Mãori } \\
\text { children and teachers' college students (p. vii) } \\
\text { p.45 Māori children are fundamentally } \\
\text { imaginative and can be helped to use this } \\
\text { attribute in their work. }\end{array}$ \\
\hline $\begin{array}{l}\text { Q3 Does the report view the long term goal as } \\
\text { being about unity, conformity and sameness? }\end{array}$ & $\begin{array}{l}\text { Q4. Does the report view the long term goal } \\
\text { as being about difference and diversity? }\end{array}$ \\
\hline $\begin{array}{l}\text { p.1 teacher must know something about Māori } \\
\text { heritage and appreciate its reality for the modern } \\
\text { Măori; also to know something about the history } \\
\text { of relationship between Māori and Pākehā. }\end{array}$ & $\begin{array}{l}\text { p.X 'A great deal will depend on the understanding } \\
\text { with which he (the child) is met. He will have to } \\
\text { adapt to the institution but the institution will have } \\
\text { to bend towards him'. }\end{array}$ \\
\hline $\begin{array}{l}\text { Q5 Is there consensus about the need for } \\
\text { change ? }\end{array}$ & $\begin{array}{l}\text { Q6. Is the unit for change basically targeting } \\
\text { the collective / group or the individual? }\end{array}$ \\
\hline $\begin{array}{l}\text { [No, only that change has to happen] } \\
\text { p.56 Most teachers with long experience of living } \\
\text { and working in Māori communities feel that their } \\
\text { lives have been genuinely enriched by the } \\
\text { experience }\end{array}$ & $\begin{array}{l}\text { p.xi 'Every teacher of Māori children should } \\
\text { be in some degree a self-effacing student of } \\
\text { Māori history and culture. When we speak of } \\
\text { understanding something of Māori culture and } \\
\text { of establishing a pupil with confidence in his }\end{array}$ \\
\hline
\end{tabular}




\begin{tabular}{|c|c|}
\hline & $\begin{array}{l}\text { school, we are concerned primarily with the } \\
\text { spirit of the people, as of the individual.' } \\
\text { p.31 At school, he is urged to succeed as an } \\
\text { individual but he may feel more capable in the } \\
\text { co-operative atmosphere of a group. }\end{array}$ \\
\hline $\begin{array}{l}\text { Q7. Is there a theory of cultural change? } \\
\text { What is said about it? }\end{array}$ & $\begin{array}{l}\text { Q8. Is there a theory of structural change?. } \\
\text { What is said about it? }\end{array}$ \\
\hline $\begin{array}{l}\text { p. } 3 \text { Walker - borrowing and reciprocating } \\
\text { p. } 6 \text { Ngata - operating within a social system } \\
\text { p.10 Kawharu - adapting Mãori social life to } \\
\text { urbanisation } \\
\text { p.13 Schwimmer - learning through listening, } \\
\text { chanting, practice and performance } \\
\text { p. } 52 \mathrm{Mead} \text { - conducting meetings and reaching } \\
\text { decisions. }\end{array}$ & $\begin{array}{l}\text { p.1 Piddington - under the impact of European } \\
\text { culture, Māori have condensed centuries of } \\
\text { material progress into a little over a hundred } \\
\text { years.....without renouncing their cultural } \\
\text { heritage }\end{array}$ \\
\hline
\end{tabular}

\section{comment:}

The literature reviewed on 'the influence of tradition' signal the authors of the handbook's bias. It begs for a sympathetic understanding of the Māori child and his/her cultural background as the way to improving his/her education. The role of the teacher is paramount but the child has to learn to fit in even as the school bends to make accommodations.

\section{REPORT 9 -Report of the Committee on Communication Between Schools and Parents, Parent - School Communication (1973)}

[Johnson Report] 56 pages

Chair: J.G.Johnson +4

Mãori members: P.R.Sharples, M. Szaszy

The two Māori on the committee, Peter Sharples and Mira Szaszy are prominent professionals in both Māori and Pākehā worlds. Both are highly qualified in both worlds with dazzling credentials for working with community groups. Over the next three decades Sharples would accelerate his profile in a number of Māori/iwicentred initiatives.

There are 65 recommendations organised under 10 categories [changes in the nature of schools (13); the visiting teacher (7); guidance counselors (2); the specialist advisory service (4); the existing inspectorate (2); staffing and teacher 
recruitment (11); teacher training (13); children having difficulty - suspensions, expulsions ( 8); secondary school boards (2); communications -general (3)]

The chair was Mr Garfield Johnson who was a prominent principal of a suburban, multi-ethnic, working-class secondary school throughout the 1970 s up to the mid$1980 \mathrm{~s}$. He was instrumental in providing the push behind a number of important cross-cultural programmes that involved working relationships between schools and communities, between professionals and lay people, and among Māori, Pacific, and Pākehā peoples across generations. One such initiative was 'Te Mauri Pakeaka - Cross-Cultural Community Involvement Arts Programme' which was conducted mainly on local marae and involving schools from the immediate locality. The programme was in the nature of an integrated arts approach to learning and teaching using professional experts and local resource people. These courses were held throughout the country.

Another very influential professional on the committee was Mr Alan Smith who was the senior officer for Māori and Pacific education in the Department of Education throughout the 1970s and early 1980s. Among other things Smith was instrumental in creating a powerful catalyst within the schools for promoting, supporting, and enhancing Māori and Pacific educational initiatives. This was the service known as Advisers on the Education of Māori and Pacific Islanders. These advisers were experts in the field in what it meant to be Māori, to be a teacher, to be bicultural and in most cases, bilingual, and by example, what it meant to be a citizen of Aotearoa New Zealand.

Both Johnson and Smith were Pākehā and both fully committed to a future New Zealand that recognised, understood and learned to respect the cultural diversity that is the heritage of all New Zealanders.

Two external influences are particularly worthy of note. The Report of the Race Relations Conciliator (1973) highlighted two areas in need of attention (a) the 
drop-out rate of Polynesian pupils from secondary schools; and (b) the nature of the relationship between parents and schools.

\section{purpose:}

The committee was to study ways of improving communication between schools and parents, particularly those whose children are having difficulty in adjusting to the school system, with special reference to Māori and Polynesian children.

The committee was set up against a background of growing concern expressed by various sections of the community over the last few years arising from suspensions and expulsions from secondary schools. Three critical introductory remarks are made:

- "It is time there was real dialogue between parents and schools about the values and attitudes which schools should be teaching (p.4);

- There prevails among the majority of teachers a deep ignorance of the values and attitudes of the Māori and Polynesian people (p.5); and

- Schools must change. There is a need for a whole shift of purpose so that schools see caring as one of their prime functions (about values and cultures of minority groups etc.) and that they involve themselves more in the community (by offering themselves much more to the community and by making fullest use of the talents of the community)" (p.6).

Table 5.4 discourse analysis

Communication between schools and parents (1973)

\begin{tabular}{|c|c|}
\hline $\begin{array}{l}\text { Q1. What are the main problems the writers of } \\
\text { the report set out to address? }\end{array}$ & $\begin{array}{l}\text { Q2 Whose interests do the writers of the } \\
\text { report think or believe they are catering } \\
\text { for? }\end{array}$ \\
\hline $\begin{array}{l}\text { P1. How to improve the communication between } \\
\text { schools and parents } \\
\text { p. } 3 \text { The difficulty of building a conservative } \\
\text { institution in the midst of constant change } \\
\text { p. } 4 \text { need for real dialogue between parents and } \\
\text { schools about values and attitudes schools should } \\
\text { be teaching. }\end{array}$ & $\begin{array}{l}\text { p. } 7 \text { The child in trouble: from 'wearing } \\
\text { unusual clothes' to 'trying to kill themselves'; } \\
\text { very unhappy, most children in trouble are } \\
\text { bored; most see little reason to be any other } \\
\text { way. }\end{array}$ \\
\hline $\begin{array}{l}\text { Q3 Does the report view the long term goal as } \\
\text { being about unity, conformity and sameness? }\end{array}$ & $\begin{array}{l}\text { Q4. Does the report view the long term goal } \\
\text { as being about difference and diversity? }\end{array}$ \\
\hline $\begin{array}{l}\text { [yes] } \\
\text { p.11 schools should change: the nature of their }\end{array}$ & $\begin{array}{l}\text { [yes] } \\
\text { p.11 schools need to provide a study of the }\end{array}$ \\
\hline
\end{tabular}




\begin{tabular}{|l|l|}
\hline $\begin{array}{l}\text { curriculum and programmes where aspects of the } \\
\text { culture of minority groups should be taught }\end{array}$ & $\begin{array}{l}\text { background of the major immigrant groups in } \\
\text { New Zealand. } \\
\text { p.22 A teacher training course for mature } \\
\text { persons who are native speakers of Māori be } \\
\text { instituted. } \\
\text { [The point to be made about Q3 and Q4 is that } \\
\text { the definition of a 'good' school/teacher is one } \\
\text { that meets the needs of all its children] }\end{array}$ \\
\hline $\begin{array}{l}\text { Q5 Is there consensus about the need for } \\
\text { change ? }\end{array}$ & $\begin{array}{l}\text { Q6. Is the unit for change basically targeting } \\
\text { the collective / group or the individual? }\end{array}$ \\
\hline $\begin{array}{l}\text { p.7 The child in trouble - viewed as an aggregate } \\
\text { p.9 The teacher - all the recommendation in the } \\
\text { world will fail unless the teachers of our schools } \\
\text { see the need to implement them. } \\
\text { p.10 People communicate with people, not with } \\
\text { systems. }\end{array}$ & $\begin{array}{l}\text { p.6 The school - to hold the schools } \\
\text { responsible for the social condition is of } \\
\text { doubtful validity, but to expect them to be a } \\
\text { major agent in the amelioration of this } \\
\text { condition is to concede without doubt that they } \\
\text { must change: }\end{array}$ \\
\hline $\begin{array}{l}\text { Q7. Is there a theory of cultural change ? } \\
\text { What is said about it? }\end{array}$ & $\begin{array}{l}\text { Q8. Is there a theory of structural change ?. } \\
\text { What is said about it? }\end{array}$ \\
\hline $\begin{array}{l}\text { p.6 School processes: } \\
\text {-caring about the values and cultures of minority } \\
\text { groups } \\
\text { - involving themselves much more in the } \\
\text { community } \\
\text { p.19 It is the quality of the person which counts - }\end{array}$ & $\begin{array}{l}\text { Appendix A - withdrawal classes or } \\
\text { opportunity classes. } \\
\text { Many of us have been concerned for some } \\
\text { time about the problems created by the } \\
\text { increasing number of disturbed children in our } \\
\text { schools'. }\end{array}$ \\
\hline
\end{tabular}

\section{comment:}

The members of this committee were predisposed to find in favour of the need for closer relations between schools and communities. This is not a criticism of their decisions because it is clear from the evidence presented to them that anything less than what was called for would have been to default on their terms of reference. It is clear that their efforts to foster cultural solutions was at the expense of suggestions which aimed at structural changes apart from the relatively banal opportunity classes which, on the surface, still seem to be about labelling and stigmatising those who are not well placed to make real changes to the way things are.

\section{REPORT 11 -Report of the Committee on Secondary Education, 'Towards Partnership' (1976).}

[McCombs Report] 112 pages

Chair: Hon. Sir Terence H. McCombs

Māori member: J.T.Rangihau 
References are footnoted. A list of reports and documents on secondary education are in the Appendix.

There is a total of 88 recommendations under categories [aims of secondary schools (2); multi-cultural education (6); community and school co-operation (7); curriculum, adaptability and autonomy (5); curriculum development and guidelines (5); assessment, evaluation and quality (10); secondary school community (3); mutual concern and guidance services (7); teachers (4); administration (4); resources (13); secondary education review (3) - some of the recommendations are multiple]

The committee was to produce a report that would make recommendations on the relationship between secondary schools and their communities. Although the membership of the committee was nicely positioned with influential principals, administrators, and academics there was only one Māori and one Pacific person present although both of these were highly respected spokes-persons of their respective communities. It is noted that the committee met on one occasion at Tira Hou Marae in Auckland. Rangihau appears on committees of other reports in this research.

The fact that no major review of secondary education had taken place since the Thomas Report of 1944 was of some concern. The suggestion that secondary schools and their boards of governors might have been providing the education that society expected might have been the reason for the long delay between major reviews. However, given the aftermath of the Second World War, the 'babyboom', the urban migration of Māori, and the influx of Pacific peoples, New Zealand society experienced a turbulent period. Three important influences are worth noting.

The Education Development Conference (1975) recommended that schools should actively seek to enlist parent interest and co-operation and make parents feel welcome in schools (p.13). 
In 1943 , it is reported, there were 166 state and private secondary schools and $70 \%$ of primary school leavers went to them. In 1976 there are 396 secondary schools, which virtually all students who leave primary schools enter. The students are of diverse backgrounds and academic ability and generally stay longer at school (p.16).

Secondary schooling, seen in the context of 'lifelong education', was beginning to appear on different agendas. As the report says, "secondary education is not a preparation for life, but part of life" (p.17)

\section{purpose:}

The report was designed to come forward with recommendations on the relationship between the secondary schools and their communities. It states that there had not been any major review of secondary education for 30 years, that is, since the Thomas Report of 1943 (Department of Education, 1959).

Most of the recommendations related to Māori education are found in chapter 5 of the report, 'A National Identity' (pp.20-29) which begins....

\footnotetext{
This chapter is about what it means to be a New Zealander.... New Zealand should deserve and enhance its reputation as a culturally well-adjusted society..... The recommendations are an attempt to compensate for differences that put any group at a disadvantage, to remove discrimination, and to provide for the development of society beyond mere acceptance of cultural complexity..... What we had to work towards was the step beyond recognition of difference, beyond respect for diversity, even beyond tolerance..... Whether we acknowledge it or not, there is no New Zealand Päkehā who is not in some sense culturally Māori and there is no New Zealand Māori who is not in some sense culturally Pākehā.
}

Three implications follow this description on 'A National Identity': the first is that no person should be put at disadvantage because of his (sic) cultural background; the second, all people should view our cultural diversity positively, even with pride; and third, just as mankind has come to appreciate the interdependence of man and environment, we in New Zealand should recognise the interdependence of culture and culture. 
Table 5.5 discourse analysis

Secondary education- Towards partnership (1973)

\begin{tabular}{|c|c|}
\hline $\begin{array}{l}\text { Q1. What are the main problems the writers } \\
\text { of the report set out to address? }\end{array}$ & $\begin{array}{l}\text { Q2 Whose interests do the writers of the } \\
\text { report think or believe they are catering } \\
\text { for? }\end{array}$ \\
\hline $\begin{array}{l}\text { p. } 7 \text { There being no generally agreed and explicit } \\
\text { statement of aims for NZ secondary education } \\
\text { (p.2) the committee was required to come up with } \\
\text { a set of 'desirable developments' } \\
\text { p.2 How to ensure close co-operation between } \\
\text { schools and their parents and communities }\end{array}$ & $\begin{array}{l}\text { p.12 [students] } \\
\text { agreed that the primary purpose of NZ schools } \\
\text { was the intellectual development of each } \\
\text { student to his full capacity (see also Appendix } \\
1 \text { of report) }\end{array}$ \\
\hline $\begin{array}{l}\text { Q3 Does the report view the long term goal as } \\
\text { being about unity, conformity and sameness? }\end{array}$ & $\begin{array}{l}\text { Q4. Does the report view the long term goal } \\
\text { as being about difference and diversity? }\end{array}$ \\
\hline $\begin{array}{l}\text { p.5 Stated as a 'set of beliefs' the committee } \\
\text { believed secondary schools should be based on } \\
\text { and exemplify the values of (a) mutual concern } \\
\text { (b) individuality (c) co-operation (d) autonomy } \\
\text { (e) adaptability and (f) quality. } \\
\text { p.14 The development of a feeling for other } \\
\text { people and the ability to live and work in } \\
\text { harmony (was) the most important aim of } \\
\text { secondary schools. }\end{array}$ & $\begin{array}{l}\text { p.15 increasing recognition of the pluralistic } \\
\text { nature of NZ society. } \\
\text { p. } 20 \text { issues of multi-culturalism are an attempt } \\
\text { to compensate for differences, to remove } \\
\text { discrimination, and to provide for the } \\
\text { development of society beyond mere } \\
\text { acceptance of cultural complexity.... What we } \\
\text { have to work towards was the step beyond } \\
\text { recognition of difference, beyond respect for } \\
\text { diversity, even beyond tolerance. }\end{array}$ \\
\hline $\begin{array}{l}\text { Q5 Is there consensus about the need for } \\
\text { change? }\end{array}$ & $\begin{array}{l}\text { Q6. Is the unit for change basically targeting } \\
\text { the collective/ group or the individual? }\end{array}$ \\
\hline $\begin{array}{l}\text { p. } 15 \text { Change in all aspects of life is the only } \\
\text { certainty. } \\
\text { p. } 4 \text { Growing dissatisfaction in the late } 1960 \mathrm{~s} \\
\text { resulted in both local and national responses. }\end{array}$ & $\begin{array}{l}\text { p. } 5 \text { The individual is given priority; the school } \\
\text { is seen as the conduit for recognizing his/her } \\
\text { culture; and for encouraging parental } \\
\text { participation in the educative process. }\end{array}$ \\
\hline $\begin{array}{l}\text { Q7. Is there a theory of cultural change? } \\
\text { What is said about it? }\end{array}$ & $\begin{array}{l}\text { Q8. Is there a theory of structural change? } \\
\text { What is said about it? }\end{array}$ \\
\hline $\begin{array}{l}\text { p. } 4 \text { massive and rapid change is neither necessary } \\
\text { nor desirable; change but only with large-scale } \\
\text { provision of resources. } \\
\text { p. } 20 \text { What it means to be a New Zealander. } \\
\text { p. } 30 \text { Real co-operation between teachers, parents } \\
\text { and community interests depends on lay people } \\
\text { being able to participate in making decisions, } \\
\text { playing an active part, and not just being told } \\
\text { what is happening. } \\
\text { p. } 21 \text { All people should view our cultural diversity } \\
\text { positively, even with pride. }\end{array}$ & $\begin{array}{l}\text { p.35 relationships between school, parents and } \\
\text { community depends partly on the kind of } \\
\text { administrative arrangements that exist. } \\
\ldots \text { school should establish a Community- } \\
\text { School Association } \\
\ldots . \text { the education Act be amended to enable } \\
\text { such an association to be a major constituency } \\
\text { of the school board of governors }\end{array}$ \\
\hline
\end{tabular}

\section{comment:}

There is a strong belief that permeates the report on the significance of culture and the role schools have in popularising or normalising the diversities of cultures that make up the New Zealand society. In the light of the Parent-School Communication report of 1973 , it is clear some kind of consensus about the 
significance of culture was circulating around educational communities. The liberal view of the school in terms of developing in individual students a sense of autonomy, rationality and self-respect along with the need to respect the rights of others (Strike, 1989, p. 40,45) comes through strongly in the report.

Once again there is a perceived weakness around concerns to create structural solutions for existing problems. The nearest this committee got was to recommend an expansion of the old Parent -Teachers Association (PTA) and replace them with Community-School Associations.

\subsection{Summary analysis, purposes and discourses - part one}

Compared with a concept like function, a purpose is something subjective, something in the mind of the participants in a group or committee. In the case of reports, the something in the minds is first in the minds of those who called for the report, who set the terms of reference, who selected the chairperson and members of the committee, and in many cases monitored the work of the committee through to the final report. An analysis, sometimes well after the production of the report must necessarily be an interpretation based mainly or wholly on the actual report itself.

One of the most notable characteristics of the reports reviewed in Part One was the high level of optimism maintained throughout with regard to the capacity of the education fraternity to 'get it right' for Māori students within the system. This judgement is a feature of the comments identified in Tables 5.1 to 5.4. The disturbing counter-balance to this affirmation is the repeating of this stance by different committees on different reports over almost two decades without seeming progress being made. Māori education is sustained - at least through reports on education - by a promissory note. After a number of years the mantra of equality of educational opportunity, special measures for Māori learners, the need to live and work in harmony, the need for teachers to be sensitive to cultural differences, 
and the need for good relationships between schools, parents and communities, begin to take on some of the qualities of what Dr Beeby calls the educational myth. He describes this as follows:

To be both acceptable and effective, a myth has to meet certain conditions: it must be in general accord with some strong - though not always clearly defined - public aspiration; it must be expressed in language flexible enough to permit a reasonably wide range of interpretations, and yet specific enough to provide practical guidance to administrators, planner and teachers; it must be attainable, at least for that generation, if it is to sustain twenty-five years of change without being constantly and confusingly modified (in Renwick, 1986:xv).

It is somewhat mean-minded to treat ideas like, "in the Mãori pupil lies the greatest reservoir of unused talent in the population" (Currie, 1962:414) as fueling nothing more than an educational myth (even in Beeby's generous definition of same) but unlike the advertising slogan of L.V.Martin's, 'It's the putting right that counts!' it is of no validity to those who depend on others to rectify problems they have encountered through educational mal-practices exercised in the past. 'It's the getting it right to start with that matters in education'. The Currie Report (1962:415) came closest to signaling this dilemma in its statement:

Two educational problems need to be solved. The first is to determine how far the education offered the Māori in our schools is in fact the most suitable for his needs. The second is how best to enable the Marori to take advantage of the education that is offered, to the extent that this lies within the control of the education system.

\section{THE REPORTS - PART TWO (1978-2000): Mā te kanohi miromiro}

\subsection{Background}

The miromiro is a small bird that searches for insects in the bark of trees. The proverb, 'Mā te kanohi miromiro,' is used to encourage anyone making a search for a missing object. In the case of the reports on Māori education for the period 1960 to 1978 , I argued that reports on Māori education were essentially about outwardly embracing Māori culture, values etc. (Ka awhi noa i waho) without getting to the heart of Māori concerns (kare i uru ki roto). In analysing the reports from 1978 to 2000 we need to ask whether these reports signal a change of heart; 
are we able to identify those elements that might transform Maori education from the promises of the previous 20 years hence, the whakataukī, 'mā te kanohi miromiro' ('like unto the eye of the miromiro'; Proverb 104, Department of Education, undated)

The notion of a transformative potential was alluded to in Watson's 'Horizons of Unknown Power'. One of the reasons it is possible to describe the Māori educational potential as 'unknown' is because the education system has not wanted to know. To know means it would have to do something about it like having to dramatically increase the volume of mātauranga (knowledge) into the system; like having to include tikanga (values and practices) into the everyday operation of schools; and like having to deliver programmes in te reo Māori (Māori language) across the board. Māori are often heard to describe the New Zealand education system and its schools as being a Pākehā system with Pākehā schools run by Pākehā, for Pākehā. Any foreign people (mainly those of non-English background) arriving in this country would not take long to reach a similar conclusion. They would soon realise the folly behind the government propaganda machinery on the nature of New Zealand society and the historical relationship between Māori and Pākehā. On learning that Māori are the indigenous people of the country and that they are approximately $15 \%$ of the total population they would likely be surprised and perhaps disappointed at the relative invisibility of the Māori world within education in New Zealand.

One might have expected that the Hunn Report of 1960 and the Currie Report of 1962 would have provided inspiration for the 1970 NACME Report. The two Department of Education publications of 1971, 'Māori Children and the Teacher' and 'Education of Māori Children' were important in providing both research support and a certain level of commonsense guidance to teachers on the recommendations fore-shadowed in the Hunn and Currie Reports while their influence on the NACME Report of 1970 is also evident. These earlier reports are the forerunners of the following batch of reports. Do they build on them? Is there a 
clear direction emerging? Is there a fit between what is advocated in Māori Education reports and what is happening in the mainstream? Whose 'voice' is coming through? What seem to be the priority areas? Is there a shift in the underlying philosophical base in terms of deep structures? How do the recommendations align with Māori perceptions of reality?

\subsection{The reports}

There are 19 works summarised in Part 2: Twelve are reports; one is in the nature of research monographs; four are monographs; one is a briefing paper; and one a report of a conference. The pattern of analysis of Part Two reports follows the same process as for Part One reports.

\section{REPORT 15 - Report of the National Advisory Committee on Mãori}

Education, He Huarahi (1980),

72 pages.

Chair: Peter Boag

Māori Committee members: TeR. Bailey, E.Waaka, J.Clarke, J.Peters, G.Marsden, E.Tawhiwhirangi, R.Walker, J.Bennett, M.Mataira, E.Murchie, W.Jaram, J.Rangihau, A.Johns, T. Reedy, M.Pewhairangi, V.Penfold, W.Herewini, T.K.Royal.

In 1976 it was decided that a working party of the NACME should be formed from its members to allow more on-going tasks to be completed. Progress on the implementation of the 1970 recommendations was hindered by the opportunities the committee as a whole had to meet and monitor developments. Although progress was being made "marked disparity between Māori and non-Māori secondary achievements remains" (p.5). This report was a reflection of that initiative.

Rather than listing the 87 recommendations it was decided instead to list the category, Objectives for the Next Five Years (pp. 14-16). The Report says that the committee wanted 'to offer some realistic criteria against which schools and 
society may measure progress' by focusing on three areas - what schools, the Department of Education, and community should aim to do (p.14).

In 1976 the Report of the Task Force on economic and social planning, New Zealand at the Turning Point, chaired by Professor Frank Holmes of Victoria University highlighted the sort of discussion New Zealand wanted in the future but made it clear that some of the old values inherited from the West such as, the need for choice (p.31), harmony and mutual respect (p.79) would remain an important feature of society. Some of the challenges included a massive shift of population from rural communities to urban and included Māori as well as Pacific groups. The Task Force promoted the idea of a multicultural bias within administration but were well aware of the difficulties posed by a majority who "revealed an extensive lack of awareness of the true nature of New Zealand society" and suffered an illusion that "minorities should somehow be content to discard their identity and merge with the dominant group" (p.77).

Whereas a reading of the Holmes Report (1976) reveals that ideas and practices related to cultural diversity and political pluralism were far removed from the consciousness of economic, finance and business peoples, the Johnson Report of 1977, Growing, Sharing, Learning - The Report of the Committee on Health and Social Education was well advanced by comparison. Both reports talk of the multicultural society but whereas the Holmes Report has little to say about the Māori contribution, the Johnson Report says, "The Māori people must be able to expect a solid Māori side of language, values and expressive arts throughout the system and not just in schools with a large percentage of Māori pupils" (p.16). The difference is also highlighted by the respective committee membership of each team, with no Māori or Pacific representation in the Task Force, but one Pacific person (Erolini Alailima-Eteuati) and four Māori (Quentin Tapsell, Neil Watene, John Rangihau; and Horowai Maniapoto) in the membership of the Johnson Committee. 


\section{purpose:}

This is the second major report of NACME and the most comprehensive. There are six main headings: An Introduction; The Place of Māori Language in the Education of Māoris and Non-Māoris; Early Childhood and Care; The Quality of Teachers - Recruitment and Training; and Continuing and Second-Chance Education. There are 87 recommendations in all, appendices which include some basic statistical data, and a reference section. It is obvious just looking at the six statistical tables in the report that the syndrome of behaviours related to differential achievement (highest qualifications, retention, and destination of school leavers) weighed heavily on decisions to be reached by the members of the committee. What is less obvious are reasons why research on differential achievement is absent but an article on multiculturalism by the well known anthropologist, Metge is actually in the report.

\section{Table 5.6 discourse analysis}

\section{National Advisory Committee on Māori Education (1980)}

\begin{tabular}{|l|l|}
\hline $\begin{array}{l}\text { Q1. What are the main problems the writers of } \\
\text { the report set out to address? }\end{array}$ & $\begin{array}{l}\text { Q2 Whose interests do the writers of the } \\
\text { report think or believe they are catering } \\
\text { for? }\end{array}$ \\
\hline $\begin{array}{l}\text { p.4 to achieve the goal of a harmonious multi- } \\
\text { cultural society in NZ. } \\
\text { p.5 to address the disparity between Māori and } \\
\text { non-Māori secondary achievement }\end{array}$ & $\begin{array}{l}\text { p.14 Although somewhat guarded the report } \\
\text { maintains that Māori people should have a } \\
\text { stake in their own education and that of their } \\
\text { children. } \\
\text { p.17 Preserving and developing Māori culture } \\
\text { through the efforts of both Māori and NZers in } \\
\text { general }\end{array}$ \\
\hline $\begin{array}{l}\text { Q3 Does the report view the long term goal as } \\
\text { being about unity, conformity and sameness? }\end{array}$ & $\begin{array}{l}\text { Q4. Does the report view the long term goal } \\
\text { as being about difference and diversity? }\end{array}$ \\
\hline $\begin{array}{l}\text { p.6 social cohesion and enhanced mutual respect } \\
\text { between the races through Māori being } \\
\text { represented in due proportions in all walks of life; } \\
\text { search for a harmonious multi-cultural society. } \\
\text { p.47 ontinuing and second-chance education fits } \\
\text { the same mold as above. [The latter is a } \\
\text { euphemism for the individual failing to take } \\
\text { advantage - the question is whether those who } \\
\text { 'failed' even had a first chance]. }\end{array}$ & $\begin{array}{l}\text { p.4 Diversity [in a limited sense]is good for } \\
\text { individuals and groups to be enriched by } \\
\text { contact with other points of view. } \\
\text { p.37 the strategy of drawing school and } \\
\text { community closer together is to move school } \\
\text { meetings into community venues such as } \\
\text { maraes and cultural centres in which Māori } \\
\text { parents are more likely to feel at ease. }\end{array}$ \\
\hline $\begin{array}{l}\text { Q5 Is there consensus about the need for } \\
\text { change ? }\end{array}$ & $\begin{array}{l}\text { Q6. Is the unit for change basically targeting } \\
\text { the collective / group or the individual? }\end{array}$ \\
\hline $\begin{array}{l}\text { p.6 Yes but schools alone cannot bear the brunt. } \\
\text { groups, the media, all have their part to play. }\end{array}$ & $\begin{array}{l}\text { p.7 We need to examine closely our } \\
\text { educational philosophy, and our classroom } \\
\text { strategies, the organization of our schools and, }\end{array}$ \\
\hline
\end{tabular}




\begin{tabular}{|l|l|}
\hline $\begin{array}{l}\text { p.36 The committee cannot accept that Māori } \\
\text { pupils must always be the ones to make the } \\
\text { greatest effort to adapt to a system which is } \\
\text { attuned to the needs of Pākehā children rather } \\
\text { than to their needs. }\end{array}$ & $\begin{array}{l}\text { where necessary, change them. } \\
\text { p.9 The emphasis so far has been on the } \\
\text { individual. But individuals are very much part } \\
\text { of the culture of their group } \\
\text { p.12 Multiculturalism places part of the } \\
\text { responsibility for adaptation on the pākehā. }\end{array}$ \\
\hline $\begin{array}{l}\text { Q7. Is there a theory of cultural change ? } \\
\text { What is said about it? }\end{array}$ & $\begin{array}{l}\text { Q8. Is there a theory of structural change ?. } \\
\text { What is said about it? }\end{array}$ \\
\hline $\begin{array}{l}\text { p.7 recognition of Māori views by Pākehās. } \\
\text { p.9 culture is the 'totality of all a person learns as } \\
\text { a member of the society' (Chinoy) } \\
\text { Rangihau - I am a product of all that my people } \\
\text { transmit to me } \\
\text { Ngata - Māori and Pākehā traditions plus }\end{array}$ & $\begin{array}{l}\text { p.8 as long as examinations remain, Māori } \\
\text { students have to be able to pass them } \\
\text { p.11 Because of the high rate of intermarriage } \\
\text { with pākehās, and because of Pākehā } \\
\text { dominance in numbers, Mäoris need the } \\
\text { psychological and social support of Päkehās to } \\
\text { help them keep their culture a living thing. } \\
\text { p.13 need to recruit more Māori teachers } \\
\text { - marae recognized as a place of learning } \\
\text { p.14 Need to take measures that are in } \\
\text { themselves unequal in order to meet special } \\
\text { needs. }\end{array}$ \\
\hline
\end{tabular}

\section{comment:}

Multiculturalism remains a central theme of the report but there is a clear message being enunciated by Māori that their culture (language, values, practices), as the tangatawhenua, has to play a far more prominent role in the general education of all New Zealanders than hitherto, that is, the humanitarian path to harmony, cohesion, and mutual respect must be through the satisfaction of their educational achievements and not just through efforts to improve their self-esteem. The research of an Afro-Caribbean academic and teacher, Stone (1981) aligns somewhat with the writers of the NACME Report but she goes much further in focusing on educational achievement by concentrating on 'relevant' knowledge and formal methods of teaching. She puts her position pointedly:

\footnotetext{
...my thesis that teachers who emphasise self-concept, self-esteem and enjoyment, do so at the expense of more concrete objectives (p.241)......the central recommendation of this study is for the use of more formal methods of teaching West Indian children throughout primary and secondary schools (p.242).
}

NACME pointed the way for a major initiative to arise out of the Mãori community 'flax-roots' in 1982. 


\section{REPORT 20-A Review of the Core Curriculum for Schools (1984) Department of Education,}

67 pages.

Chair: Jim A. Ross (of the Curriculum Review Working Parties +19 and Conference +23 others)

Māori members: (of Working Parties, nil out of 21), (of Conference, 4 out of 30: John M. Bennett (Māori Education Foundation), John Clarke (rural, mainly Māori secondary school), Lorraine P. Nikera (urban primary school), Awi Riddell (secondary Māori boarding school). Each of the Māori members has both high professional credentials and credibility in Māori communities.

There are appendices but all references are in footnotes. Instead of recommendations there is a set of 16 proposals two of which specifically address Māori education, namely, the teaching of Māori language as a special need, and secondly, the inclusion of 'taha Māori' as an integral part of each school's programme. In a section on the curriculum for schools 18 issues are reported but none are specifically related to Māori. In the slip-stream of the NACME Reports (1970, 1980), the New Zealand Educational Institute Māori education report, 'Te Tatai Hono' (1982), and the controversial report from the Race Relations Conciliator, 'Race Against Time' (1982) no curriculum issue related to Māori education seems to be an extraordinary omission. In defence of the Department of Education it could be construed that Māori were beginning to resist the multicultural agenda at this time on the grounds that multiculturalism was replacing biculturalism in the minds of many educationalists. Perhaps the Department was biding time and putting out feelers for its latest policy direction, taha Māori (the Māori dimension) ${ }^{4}$ that it outlines briefly in the middle of the report under the heading 'Biculturalism, Multiculturalism and Māori Education' (p.31).

\section{purpose:}

The report sets out to define, justify and describe a core curriculum for New Zealand schools. The core curriculum is the compulsory and formal part that constitutes the heart of the education offered by a school. In their own words, "the

2. Elsewhere, Penetito (1984) was less generous in his critique of 'taha Mãori' in the curriculum seeing it as tokenistic at best and marginalising Māori further, at worst. 
main purpose of the core curriculum is to ensure that students have the essential knowledge, skills, attitudes and values which all citizens need to lead effective lives in New Zealand society" (p.7). The reason for having a core curriculum is summarised in three inter-related statements:

(a) to protect the interests of all students;

(b) to ensure equality of opportunity; and

(c) to enable all students to develop as fully as possible.

If one looks back at the liberal education model discussed in chapter 2, this definition of the core curriculum sits comfortably within the aegis of that educational philosophy. It also is consistent with the centralised nature of the New Zealand education system in which virtually all major decisions related to the curriculum are made by members of the educational fraternity, albeit, most of whom are public servants who were ex-school teachers. Educational professional associations are involved in the discussions (teacher unions, education boards, and independent schools, but lay members of communities are not included).

Table 5.7 discourse analysis

Review of the core curriculum of schools (1984)

\begin{tabular}{|l|l|}
$\begin{array}{l}\text { Q1. What are the main problems the writers of } \\
\text { the report set out to address? }\end{array}$ & $\begin{array}{l}\text { Q2 Whose interests do the writers of the } \\
\text { report think or believe they are catering } \\
\text { for? }\end{array}$ \\
\hline $\begin{array}{l}\text { p.6 the compulsory core of the formal curriculum } \\
\text { p.31 Taha Māori (Māori dimension) as } \\
\text { component parts of the curriculum - not a } \\
\text { separate subject. }\end{array}$ & $\begin{array}{l}\text { p.7 The main purpose of a core curriculum is } \\
\text { to ensure that students have the essential } \\
\text { knowledge, skills, attitudes and values which } \\
\text {-NZers sense of national identity and an } \\
\text { acknowledgement of ethical and cultural diversity } \\
\text { society. } \\
\text { p.8 the interests of all students.. through the } \\
\text { study of a balanced curriculum, to ensure } \\
\text { equality of opportunity, to enable all students } \\
\text { to develop as fully as possible. }\end{array}$ \\
\hline $\begin{array}{l}\text { Q3 Does the report view the long term goal as } \\
\text { being about unity, conformity and sameness? }\end{array}$ & $\begin{array}{l}\text { Q4. Does the report view the long term goal } \\
\text { as being about difference and diversity? }\end{array}$ \\
\hline $\begin{array}{l}\text { p.17 fulfilment as individuals - in our democracy, } \\
\text { there should be a balance between personal } \\
\text { freedoms and civic and national responsibilities }\end{array}$ & $\begin{array}{l}\text { p.31 There are 3 grounds for giving priority to } \\
\text { taha Māori: Māori culture is unique to NZ; it is } \\
\text { a distinctive characteristic of the NZ identity; it } \\
\text { is a model and springboard for the study of } \\
\text { other cultures. }\end{array}$ \\
\hline $\begin{array}{l}\text { Q5 Is there consensus about the need for } \\
\text { change ? }\end{array}$ & $\begin{array}{l}\text { Q6. Is the unit for change basically targeting } \\
\text { the collective / group or the individual? }\end{array}$ \\
\hline
\end{tabular}


p.13 The consequence of the philosophy of 'all schools being multi-cultural' is schools predominantly Pākehā must see the promotion of Māori language and culture within their walls as essential.

p.36 The committee cannot accept that Mãori pupils must always be the ones to make the greatest effort to adapt to a system which is attuned to the needs of $P$ ākehā children rather than to their needs. p.6 Young Mãoris must acquire the academic skills which make them more acceptable to employers, as well as those personal and social attributes which spring from selfconfidence and self-respect.

p.9 The emphasis so far has been on the individual. But individuals are very much part of the culture of their group

p.12 Today we have a better realization that an education system designed to preserve western traditions may not necessarily meet the special needs of culturally different groups.

Multiculturalism places part of the

responsibility for adaptation on the pākehā.

Q8. Is there a theory of structural change?. What is said about it?

p.36 Changes have occurred in part as a response by schools to the social, economic and cultural changes outlined earlier (Māori and $\mathrm{m} / \mathrm{c}$ studies, bilingual education in some localities, community schools).

p.32 The full integration of taha Māori within the life of the school is an ideal to be aimed at..

\section{comment:}

The writers of the Review of the Core Curriculum are correct when they say "schools have to make choices about what to include in the curriculum" (p.38). The British sociologist, Lawton (1983) made a similar point when he argued that the curriculum is a 'selection from the culture(s)' since it is obvious that schools can't teach everything about the cultures within any society, it becomes necessary that a selection be made. The questions then becomes, on what basis should a selection be made and who makes it? The Review of the Core Curriculum made the selection based on the historical precedent and what it takes to be new developments. Taha Mãori is one of these new developments. But then the committee, apparently, suffered a loss of nerve. Whereas all other curriculum areas are given an allocation of time across the years of schooling, for taha Māori all it says is 'no time allocation specified' (p.41). It seems the committee may have concurred at this point with the pragmatic but nevertheless hollow words of the Canadian sociologist, Friedenberg when he maintained, 
Schools have no option but to bow to the particular culture from which they spring, to teach that culture's ideology through an efficient core curriculum, and at least to do it well without pretending that it is anything but cultural hegemony that they serve (1982).

The problem for some in accepting a statement like this is that going to school is not a choice for individuals and so long as schooling is compulsory for at least 10 years there is an obligation on the part of the school to educate all students. If the culture of the school favours one group of students over another then it is disadvantaging one group. If the reflection in the school of a student's culture is an important factor in whether a student succeeds or fails then schools must either do all it can to accommodate the culture of all other students or provide systemic alternatives. Cultural hegemony in education is only acceptable if other than mainstream cultures have access to schools that privilege their cultures.

\section{REPORT 27-Report of the Taskforce to Review Education Administration (1988)}

\section{[Picot Report] 138 pages}

$\begin{array}{ll}\text { Chair: } & \text { Brian Picot }+4 \text { others } \\ \text { Māori member: } & \text { Whetumarama Wereta }\end{array}$

This is a major report with more than 700 submissions. There are 10 chapters organised into four sections.

There are several indicators as to the critical importance of the Picot Report. One is that it is labeled a taskforce and not a committee or a review group. Second, it was requested to report directly to three cabinet ministers, the Minister of Education who happened also to be the Prime Minister, the Minister of Finance and the Minister of State Services. Third, it was to review all aspects of educational administration within the New Zealand education system and had nine months to complete its tasks. In a significant departure from previous practice, at least in education, the taskforce for such a massive exercise was to be chaired by a businessman, with one Māori Affairs social researcher, two tertiary level educationalists, and a company director. If the educational world felt a taskforce 
was out of character with its activities, and that the highest level of political interest was way beyond what they were accustomed to, having two business men out of five with one as chairperson was out-done by the selection of only two educationalists both of whom were attached to tertiary institutions.

\section{purpose:}

The task forces were given high level terms of reference in which they were required to examine the functions of the Head Office of the Department of Education with a view to focusing them more sharply and delegating responsibilities as far as was practicable. The work of the administrative bodies of tertiary institutions (excluding universities), secondary and primary schools were to be examined with a view to increasing their powers and responsibilities. The role of the Department of Education in relation to other educational services was the third requirement of the terms of reference. The final activity of the taskforce was to examine changes in the territorial organisation of public education with reference to the future roles of education boards, other education authorities, and the regional offices of the Department of Education.

Requirements from Māori according to Picot are: first, the provision of the opportunity for all Māori children to be educated (either wholly or in part) in the Māori language; and second, where the Māori language is used for the transmission of knowledge, an environment that reflects Māori values and uses Māori forms.

The report sees the need for a system that recognises and supports the culture, values and language of the Māori people. In order to promote this objective, the system opted for changes that would encourage community involvement in determining the character and direction of local institutions. The key recommendation in this respect is the requirement that institutions operate according to a charter to be drawn up in consultation with local groups and to be approved by central government. 
Table 5.8 discourse analysis

Taskforce to review education administration (1988)

Q1. What are the main problems the writers of
the report set out to address?
p.22 Overcentralisation of decision making;
complexity; lack of information and choice; lack
of effective management practices; feelings of
powerlessness
- inflexible procedures
- the system stifles initiative

Q3 Does the report view the long term goal as being about unity, conformity and sameness? p.65 It is clear that the revival of the Mãori language and culture is not seen as an end in itself, but as the key of lifting the educational performance of Māori children.... Education in the Māori language and in a Māori environment serves to reinforce the identity of Mäori children and to give them the emotional security and psychological strength needed to 'take on' the material knowledge of the Pākehā.

p.66 In order to promote this objective, we opted for changes which would encourage community involvement in determining the character and the direction of local institutions.
Q2 Whose interests do the writers of the report think or believe they are catering for?

p. 3 Objectives of public education:

- every learner should gain the maximum individual and social benefit from the money spent on education - education should be fair and just for every learner regardless of their gender, and of their social, cultural or geographical circumstances

Q4. Does the report view the long term goal as being about difference and diversity? p.44 Each institution set its own objectives, within the overall education objectives set by the state. These objectives would reflect the particular needs of the community in which the institution is located, and would be clearly set out in a 'charter' drawn up by the institution. This charter would act as a contract between the community and the institution and the state.
Q5 Is there consensus about the need for change ?

p.6 The time has come for radical change in the education system's administrative structure p.36 Tinkering with the system will not be sufficient to achieve the improvements now required.
Q6. Is the unit for change basically targeting the collective / group or the individual?

p.5 In essence, our views are that the government should take only those administrative decisions it needs to take. p. 43 Learning institutions should be the basic 'building block' of education administration, with control over their educational resources; that the running of the learning institution be a partnership between the professionals and the particular community in which it is located.

Q7. Is there a theory of cultural change ? What is said about it?

p.4. Education must be based on the notion of a partnership of equals

p.81 It is essential that the change is made in such a way that everyone feels that they have been properly informed of the changes to be made; that they have been treated fairly and equitably.
Q8. Is there a theory of structural change ?. What is said about it?

p.36 The idea of a separate system to cater for their children's educational needs was made especially strongly by Mãori people who made submissions to us. 


\section{comment:}

From the perspective of the education system the Picot Report is probably the most important educational report released within the period examined by this research, that is, 1960-2000. Its importance, from the point of view of the education system as a whole, derives from its political support to dismantle the machinery of the current system, to shake it up, and then to reconstruct it following an economic or market model of accountability. The reforms Picot recommended were to create an education system where every learner would gain 'the maximum individual and social benefit from the money spent on education' and would be 'fair and just regardless of gender, social, cultural or geographic circumstances' (Barrington, 1991:10). For Māori education the Picot Report was also important in the sense that it provided official recognition for the educational transformations that were already under way among several Māori groups. From the time of its release in April 1988 to the moment of its implementation on 1 October 1989 the administration of education within New Zealand would undergo a massive transformation. For a society that espoused the virtues of gradual piecemeal change for decades the impact of the educational administrative reforms were revolutionary and transformative. In Mäori education the possibility of a separate system, the notion of a partnership of equals, accountability to the Treaty of Waitangi, and charters which gave communities a legal say about what local schools would teach seemed too extravagant to believe. And so they were. Attempts at decentralisation were eventually stymied and if anything, the centralised system is at least as pervasive as it ever was. There is no partnership of equals, but partnerships between the central bureaucracy, the Ministry of Education, and Iwi Education groups have burgeoned from the late 1990s. This is research for another day. The Treaty of Waitangi remains an active component of rhetoric rather than reality. Charters simply became submerged under the proliferation of official requirements so that eventually there was no time or space in the official life of the school that the community could say 'this is the flavour, the essence we want to permeate our school. This is what will make us distinctive. This is us. This is what we want our children to know about our place in the 
world'. The taskforce was undoubtedly genuine in its belief that the charter was 'the 'lynchpin' of the structure (boards of trustees) and would act as a contract between the community and the institution, and the institution and the state" (p.xi). Of course, it is possible that they could have underestimated the centrality of the New Zealand system of education and the level of social control needed to get a society to shift its major underlying assumptions from ones which upheld education as a good in itself to one which saw education as an investment in the young to benefit the nation in the future.

\section{REPORT 31-Report for the Ministry of Education, Māori Participation and Performance in Education - A Literature Review and Research Programme. (1996)}

Simon Chapple, Richard Jefferies and Rita Walker. NZ Institute of Economic Research (Inc.) 142 pages, fully referenced.

The two Mäori researchers in this project are well qualified as researchers as well as having credibility in Māori education; Jefferies as an experienced secondary school teacher and public servant, and Walker as an experienced early childhood educator and tertiary lecturer. Chapple is an economist who works for the New Zealand Institute of Economic Research (Inc.) and led the project commissioned by the Ministry of Education.

Excluding the appendices and references there are 11 chapters in the report of 130 pages. There is a comprehensive set of tables and figures and an expansive references section.

Following the Treasury Briefing papers to the Incoming Government (1987) on education issues, its influence was so comprehensive and penetrative that economists and economic theories became a part of the educational zeitgeist, at least at the level of administration, never before experienced in this country. The Chapple et al Report (1996) provided the in-depth review of the literature and the research the Ministry of Education needed to orient its policies. In order to make a relatively large and 'jargony' economic report more readable for a wider audience 
than public servants a 'Summary' was also written by Anne Else (1997). Other economists provided the necessary training in economic theory to assist educational policy analysts ${ }^{5}$.

\section{purpose:}

In its introduction it says, "This study surveys the literature on disparities between Māori and non-Māori education participation and performance. The aim is to provide input into a policy process aimed at improving relative Māori labour market outcomes" (p.12). The report does not assume that there is a gap in participation and performance between Māori and non-Māori. However, where the definition of performance comes under considerable critical scrutiny, participation does not and yet there is, in my experience, as much a tyranny of participation as there is of performance when it comes to research and policy in Māori education. The report was to show:

- what research has to say about the education gap;

- what we still do not know about the education gap;

- $\quad$ what research needs to be done to fill the gaps in what we know; and

- $\quad$ what kinds of education lead to better results for Māori

Table 5.9 discourse analysis

Māori participation and performance in education (1996)

\begin{tabular}{|c|c|}
\hline $\begin{array}{l}\text { Q1. What are the main problems the writers of } \\
\text { the report set out to address? }\end{array}$ & $\begin{array}{l}\text { Q2 Whose interests do the writers of the } \\
\text { report think or believe they are catering } \\
\text { for? }\end{array}$ \\
\hline $\begin{array}{l}\text { - the education gap between Māori and non-Māori } \\
\text { with only one aim: to help find ways to close the } \\
\text { gap in 'labour market performance' between } \\
\text { Māori and non-Māori. } \\
\text { - the literature on disparities between Māori and } \\
\text { non-Māori education participation and } \\
\text { performance. The aim is to provide input into a } \\
\text { policy process aimed at improving relative Māori } \\
\text { labour market outcomes. }\end{array}$ & $\begin{array}{l}\text { - current policy writers. According to the } \\
\text { writers the gap between Māori and non-Māori } \\
\text { is ever widening is a myth... the evidence } \\
\text { suggests the exact opposite - the gap is slowly } \\
\text { and unevenly narrowing.. }\end{array}$ \\
\hline $\begin{array}{l}\text { Q3 Does the report view the long term goal as } \\
\text { being about unity, conformity and sameness? }\end{array}$ & $\begin{array}{l}\text { Q4. Does the report view the long term goal } \\
\text { as being about difference and diversity? }\end{array}$ \\
\hline $\begin{array}{l}\text { This is their priority on the grounds that since } \\
\text { education in NZ has largely been supplied by } \\
\text { govt, it may be that Māori have similar }\end{array}$ & $\begin{array}{l}\text { Their support of Gould (1996) who comments, } \\
\text { 'It is fair to say as far as it goes, the evidence } \\
\text { produced here does suggest quite strongly that }\end{array}$ \\
\hline
\end{tabular}

3. See for example, course work by the consulting economist, John Savage (1998) 
preferences for education overall, but have a low demand for the type of education provided. They half-heartedly say that schools may not be teaching Mãori the things they want to know but they have nothing to add. as far as between what one might call the assimilation/modernization and the mana motuhake/cultural preservation paradigms of Māori policy, it is the former which holds out better hope of continued improvement in Māori socio-economic standing', makes the answer no.

\section{Q5 Is there consensus about the need for} change ?

No, but where changes are occurring there is a belated acceptance eg. the development of Iwi Education Plans by some iwi may be seen as a proactive statement in support of these views (educational provision on a tribal basis) but there again appears to be little known about what has happened or is happening with these plans and whether or not they shed any light on the preferences of Māori in education.

Q7. Is there a theory of cultural change ? What is said about it?

$-2 / 3$ to $3 / 4$ of the gap can be put down to family resource factors.

- moves away from a deficit approach to explaining problems of Māori participation and achievement towards recommending changes in the education system which were claimed to be part of the problem

- growth of Māori delivered initiatives (TKR, $\mathrm{KKM}$ etc.) is indisputable

\section{Q6. Is the unit for change basically targeting} the collective / group or the individual?

- there is considerable evidence that on average Māori families have fewer resources available to them to ensure that their children succeed in the education system; the individual having access to additional resources through the family is the agent of change eg. to overcome the influences of peer pressure

Q8. Is there a theory of structural change? What is said about it?

p.10 The relative family resource position of Māori is a significant and substantial cause of educational disparities.

- by the early 1970 s, educationalists began to focus on school structures as a cause of Māori educational disadvantage

- supply-side problems in the education system (low tchr expectations, lack of cultural relevance, racism)

\section{comment:}

The report suggests that there exists strong evidence that Māori on average perform worse because they do not have the resources to succeed. That sounds like a reasonable explanation. They speculate that perhaps two thirds to three quarters of Māori educational disadvantage is the result of resource factors. This relates roughly to a third to a quarter to be accounted for by the various ethnicity related factors operating via tastes and preferences, labour market discrimination, peer pressures and school barriers. Why don't they have the resources is related to the second part of their explanation. In order to get access to the necessary resources Māori have to overcome the structural discriminations inherent in the system in the form of an ethno-centric curriculum, cognito-centric resources for learning, sociocentric teachers, and a system culturally biased toward European values. If anything the report ties down explanations of negative Māori outcomes in 
participation and educational performance to yet another generation of deficit theory explanations. Some of the most exciting developments in Māori education over the last 40 years have been those that originated from Māori sources such as Te Kōhanga Reo, Kura Kaupapa Māori, and Wānanga. The report is almost mute on that point

REPORT 32-Report for the Minister of Māori Affairs, Māori Education Commission (1998, 1999a, 1999b)

Chair: $\quad$ Retired Judge Michael J.A.Brown

Māori members: Dr Pita Sharples, Dr Rose Pere, Margie Hohepa, Terry Morrison, Pauline Waiti

The Commission arose out of a decision by the Minister of Māori Affairs to create 'think tanks' in the critical areas of Māori development. Education was one of those commissions. The group is totally Māori, some of whom are high-profile national and international figures (Brown, Sharples and Pere) and all are well qualified academically and professionally.

The members were commissioned to consult with the public and "to provide a link between grass roots opinion and the expertise they brought to the tasks and to work with the other Māori Development Commissions to find sustainable, beneficial and accelerated ways of strengthening the future for Māori” (1998(b):3). The life of the Commission was finite, beginning in September 1997 and ending June 2000.

One of the major external influences driving the work of the Commission was the Government's much promoted and much maligned policy of overcoming disparity and reducing gaps especially in the educational performance of Māori in respect to non-Māori. The Commission operated under the administrative framework of Te Puni Kokiri, the Ministry of Māori Development. 


\section{purpose:}

As set out in the first report of the commission (Feb 1998:9-10) there are three key purposes of the Commission: to be a think tank for the Minister of Māori Affairs; to provide a link between Māori grassroots and the Minister; and to contribute as one of four Commissions on Māori development.

The net effect of the Commission(s) will be to provide Government with a further source of contestable policy advice on Māori development.

Table 5.10 discourse analysis

Māori Education Commission (1998-99)

Q1. What are the main problems the writers of the report set out to address?

- how to represent the 'authentic' voice of Māori communities to government

- what previous knowledge could be of direct assistance to their task

- identification of educ practices that work for Māori

- how to maintain meaningful liaison with other commissions

Q3 Does the report view the long term goal as being about unity, conformity and sameness?

-strategy to enable Māori to leap the 'disparity gaps' as well as minimize the development of a new gap is status quo oriented $(02 / 99)$
Q2 Whose interests do the writers of the report think or believe they are catering for?

The fact they state their 1st purpose as being a 'think tank' suggests they put advice to the Min. of MA first

Next is the Māori 'grassroots' presumably whānau, hapū, iwi

Māori dvpt through iwi participation.

Q4. Does the report view the long term goal as being about difference and diversity?

Reports Feb. 1999 (No 3) and Sept.1999 (No 4) prioritise te reo Māori, kaupapa Māori, and a Māori education authority highlighting the need for an alternative structural response to diversity. Newsletter 2 is devoted to a philosophical discussion of same although ambivalence is shown in other items in the newsletter eg. Alan Duff Charitable foundation.

Q5 Is there consensus about the need for change

There is no innovation or intervention recommended that does not already exist in the system in some shape or form. However, they are looking for more Māori control of Māori education, better resourcing of current te reo/kaupapa Mãori provision, improved information technology access, and greater accountability of mainstream to Māori initiatives.
Q6. Is the unit for change basically targeting the collective / group or the individual?

- a holistic rather than a sectoral approach to the needs and aspirations of Māori is more likely to produce both immediate and long-term benefits for Māori.

- policy development must relate to Māori according to a Māori worldview (09/99)

- report focuses on the state compulsory education sector, which is totally regulated and monitored under a legislative umbrella

- need for a critical mass of expert teachers who are also Māori (08/98) 


\begin{tabular}{|l|l|}
\hline $\begin{array}{l}\text { Q7. Is there a theory of cultural change ? } \\
\text { What is said about it? }\end{array}$ & $\begin{array}{l}\text { Q8. Is there a theory of structural change ? } \\
\text { What is said about it? }\end{array}$ \\
\hline $\begin{array}{l}\text { - An ad hoc separate system already exists in } \\
\text { Wānanga). educ. (TKR, KKM, Wharekura, } \\
\text { - ethos of the school needs to be bicultural, with } \\
\text { bilingual/bicultural teachers }\end{array}$ & $\begin{array}{l}\text { Supporters see a Mãori education structure as } \\
\text { an intervention into education delivery, that has } \\
\text { produced unsatisfactory results for Măori over a } \\
\text { period extending for generations. It is seen as } \\
\text { an innovation aimed at placing control for } \\
\text { Māori educational development squarely in the } \\
\text { hands of Māori. It is a proposal for Māori } \\
\text { ownership, co-operation and group } \\
\text { development. It is perceived as being totally in } \\
\text { accord with the concept of tino rangatiratanga } \\
(08 / 98)\end{array}$ \\
\hline
\end{tabular}

\section{comment:}

An overall impression gained in reviewing and analysing the reports of the Commission is that they, as a group, were overwhelmed by the task they faced. Each member was Mãori and they each brought a huge and Māori-specific experience base to the work. Judge Brown had considerable respect from both Māori and Pākehā as a lawyer and especially as an innovative youth court judge. His selection as chair of the commission was generally accepted by Māori educationalists as somewhat inspired along similar lines to that of Picot's selection (a businessman) as chair of the taskforce to review educational administration. Pere has extensive experience in the education system at all levels and is a passionate advocate in Māori education. Waiti comes from a strong Māori educational background with particular strengths in the sciences field as well as curriculum development. Hohepa is an academic researcher in Māori education with specialisations in psychology and linguistics. Morrison has a lengthy background in primary schools as both teacher and manager. Sharples is debatably the most high profile member of the commission with considerable background and leadership in Māori performing arts and the kura kaupapa Māori movement. There was no shortage of experience or expertise in the group but what it lacked, in the view of the researcher, was a leader with the vision to choose a goal and the courage to pursue it with all the resources at their disposal. This criticism is not about the chairperson. Indeed, the commission as a whole was probably deluged 
with vision proposals and there would certainly not be any shortage of courage in the group. But therein lies the problem. What vision from those being espoused? The kaupapa Māori agenda; a Māori education authority; increased access to modern technology; closer relations to community; establishing a full-blown separate system; a more penetrating integration with the mainstream and so forth. Almost any of these 'visions' could transform the state of Māori education if the group was convinced and committed to pursue it with vigour. The Minister of Māori Affairs was almost begging for this kind of leadership at the outset. In fairness, the commission was operating part-time with minimal resources at their disposal but the Commission itself in its stated 'preferred approach' (Report 1, Feb. 1998, p.8) travelled the conservative and massively overdone route of 'consulting with the people'. The next chapter in this thesis (Chapter 6) explores the strategy of consultation in greater depth. As every Māori consultation group repeats, 'we have had enough of being consulted; we want to see some action'.

The reports echo an old problem that Mäori often present as a solution and that is, by focusing on the familiar elements of culture (language, religion, schooling, perceptions etc.) almost everything becomes potentially achievable except that power relations remain unchanged. We can accept that the cultural has become more political and that has been a necessary shift but 'placing too many eggs in the culture basket' has a way of detracting from the concerns of structure and power relations. A change of government, and two years after the Commission ended, the work of the group has disappeared altogether. Reason, because there has been no major structural intervention that has succeeded in disturbing the status quo. Efforts to support Māori authority and responsibility in education have been on the Ministry of Education agenda since at least 1992 (Annual Report of Māori Education, 1992). If the Māori Education Commission was going to achieve anything that could have transformed the status of Māori in schools and in society, it would have had to result in interventions aimed at changing historical and existing power relations between Māori and Pākehā. 
In Report 2 (August 1998) the Commission comment on the way the 'one-size fits all' ideology is under attack by proponents pushing the advantages of policies based on increasing choice, diversity, let the market decide, egalitarianism, equality of opportunity, level playing fields etc. yet contradict themselves by not recognizing the complexity of problems facing Māori through the simplistic and reductionist solutions they advocate. The Commission falls into its own reductionist thinking by advocating the need for attitude change without considering the fact that attitudes come from predispositions that are based on historical ignorance and often times, institutional racism. Attitude change rarely leads to structural change.

\subsection{Summary analysis, purposes and discourses - part two}

Comment was made on the level of optimism showing through in the part one reports. The same can also be said about part two reports but there is a difference. Part one reports (1960-77) were keen to point out that where gaps existed, for example in academic achievement, linguistic facility, cognitive development, levels of home support and so on, these problems could be rectified or corrected to achieve equitable outcomes without necessarily having to disturb or disrupt the underlying framework or structures. This period in the development of Māori education falls within the scope of what was called in Britain and the United States at the same time, 'compensatory education'. Head Start programmes in America were designed to make up for, and to compensate for, disadvantaged children through the introduction of special education programmes ${ }^{6}$. During the period of the part two reports (1978-2000) there is a 'hardening up' of Māori perceptions of where the problems lie and the sort of solutions needed. The correction of

4. Penetito (1975) wrote a critique of an article by Anne D.Lopdell (1974) entitled 'Complementary education for educationally disadvantaged pupils' in Bray \& Hill (eds.). The article formed the theoretical base to a Department of Education handbook for teachers called, 'Language Programmes for Māori Children'. Penetito argued that although complementary education was an advance on compensatory education, in practice teachers would continue to treat complementary as compensatory, deficit as deficient. 
inequitable outcomes is not the starting point. What Māori want leads to a redefining of what the outcomes ought to be and how they can be achieved. For the first time in the history of the New Zealand education system, the underlying generative structure of what it means to be educated in New Zealand, and what it means to be a New Zealander is called into question by Māori New Zealanders who are no longer accepting that they are the ones who must always compromise on their values, aspirations, and practices in order to maintain a society bent on harmony of interests no matter what the costs. Māori have always known that collaborations between themselves and Pākehā are hardly ever equal or reciprocal. How can they be when the modes of interaction are almost always of the dominant - subordinate kind, when the language of discourse is predominantly English, and when one party has the resources and the other does not.

\subsection{Māori Education reports as mediating structures}

The period 1960-1977 was an extraordinarily important time for the future development of Māori education especially the second half of that period. It is no exaggeration to say that the 1970 s laid the foundation for kōhanga reo, that laid the foundation for kura kaupapa Māori, that laid the foundation for wharekura, and so on. When the contradictions in the system become too numerous and therefore too obvious something has to happen. At the 'grand' level, what we see occurring on a small scale is what Kuhn (1962) called revolutionary science and it happens when the prevailing paradigm, or central set of assumptions about what Māori want and need, and how those demands can be met and who can meet them, are no longer tenable. The NACME Report of 1970 can be seen as the catalyst for a 'soft revolution'. The paternalism in the system was the inevitable consequence of the earlier forms of colonialism. It was not unusual to hear patronising Pākehā officials, professionals and lay people talking about 'our Māoris' as though they carried these caricatures around in their pockets. The post-colonial writer, Slemon (1997) warns of using "the concept of colonialism as an ideological or discursive formation: that is, with the ways in which colonialism is viewed as an apparatus 
for constituting subject positions through the field of representation" (p.46). The constitutive power of an ideological state apparatus, like education in New Zealand, is able to influence who can be selected to represent Māori, and how they represent Māori. This is not achieved by any crass form of 'brute force' or even indirect forms of ideological regulation but by dividing practices, such as, Māori members of committees having to educate non-Māori members about what Māori want within contexts which are frequently antithetical to those aspirations. The result is that Māori have to make compromises to content while non-Māori make adjustments to processes. Accumulated over the period of a committee meeting and working on a report the outcomes are often watered-down Māori contributions to the project to such an extent that a sense of being co-opted and therefore dissatisfied with the product is understandable. The outcome for Māori on committees is the sense of having a regulated colonised identity that manufactures two conditions: dependence and symbolic violence. The dependency condition allows for investigation of educational mechanisms that perpetuate the subordinate and marginalised position of the Māori. It is common for Māori on committees to hear statements like, tell the committee members what you think Māori want but keep it reasonable (that is, keep it within existing frameworks). Symbolic violence occurs when the power of the system is able to impose and inculcate a group of people, for example, Māori with a culture (that of committees in this instance) which reproduces social conditions and relations which are supportive of the dominant group. A private communication with a respected Māori elder who had over the years sat on several national committees said, "It's no use being too Māori on these committees - you'll never be invited back onto another one". I wonder if Pākehā members on these committees ever thought they might actually be too Pākehā for the Māori on them!

There is no suggestion that Māori on committees have no genuine say about their views on any topic. A perusal of the names would put a prompt end to that notion. However, a reminder of the distinction Mills makes about 'personal troubles of milieu' and the 'public issues of social structure' would not go amiss at this point 
(1977:14). "A trouble", Mills says, "is a private matter such that values cherished by an individual are felt by him or her to be threatened. On the other hand an 'issue' is a public matter where, for example, some value cherished by publics is felt to be threatened", for example, mana Māori, mātauranga Māori, and tikanga. It is argued that Māori education reports from 1960-2000 have played an important role as mediating structures but unless and until they cease their hegemonic bias their benefit to Māori will always remain peripheral. This chapter has been an exercise in unmasking. 


\section{Chapter 06}

\section{'We're all New Zealanders' - processes of consultation in Māori education}

\subsection{Introduction}

In chapter five it was argued that mainstream and Māori participants involved in reporting on Māori education, are only able to meet their terms of reference when both parties indulge in a series of micro processes aimed at resocialising each other to accept what each party perceives as 'bottom lines' to the negotiation of a consensus. In brief, Māori want to convince non-Māori firstly, that as Māori working in the field of Māori education, they have a unique contribution to make that comes from being Māori, and secondly, that the mainstream system has always operated in the primary interests of the mainstream and as a consequence, disadvantage Māori structurally no matter what the influence of agency ${ }^{1}$. The micro-processes played out in the interests of 'taking Māori on-board' include such activities as allowing karakia (prayers) at the beginning and end of each day; whakatau (speeches of welcome) to open proceedings; poroporoaki (farewell speeches) to conclude proceedings; perhaps even waiata (songs) as an embellishment to speeches. There is also every likelihood that whenever anything that has to do with Māori culture comes onto the agenda, the Māori participant will be called on to inform non-Māori present. Raising these matters in this way is not a cynical ploy since both parties accept these practices as authentic to Mãori and important for non-Māori to understand or at least to accept as gestures toward bicultural understanding.

\footnotetext{
${ }^{1}$ I have never understood those who maintained that being an 'insider' did not advantage perceptually those who had insights about other insiders. Not being able to see the forest because of the trees, or familiarity breeding inattention are problems for the insider but no less serious than those who see the trees but not the forest or those who because of familiarity have contempt. An article by the noted New Zealand anthropologist Sorrenson (1982) with regard to the views expressed by Ngata and Buck as to the advantages they had, as Māori in understanding other Māori, vis-à-vis non-Māori seems to me to be entirely reasonable and rational but Sorrenson argues otherwise. I claim that insiders have as much and no less insight than outsiders with regard to perceptions about any phenomenon.
} 
Pākehā participants on the other hand, take it as their responsibility to protect and defend the deep underlying values and structures of the existing logic of the system but where evidence has shown areas of weakness where improvements can be introduced that do not disturb the overall balance of the system then negotiation and compromise are permitted. The interesting thing about this 'responsibility' is that it seems to emerge out of a kind of tacit agreement among Pākehā present on committees, that is, the system needs to be shielded from unnecessary manipulation. This is probably what Shuker (1986:16) was referring to when he maintained,

The concept of ideological hegemony was advanced by Gramsci to explain how a ruling class maintains its dominance through achieving a popular consensus mediated through the various institutions of society, including the schools, mass media, the law, religion, and popular culture. Ideological hegemony thus represents the organisation of consent, a process underpinned by the threat of actual physical coercion by the state.

To co-opt Māori members of committees into the stream of consciousness needed to build consensus, giving and taking is needed by both sides but it is rarely an equivalent exchange given the unequal power relations that the parties bring to the negotiation $^{2}$. What eventuates, despite the intentions of the participants, is an insidious mode of social control. The paradox, according to Cooke and Kothari (2001:146) is "that the more 'participatory' the enquiry the more its outcome will mask the power structure of the community". The implicit appeal from mainstream to Māori members in the preparation of education reports is to maintain equilibrium and not to 'rock the boat' unnecessarily which in other language is, 'know your place'. It is argued that the effects of the processes of ongoing microsocialisation create dividing practices, which are, contrary to expressed intentions, manufacturing reports on Māori education as negative mediating structures.

Chapter 6 investigates consultation in Māori education as the second of those 
'constructive dialogue' (Nader et al, 1997:1). The mode of cultural regulation or the mode of objectification as called by Foucault, helps transform human beings into subjects. Whereas 'dividing practices', identified as forms of co-option, helped subject Māori participants in the construction of reports in Māori education, it is the 'mode of inquiry' that characterise processes of consultation. Peters (2004:57) refers to these modes of inquiry as "games of truth" where "the emphasis falls on how the human subject constitutes itself by strategically entering into such games and playing them to best advantage".

For the first part of this chapter consultation is contextualized within an ideology of 'We're all New Zealanders' which has its beginnings at the time of the Treaty of Waitangi and Governor Hobson's well-known assertion, 'He iwi tahi tātou' (we are now one people). Māori were not to know it at the time but Hobson was sealing their fate with his assertion of British sovereignty. Even the exercise of taking copies of the Treaty around the country to gain further signatures of chiefs was, according to Orange (1987:91), "inconsequential" because surrender through treaty was sufficient to satisfy the legal requirements of the Colonial Office. Early communications between Māori and Pākehā, of which the Treaty of Waitangi was the most important, established the logic behind consultative approaches to participatory democratic methodologies. They are foundered with notions of ethno-centrism (cultural superiority), racism (white is right), cognito-centrism (priority of individualism), and ideals of material improvement through acquisition (property rights). These are defined in the various government department publications and what these mean in practice are also elicited from these sources.

We then turn to a case study of consultation in which the researcher was a leading participant. The objective is to outline the processes by which the consultation was conducted rather than the effects or outcomes of the exercise, although reference is made briefly to official responses that derive from the consultative outcomes. The chapter concludes with an evaluation of consultation as a mediating structure. 


\subsection{We're all New Zealanders}

The processes involved in establishing the Treaty of Waitangi as the founding document of New Zealand could be seen as the first official exercise of consultation of the Crown with Māori. Even the tenor surrounding the process can be seen as a blueprint for further consultations:

- donor party prepares a document in advance of what it wants;

- have the document translated into the language of the recipient;

- donor invites members of the recipient group to a formal gathering;

- donor presents the document using the formalities of the presenter in the context of the recipient (sign the document on the marae);

- ensure as many recipients as possible are given the opportunity to discuss the contents of the document and to sign-up to it; and

- leave the finalised arrangements of the document in the hands of the donors.

The process is taken as a fair and reasonable way of getting 'buy-in' through participation, at least as perceived by donor societies. The very definition of New Zealander can be seen as a mirror image of the sentiments expressed through the Treaty and through processes of consultation. The Crown representative of the day, Governor William Hobson may well have been the first to utter the words, 'He iwi tahi tātou', 'We're all New Zealanders', 'We are one people', at the signing of the Treaty of Waitangi in 1840 but they have been endorsed by virtually every politician, minister of the church, and school teacher since then. From a Māori perspective the phrase represents the ultimate cultural 'clobbering machine'. How can two fundamentally different peoples and cultures become one as the result of a treaty? The answer of course, is that it is not possible unless Hobson and others who share his sentiments have something else in mind. The idea of a partnership for example, is high in the rhetoric stakes except it is not referring to

\footnotetext{
3 "Not all Māori have been convinced by this assertion. Given the wars and the land confiscations of the early 1860s, it would be surprising if this were not so" (Sinclair, 1986:14).
} 
partnership in the legal sense but rather "like a partnership" as a leading politician of the 1990s would have it (Graham, 1997).

The psychologist, Ritchie (1971) wrote about Māori and Pākehā relations and posed the question, 'One nation - or two?' to get people to think outside their prejudices instead of assuming the priority of the assimilated New Zealander ${ }^{4}$, that is, the Māori. The historian Sinclair (1986:14) poses a different sort of question when he asked "have the Māoris chosen to join the predominantly Pākehā nation?" This rather peculiar question is based on the idea that Māori at the time of annexation were not a nation in a European sense. That omission seems to have disqualified them from being equal partners in the establishing of a national identity on any other grounds. The political academic, Mulgan (1989:6) argues in line with Ritchie (op cit.) and suggests that a re-reading of Hobson, in present day English, shifts from "we are now one people to we are now one nation" (p. 7); the question of sovereignty is no longer an issue. The Mãori teacher, public servant and scholar, Penfold (1973) affirmed the cultural identity of New Zealander in line with a social harmony view, so long as it took account of cultural differences. These differences were likened to individual differences which "we cannot hope to abolish (therefore) we must learn to live with them".

The debates around the search for national identity and the role education plays in this regard, revolve around questions of participation, especially participation of Māori. The notion of the emerging New Zealander weighs heavily as an underlying principle in the process of participation through consultation. We have already seen how Māori participation in official reports on Māori education operate (Chapter 5) and now we will explore a second approach by which Māori are encouraged to participate in education.

\footnotetext{
${ }^{4}$ In the nineteenth century the Mãori was referred to as the 'New Zealander'. See Kendall in Ritchie (1971, inside cover): "The true character of the New Zealanders is not so despicable as Europeans are apt to imagine".
} 


\subsection{What is consultation?}

It was suggested earlier that consultation, at the time of the Treaty of Waitangi, was a manifestation of what Weaver (2003:145) describes as the "evangelical influence" of the Colonial Office "to exemplify humane colonisation", that is, to take into account lessons learned from earlier colonial acquisitions in the United States and Southern Africa. The pressure from settlers for the immediate availability of land put paid to the distant influences of humanitarian principles. As Weaver says,

The slide from protection and good intentions, through negotiations, to deceptions, and finally to the use of force showed that frontier avarice throttled principle (ibid.).

It might seem overly dramatic to view consultation in the world of education following such coercive measures but not so in the world of Māori-Pākehā relations or of Māori education. Three examples will illustrate the point. The former Director-General of the Department of Education, Renwick (1978), commenting on the implications of article three of the Treaty in 1840 and the interests of Māori being protected by a governor wrote,

One of [the governor's] responsibilities was to stand between the settlers and the Māoris on everything that affected Mãori interests. It was a noble intention and it failed. The primrose path to the land wars of the 1860's was paved with good intentions.

The failure was brought about by the expediency and avarice of the early settlers. The second example is from Simon (1984), the researcher on the Māori Native Schools system who wrote an article entitled, 'Good intentions but...' (1984) summarises her research from her master's thesis. The suggestion is that a system which continues to devise new policies, to resurrect new structures, and to pour in more resources to improve the level of education for Māori students without having the desired effect of uplifting Māori as a people is a waste and a failure whatever the rhetoric of intent. In more recent times Māori have initiated educational interventions in their own interests, without the blessing of the state, without tax-funded resources, and, in the case of kura kaupapa Māori (KKM), outside the existing legislation at that time. The kōhanga reo (TKR) movement 
was the first of these structural interventions but it, like KKM, was doomed to failure without state resourcing. Now, all TKR and KKM receive state funding. With state funding comes philosophical underpinnings and contractual obligations, and these, if one notes the voices of the respective leadership of the kōhanga reo and kura kaupapa Māori, are deeply frustrating to whānau who are obligated to make these interventions work within the kaupapa (philosophy) and within the accountabilities of the state. To illustrate the point, kōhanga reo has always operated under the umbrella of Māori whānau development but official recognition and with it funding, has, from the beginning of state resourcing treated kōhanga reo as a form of early childhood intervention like kindergarten, play centre and so on. Both kōhanga reo and kura kaupapa Māori are critical initiatives in attempts to revitalise the Māori language but if the kaupapa (or basic philosophy) suffers as the result of trying to meet the requirements of external accountabilities we have, once again, a situation of the tail wagging the dog.

It is claimed in each of these three examples that coercion is not intended, that there is no conspiracy of action on the part of the system. However, the effects suggest what might be termed a conspiracy of belief, does seem to hold some credibility. Ball (1978:102) describes this form of coercion as "liberal and ontological":

Through all their contact, collision and interaction, human individuals...retain their separate identities. Individuation is, liberal theorists maintain, a simple and straightforward matter; as distinct bodies can be observed and described, so too can 'individuals'.

The priority of the individual through causal - and coercive - relations is seen to indicate contingent relations between individual elements and not about any "socially constructed ensemble of relations" (ibid.). There is no intentionality, therefore, if the system does not work for Māori, the system cannot be held to account. Māori are not participating as fully as they might.

Two related discussions about the way consultation is applied in New Zealand with regard to Māori-government relations follows: 


\section{Constructive dialogue as the mode of inquiry}

In order to recognise the differences that exist between Māori and mainstream most government departments prepare their own documents on the use of appropriate methods of consultation with Māori (Ministry of Justice - A guide for consultation with Māori, 1997; Department of Internal Affairs - Guidelines on consultation with Māori, 2002; and State Services Commission - Partnership dialogue: a Māori consultation process: He kōrero rangapū, 1989). Departmental guidelines are likely to be influenced by guidelines established by the government's Department of Māori Affairs (Te Puni Kōkiri - A guide for departments on consultation with iwi, 1993) that in turn will be modeled by the guidelines established by the government of the day. The best known of this latter document is that established by the Labour Government of 1988 entitled $\mathrm{Te}$ Urupare Rangapū - Te Rārangi Kaupapa (Partnership Response - Policy Statement).

An examination of these documents reveal, not surprisingly, a fair degree of agreement about what should be considered a quality consultation. Te Puni Kōkiri (1993) lists seven criteria. First, is clarification of purpose to ensure an understanding of what outcomes can be expected and thus avoid failing expectations and allegations of bad faith. Second, is the need for sufficient preparation and lead-in time, that is, time for Māori groups to absorb background material and to consider their own responses to that material. The third criteria is about the conduct of the actual consultation and the time taken to debate the issues publicly before reaching conclusions. This is also the time for 'fronting up' or as the whakatauki proclaims, 'he reo e rangona, engari he kanohi kitea' (a voice may be heard, but a face needs to be seen). Fourth, relates to the opportunity to participate for all those with an interest in the kaupapa. In the world of education, consultation need not follow traditional iwi or hapū lines and might include any number of pan-Māori organisations. Depending on the topic for debate, who is consulted becomes a critical issue and it is better to err on the side of inclusivity than the opposite. Fifth is described as the need for genuine consultation. 
Consultation that is not genuine is thought of as debate over proposals that are in fact non-negotiable. Such debate may take the form of not being prepared to accept any contrary advice unless it fits with the existing framework. Most genuine consultation it is suggested comes from relation-driven consultation rather than issue-driven consultation. The sixth criteria is about post-consultation activity such as reporting back to groups consulted about the process, and further down the line, about the results of the consultation. And finally, is the important question of transparency. Transparency relates to honesty and integrity that is the mode of inquiry. The dialogue between participants in consultation will be constructive so long as transparency is maintained throughout.

It is important to note that since the Court judgements regarding Treaty of Waitangi debates of the $1980 \mathrm{~s}^{5}$, consultation between Māori and government departments has followed principles related to the articles of the Treaty, for example, in the State Services Commission (1989) document on consultation under the heading, 'Categories of Māori Consultation' argue that article 1 is about sovereignty and "apart from effective compliance and co-option is not an area characterised by great demand for consultation". Article 2 speaks about natural resources and taonga and in answer to the question 'who should be consulted?' and suggests it should be those with manawhenua, that is, the respective tribes. Article 3 addresses rights of citizens, personal, not tribal rights; duty of consultation is with the total Maori community (p. 10-11).

\section{Consultation as the hegemony of consent}

The greatest challenge the education system faces in using consultation to effect change among Māori is that of action organised by a conception of means-ends relationships. This kind of action is described by Bhola (1975) as "artifactual action" that is "those actions which create social-symbolic artifacts - new social

\footnotetext{
${ }^{5}$ New Zealand Māori Council v Attorney-General (1987), 1 New Zealand Law Report, p.641 (Court of Appeal); Tainui Māori trust Board v Attorney-General (1989), 2 NZLR, p.513. See McHugh (1997) p.50, footnote 31.
} 
systems, cultural patterns, organisations and ideologies. Artifactual action, thus involves culture-making through systematic interventions."

The framework emerging around the concept of consultation is taking on the following characteristics. Any plan that wants to get at the heart of Māori education must start with the Māori people themselves and whatever it is they aspire to for their young people. Any plan is doomed to failure that does not articulate with the voices of Mãori. A plan that assumes prior knowledge of the outcome goals and views consultation as a confirmatory exercise focusing mainly on issues of implementation foolishly believes in its own propaganda. An education strategy for Māori might be about 'closing the disparity gap', it might be directed around 'upskilling Māori youth for the job market', or it could focus on 'the revitalisation of Māori culture'. It might be about all these goals, some of them, or a different set of goals altogether like 'becoming a good kiwi', 'biculturalism', 'multiculturalism', or 'preparation for the good life'.

Those of us who were responsible for conducting the consultation with Māori in the period 18 November to 18 December 1997 set out to elicit support for the proposition that (a) with the engagement of Māori and (b) the responsiveness of the system (c) Māori educational achievement would be enhanced. In the words of the Cabinet decision (Cab EEP (97) N9/1), the education strategy that would eventuate from the consultations would focus on maximising the education system's contribution to the elimination of educational disparity between Māori and non-Māori. As the manager of the consultation process my major organisational role, as I saw it, was in interpreting what Government was seeking in the light of what Māori community groups might contribute. I did not see my role as simply a technical one as in managing a national project, organising venues, introducing a discussion document, setting the context for Government consultation, analysing the data collected and similar activities, however important these are. 
One of the classical scholars in the hermeneutic tradition, Ricoeur, (in Connerton, 1978) writes about two basically different hermeneutic styles. The first is "interpretation as recollection of meaning" (p. 195) and the second is "interpretation as exercise of suspicion or demystification" (p. 199). I saw my role as the main facilitator of the consultations involving generous helpings of both styles.

My analysis of the process of consultation in the Education Strategy for Māori (ES4M) project involves both forms of interpretation but the emphasis without doubt is the latter, that is, as demystification. As part of the Marxist tradition we can also refer to 'critique' in a similar manner in that it rests, according to Jacoby (1975:xviii), "on a notion of truth that resists mindless tolerance; it is a challenge through the application of critical intelligence". In yet another and parallel interpretation, we are engaged in the exercise of discourse analysis. The Massey University sociology of education scholar, Nash applied the notion of discourse analysis in Māori education in a discussion of theories of differential achievement. "At the heart of discourse analysis", he argues, "is the concept of symptomatic reading: a reading of what is said for what is thus not said" (1983:69).

\subsection{Education Strategy for Māori (ES4M) - Methodological considerations}

For five weeks between mid-November and mid-December 1997 a joint project team managed by the Ministry of Education (Te Tāhūhū o te Mātauranga) and the Ministry of Māori Development (Te Puni Kōkiri) consulted with 25, mainly Māori groups between Invercargill in the south and Kaitaia in the north, New Plymouth in the west and Ruatoria in the east on strategic directions for the development of Māori education. The project, officially known as 'Education Strategy for Māori' (ES4M), arose out of a cabinet decision (June 1997) to maximise progress towards "the elimination of education disparities between Māori and non-Māori" [CAB (97) $\mathrm{M} 41 / 6 \mathrm{H}$ and $\mathrm{CAB}(97) \mathrm{M} 22 / 3 \mathrm{E}$ refer]. The decision charged the named two 
government departments with three tasks: first, to prepare a discussion document; second, to conduct regional consultations; and third, to develop an education strategy for Māori on the basis, at least partly ${ }^{6}$, of an analysis of the consultations.

From the consultations the analysis was required to take into account the verbal submissions from the face-to-face consultations, written submissions from the pro forma found in the discussion document, and the literature research on participation and achievement of Māori previously undertaken by Chapple, Jefferies and Walker (1996) for the New Zealand Institute of Economic Research (Inc.).

It was intended that the education strategy would also be informed by the Government's stated commitment spelled out in Strategic Priorities 1999-2000, advice from the Māori Education Commission to the Minister of Māori Affairs (see Chapter 5 of this thesis), as well as current research and practice.

The writer was contracted for seven months as the project manager with the main task of fronting the consultation process. Much of the earlier project work related to the discussion document, 'Making Education Work for Māori: Talking Points for Parents and Whānau' (1997) was well under way before my arrival, while completion of the analysis post-consultation and the submission of papers/reports to Government was not part of the contract. The major contribution of the writer was related to the organisation and management of the project team and all the processes involved in planning, carrying out, and finalising the consultation exercise.

My precise involvement as the project manager was for the immediate ten weeks before the consultations began, five weeks of the consultation, and ten weeks after the consultations ended. This 25 week period required my full involvement as a

\footnotetext{
${ }^{6}$ No government policy would rest on any one source of information but rather a combination of research findings, expert advice, its own political direction, resources available, and consultation with interest groups among other sources.
} 
member of the project team in setting up and undertaking the consultations, and completing the first round of analysis of the submissions at the end of the consultations. The subsequent report to the respective Ministers (Creech, Donnelly and Henare) was scheduled for somewhere around mid-year 1998, well after my contract ended.

\section{Working within the official parameters}

The discussion document, 'Te Whakamahi i te Mātauranga mō te iwi Māori Making Education Work for Māori' (1997) is introduced by the chief executives of the Ministries of Education and Māori Development. Among other things they make four statements particularly relevant to this section. The first is an assertion about the embedded value of education for everybody's future: "Education is a key to personal, social, and economic success". The next two quotes are statements about the Government's position on Māori education: "The Government's goal is to see all Māori getting an education that is as good as that achieved by any other New Zealander", and "It wants to see Māori confident in their own culture and well equipped to contribute to the local, national, and international communities".

The last statement is a reminder to the public about what is needed to make any education strategy successful: "There must be a strong practical focus on what works best on the ground".

The focus for the strategy was to maximise the education system's contribution to the elimination of educational disparity between Māori and non-Māori through increasing the 'engagement' of Māori with the mainstream system; for engagement, read participation.

The traditional problems the system has had with Māori education juxtaposed with the Māori definition of 'confident in their own culture' and 'what works best on the ground', makes it clear much more has to be done to transform Māori education at the system level, and to organise it considerably better at the 
community level, than exists in most communities at present. By 1997 the Ministry of Education was also involved in establishing educational partnerships between itself and quasi iwi authorities and was using the consultation exercise to seek confirmation of this strategy as a way of enhancing engagement of Māori and responsiveness of the system as an approach or strategy for improving Māori educational achievement. A major outcome of the consultations was to elicit people's views about the middle and long-term goals for Māori education.

\section{Planning the consultations}

The venues for the consultations were organised by Te Puni Kōkiri (TPK) managers in collaboration with district Ministry of Education (MoE) offices, local Māori communities and the schools serving them. The project team agreed that tikanga Māori (Māori custom) would prevail in terms of the protocols for the meetings, that is, pōwhiri (formal welcome) where the project team and government officials would be manuhiri (the visitors) and the local people, the tangatawhenua (hosts); there would be whaikōrero (formal speeches of welcome with responses); karakia (an opening prayer) followed by hariru me te hongi (shaking hands and pressing of noses) and then ending with something to eat (more in the nature of finger foods rather than a full meal). Those who have experienced pōwhiri will know that they can continue for hours depending on the nature of the occasion. Given the number of consultations, the time to conduct and conclude them, as well as the available budget for the project, it was determined that each consultation be planned to last four hours maximum inclusive of the pōwhiri, the meal and the poroporoaki (farewell speeches).

This schedule would permit one consultation a day taking into account travel to the venue, the actual consultation, travel to the next venue, book into accommodation, debrief from the previous consultation, organise the data from that consultation, and prepare for the next venue. This process was repeated for the 24 consultation meetings running from 18 November to 17 December 1997. One further meeting was held in January 1998. 
The project team planned to have officials from the MoE and TPK at every hui (meeting) and their responsibilities were to record their own notes of the discussions, to join in with discussions but not to lead at any time, and to try and involve as many community people as possible in the discussions.

The project team agreed to keep a register of everybody who attended each hui so that the record could be returned to them when the write-up was complete. Every hui had two official observable records; the first was an electronic whiteboard record with statements as close as possible to verbatim as we could manage while the second was a laptop computer record taken by a bilingual Māori-English typist. The audiences were told at the outset that the note-takers were asked to capture as many of the actual utterances made as they could of those speaking rather than listen and make interpretive statements. Audiences were told that if they saw the record was being interpreted by whoever was writing on the whiteboard they were to interrupt and set the record straight immediately. They were also advised that they would receive by mail both records (the laptop and whiteboard versions) within six weeks of the consultations concluding. The audiences, without exception were extremely grateful for the openness of the process and said so on several occasions.

From the point of view of the project manager perhaps one of the perceived most difficult problems in anticipation of the consultations was that of encouraging community people to do the talking without having officials influencing their views. On the other hand it was also assumed that in some of the venues Māori community leaders were likely to attempt to capture the hui for ends not necessarily consistent with those as defined by the consulations. The definition of the problem can never be assumed to be shared by officials and Māori community groups, especially if the venue for the consultation, is in the Māori community where prominent political figures are present. This next section will comment on these three cautions: first, the definition of the problem; second, the possibility of 
local capture of the hui agenda; and third, strategies for encouraging community discourse within familiar practices ${ }^{7}$. In relation to process these three concerns can be thought of as having the greatest influence on the success or otherwise of the consultation from the point of view of government and of Māori community members.

\section{Participant observer}

As stated earlier the rationale for the ES4M project is that Māori students, in comparison with non-Mãori students need to improve their levels of achievement and this is best accomplished, on the one hand, by Māori engaging more with the education system, and on the other hand, by the education system being more responsive to the aspirations of Māori. It was clear that such abstractions as achievement, education system, and aspirations needed to be spelled out with examples so that each of the parties could engage having taken some steps to share key understandings.

At every consultation hui these three concepts were discussed in some detail by the project manager. Achievement through schooling always needed to be thought of as a lot more than the traditional ideas of the 'Three-Rs' however important they were as the fundamental building-blocks of future learning. The message of learning about those things important to the Mâori world such as being able to converse, discuss and debate topics in te reo Māori, as well as in English, was a major accomplishment in a society where the English language was so pervasive. Knowing how to manaaki tangata (look after people), to relate stories of heroes from Māori history (ngā tāngata rongonui), and to use the oral tradition to set in memory such activities as pepeha (local sayings), whakapapa (genealogies) and karakia (incantations) were always seen as learnings at the heart of what it meant

7 See Best \& Kellner (1991:26). For them, discourse theory emphasises the material and heterogeneous nature of discourse. For some, like Foucault for example, an important concern of discourse theory is to analyse the institutional or community base of discourse, the viewpoint and positions from which people speak, and the power relations these allow and presuppose. Discourse is a site and object of struggle where different groups strive for hegemony and the production of meaning and ideology. 
to be Māori. These made up the 'Three-Rs' of Māori achievement. Being able to 'get on' with other people, to be generous of spirit, to value sharing and the plethora of ways of living in the world other than those dictated by the modern, competitive, acquisitive world were the sort of messages Māori needed to hear from those who were enquiring about their aspirations for education for their tamariki and mokopuna (children and grand-children).

The education system is commonly referred to as though it was some distant allpowerful bureaucracy that made decisions on high at the centralised level of government about things going on in classrooms and schools at the community level. In a centralised system such as we have in New Zealand there are legitimate grounds for thinking this way. The consultations with their official branding obvious for all to see (check the government cars and rental cars in the marae carpark; check the number of strangers present wearing dark suits, carrying satchels, cell-phones and laptops; check the variety, quantity and types of foods made available for meals) make it clear that the hui is being manufactured for the specific purpose of serving government first and then the abstract generic Māori. At the ES4M consultations the project manager was adamant that 'education system' in this context needed to be thought of as local members of boards of trustees, local principals and school teachers as well as all the official government agencies such as the Ministry of Education, the Education Review Office, the Early Childhood Development Unit, the New Zealand Qualifications Authority and so on. I was often conscious of the fact that members of these clusters of the education system, especially those resident in the communities were not always pleased with my definition of the system; the notion of an abstract, centralised and distant system, was something of a buffer between local and central decisions and actions.

'Getting at' central concerns and aspirations about future directions before the gathering, analysis and reporting of consultation data was one of the more difficult challenges for the project team. Over the last 20-30 years the most vibrant, 
exciting and successful initiatives in Māori education have been those which have arisen from Māori acting outside the system, that is, not from engaging more with the system but less. Kōhanga reo, kura kaupapa Māori, wharekura, wānanga and tū tangata, for example, would likely never have eventuated if left to the mechanisms and wishes of the state. This is not to say that the state played no part in these developments because it certainly did. Without the democratic nature of New Zealand society, without the historical goodwill between Māori and Pākehā, and without the financial assistance of the state in accepting national and regional hui as a viable means for facilitating Māori aspirations for the future, the emergence of developments like those of kaupapa Māori may not have eventuated. It is also clear that developments like these would likely de-rail if not for the intervention of the state.

The task of generating talk from the audience was built around three assumptions. The first was from the project manager who insisted that officials at each hui (meeting) said only what needed to be said. This assumption has its beginnings in the asymmetrical relationship that exists between those representing government and those members of a community most of whom will be a sub-culture of the community except in those communities predominantly Māori. Whether predominantly Māori or not, the community will always be in a less powerful position than government officials, all of whom will be carrying a single agenda (to elicit community views on the purpose of the consultation) while community members are likely to be conscious of a multiplicity of agendas including what was the outcome of the last consultation, what do these officials really care about our little community, is our school likely to survive the latest government move to close small schools, and many others. Our first task was to make clear what the hui was for and to let the audience know that they could choose to respond in three different ways (verbally at the hui, through filling in the questionnaire in the discussion booklet, and by telephoning an 0800 number at the Ministry of Education). Officials were asked to note but not respond to challenges either in the pōwhiri (welcome speeches) or audience responses through the consultation and to 
answer honestly and briefly to queries. In the event of a challenge that could not be avoided, facilitators were informed to answer by placing the argument within an historical, policy or political context, and avoid anything personal or defensive like feeling the need to apologise for the system, for the government, for the bureaucracy, etc. They were told that humour helps if appropriate but most important was the need to be 'straight up' (honest), 'telling it like it is' (matter-offact) where the issue is being addressed and not the personality. This is often exceedingly difficult if the source of the challenge is well known, and/or if the challenge is personalised to the facilitator. Focus on the issue is the most helpful thing to do

Another component of this first assumption was related to participants not having read the discussion document. It was safely assumed that most people in the communities would not have had the chance to read the discussion document (Making Education Work for Māori) because it was not made available until the consultations got underway. This was especially true for the first half of the consultation meetings. In the case of the ES4M project the document was only 20 pages long, attractively presented with a mixture of bullet-pointed text, photographs, a table showing venues for consultation meetings, and most importantly, presented in both Māori and English. However, it is well known among officials that Māori audiences in particular are loathe to be influenced by external parameters being placed on their perceptions of what needs to happen in any situation. One does not have to dig too far to find justification for the cautious Māori approach. The discussion document is organised around the traditional sectors of early childhood, schooling, and post-compulsory education when initiatives from Māori have indicated a need to rethink the organisation of structures, for example, te kōhanga reo perceiving of themselves as whānau development units rather than early childhood institutions. The text following each sector emphasises a selection of enterprises that have been seen to work in the interests of Māori learners but they appear as though they are government initiatives when in fact many have emerged out of Māori communities and have 
survived only after bitter and frustrating battles with officialdom. Facilitators at hui were asked to underline the purpose of Making Education Work for Māori: Talking Points for Parents and Whānau which was that it was to be thought of as a starter kit for thinking about what to include in a submission. Facilitators were also asked to emphasise the fact that in the long history of state provided Māori education, these consultations marked the first time a long-term strategic plan was being mooted by the Government of the day. Being involved in the making of history is motivating for most people.

The second assumption for the facilitators simply reads, 'leave the audience to do as much of the talking as possible'. Their instructions were, do not allow individuals to dominate (as soon as speakers begin to repeat themselves direct questions to others; check on who agrees or has a different point of view; identify the talkers early and encourage them to chair a discussion group). Of course, all such advice is easier to talk about than to action. Talkers dominate discussions because they know how to manipulate situations that allow them to keep talking. One needs to be patient and courteous while making it clear through one's actions that dominating talk is not approved. Actions like attempting to interject, standing up, looking to someone else to say something, and quietly thanking the person for their contribution are useful ways of quietening the constant talker who doesn't allow others to speak.

Another aspect of this assumption about who does the talking takes a look at the facilitators. They were asked to ignore verbal statements from the participants that were factually incorrect and not to interrupt dialogue among the audience. The caution was intended to prevent a 'them and us' situation, a lay versus professional scenario. Interruptions from officials can easily prevent a flow of ideas from emerging. It is better instead to redirect incorrect statements to the views of others in the audience or even to ignore them. In a public forum one needs to be prepared to hear outrageous comment presented as fact but it is only a problem if the speaker is perceived as being knowledgeable in the area and/or if the incorrect 
comment begins to take on the trappings of truth. At that point the main person running the consultation (the project manager in this case) would intervene and either reveal the facts if they were known or redirect the comment to whoever had the necessary information. The power relationship between the mainly Māori public and public sector bureaucrats (even Māori ones) is considerable and no one likes to look a fool in public even when one is foolish.

The third assumption is about parochialism versus the national interest. It stands to reason that most people at a consultation meeting will want to talk about their own school in their own community in their own district. Why else would the government want to consult with them if it was not for this parochial flavour that they were seeking - a sensible question. Paradoxically, however, government departments who consult with local community groups are looking for support for their proposed policies whether this is in education, health, justice, social welfare or any other sphere of governance. The facilitators were briefed to encourage local level responses as much as possible and to do so by requesting specific examples at every opportunity. It was suggested that those who were less talkative would be more likely to participate when they heard the sorts of things other people talked about. The idea of making verbal submissions can be daunting to some until they hear the sort of things people talk about which are accepted as submissions. Specific educational interest groups such as teachers, teacher union representatives, and specialist services should also be encouraged to participate. They are likely to be better organised and better informed than the lay public. The power differential made possible through the bias of organisation is likely to put less organised groups at a disadvantage. A person may want to comment but without the advantage of prior debate, the vocabulary for debate, or even knowledge about who might be supportive, could easily render the potential speaker silent. 


\subsection{An initial analysis of the data}

At the system level the consultations were conclusive about one thing: "getting an education that is as good as that achieved by any other New Zealander"8 is far from acceptable for most Māori given the generalised ignorance in the public about Māori history, knowledge, values and institutions. At the community level formal education is the poor relation in the system and in terms of Māori education is virtually non-existent. The latter is the focus for this chapter.

During the consultations the project team met with a number of groups who represented certain sectors or specific initiatives: sectors such as early childhood education, and parents with children in mainstream classes participating in bilingual programmes, for example, or specific initiatives (awhina mātua, and tū tangata) who were passionate about the work going on in their field and wanted to broadcast their successes. These were all very influential enterprises but none exceeded the excitement and obvious commitment of those representing the 'Tū Tangata Way', which, as their brochure proclaims is "where everybody wins". In brief, the 'Tū Tangata Way' positions the community on site with their children everyday, and provides community teams working everyday and all day with all students inside classrooms. The sense of 'ownership' and 'belongingness' as well as 'success' needs to be explained. Those involved in Tū Tangata would likely ask, 'what has to be explained'? The explanation offered is a central theme developed through the paper and relates to the question of real interests.

What counts as real interests is a moot point. According to Lukes (1974: 34-35) 'real interests are connected with (relative) autonomy and choice'. I will argue that so long as the organisation of education at the levels of whānau, hapū, and iwi remains problematic the real interests of Māori will never be addressed. Organisation of education at whānau, hapū and iwi levels is necessary because Māori parents could then judge what they wanted and preferred were they able to

\footnotetext{
${ }^{8}$ All the phrases in quotes above are from the introduction to the discussion document.
} 
make the choice. One of the clearest messages coming through from the consultations was the desire by Māori for an education into the best of all worlds. The best of all worlds included the creation of a Māori educational environment in their own best interests rather than what already existed, which was perceived as an educational environment created by Pākehā in their best interests with Mãori attachments. Almost every consultative meeting had something to say about the urgent need for some form of overarching Māori educational authority although none of them had much more to say about what it would look like or what it would do. Some saw these authorities at hapū level, some at iwi level, and others, saw some kind of national authority.

What follows is an analysis of Question 1 taken from the questionnaire and a discussion of the responses. The responses illustrate many of the points raised in the section under methodological considerations. The numbers in parentheses represent actual labeled respondents while the phrases in italics represent typical answers.

Question 1: How would you like to work with others involved in education, like teachers, parents or boards?

The answers to this question fell into two broad categories: those who saw solutions at the systemic level and those who felt it best to intervene at the schooling level.

\section{Those who saw solutions needed in terms of the system suggested:}

(a) the need for attitude changes:

Public perception of the place of Māori education within the system varies along a continuum that at one end accepts a limited form of biculturalism/bilingualism and at the other, the establishment of bilingual units, classrooms and schools. Extensions of the continuum to target language immersion and structural separation, that is, kura kaupapa Māori, are generally viewed with some suspicion 
even though the curriculum for the whole system remains the same. The solution to this problem for some was to:

Change attitudes; Māori education is viewed as unimportant, elitist, separatist, as going no where $(202)^{9}$.

(b) better knowledge about what is going on:

The difficulty of participating in a system when one is not sure about any of the many things going on, what the purpose is for the practices one can observe, why schools are organised the way way they are, and especially, why it is that one's children are 'turned off' by the experience of going to school, is not too difficult to understand. People are more likely to choose to work with others when they understand what is happening even if they do not necessarily agree with how it is done. As one person put it:

We need to be more aware of curriculum expectations (166).

(c) Māori should take more control of their own education:

Quite a number of people had comments about taking greater responsibility for their own children's education. Some wanted to do that by creating a parallel structure:

By establishing a collective of Māori communicators, facilitators, educators and others skilled at delivering a quality kaupapa Māori education service using key strengths of the collective to manage the project effectively and efficiently (188).

Another wanted:

A collective process of working together with all levels of tamariki learning, a process in which kōhanga reo, kura kaupapa and wānanga groups come together. This same process also applies with playcentre, primary, secondary, and tertiary groups (264).

Others thought it best to work within existing arrangements through improved support networks:

\footnotetext{
${ }^{9}$ The number in parenthesis refers to an actual individual response from the consultation questionnaire.
} 
By consulting in ways in which we as parents can contribute to the education of our tamariki (86);

Through having a facilitator that is able to bring groups together to work through a strategic Mãori education plan (287);

If Mäori themselves could have effective partnerships and pool their talents instead of all going off and doing their own thing we would be able to provide higher quality schools for our children instead of splitting our resources far and wide (253).

(d) better representation:

Membership of Māori on boards of trustees and the process for putting them there was a concern for a number of people. Comments about board membership include:

In a town such as (ours) with a low Māori population provision should be made for Mäori representation to be mandatory on all boards of trustees. Strong Pākehã dominance ensures that Mäori parents have little or no chance of election (228); and

The need to have representatives from the Mãori community on each board of trustees, one being tangatawhenua of the area (285).

Comments about the shortfall on the way boards operated were inclined toward either censuring:

Partnership is not about good communication, understanding and sharing of information - it is about shared decision making (190);

or suggesting subsidiary bodies like:

area forums to analyse, promote and facilitate education of our kids. To look at it for the town, area etc. rather than just a school perspective (217).

\section{Those who saw solutions at the compulsory schooling level suggested:}

(a) closer active involvement between parties:

Some were prepared to use coercive measures, or at least relatively aggressive approaches to bring about closer relations between schools and parents:

Enforce parent involvement; as a community-based but school-lead group, educate parents by showing them ways to help their children (243). 
Others looked for more conciliatory ways of achieving the same goal:

Co-operation from all agencies when a child presents with a need; complementary monitoring (166);

Encourage parents to be more proactive in the education of their children, for example, attending hui called by the schools and getting involved in the day-today running [of the schools] (160); and

Being active in the classroom and in other school activities (194).

Some thought the students themselves were too often left out of the equation:

High school graduates could visit and meet with primary students re career choices etc. (236);

They should have more regular contact with [the] teacher, say once a month (104); and

To have any effect teachers and parents and boards must invite students to meetings; if policies are developed for any group of people, large or small they should be consulted and given every opportunity to take part (222).

(b) recognition of cultural differences:

The potential for conflict of interest between parents and school and between teachers and students will likely be a characteristic of compulsory schooling so long as the phenomenon lasts. Yet, good relationships across this foursome, if high quality education is to be the outcome, are imperative. Differences between school culture and home culture were evident in comments like:

Less formality; even though it is highly impractical, Māori are more comfortable with a 1:1 ratio; large group conferencing can only be achieved if the majority in attendance are Mãori-therein lies the problem (97);

Sharing more with parents; getting them into schools and classrooms; making schools friendlier to parents (75);

Working together is the only way we will succeed in achieving the outcomes that we seek (214); and

Working together is the way to go; I'd like to see the communications between schools and communities improved (258).

Differences between student culture and teacher culture came out in comments like: 
We don't like teachers that give us theory all the time; we like the fun thing, a cool teacher (138); and

We would like them to listen to our opinions and our views on education; we would like education to be fun and exciting so it stimulates our learning capabilities; to learn new and a different variety of education (300).

Some respondents used rights arguments to debate their place in the partnership stakes:

My husband and I would like all others to recognise us as our children's caregivers; as such we would like others to recognise our right/responsibility (inclusive of accountability) to determine the most appropriate form of education direction [for our children] (49); and

Some secondary schools don't seem to grasp the implication and responsibility of biculturalism; until they make a total commitment to acknowledging the unique place of Māori, then college life will continue to be bureaucratic and culturally insensitive (238).

(c) introducing a structural change

Those who come up with recommendations in this area wanted practical changes of structure to facilitate improved relationships among the parties. The idea of a 'go-between' or mediating process/structure was popular:

Have a Mãori liaison person in the school so that Mãori people feel more comfortable talking to a Māori person (270);

Secondary schools could have whānau support groups attached to each form or vertical class. These groups would be parents of students and the teacher of the class (159); and

We would like to form a Mâori advisory committee which would be a subcommittee of the board of trustees; the Mãori advisory committee would be involved in all decision making processes (192).

The idea of better co-ordination through agencies that operated at a broader level received some attention:

I would like to see the introduction of Education Committees set up in each district with more than one school comprising representatives of all sectors (pre-school to secondary) of parents, trustees, teachers and students (297); and

Regionally based education committees are needed so primary and secondary teachers and board members can meet to co-ordinate a programme pertaining to each role; it should be government funded (296).

Lobby groups were recommended to help 'keep existing structures honest': 
Parents should be encouraged more to form a parent collective, to meet with each other and in turn, the board of trustees, on a minimal regular basis. (147); and

I'd like' them' (existing structures) to come to' us '(Māori parents) on the marae and in the community. In practice most teachers in mainstream schools are culturally unsafe and unwilling to listen (to us). Grassroots communication is not occurring. I can't get myself heard and I'm on the board of trustees (261).

School specific recommendations include:

Have fewer subjects but work longer in those subjects (119); and

I would like to see teachers invite parents to meet and speak with them about issues on a frequent basis. It would be an idea for boards to require compulsory attendance from parents, possibly run on a scheduling basis (164).

\section{Discussion}

It was clear respondents thought it was important to remind the officials that all stakeholders were first interested in the education of young people and secondly, were entitled to have a say in the sort of education those young people received. If anything there was an unsurprising level of impatience with delays in creating closer associations between whānau and the professionals:

Boards, teachers and parents need to face up to Mãori issues instead of putting them in the 'too hard basket' (198).

Yet there seemed to be some reluctance in most places to initiate activities that most people seemed to agree were desirable. As an external facilitator, for example, the project team was an important catalyst to bring about dialogue between the interested parties. There may well be problems of educational leadership in the majority of our communities. There was strong support for Māori-led initiatives including ones that called for relatively dramatic specific structural developments:

Establish a Māori education authority which is Mãori funded, Mãori controlled, Māori devised, with Mãori employees who can cater more effectively for Māori education from kōhanga reo through to whare wānanga institutions, government and (state) education institutions (247).

Quite a number of the recommendations were a lot more mundane than the example above but gave a clear signal that Māori participation in the education of 
their own children was mainly dependent on how well the schools reflected or encompassed Māori values and ways of operating:

\begin{abstract}
Make us feel wanted, that we have a contribution to make, approach us personally, give us time to come to terms with things; empower us to challenge what is happening and not accept it (93);

Have a community meeting on the marae to form a community network with school, marae, AHR Centre, parents (239); and

Through my iwi; there is too little cognizance taken of the position of mana whenua especially at tertiary level (99).
\end{abstract}

\title{
6.6 Policy or politics?
}

The mood of the participants during the ES4M consultations was influenced by a number of very specific factors. The face-to-face consultation period was 18 November to 18 December 1997 which many people thought was not satisfactory because proximity to the end of the school year was a very busy time for schools and teachers making it difficult for them to attend. Those who were present made their annoyance public and argued many more of them should have been attending a meeting as important as this one was. A number of parents felt the scheduled time for consultation (between 10.00am. and 2.00pm) was not convenient for those with young children and would have much preferred an evening meeting. Most consultation meetings had some people who challenged the honesty of the Ministries and Government in carrying out a consultation 'yet again' when very little evidence existed that the findings and the recommendations of previous Maori education consultations led to substantive ameliorative action. Some people also challenged the relative absence of Pakeha from the consultation meetings, yet approximately $85 \%$ of all Maori students were enrolled in mainstream schools and other educational institutions as well as being taught by Pakeha teachers.

Each one of these elements posed a challenge to the consultative team to prevent participants 'de-railing' the purposes of the project that were to hear what Maori parents specifically wanted for their children's educational future. Allowing participants to debate two earlier questions, namely, 'why do Maori have problems 
with the education system?' and 'what is working in the system for Maori right now?' helped considerably to allow participants to vent their frustrations and then to focus on a separate reality revolving around present circumstances. These two sets of concerns are listed in table 6.1 below:

Table 6.1 Concerns about the consultation from the system and from the community perspectives

\begin{tabular}{|l|l|}
\hline \multicolumn{1}{|c|}{ SYSTEMIC } & \multicolumn{1}{c|}{ COMMUNITY } \\
\hline How to elicit the 'voices' of Māori parents. & $\begin{array}{l}\text { How to get the system to listen to what Māori are } \\
\text { saying. }\end{array}$ \\
\hline $\begin{array}{l}\text { How to consult with a reasonable representation of } \\
\text { Māori communities. }\end{array}$ & $\begin{array}{l}\text { How to convince the powers-that-be that 'action' } \\
\text { and not consultation is the issue. }\end{array}$ \\
\hline $\begin{array}{l}\text { How to ensure consultations are kept within the } \\
\text { terms of reference'. }\end{array}$ & $\begin{array}{l}\text { How to ensure 'tikanga Mãori' prevailed at the } \\
\text { consultation meetings (with respect to talking } \\
\text { rights). }\end{array}$ \\
\hline $\begin{array}{l}\text { How to maximise the Government's agenda } \\
\text { (decentralised accountability, closing the gap...) } \\
\text { without diminishing Māori aspirations. }\end{array}$ & $\begin{array}{l}\text { How to maximise the Māori agenda (whakamana te } \\
\text { whānau, te hapū me te iwi) while addressing the } \\
\text { concerns of Māori in mainstream institutions. }\end{array}$ \\
\hline
\end{tabular}

Every consultation meeting ended with the final hour closely focused and positive about what the future for Māori education ought to look like. Where meetings broke into groups to discuss the questions, a lot more information was being offered by a wider cross-section of participants compared with those few meetings (about $23 \%$ ) where everybody choose to stay as a single entity. The only real advantage of working in small groups was dictated by the period of the consultation, that is, with a longer period of consultation the single group could have achieved as much as those who broke into several groups.

If there was one defining characteristic of all the consultation meetings it would be of heightened expectations of conscious, deliberate and planned changes in the future of Māori education policy and practice. A number of key issues arose from the consultations and these are explored in further discussions with regard to meaning, consequences, and policy implications. Not in any order they are:

- a need to generate a positive image;

- need for support systems for students, whānau, and teachers;

- urgency regarding the provision of Mãori medium education resources; 
- need for an independent Mãori education authority of some description to manage accountability to whānau, hapū and iwi;

- need for Treaty of Waitangi obligations to maintain accountability to Māori in the mainstream;

- need for an overarching Māori education philosophy to guide all practice; and

- the need for relevant research to empower Māori in terms of confidence in planning, promotion and development.

These seven concerns are elaborated below.

\section{Positive image}

Many participants were conscious of the fact that Māori had a public image problem, or as others saw it, many non-Māori had a negative perception of Māori. Whichever perception, the consequences were disadvantaging for Māori and action was needed to portray a positive picture. Role models were mentioned frequently as a way to raise expectations and build up self-esteem. Some called for a media campaign to advertise successful programmes and to draw attention to Mãori who had succeeded in the schools, in the system, and in society. Successful programmes and initiatives raised included: kohanga reo, kura kaupapa Māori, wānanga, te rangakura, tatari-tauawhi-tautoko, iwi education plans, tū tangata, te whāriki and such like. It was felt the public was so ill-informed about such initiatives yet most people seemed to have a view about why Māori students fail in the system, get suspended, leave school without qualifications, and the many pathologies associated with young Māori people. A campaign of good news was seen as well overdue.

\section{Support systems}

People throughout the country advocated the need for more parental/whänau involvement in education. It was noted that parental involvement tended to be hindered by the lack of knowledge about how to assist and support their children at school. Many parents felt ill-equipped to help their children in school matters and 
wanted structural support and not just encouragement. They wanted both knowledge and skills.

The questions that needed to be addressed included:

- What does the current Government policy, 'from welfare to independence' mean for education?

- What has been the effect of the inter-sectoral initiative, 'strengthening families' and what influence has 'parents as first teachers' had on Māori families and communities?

- When does support become interference?

- Are the models promulgated ethno- or socio-centric?

Several people went out of their way to tell the consultation team how programmes designed to support families often were based on Pākehā models about what good parenting was and what a family ought to be.

\section{Māori medium education}

A large number of people had views about Māori medium education but the gist of what we were told was that the various forms of this option would need considerable strengthening if it was to become a real choice, or a viable option to mainstream non-Māori medium education. At present the resourcing of Māori medium education at every level of the education system is seriously inadequate (a dearth of competent teachers and appropriate teaching/learning resources are the most serious inadequacies).

The fact that most Mãori remained with the mainstream could be seen as a consequence of the inadequacies of provision of Māori medium facilities although history would suggest (McKenzie, 1982) that Māori have always been steadfast supporters of mainstream education wherever it existed. Mäori parents, in general, have neither the incentive nor the encouragement to pursue a Māori medium 
education given the obvious problems of drastic resource shortage, a limited supply of teachers matatau i te reo Māori (fluent in the Māori language), and the absence of solid research confirmation about the benefits of Māori medium education.

The standard bearers, culturally and philosophically for Māori medium education are kōhanga reo, kura kaupapa Māori, and wānanga. Each of these are more strongly associated with whānau, hapū and iwi development than any of the other Māori medium initiatives (bilingual, rūmaki reo) and they are generally keen for government to facilitate the development of strategic plans for Māori education at whānau, hapū and iwi levels.

There was a general consensus that targeting of mainstream teachers to improve their facility in Māori language and knowledge of tikanga (custom and ethics) and mātauranga was a necessary prerequisite to the continuing development of Māori medium education in mainstream classrooms. The Māori language syllabus (Tihei Mauriora) in mainstream schools was seen by some as being a current weakness and an unnecessary compromise to the Māori language maintenance and revitalisation policies because schools could choose whether they implemented it or not.

\section{An autonomous Mãori governance authority}

The concern for a Māori education authority of some sort was raised at every hui throughout the country. Although there was no general agreement about its purpose, function, role or membership, there was certainty that some sort of authority outside existing government education agencies was necessary for the wellbeing of Māori education into the future.

The reason for this body seemed to be related to questions of confidence and accountability. The rhetoric followed three streams: the system is never going to provide an education for us in our best interests; Māori are a minority and the 
interests of the majority will always have priority; and what was needed was a prioritising of our own interests to ensure the continuation of Māori as Māori into the new millennium. The bicultural continuum (Durie, 1994) already exists in various forms throughout the country but most developments cease at the level of dual involvement and participation. Few if any organisations are willing to extend Māori development to parallel delivery modes let alone the ultimate choice of independence. The call for an autonomous Māori governance authority is an appeal to honour the parallel or independent options as viable choices.

Accountability to government and to the taxpayer would be no less than at present but requirements would make explicit the accountability to whānau, hapū, and iwi Māori. The consultations revealed a genuine frustration among Māori with continuously having to satisfy a system at every level and in every way when that same system refused to accept Māori may have different ways of doing things, may actually have different priorities and perhaps even different goals than it. This certainly seemed to be the case with many who talked about their involvement in Māori medium education.

\section{Treaty of Waitangi and mainstream accountability}

Wherever concerns about the Treaty were raised the context was related to strengthening the contractual requirements, whether through legislation, regulation or policy, for delivering in the interests of Māori. The consensus seemed to be that partnership under the Treaty was certainly worth fighting for so long as the obligations and benefits applied equally to both parties.

The law has little to say, specifically, about education for Māori except for rights to learn the Māori language, and consultation when the charter is being altered. Māori are assumed to be inclusive of the population as a whole which would be fine if being inclusive actually worked but the fact Māori education is a problem for the system and vice versa, is testimony to the gap between the ideal and reality. 
The principle of empowerment is how the project team has summarised how to address most of the concerns from the consultations. The lack of power on the part of the students, parents/whānau, and community/hapū is the problem that needs to be addressed. We have tentatively defined empowerment as (a) knowledge of how to take advantage of the system, (b) desire to participate in the system, (c) ability to make a contribution, (d) acceptance by others of at least some of one's contributions, and (e) the feeling that one's contributions may make a difference.

There are some obligations to the partnership that sit firmly on Māori shoulders (engagement of Māori) while others are positioned clearly on the system's shoulders (responsiveness of the system). In any partnership there will always be some responsibilities held in common (collective responsibilities). Educational empowerment of Māori (and therefore both parties) occurs when both parties' ways of being, knowing and doing are accepted as viable alternatives for being educated. The system falls short in providing an education where Māori can be Māori. In fact, the norm for the system as far as Māori education goes, is about the negation of Māoriness. The evidence is compelling.

\section{An overarching Māori educational philosophy}

Many people were excited by the Māori education initiatives currently acknowledged such as kōhanga reo, kura kaupapa Māori, and whare wānanga. Other less known but equally exciting innovations included tū tangata, tātaritauawhi-tautoko, and te rangakura. What made these innovations attractive to Māori was that each was distinctively Māori in character, in the way each went about its business, in the knowledge that was transmitted, and in fundamental ways of operating. This is my understanding of the notion of an overarching Māori education philosophy.

The KKM movement wants to entrench its philosophy of Te Aho Matua in legislation to protect it and them from outside pollution, and from external appropriation. Whatever one's views are about legislating philosophy, it is rational 
behaviour on the part of KKM to attempt to keep their model of cultural transmission from being eroded and interfered with by others who are less empathetic with the principles and values they espouse. Te Aho Matua is a Mãori education philosophy specifically for KKM in the same way that Kiingitanga is for Rākaumanga and Morehutanga is for Ratana. They each set out to answer three basic questions every education system must address: what should we know, what do we need to do, and what can we be. The real difference between these philosophies and the system's is that Māori identity, first and foremost, is at the heart of Te Aho Matua, Kiingitanga and Morehutanga and not the mainstream identity, whatever that is.

The new Māori curriculum statements are a brave initiative but there is a sense in which most of them are in essence a Māori translation of the mainstream versions. There is no necessary problem in that, in fact it is probably the most reasonable and sensible thing to do given there is no precedent in New Zealand where official curricula has been translated into a second language, albeit, the original language of this country. However, much work needs to be done to produce a curriculum statement that begins with Māori values and Māori thinking at the centre of the enterprise. This is an absolute imperative for the future wellbeing of Māori culture and society.

\section{Research to empower Māori}

Despite all the talk about being the most researched people in the world there is, nevertheless, a real urgency for more Māori education research. Too often research is done to see how well Māori education policies have been implemented. Research to empower Māori will likely be longitudinal and likely be actionoriented. It will address the questions Māori are asking about their own education. It will address questions the system will likely find uncomfortable such as those to do with unequal power relationships, ethnocentrism and racism. It has been popular for some time to describe Māori education as being in crisis. Any concern that has been around for as long as the concerns in Māori education cannot be 
accurately described as crisis since that concept holds the understanding of shortterm emergency. Those of us who attended the consultation meetings certainly felt a sense of urgency and a powerful desire on the part of the participants for the government to get it right. There was little talk, if any, about crisis but there was a definite impatience and frustration with the perceived lack of definitive action.

If there was one idea that encapsulated the consultations it was the desire among Māori to see the education system support Māori endeavours to maintain and project Māori culture, through their children and young people, into the future.

If there was one major problem that has to be resolved it is the concern about the dislocation and disconnectedness of Māori whānau, hapū, iwi from schools, from teachers, from curriculum, and from governing bodies. In a paper published in 1996, I described the education system as 'lacking intellectual coherence and moral force' when it comes to Māori education. There is little about the educational hierarchy to remind Māori parents that the system belongs to them as much as it belongs to anyone else. The curriculum describes a world that is too often not the reality experienced by Māori students. Teachers want to value their emotional bonds to all students but how can they when their knowledge of the Māori child and her whānau lacks authentic connection. Whānau love and care for their young ones yet send them off to the school for the school to weave its own brand of magic on them - many don't know how to engage and are not sure they want to. To make a difference in Māori education the system has to give whānau hope. Those who attended the consultation meetings were impressed with the general level of positive energy. There was a clear understanding that even the numerous good things happening in Māori education needed to be anchored and grounded, and attached to a broader and more substantive reality. As Hargreaves and Fullan (1998) explain, "It is not only possible, but also essential to build connections between hopefulness and the structural conditions that promote it". 


\subsection{A fiduciary relationship and consultation as a mediating structure}

Some years ago the British peace educator, Robin Richardson had an article in Connerton (1978) published in the Post Primary Teachers' Association journal with the intriguing title, 'Now listen children...' (1984). The article was about what he called the 10 commandments on the nature of bias in education and the role and responsibility of educators. One of those 'commandments' read, 'Never say or imply that your own view is the only view. Sometimes the consensus view is the best view; but always remember that it is the consensus view because it is the best view; it is never the best view because it is the consensus view". In many ways this statement epitomises the dilemma that is inherent in the act of consultation, and the ES4M project showed up many of the flaws in the practice. In recognising the vulnerability of Māori to the decision-making power of the government and its policy ministries, consultation is implemented as an equity mode of inquiry based on what is called a "fiduciary principle or standard" (Wardill, 2001: 35), and "demands that one party acts selflessly and with undivided loyalty in the interests of the other".

The construction of dialogue around pre-arranged decisions represented in a discussion document prepared by government through its officials leaves little doubt that consultation as a process operates as a mediating structure similar to that of Māori education reports. When consensus, whether reached through reports and the contribution of a few selected Māori or through community consultations and the contributions of several hundred Māori, is the only legitimate decision that can be arrived at, then consultation is arranged in the interests of the dominant group. This is the negative side of the 'we are all New Zealanders' ideology. As a Māori graduate remarked more than 30 years ago, "The schools must produce 'educated Māoris' - not imitation Pākehās" (cited in Fitzgerald, 1970, p. 60, footnote 2). 


\section{Chapter 07}

\section{'Tangata-whenua, tangata-tiriti' - institutional marae}

\subsection{Introduction}

The institutional marae is the third of the mediating structures explored in this study. We begin by considering what a marae is, what its features are and its significance to Māori. We will then turn our attention to the concept of 'institutional' marae and ask how they came about, what their purposes are, and perceived problems they might have. The case for institutional marae, using the data available, will then be examined and analysed in respect to the key research question about how the system goes about transforming Māori subjects from one generation to the next. It is hypothesised that forms of cultural control through self-subjectification is a consistent feature of institutionalised marae and that this phenomenon is not shared by traditional marae. It is supposed, therefore, that institutional marae play a really important role in socialising Māori and non-Māori students and staff into a limited version of te ao Māori (the Māori world). On the whole, the institutional marae is a mediating structure operating an acculturation model of participation, emphasising the merit of prioritising the features of lifestyle. Through acceptance of the concept of the traditional marae into Pākehāoriented institutions it is assumed that improved participation among Māori students will mean that they will engage, respect, accept, feel included, gain a sense of belonging, be empowered, and experience active agency within the institution in its entirety.

\subsection{What is a marae?}

A marae is a kin-based community. The original Māori inhabitants of Aotearoa New Zealand brought the institution of the marae with them from their ancestral homeland of Hawaiki. Without delving into the esoteric knowledge of the marae it is enough initially to comprehend that for Māori, the marae is a comprehensive cosmology. The main characteristics of the marae can be likened to a small village 
made up of homes for the residences, around an enclosure that has a main building at its centre, which often will be larger and more highly decorated than any of the others, and a space in front of it where ceremonies are enacted and rituals performed. The large building (wharenui) will have a name, usually that of an eponymous ancestor. The naming of the wharenui is the ancestor name that links all the members of the marae and is one of the early rituals that make up the opening of the marae.

When the meeting-house at Victoria University was opened in 1986 these were the first exchanges ${ }^{1}$ and are more or less the same for most iwi (tribes) across the country when opening an important house.

Ko wai te ingoa o tēnei whare?

What is the name of this house?

Ko te Tumu Herenga Waka.

Ko te Ako Pai.

Ko Tāne-nui-ā-Rangi.

No wai tēnei whare? Who owns this house?

No Te Ati Awa

No Te Whare Wānanga o Wikitoria.

No te iwi me ngā karangatanga hapū o Te Ati Awa.

No ngā uri whaimuri ake.

\section{Mo wai tēnei whare?}

Who is going to use this house?

Mo Te Ati Awa.

Mo ngā tauira o ngā whare wānanga.

It is important to recognise that a wharenui erected as part of the university on university land cannot be a traditional marae in the true sense because it does not have a kin-based community serving it and it is not located on ancestral land. The words of the above ritual convey some of this message. The house is named $\mathrm{Te}$

\footnotetext{
${ }^{1}$ From a kōrero with Dr Huirangi Waikerepuru 15 Oct. 1996. He was one of the three tohunga (spiritual leaders or experts) that conducted the dawn ceremony.
} 
Tumu Herenga Waka (the hitching post for the many canoes, meaning the place where everyone can belong). But when asked who 'owned' the house the answer was according to tradition, or as close to it as one could get given the circumstances, that is, Te Ati Awa, the resident iwi of the Wellington Block but also Victoria University. The users of the house were ranked as Te Ati Awa first and then the students of the university.

\section{The traditional marae - The türangawaewae for tangata-whenua}

Hippolite, Samuel and Winiata (1996) explain that the origins of the marae belong in its mythological charter from Rangiātea located in Toi-o-ngā-Rangi that is the twelfth and highest of the Māori heavens. It is a widely established phenomenon located throughout Polynesia.

'The marae', according to one source, "is one of the oldest social institutions in the world" (Marae, 1975:18). The article goes on to discuss what it describes as "compelling reasons for perpetuating marae" as set out in a submission to the Minister of Māori Affairs of the day, Mr Matiu Rata. The submission was prepared by Tuhoe elders and reads as follows:

Ko tātou marae he wāhi piringa mo te iwi, he wāhi totika hei tiaki $i$ o tātou ahuatanga Mãori $i$ runga anō $i$ o tãtou kawa, $i$ o tãtou ture, i o tātou mana motuhake. Kia pumau ki i o tãtou marae kia taea ai-

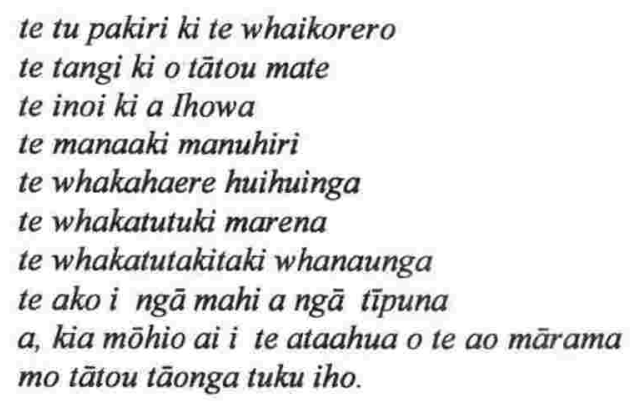

Marae are places of refuge for our people and provide facilities to enable us to continue with our own way of life and within the total structure of our own terms and values. We need a marae for a whole host of reasons -

That we may rise tall in oratory That we may weep for our dead That we may pray to God 


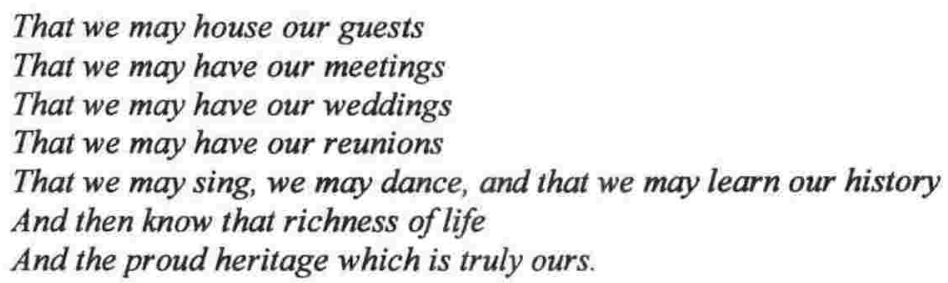

This kōrero (discourse) gives something of the cosmological nature and significance of the hapu-based marae. The traditional marae is situated as the tūrangawaewae (the place to stand) for tangata-whenua (the people who are genealogically bound to that place). It is, as Walker maintains (1975:21), "an institution that has persisted from pre-European Māori society" but it is also an institution that, along with traditional form, still has modern relevance. Walker's article in Te Mãori (pp.41-47) on the concept of urban marae is a good example of institutional change, "Where adjustments had to be made to the demands of city life, provision had also to be made for cultural and social needs" (ibid. p.43). Another of those changes to the traditional marae is what I am calling 'institutional marae', an institution within an institution, a marae within a mainstream educational facility.

\section{Institutional marae - The tūrangawaewae for tangata-tiriti}

Over the last 20 years the phenomenon of what I am calling 'institutional marae' emerged within many secondary and tertiary institutions throughout New Zealand. It is difficult to ascertain when the first 'marae' was established in a secondary school in New Zealand but according to Clareburt (1992), Te Roopu o Kakariki Marae at Greenbay College was the first such school-based marae established in the Auckland area and opened in 1978. An important part of its purpose at that time was to serve as a resource facility for teachers and as a specific place for school-community liaison. The first institutional marae established on a tertiary institution was Te Kupenga o Te Mātauranga (The Net of Knowledge) at Palmerston North Teachers College and opened in 1980.

This chapter describes the institutional marae as a mediating structure. It is argued that such an institution exists as a 'half-way house' for Māori students looking for 
sanctuaries within often unfamiliar and sometimes hostile environments. It is also a 'half-way house' for non-Māori students who are learning how to get involved in a Māori world, albeit a 'mis-placed' one in the sense of being located in an unfamiliar location, out of context. The investigation raises questions about the impact of the institutional marae as a mediating structure on the identity of Māori students and staff. Questions are raised about the influence the marae has on the institution as a whole in effects like coalition building, cultural appropriation, and intellectual property rights. ${ }^{2}$

\subsection{The case for institutional marae}

When considering the idea of institutional marae as an example of a mediating structure, I wrote to all the tertiary institutions in New Zealand to ask them whether they had such a facility on campus and if they did, what reasons were established for its existence and if not, why not. The initial enquiry was exploratory and indicative only because I already had access to many of the files related to Ako Pai Marae at Wellington College of Education and Te Herenga Waka Marae at Victoria University of Wellington. Some of the respondents provided me with additional information, all of which I have analysed to make this case. The institutions that responded are listed in Appendix 7.

\section{Reasons for establishing a marae on campus}

In no particular order, what follows are the stated reasons and purposes for having a marae on the tertiary campuses listed. In most cases the respondents to my enquiry were senior Māori academics from each institution.

\footnotetext{
${ }^{2}$ It is not suggested anywhere that the institutional marae is any way inauthentic in the sense of 'falling short' of the definition as set by the Tuhoe elders. My only claim in this chapter is that because the institutional marae is 'owned' by the institution, its potential for educating and socialising mainstream New Zealand society into the unique cultural invention which is Aotearoa New Zealand, is substituted to a place for ceremony where mainstream New Zealand can feel comfortable that it is catering for the wishes of Māori.
} 
Auckland Institute of Technology:

- to expect students to study at Te Ara Poutama without a marae is like asking an art student to study without a studio (1996 - in the process of being built).

Manukau Institute of Technology:

- to provide a proper environment for all Te Tari Mātauranga Māori activities

- a living demonstration of the bi-cultural nature of Aotearoa society;

- a living demonstration of the bi-cultural nature of the activities within the Institute;

- opportunity for all tauira Māori (Māori students) to learn and understand the unique nature of their identity, language and culture;

- opportunity for all non-Mãori tauira, kaiako (teachers) and kaimahi (workers) to learn and understand tangata whenua history and aspirations (1996 - being built in 1997).

\section{EIT Hawke's Bay:}

- to provide staff with a whare-wānanga, that is, a place to wānanga (learn);

- in part, to fulfil Treaty of Waitangi obligations;

- not a community marae for tangihanga, birthdays, unveilings etc. (local marae is in close proximity) but rather a whare wānanga for learning inside of (1994 - marae opened).

Aoraki Polytechnic:

- to promote the concept of partnership;

- to promote and enhance Kaupapa Māori in all Departments/Sections of the Polytechnic;

- to provide an environment which radiates bi-culturalism, providing cultural enrichment for all;

- to offer a learning environment alternative to a formal classroom, for Taha Māori/Cultural sessions;

- to promote/enrich the climate of campus life by providing a Türangawaewae (standing place) for all people;

- to ensure the inclusion of aspects of Mãori culture and language in the philosophy, organisation and curriculum of the Polytechnic, thus enhancing student and cultural esteem;

- to strengthen cross-cultural communication;

- to ensure the survival and protection of tikanga Mãori;

- to provide a base for the Māori and Pacific Island Liaison Tutor, Māori Tutors and educational resource material;

- foster student learning and achievement of potential (1988 - marae established).

Wellington Polytechnic:

- to have a proper place to teach and protect our Mãori language and culture;

- a place to perform karanga and whaikōrero in the appropriate way without the danger of people walking across the marae while this sacred ceremony is being performed;

- to conduct karakia without interference from other elements;

- to have a sacred place to talk about tapu and noa;

- to have a place where one can trust to go and relax and feel peace and serenity;

- to have a place that can be used by both the Polytechnic and the community (1990 - marae opened).

Whitireia Community Polytechnic:

- to provide a platform on which marae practice can happen and to provide a culturally supportive environment for participants; 
- $\quad$ to provide a spiritual base for all Māori across the institution and a learning ground for all non-Mãori also (1996 - intention to build in current strategic plan).

University of Auckland:

- $\quad$ to make the University more user-friendly to Mãori (1988 - house was opened).

UNITEC Institute of Technology:

- $\quad$ to provide a specialised teaching space for pūkenga (staff);

- to be available to community organisations for weekend seminars (1993 - building opened).

Victoria University of Wellington:

- $\quad$ to serve as the context for giving purpose to the courses offered in Mãori Studies;

- $\quad$ to provide the appropriate facilities that would allow the university to hold hui (meetings) on its own territory;

- to allow for the preparation of students for active and competent participation in Māori organisations;

- to allow the university to play a part in the multi-cultural society of New Zealand and to help expose the students to such a society;

- $\quad$ to help link the diverse elements of the university population into a corporate community by providing a focal point of unity (1986 - opening ceremony).

Central Institute of Technology:

- $\quad(1996$ - at this time a marae is but a pipe dream).

University of Otago:

- $\quad$ (1996 - in consultation with iwi it has been decided not to include in a new complex a marae of a traditional nature),

Massey University:

- (1996 - Massey did not have a marae until the merger with the Palmerston North College of Education - see above).

Dunedin College of Education:

- $\quad$ (1996 - there is no marae but local traditional marae are used on occasions).

Hutt Valley Polytechnic:

- (1996 - there is no marae but staff work very closely with local iwi and when required plan hui, powhiri etc. to take place at Arohanui Ki Te Tangata at Waiwhetū Marae).

Hamilton Teachers College:

- besides being a focal point for the learning of Māori studies and Māori language, the marae/wharenui provides a türangawaewae for all members of the college community, staff and students, regardless of cultural affiliation;

- to make the widest and best use of the marae so that all students may learn to feel the spirit of whanaungatanga and what it means to be tangatawhenua (1987-marae opened).

The key purposes from this data are ones to do with the appropriateness of context, that is, whether the environment is conducive to the learning and teaching of Māori ways of knowing, ways of doing, and ways of being. This is reflected in the use of concepts like safe place, relaxing place, and spiritual base. Another 
expected commitment was related to issues of identity and associated values like, tūrangawaewae (stance), whanaungatanga (maintaining relationships) and tangatawhenua (a sense of belonging). A third theme was the concern for protection especially of processes linked to kawa (protocols) such as karanga (the first voice of welcome onto a marae), whaikōrero (formal speeches of welcome) and karakia (ritual incantations). It was taken for granted in each response that te reo Māori (the Māori language) would find its full expression in the context of the marae. I think a fourth theme is also generally sponsored across the institutions and that is, forms of coalition. In the Māori context, coalition is almost an extension of kinship. Parker (1991:1195) describes a successful coalition as incorporating a "diversity of viewpoints and people (whether as individuals or organisational representatives). Unity is not achieved through homogeneity but by bringing heterogeneous elements into a whole". Māori understand this idea intimately. The purposes that support this notion of coalition are those that are about the Treaty of Waitangi, partnership, biculturalism and multiculturalism.

The purposes as they are listed in the raw data and as I have interpreted them in the analysis are more or less universally agreed as the Mãori contribution to New Zealand society. That does not mean that they are necessarily approved by Pākehā New Zealand. Indeed, the struggle to get approval, on almost any single item in the several lists, is an exercise in patience and doggedness.

To illustrate, Te Herenga Waka Marae on Victoria University, has its beginnings in 1963 with the establishment of a Māori Studies Department linked to the Department of Anthropology ${ }^{3}$. In 1972 a proposal to establish a Chair of Māori and Polynesian Studies separate from the Department of Anthropology was recommended but not upheld. In a quinquennial submission to the Council in 1973 a proposal to establish a marae on campus was recommended. By 1975 the position for a Professor of Māori was advertised and a senior Māori lecturer,

\footnotetext{
${ }^{3}$ All the documentation for this section is from the Vice-Chancellor's archives, DA and MS, Department of Anthropology and Mäori Studies [762] 4/2/2, 1963/69; [767] 4/2/2, 1972; [225] 4/2/2/1; [2315] R/98/44, 1981-84.
} 
writing on behalf of Māori language teachers wrote to the Vice Chancellor suggesting the qualities needed for a Mãori professorial appointment and the appropriate processes to be followed. The first Professor of Māori was appointed in 1977. In 1980 the Council received for the second time an application to establish Māori Studies as a separate department from Anthropology. This was now almost 20 years since Māori Studies began on campus and the establishment of the marae was still six years away but that did not prevent opposition in advance of the marae appearing on campus. In 1984 a vigorous debate occurred on campus on the speaking right of women on the marae. The historical and philosophical position of the university was that freedom of speech was sancrosanct. On most marae throughout the country the role of women excluded them from formal speech-making on the marae proper but not anywhere else on the marae. On most marae throughout the country men are excluded from doing the karanga. This is the tradition. Under protest from Women's Studies and a group of students the Council and the Māori Studies Department were under siege on the grounds that as a non-traditional marae they were discriminating against women. The Council's view was that it was "imprudent if not improper for Council to attempt to influence the Māori Department" (Axford to Poata, May, 1984). In today's world, the Council's getting it right by doing nothing would probably count as a fair example of 'political correctness'.

The institutional marae appear to arise out of Māori collectivities (Māori Studies Departments in the cases explored) choosing to participate in tertiary education in a manner familiar to them. Where the tertiary institution reflects Western Pākehā ways of operating, Māori look to establish a context that has an inherent inner meaning to them. Where the tertiary institution recognises itself through its historical and legal ownership of the institution, what Māori experience as social reality is a "constellation of cultural structures" that are structured and transformed in ongoing practice that appear as obstacles to their progress. Their response is to fall back on their cultural authority, for example, cultural control of the language, signs and symbols, and most importantly, the day-to-day protocols that operate on 
the marae ${ }^{4}$. The Māori response is not that of a mere aggregate but rather a collective. Johnston argues (1989) that

Collectivities are 'self-collecting' in the sense that the members engage in rulefollowing activity of a sort that constitutes the collectivity. The notion of 'selfcollection', is intended as an analogue to 'self-reflection'. If self-reflection is basic to individual identity, self-collection is also basic to collective identity...

Rule-following activity is embodied in concepts like tikanga (custom), kawa (protocol) and karakia (ritual). Evidence suggests that the institutional marae as perceived through 'Māori eyes' is mainly about the survival of a Māori 'life-style' albeit within a mainstream setting.

\title{
7.4 Life-styles or life-chances
}

Citing Dahrendorf's work on Life Chances (1978), Corson talks about the concepts of 'options' and 'ligatures' as the two distinguishing kinds of 'life chances' that societies offer to their members.

\begin{abstract}
Put simply, options in education are the range of choices (or primary goods) that people receive as a result of their education; the wider range of options, the greater are the life chances that individuals are deemed to possess. Ligatures are life chances of a very different kind; these are the bonds between people that are established as a result of their membership in society or...participation in that society's education....In some societies and among some cultural groups ligatures are regarded as positive ends in themselves to be cultivated as a goal in life, and not as the instruments to other ends that other cultures sometimes hold them to be (1992:193).
\end{abstract}

The ugly word ligatures is Dahrendorf's attempt to find an objective concept that means bonds, allegiances and connections. In terms of the purposes of institutional marae as set out by the various tertiary respondents, there is undoubtedly a stronger inclination toward notions of ligatures or bonds than to the establishment of options, although it would be wrong to say they are ignored. Instead of life chances defined as options and ligatures I prefer to equate life chances with options and life styles with allegiances. From a Māori point of view tertiary institutions are better equipped to provide students with options through the nature

\footnotetext{
${ }^{4}$ A similar argument is found in Rosemary J. Coombe (1991).
} 
of their system of credentialing (the higher the qualification the greater the number of options available) than they are in providing students with a strong sense of allegiances, except perhaps, in relation to a discipline or field, for example, mathematics scholars or historians.

The question is whether focusing on life styles to the detriment of life chances is like cutting off one's nose to spite one's face. This is what I mean by self exploitation. There is a very narrow gap between seeking to enhance one's cultural identity at the expense of one's choices in life.

\subsection{Institutional marae as mediating structures}

In sociological jargon the marae is a milieu or total environment. It is a link between the Māori of yesterday and an emerging Aotearoa New Zealand of today. To visit and work on the marae is 'to be transported into the past' and such contact with 'our deepest roots' is crucial to the ongoing vitality of national culture (paraphrased from Handler, 1985:203-4). In these terms the institutional marae is a mediating structure for Māori in two ways: to learn about the past, and to learn about the institution as a whole. The institutional marae is a campus within a campus but all is not well in either campus.

"There is a basic social division between Māori and Pākehā" according to Mahuta (1979). "This social dichotomy involves ideological differences (emphasis in original) which are reflected in the oral traditions of the Māori and written history of the Pākehā". The ideological differences have their substance in policies like acculturation. This policy was present in Pākehā thinking and acting from the very beginning: Māori people would change and become like 'them'. If it didn't happen quickly, it would certainly happen over time and 'diffusion' or the exchange of characteristics across cultural boundaries would inevitably occur. Socialisation, miscegenation and co-habitation would take place but the exchange of values might never be completed. In a different but parallel situation, Urion (1991:3) 
writes about First Nations peoples and white Canadians. "Both cultures were in conflict from the beginning and one was certainly dominant while over time the other culture became subordinate. The problem with the acculturation model is that it affirms the reality and stasis of cultural boundaries".

Despite the willingness to use the institutional marae in tertiary institutions as a bridging mechanism it is unlikely to bear fruit until such time as at least most of the schools, departments and faculties on campus are able to achieve a modicum of what might be called, dual epistemologies within the structure of the courses they offer, the staff they appoint, and the material they produce. Until that time, Māori will continue to promote the institutional marae as a home away from home, as a sanctuary, as a half-way house, and as a concentration camp for culture. 


\section{Chapter 08}

\section{'Our Pākehās' - The rise and rise of Māori medium schooling}

\subsection{Introduction}

Up to this point we have explored three of the four elements Van Til (1984) argued were critical for development through participation. The first of these was the element of social justice that was defined historically in Māori education as a trend to maintain status quo relationships; reports on Mâori education were seen as the mediating structure (Chapter 5) critical to the maintenance of this relationship. The second critical factor in achieving Māori participation was that of communication via a popular form of participatory democracy known as consultation, the process for which was explored in Chapter 6 in the national project known as the Education Strategy for Māori. Institutional marae is the third mediating structure (Chapter 7) and discusses lifestyles/lifechances as the third critical factor shaping Māori participation in education. This brings us to the fourth factor affecting participation that Van Til (ibid) describes as cultural mobilisation. The mediating structure applied in this instance is that of Māori medium schooling and makes up the content of Chapter 8 . The political shift from a highly centralised education system to a more decentralised one such as that intended in the educational reforms of the late 1980s and early 1990s helped legitimate the Māori medium schooling movement that began with bilingual schools and expanded dramatically into kaupapa Māori schooling.

The development of institutional marae and kura kaupapa schooling share some important characteristics. Both depend on modes of cultural regulation that make self-subjectification an important mechanism for asserting difference; both rely heavily on cultural control mechanisms that are fundamentalist and essentialist in nature; and both emerge out of Māori discontent in education coupled with a powerful desire to take control over their own institutional as well as educational 
future vis-à-vis the mainstream. This latter mediating structure of Māori medium schooling is explored in this chapter.

Before delving into the intricacies of the mediating structure under investigation the pattern followed thus far has been to outline, albeit briefly, the historical, sociological and educational background of Māori medium schooling.

\section{2 'Our Pākehās'}

Some of the central themes of this chapter run a parallel course to those reports on Māori education discussed in Chapter 5. Where that chapter began with the patronising heading 'our Māoris' this chapter on kaupapa Māori schooling begins with the equally patronising 'our Pākehās'. Whereas 'our Māoris' is premised on the view that Pākehā situate themselves in an hierarchical power relationship that places them in control over the negotiation of what will count as the content of reports (even when the topic of the reports is Māori education), those promoting Māori medium schooling (especially at the kaupapa Māori end of the spectrum) are endeavouring to send precisely the same patronising message to 'our Pākehās' except that those in control of the negotiation of what will count as kaupapa Māori schooling are Māori. The leadership in the kaupapa Māori movement, with the assistance of some Māori members of parliament, took the action of placing the philosophy of KKM into legislation, supposedly for the purpose of protecting it from those who would appropriate it for different reasons and different ends. At the time leading up to parliament debating the Bill on the KKM philosophy (Te Aho Matua) it became a concern to their leadership that the Ministry of Education was considering redesignating mainstream primary schools with significant numbers of Māori students, where the support of the majority of parents was established. That is, mainstream schools could become official KKM by having a significant number of Māori students and parents who agreed that their schools could become KKM without having to do anything more. They would simply adopt the KKM philosophy and that would be it. Where a Government had a 
policy to establish, say five KKM a year over X number of years, no new monies would be needed because selected existing schools would fill the quota. Those parents who sacrificed time, energy, finances, and considerable stress as a result of having to establish their alternative KKM 'schools' outside the existing legislative framework ${ }^{1}$, as well as having to write an educational philosophy that reflected their aspirations, were not about to lie down and allow the officials to sabotage all their efforts by simply renaming mainstream schools, KKM, hence, the legislation. Now, mainstream schools predominantly Māori in composition, where there is a strong Māori community resource, and where parents wish their school to be redesignated Māori can only do so with the agreement of the Ministry of Education and Te Rūnanganui-o-Ngā-Kura-Kaupapa-Māori o Aotearoa which is the national umbrella organisation of all KKM and Wharekura (primary and secondary sectors).

There is, in Māori terms, a major tension in the two contexts of Māori education reports (Chapter 5) and KKM (Chapter 8). The power relationship in terms of who has the final say rests in both cases with mainstream Pākehā. Mãori must do everything possible to win the hearts and minds (and resources) of the mainstream ('our Pākehās') in order to advance its case for kaupapa Māori schooling, but, in the end, if consensus is not reached, the decision will be made by mainstream Pākehā as the dominant force. To maintain this relationship it is imperative that the mainstream establish systems, structures, policies, regulations and processes where Māori are seen to be treated equally. The history of the education system is filled with these equal treatment measures. The structural-functional approach, outlined in the next section (8.3), along with a liberal philosophy of education (discussed in Chapter 2) spells out how this cultural hegemony has become reified in the system. The real problem as far as Māori are concerned is not to be 'treated equally' but rather to be 'treated as equals'. The need, they claim, is for differential treatment rather than equal treatment. Differential treatment accepts the fact that Mãori are

\footnotetext{
${ }^{1}$ See Nepe (1991) and Rata (1991) for some of the background on the development of KKM that prompted the move to 'protect' the KKM philosophy.
} 
not merely brown Pākehā. This theme is played out in the remainder of this chapter from 8.4 onwards.

\subsection{Structural-functionalist sociology}

The structural and functional approaches to sociology were introduced earlier (Chapter 4). Functionalism is described as being concerned with explanations of the way things are, with equilibrium, with consensus approaches, and with the maintenance of the status quo while structuralism has as its main commitments, change of the social order by changing structures and/or modes of domination. In earlier sociological thinking structural and functionalist approaches would have been represented as conflict and order theories but the work by Burrell and Morgan (1979) argues that the distinction between the two is much more of a continuum than was recognised by many earlier sociologists. Given what is already known about the emergence and development of kaupapa Māori schooling it is possible to explain these developments in terms of functionalism, in the sense that need satisfaction, through an emphasis on Māori language to maintain social cohesion and cultural solidarity against the hegemony of the state, is seen as a priority for survival as a distinct people. On the other hand and seemingly in a contradictory aspect, kaupapa Māori schooling can also be explained in structuralist and even radical structuralist terms. The mere existence of a structure within the mainstream system that is an alternative clearly demarcated on the grounds of race and culture, suggests a radical departure from status quo policies. A comparison with the Native Schools System of 1867 to 1969 is not a parallel case because that development arose out of the state as a mechanism to appease and civilise the Māori (Simon \& Smith, 2001) whereas kaupapa Māori schooling arose from the dissatisfactions of Māori not getting a 'fair-go' in the existing system (Penetito, 1988; Nepe, 1991; Smith, 1997).

In general terms the kaupapa Māori agenda is about both the reproduction of Mãori culture through schooling and the transformation of dominant structures 
within the broader context of education. Māori medium schooling focuses on the acquisition of a second language as a target language and generally appeals to liberally inclined mainstream communities, whereas kaupapa Māori schooling is really about the revitalisation of the Māori language and culture through immersion. Kaupapa Māori therefore shares more of the characteristics of mainstream education than does bilingual schooling except that the language of communication and instruction is Māori, as is the philosophical base for curriculum, pedagogy, assessment, organisation etc. Transformation is sought through programmes that:

(a) target increased attempts at self-governance at both local and national levels (Māori education authority initiatives);

(b) dramatically increase the number of Māori with research degrees at the highest level (the doctoral programme initiated by Graham and Linda Smith from the University of Auckland); and

(c) involve Māori in working relationships with other indigenous peoples world-wide (the World Indigenous Peoples Conference on EducationWIPCE and the World Indigenous Nations Higher Education ConsortiumWINHEC).

The proliferation of kaupapa Māori-oriented programmes across all sectors of society, from government and business, through sport and the arts, and every other societal domain is having a transforming effect on mainstream society whether prepared for or not, asked for or not. Those who doubt the veracity of such a view should peruse the pages of the 60 plus volumes of the ubiquitous 'Mana' magazine, subtitled 'The Māori news magazine for all New Zealanders'. This magazine also lists the government departments and the specific policies they are promoting to build Māori capacity in line with at least modified versions of kaupapa Māori. 
Work by the British educational sociologist, Margaret Archer (in Morrow \& Torres, 1995:101) describes a morphogenic process that seems to relate quite closely to the processes of kaupapa Māori discussed above.

Clearly the concept of morphogenesis relates to the problem of complex reproduction and even transformation, and provides an important alternative to the older mechanical functionalist equilibrium models and a challenge to structuralist-type approaches.

Table 4.1 of Chapter 4 highlights the realist/objectivist orientations of functionalist and structuralist approaches in sociological thinking. Central to these approaches is the problem of agency and structure, or, in Archer's terms the relations between agency and culture. If we take a step back and remind ourselves of the early 'order' and 'conflict' orientations of sociological theorising we could just as accurately re-label these orientations 'liberal' and 'Marxist'. The liberals subscribe to an individualist ontology arguing that the world is made up of discrete and wholly separate entities called individuals. The Marxists on the other hand subscribe to a relational ontology that insists that the world consists not of entirely distinct objects and things, but of relations. One can be seen to focus on 'agency' and the other on 'structure'. The agency orientation directs our attention to individuals who act intentionally. The structural orientation directs our attention away from motives and intentions of individuals and leads us to focus upon objective relations. In this way, different actions are a feature of structures not a product of intentions ${ }^{2}$.

What makes the rise of kaupapa Māori schooling structuralist is the commitment by those closest to the movement to assert 'being Māori' culturally, economically, politically and spiritually rather than setting out to change dominant structures or trying to change the mind-set of the dominant society. It is preoccupied with trying to change itself rather than allowing itself to be side-tracked or appropriated by the dominant agenda.

\footnotetext{
${ }^{2}$ I have borrowed liberally from Ball (1978:97) for the liberal/Marxist approaches to his discussion about coercion.
} 
The issues of agency, structure and culture will be explored further in the discussions that follow.

\subsection{The rise of 'Māori-medium' education - a catalyst for transformation}

There is a reasonable quantity of material on the growth of 'Māori-medium' education in New Zealand although there are also many gaps in the research especially that produced by Māori researchers. No one person figures more prominently in Māori language research than Richard Benton (1981). His research is seen by one of the early pioneers in the 'kaupapa Mãori movement' (Smith, G.H. 1997) as being the major catalyst for the emergence of Mãori-medium eduction. Benton's research showed that unless drastic measures were taken to rescue te reo Māori from its moribund state (Benton, 1991) it would become like the moa, extinct. Benton was also clearly aware that promoting Māori language programmes into schools was not enough in itself and that structures needed to be in place that could support such programmes (Benton, 1988). Others outside the schools were also busily pursuing initiatives to ensure the home base for intergenerational language transmission was being catered for (Mataira, 1980) ${ }^{3}$. Māori language initiatives through the education system were in place, especially in mainly primary school bilingual units, classes and schools, as a secondary school external examination subject, and as an undergraduate tertiary study, well before the influences of Benton, Smith or Mataira (National Advisory Committee on Māori Education, 1970) however, there is no doubt that the burgeoning of Māorimedium education began with the introduction of Kohanga Reo in 1982. Indeed, the rise was so dramatic and the effect so deep that by 1985 it was clear to those most intimately involved in what was happening that revitalisation of te reo Māori was really about revitalisation of the Māori people, and revitalisation of the people meant a revitalisation of institutions and those structures that under-gird the

\footnotetext{
${ }^{3}$ Katarina Mataira's MA Thesis (1980) was the methodological basis upon which an adult Mãori language movement was established (Te Ataarangi).
} 
language ${ }^{4}$. Thus was revealed, in the eyes of the Māori-medium advocates, the need for a full-blown kaupapa Māori schooling, which would develop into kaupapa Māori education, system wide.

\subsection{What is 'kaupapa Māori schooling'?}

In answering this question three separate but interlinking moments will be explored across four historical periods listed in Table 8.1.

Table 8.1 Historical moments in the emergence of kaupapa Māori Schooling

\begin{tabular}{|l|l|l|l|}
\hline & \multicolumn{1}{|c|}{$1970 \mathrm{~s}$} & \multicolumn{1}{c|}{$1980 \mathrm{~s}$} & \multicolumn{1}{c|}{$1990 \mathrm{~s}$} \\
\hline $\begin{array}{l}\text { Key Historical } \\
\text { Developments }\end{array}$ & $\begin{array}{l}\text { Struggle for survival in } \\
\text { the system -assertion of } \\
\text { Mãori cultural capital }\end{array}$ & $\begin{array}{l}\text { Politicisation and } \\
\text { creation of an infra- } \\
\text { structure - the New } \\
\text { Right to the rescue }\end{array}$ & $\begin{array}{l}\text { The rise of Mãori } \\
\text { medium schooling - } \\
\text { cultural mobilisation }\end{array}$ \\
\hline
\end{tabular}

\section{Assertion of Māori cultural capital}

In 1970 the National Advisory Committee on Māori Education (NACME) published a report that among other things stressed the importance of

Pākehā, particularly children and teachers, be made more aware of the Māori way of life in a changing society (p.3).

Compared with earlier reports like the Hunn Report of 1961 and the Currie Report of 1962, the NACME report was unique in that a strong emphasis was placed on providing Māori studies and Māori language in the mainstream school curriculum. Where the earlier reports emphasised the need for Māori to adapt to a Pākehā context and a Pākehā system, this report called on the reciprocal requirement for Pākehā to understand and be able to respond to the needs of Māori.

\footnotetext{
${ }^{4}$ A survey undertaken in 1995 by Te Puni Kōkiri (The Ministry of Māori Development) and Te Taura Whiri i Te Reo Māori (The Māori Language Commission) of 2,441 Māori adults found that although the statistics were improved from 20 years previous, the situation was still extremely serious with approximately $60 \%$ of Māori adults with some facility in te reo Māori but most ( $83 \%)$ had low fluency or did not speak Māori at all.
} 
Out of this policy initiative came a series of marae-based in-service courses on 'Education in a Multi-cultural Society'. They ran from the mid-1970s through to the mid-1980s. The courses were attended by senior administrators from the central offices of the Department of Education and Education Boards, primary and secondary inspectors of schools, principals of schools, professional advisers and teachers. The courses were run by members of the Māori Advisory Service, senior education officers of the Māori and Island Division of the Department of Education, the tangatawhenua (people of the marae), experts on Māoritanga as well as experts on Pacific matters. Marae elders as well as the ringa wera (cooks) were an integral part of each course as well as being called on at every marae to outline local history. Each course was from two to four days duration and course members stayed on the marae throughout, eating, sleeping, singing, talking and participating in many other authentic matters associated with life on the marae. An evaluation research report outlines the purpose of these courses as:

\begin{abstract}
The experience of marae life was intended to bring about an awareness of the feelings of a people of a minority culture when they were exposed to and involved with a different majority culture. Course members heard from Māori people of their doubts, their fears, and of the needs of their children in education (Department of Education, 1982:ii).
\end{abstract}

The key figure on most of these courses was a respected Tuhoe elder by the name of John Rangihau referred to in earlier discussions. Many times over a number of years Rangihau espoused his theories of Māori-Pākehā relations, explaining, interpreting, remembering, and experiencing what it meant to him 'to be' Māori, and 'to be' Tuhoe. One could never become tired of these multi-layered representations of knowledge and experience, of ways of seeing, doing and being that arose out of the consciousness and practice of one kaumātua (elder). Yet it became obvious to some that Rangihau talking about Māoritanga ${ }^{5}$ was not Māoritanga but rather Rangihau talking about Māoritanga. The context of the presentation on the marae went some distance to focus audiences on 'Māoritanga' as a lived cosmology, that is, as a comprehensive and integrated perspective, but

\footnotetext{
${ }^{5}$ Māori is the generic term for the indigenous people of New Zealand; the suffix 'tanga' denotes 'qualities of', therefore Māoritanga is the invented concept that stands for the qualities of what it means to be an indigenous person of New Zealand or more simply, Mãoriness.
} 
the audience still needed to experience the deeper meanings of each of the concepts in order to better understand the implications of each on the whole. On at least one of the marae inservice courses a local elder died and the marae immediately transformed into its traditional form as an institution to honour the deceased and to bring, the often disparate extended families together in mourning the dead and celebrating the living. The organisers of the inservice were persuaded to remain on the marae and to participate in the tangihanga. The members of the course had the opportunity to learn one of the many lessons of the meaning of Māoritanga first hand, rather than through the interpretations (however expertly presented) of a single person. There is no substitute for an emotionally deep relationship with Māoritanga (or any other culture). Those who experience the relationship can never unlearn it. There is a brief description of the Māoritanga model introduced in Chapter 2 as figure 2.1.

It makes sense to think about the Māoritanga narrative as in some way equivalent to Bourdieu's concept of cultural capital. It seems entirely reasonable that Rangihau's endeavour to make his private words and worlds public should have left him feeling anxious and somewhat ambivalent. As a kaumātua in the Māori world and as an expert in the Pākehā world his views about what constituted being Māori would constantly be in need of protection from the dangers of misinterpretation and mis-representation and yet this was not a problem in any public sense. Why? Traditional Māori social organisation (whānau - extended family; hapū - community; iwi - tribal group) hold fast to the view that every hapū (community) has its own stories about what constitutes its cultural capital. Yet Rangihau is able to tell his particular 'Tuhoe' story on marae all over the country without serious challenge. As a universally respected kaumātua he was in a position that allowed him the freedom to reveal his own interpretation of things without being pressured to provide justifications. Another interpretation might be that there is virtual tacit agreement across the whole of Mãori society, at least when it involves the classical traditions, as to what constitutes the critical components of what it means to be Māori. The essence of Māori cultural capital 
must include elements such as te reo Māori (the Māori language as in the vernacular), wairua (those momentary glimpses beyond time and space), mana (as spiritual authority and power manifest in the integration of body, mind and intellect), and whenua (the sense of belonging in time and space similar to Bourdieu's concept of habitus ${ }^{6}$ ).

The assertion of Māori cultural capital throughout education in the 1970s can be viewed in hind-sight as what the international linguist Spolsky describes as "the continuation of a long process of negotiation of accommodation between autochthonous Māori and European settlers" (2003:553). It became evident to those working within the developing Māori medium field that the goodwill of teachers, public servants and politicians was neither adequate nor sufficient to rescue a dying language. Goodwill without the pre-requisite resources, goodwill without a sound infra-structure, and goodwill without supporting research was like a promissory note. The 'movers and shakers' within the emerging kaupapa Māori domain were ahead of the field by the time the educational reforms of the $1980 \mathrm{~s}$ came into effect.

\section{The educational reforms}

A strange thing about the timing of right wing politics in education in New Zealand is that it was not responsible so much for censuring the emergence of kaupapa Māori schooling as for compelling it to come out of the closet so to speak. That is not to say that there was no attempt to discredit the whole kaupapa Māori movement for there certainly was (Marshall, Peters \& Smith, 1990). The discussion on the 'New Right' as a political movement is not central to this thesis but the propaganda surrounding its implementation was evident in slogans like: 'minimise government', 'I'm proud to be a Kiwi/New Zealander', 'kaupapa Māori initiatives are separatist', 'children should be trained in schools for jobs', 'troublemakers should be given a stint in the army', 'unions need to be legislated from

\footnotetext{
${ }^{6}$ Bourdieu (1989:19) says that "habitus implies a "sense of one's place" but also "a sense of the place of others"...It is both a system of schemes of production of practices and a system of perception and appreciation of practices'.
} 
holding the country to ransom', 'the market is the solution to all our ills', and 'send immigrants home to where they come from'. In the world of education, Marshall, Peters and Smith (1990), in a critique of Sexton (1990) claim that his report to the New Zealand Business Roundtable is "an unabashed example of new right ideology" because it celebrates the 'market' as the solution to all of New Zealand's 'ills' in education and recommends full privatisation. It also proposes that all schools become self-managing, that parents and their children become the consumers of the system and by so doing enhance the value of competition. What follows from such policies is a clear focusing on the virtue of individualism.

Māori were quick to identify problems that lay in wait for them through strict adherence to new right politics (expressed through 'Today's Schools'-The Lough Report and the Sexton Report, 1990) but saw some promise in the Picot Report (1987) that had not appeared anywhere prior. Picot offered an 'opt-out' clause where there was sufficient support to establish schools outside the mainstream. But, as for the Sexton Report (1990), Marshall et al (1990:27) are unequivocal in their criticism.

\begin{abstract}
...(It) is an unmitigated, ethnocentric attack on New Zealand schooling and education generally and on Mãori in particular. The attack on Mãori is sustained through the alliance of racist policies and propaganda, new right ideology and big business interests. There has been a deliberate attempt to co-opt racist hysteria and to fuel Pākehā paranoia of the 'Brown Peril' - Mãori presence and competing needs in schooling. Sexton endeavours to not only report on the 'crises' created by Mäori in schooling, he is guilty of also creating the 'crises'. For example Sexton devotes two full pages to denouncing Māori language, falsely implying that all pupils in all schools are being required to learn Mãori language, thereby fuelling 'fear' among the Pākehä community (emphasis in original).
\end{abstract}

Despite the initial warm 'fuzzy feelings' Māori educationalists and Māori academics showed toward the receipt of the Picot Report there was no suggestion that the recommendations of Picot or the subsequent government policy document, Tomorrow's Schools might supercede the kaupapa Māori initiatives as evidenced in Te Kōhanga Reo and KKM. These initiatives have been well documented in Smith $(1990,1991)$. He has argued persuasively in favour of the Māori initiatives vis-à-vis those of the state on the grounds that much of what is advocated by the 
state has been tried earlier and failed and secondly, that what are seen as new directions often do not address Māori needs. On the other hand, kaupapa Māori initiatives, described by Smith (1992) almost seem to rise like the sphinx from out of the ashes of despair. He describes them as 'resistance strategies' and goes on to analyse what it is about these resistances that can be utilised to greater effect in the transformation of Māori education (1997). My view is a little less dramatic and inclined toward the idea that evolutionary change laid down in earlier periods of development but especially through the 1970s hastened the emergence of kaupapa Māori education. This is not to say that mainstream education would have 'discovered' kōhanga reo and kura kaupapa Māori because I think that most unlikely. What is probably at least equally problematic is why Māori took so long to force the issue of demanding an education in their own real interests by taking direct action a lot earlier, for example, from the days when using Māori language in schools was forbidden.

\section{Cultural mobilisation}

Māori-medium education in pursuit of a kaupapa Māori was the critical factor in the late 1990s. The Kohanga Reo Movement (1982) and the Kura Kaupapa Māori Movement (1985) are often talked about as though they were the beginning of the 'browning of the education system', and while there can be no argument with the impact they have had, the 'browning' occurred at least 10 years earlier, as Table 8.2 shows. TKR and KKM did much more than 'brown' the system, they put Māori in, in a way that radicalised change but the earlier interventions of the 1970s created a platform from which real change became possible.

The Māoritanga intervention discussed earlier did a lot to conscientise Pākehā educationalists as well as providing Mãori with real opportunities to discuss their perceptions of history, education, race relations and much else within a context that was at least culturally familiar to them. Now it was Pākehā educationalists that were forced to experience being the 'Other'. 
Table. 8.2 Interventions, catalysts for change, and strategic foci for systemic-wide change in Māori Education 1970-2002

\begin{tabular}{|c|c|c|c|c|}
\hline & $1970 \mathrm{~s}$ & 1980s & $1990 \mathrm{~s}$ & $2000 s$ \\
\hline Intervention & $\begin{array}{l}\text { 'Māoritanga' } \\
\text { teacher in-service } \\
\text { courses }\end{array}$ & $\begin{array}{l}\text { Tu Tangata } \\
\text { reforms and pan- } \\
\text { Māori } \\
\text { educational } \\
\text { administrative } \\
\text { bodies created }\end{array}$ & $\begin{array}{l}\text { Whānau, hapū, } \\
\text { iwi education } \\
\text { plans }\end{array}$ & $\begin{array}{l}\text { Hui Taumata } \\
\text { Mātauranga. } \\
\text { Te Ao Māori - } \\
\text { Te Ao Whānui } \\
\text { interface }\end{array}$ \\
\hline $\begin{array}{l}\text { Catalysts for } \\
\text { change }\end{array}$ & $\begin{array}{l}\text { John Rangihau, } \\
\text { Alan Smith }\end{array}$ & $\begin{array}{l}\text { Kara Puketapu, } \\
\text { Iritana } \\
\text { Tawhiwhirangi }\end{array}$ & $\begin{array}{l}\text { Pita Sharples, } \\
\text { Katarina } \\
\text { Mataira, } \\
\text { Whatarangi } \\
\text { Winiata }\end{array}$ & $\begin{array}{l}\text { Tumu Te } \\
\text { Heuheu, } \\
\text { Mason Durie }\end{array}$ \\
\hline Strategic focus & $\begin{array}{l}\text { Māori culture - } \\
\text { learning 'about' } \\
\text { Māori; changing } \\
\text { consciousness }\end{array}$ & $\begin{array}{l}\text { Māori language - } \\
\text { learning 'in' } \\
\text { Māori; } \\
\text { politicisation; } \\
\text { getting better } \\
\text { organised }\end{array}$ & $\begin{array}{l}\text { Māori language } \\
\text { - learning 'for' } \\
\text { Māori; } \\
\text { curriculum; } \\
\text { creation of infra- } \\
\text { structure }\end{array}$ & $\begin{array}{l}\text { 'Being' Mãori ; } \\
\text { philosophical } \\
\text { base; community }\end{array}$ \\
\hline
\end{tabular}

By the 1980s, bilingual schooling was in existence and kaupapa Māori education in the form of TKR, KKM and wānanga was generating excitement among a rapidly growing proportion of Māori who were determined to revitalise te reo Māori as a language of communication and a language that could be the medium for learning anything else. The need to be better organised locally, regionally and nationally was seen as imperative so long as mobilisation of the kaupapa (philosophy) of Māori immersion was going to be accepted as right for those Māori who saw this as in their best interests in future developments ${ }^{7}$.

The 1990s was marked by a further 'logical' step in the movement toward full participation of Māori in education. Educational governance initiatives involving whānau, hapū and iwi (the three key social organisational forms of Māori society) generally referred to as 'Iwi Education Plans' began to emerge out of the communities. These were initiated by the Māori communities themselves, in most cases, but the Ministry of Education has played a guiding role with each of them.

\footnotetext{
${ }^{7}$ Bilingual schools were seen as too little too late. Ethnic minority groups in other countries had tried to establish special interest schools, for example, supplementary schools in Britain (McLean, 1985) and charter schools in America (Apple, 1998; Royal, 2002), all with mixed success.
} 
There have been sporadic attempts by Māori to establish a governance model at the national level but up to now support has not been forthcoming from either Māori or official sources.

By the turn of the twenty-first century kaupapa Māori initiatives have become relatively stable and the remaining work mainly revolves around continued improvement of facilities, improved provision of kaupapa Māori teacher education, improving standards of student performance, better quality educational resources and so on, exactly like mainstream schooling. The emphasis now is directed by Māori at mainstream education where the majority of Māori students are located. It is no longer seen as acceptable that mainstream schools can be permitted to continue to virtually ignore the heart of Māori knowledge and practices. A New Zealand school must reflect the fact that it is a New Zealand school and not a transplanted British one, a slightly modified Australian one, or an emotionally bereft Māori one.

\section{Does this feel like transformation?}

One of the important questions that needs to be answered about the sort of influence generated by kaupapa Māori education is whether things are any better or not. If they are, then for whom are they better, in what way, and with what effect? As already mentioned, it has become agreeable to read about the transformative potential of kaupapa Māori schooling but what does that mean, what is actually being transformed, and how do we know? I'm reminded of the work by the American educationalist, Ellsworth (1989:298) who asked, "Why doesn't this feel empowering?" when commenting on repressive myths of critical pedagogy. The critical theorists of education like to write about "oppressive social formations", "relations of domination" and the like under the umbrella of emancipation but who actually benefits from such abstract discursive arguments? She writes,

In my view of the literature, I found ....that educational researchers who invoke concepts of critical pedagogy consistently strip discussions of classroom practices of historical context and political position. 
Much of the research on kaupapa Māori education has derived from the Smiths at the University of Auckland and their students with occasional works from the Universities of Otago (Bishop), Victoria (Irwin, McCarthy), Waikato (Vercoe), and Massey (Durie, A.) but by far the most common have been those from Auckland. Most of the works are sociologically-oriented and written for academic consumption ${ }^{8}$.

Kaupapa Māori schooling, judged against criteria such as level and quality of participation in activities like the national Māori speech competitions, and regional and national kapa haka competitions, has clearly had a transformative effect on its pupils. There might even be grounds for arguing that kaupapa Māori in its broadest terms is having a transformative effect on the Māori population in general if we take into account the massive Hikoi (political protest march) against the Government's actions related to the 'foreshore and seabed' legislation in 2004; the opening of Māori Television can also be considered in a similar light.

Whether kaupapa Māori is having a transformative effect on mainstream society is less difficult to judge but there are indications that a 'generosity of spirit' has made it possible for transformations to occur that in many instances can be seen as extraordinary; the emergence of a Māori Party to contest the recent elections is one of those; the ongoing work of the Waitangi Tribunal must be another.

\subsection{Kaupapa Māori schools as mediating structures}

For KM schools to become mediating structures the work of Māori-medium education has to progress a great deal further than anything envisaged up to now. At least three inter-related philosophical questions need to be addressed. The first is a theme that is taking on a more strident note on the lips of many Māori and is

\footnotetext{
${ }^{8}$ There are some exceptions, for example Bishop and Glynn (2000) write specifically to inform the mainstream about the development of kaupapa Māori education whereas Vercoe (1995) explains why kaupapa Māori schools are a virtual escape valve for Māori discontent with the existing education system.
} 
what I will refer to as the desire 'to be Māori'. The second is about the vexed question of the 'ownership of knowledge', while the third is about the nature of Māori knowledge versus the nature of knowledge that gets into the education system. There are many incentives for both parties to get it right but there also remain some major contradictions that need to be fronted up to. O'Sullivan (1999:xiii) sums it up rather poignantly:

\footnotetext{
The fundamental difference between the attitudes of modern and ancient man as regards the surrounding world is this: for modern, scientific man the phenomenal world is primarily an "It"; for ancient - and also for primitive - man it is a "Thou".
}

After almost 200 years of acculturation into traditional Māori and European modernisation, Māori can no longer be considered primitive but those distinctive cultural attributes Māori have retained as tāonga (valued possessions) will not be separated from them by attempts to objectify the environment. Where the system has to change nowhere will that be experienced more sharply than by the classroom teacher who must struggle with the question:

What is the knowledge that is needed in order for teachers to better:

(a) understand the Māori child; and

(b) participate in the Māori community?

I will try to answer this question by discussing three underlying assumptions about our education system that we should know about before we begin the task of implementing the production of local Māori knowledge into our learning institutions. The assumptions are:

(a) the need to contextualise Māori knowledge for New Zealand teachers;

(b) the need to face up to the moral dilemma of the ownership of knowledge; and

(c) the need to unravel the priority of universalism over particularism; 


\section{Contextualising Mãori knowledge for New Zealand teachers}

In the last 20 years in particular, Māori have come out fighting to retain their language but in the next 20 years it is likely that 'mātauranga' (knowledge) in its many manifestations, for example, 'mōhiotanga' (skills), and māramatanga' (enlightenment) will become the touchstone for judgements about the progress being made in the field of Māori education and its contribution to mainstream education.

The New Zealand education system has always operated as though all its clients were either Pākehā or wanted to become Pākehā; Māori had much to learn from Pākehā society but Pākehā, so it seems, had little to learn from Māori. The following quote from Kirkness (1992:34) is a telling one but mainly because it is not realised in practice as far as Māori (or in Kirkness's case, Canadian First Nations peoples), are concerned:

\section{Unless children learn about the forces which shape them: the history of their people, their values and customs, their language, they will never really know themselves or their potential as human beings.}

The message from kaupapa Māori schooling is an appeal to all teachers to know the Māori children we teach, as individuals, as members of whānau, as tangatawhenua, as manuwhiri, as members of hapū and iwi, as New Zealanders, and as thinking and feeling human beings. Despite 200 years of colonialism the Māori population is numerically stronger than it has ever been. It could be argued that Māori identity is weaker because of inter-marriage, urbanisation, industrialisation, and other forces related to the push for modernisation. Māori language loss and similar characteristics are the constant effects of colonialism, If by that is meant Māori language and culture is no longer like it was prior to Europeanisation then that is obviously true. But one of the reasons Māori have survived culturally is because they have been able to adapt to changes (sometimes through choice and sometimes through coercion) and as a result are stronger today than they have ever been. But they have paid a price. The lesson Māori need to 
learn is an equally obvious one and that is 'there are many ways to be Māori' and there is no such thing as 'the' Māori identity, there are only Māori identities.

What is Māori knowledge and what components of Māori knowledge would educationalists find most helpful in coming to understand Māori students? As a Māori educationalist of some experience I have often reflected on the questions teachers have asked me about Māori knowledge. I have thought about the things I have done with teachers over the years that they may have enthused over. I could remind myself of things I have seen and heard which I wish teachers had asked me about beforehand but didn't. If one thinks about current curriculum, pedagogy, assessment and evaluation, management and governance, to name but a few of the key components that make up the educational enterprise, it soon becomes obvious that one cannot do justice to local Māori knowledge by steering a piecemeal intervention course. This assumption then asserts the wisdom of a planned approach to knowledge production.

Apple and Franklin (1979:178) remind us that the knowledge that got into schools in the past and gets into schools now is not random. It is, as has already been mentioned, selected and organised around sets of principles and values that come from somewhere, that represent particular views of morality and deviance, of good and bad, and of what 'good people act like'. Local Māori knowledge, just like Pākehā universal knowledge, is constructed; it reflects local Māori powerful groups. This makes on-the-ground negotiations with communities over what will be legitimate knowledge absolutely critical.

There is no one fixed idea of what Māori local knowledge is. There is really no such thing, traditionally as 'Māori' knowledge. There is only whānau/hapū/iwi (WHI) knowledge. However, in today's world, the generic knowledge made universal, such as 'the Māori migration to Aotearoa' and 'Māori were cannibals before the arrival of Christianity' is perceived as being legitimate 'Māori' knowledge (not tribal knowledge). Neither of these items of Māori knowledge 
originate from Māori sources nor do they originate from WHI sources yet they are still treated on the whole as legitimate Māori knowledge.

I will begin by unravelling three inter-related agenda items that we as New Zealand teachers need to know more about.

\section{The moral dilemma of ownership of knowledge}

The answers to the question about what knowledge teachers need if they are going to make a difference to Māori students raises a moral dilemma. In order to acquire this knowledge, that is, to learn it, the knowledge must become things that teachers possess but at the same time such knowledge need not be essential to the being that they are. For example, as an infant or primer, as they were called when I was at primary school, I learned to recite rhymes like 'Hickory dickory dock', to sing songs like 'Frere Jacques', and to read and relate to historical stories like 'Robert the Bruce and the Battle of Bannockburn', but at no stage was I ever convinced I was European because even though these were knowledges that I possessed they were not essential ingredients to my being as a Māori. The acquisition of Māori knowledge poses no threat to a teacher's identity but the mere fact that the teacher has it can make a world of difference to a Māori child.

On the occasions when we did learn Māori knowledge we behaved as children do, that is, we accepted what the teachers told us and even defended our teachers against our parents who often criticised what the teachers had told us. Our parents said things like, 'You don't pronounce his name T'Cootee it's Te Kooti; and he wasn't a rebel either, he stood up for his people against land sharks who were ripping off our people.' We would reply, 'What do you know about history any way, you hardly even went to school and the only book you can read is the Best Bets. Our teachers know about Māori better than you do.'

Sentiments like these have echoed around the corridors of schools and the kitchens of homes for generations. Most teachers still do this grave injustice to Māori knowledge and Māori parents still argue with their children about their teachers 
without either party doing anything constructive about rectifying the problem. I too have been one of those parents and a variant form of one of those teachers: I taught the generic Māori topics like, 'How the Māori came to Aotearoa' and 'How the Māori lived before the white man came' but never really made it personal, and never really attached it to people living today. It was an outdated museum study. The second element of a context for building a Māori knowledge platform for teachers focuses more specifically on the sort of knowledge that might become part of the curriculum.

\section{Particularism versus universalism.}

In Māori terms knowledge is particularistic whereas school knowledge, traditionally, is perceived as being universalistic. This has the potential to pose another dilemma for education, namely, what knowledge should be made available for teaching and evaluating in the classroom? What knowledge should teachers have of their pupils in order to be able to empathise and help them learn more effectively? I think that the Māori knowledge that gets into the learning institutions should be a selection from local whānau/hapū/iwi sources. This follows the same argument that Denis Lawton (1983) makes with regard to his definition of the curriculum for schools. His definition of curriculum is 'a selection from the cultures' that are served by the learning institutions. Not all local knowledge is appropriate in institutionalised settings and nor would these local sources want all their knowledge to be made available publicly if that was possible, which of course it is not.

My argument is that local whānau/hapū/iwi must decide what should be available and how it should be made accessible. In traditional Māori terms knowledge has a spiritual dimension in that it is handed down from one generation to the next and is often referred to as ngā tāongo tuku iho (the treasures handed down). Knowledge is always perceived in relational terms rather than as something fixed in time and space, tuia i runga, tuia i raro, tuia i roto, tuia i waho, tuia te here tangata, ka rongo te po, ka rongo te ao (combined across all space and time). Knowledge is 
specific to place, Mokau ki runga, Tamaki ki raro (the region designated by Mokau above and Tamaki below). Knowledge is tied to one's identity through language, ko te reo te mauri o te mana Māori (my language is the foundation of my being as a Māori). Māori knowledge serves all these purposes and much more. It is contemporary as well as being traditional; it is secular as well as being sacred; it is theoretical as well as being practical; it is both idealist and materialist, otherwise, how could we talk about Māori being and existing in the world if the only knowledge we valued was traditional, ngā tāonga tuku iho? Pākehā do not have a monopoly on 'universalistic' knowledge. Almost 200 years of colonialism cannot deny the liberating effects that European universalising knowledge has had on countless Māori people. But as stated earlier, there has been a price. With particularism comes community, solidarity, connectedness and meaning which is the counter or up-side of what Berger (1979:169) refers to as "the rootlessness of modernity".

The final agenda item for the teaching repertoire in order to contextualise Māori schooling is the separation of socialisation from education.

\section{Distinguishing socialisation from education}

The missionaries were the first to exploit the Māori predisposition and capacity to learn. History books on the Native Schools, ethnographic anthropological studies of the old time Māori, and travelogues of nineteenth-century Europeans are filled with wonder at the Māori capacity to learn from others. With the formalisation of education through schooling and the shift from the original agenda, to start where learners were and progress along paths determined by those learners, to 'this is what we want you to know and how we want you to know it', marked the beginning of the so-called 'Māori problem in education'. By using schooling to socialise Māori, the exercise of 'pastoral power' (Foucault, 1982:782-783) became embodied in what it meant to be educated; it was salvation oriented as part of the 'civilising mission'. The exercise of pastoral power created a condition whereby the logic of the priority, 'the individual over the collective', becomes a matter of 
conscience exploited by the mainstream. Processes of acculturation (assimilation, integration, amalgamation, multiculturalism, mainstreaming) remain unidirectional. Teachers, by what they do with students in classrooms, need to work to make acculturation a two-way process. 


\section{PART III Place and the politics of whānau, hapū, iwi and Māori education : education for all}

\section{Introduction to Part III - Beyond Mediating Structures}

A British academic once wrote, "Education is fundamentally about what people (those in power) have wanted of it and have been able to do to it" (M.S.Archer, 1984). The New Zealand education system is no exception to this assertion even when the only system that existed was the missionary village schools for Māori. The Education Act of 1877 set up the 'shape' of the system, the way it was to be financed, what was to be taught, and who was to control which aspects. The system was to be centralised, run by governing elites, based on the Scottish system, which implied an academic curriculum, assimilationist with regard to Māori, and expected to promote a liberal philosophy.

The system was to establish its hegemony over Māori through policies variously described as Europeanisation, civilisation, amalgamation, assimilation, integration, and today, mainstreaming. The emergence of kaupapa Māori schooling in the mid1980 s posed a challenge to the mainstreaming agenda. Typically, mainstream New Zealand responds negatively to organised Māori attempts to assert their mana Māori outside a perceived Māori context. The 'cultural safety' in nursing debate of the 1990s, the establishment of the first 'kura kaupapa Māori' outside the legal definition of schooling in the mid-1980s, the creation of a Māori television station in 2000, are projects that 'survived' the severest of challenges from the mainstream. The fear appears to be about separate development, even when the leadership of these initiatives (Irihapeti Ramsden, Pita Sharples, Whatarangi Winiata) argue that these initiatives were about giving Māori development a fair chance and not about separate development. Their agendas remain tentatively 'on the table', awaiting final approval, gestating within the collective mind of Pākehā society. 


\section{Mainstreaming and/or Separate Development}

Mainstreaming is a 'way of thinking' as much as a policy that recognises most Māori students in the system choose to be educated alongside all other students under the same conditions as all other students. Mainstreaming is consistent with all other historical policies aimed at assimilating Māori into the general stream of education (integration, taha Māori, multiculturalism, and biculturalism). Mainstreaming always begins by asking what the majority population wants, no matter what the topic (including Māori), and only when that demand has been satisfactorily met, does it turn its attention to asking how Māori fit in, only then does it ask what should be done to satisfy their requirements. Mainstreaming demands that everything done to meet the alternative wants of Mãori, be assessed against mainstream standards/norms/criteria.

Arguments for greater Māori control over an education in their own best interests, for separate development, and for the establishment of a Māori education authority are almost always seen as a kind of threat in which power relations are called into question. The mainstream has not recognised the specific nature of specific problems as they applied to Māori education (loss of language and the relationship to self identity, cultural identity, and cognitive development) because it, that is mainstream, responds as though it has the solution. When and if Pākehā did recognise, or were forced to identify, a specific problem, they constructed the solution in terms which had validity within the experience of their own culture (e.g. taha Māori in the core curriculum).

Māori communities have followed a dynamic need to express themselves within the context of their past and present experience by creating structures which flowed from their perception and understanding of that experience (the Māori Battalion, te kohanga reo, kura kaupapa Māori, wānanga, Māori radio etc. are examples). At the heart of these initiatives is the connection to place through the social organisations of whānau, hapū and iwi (WHI). 
Separate development is about Māori control and claims that Māori must repossess their own knowledge and custom by re-learning, on their own terms, what it is that belongs to them; separate development as Maori control, aims to serve the specific needs of Māori people within a framework of activity originating from, controlled and supervised by, persons who are themselves Māori. At the centre of Māori control is the educational agenda of maintaining, supporting, developing, and promoting Māori language, customs and knowledge.

\section{Beyond mediating structures}

One cannot translate one set of cultural labels into another culture and expect them to be equivalent. The labels are not only in another language, their meanings are often different as are their levels of priority. The relationship between Pākehātanga and Māoritanga has been based on a continuous tension between forces recognising diversity and others recognising assimilation. Because the major factor influencing relations between Māori and Pākehā is that of dominationsubordination, tensions toward assimilation predominate in all state institutions. The current manifestation of this asymmetrical relationship is a rising force within Māoridom that is asserting such goals as tino rangatiratanga (self-determination), and mana Māori motuhake (separate development) both of which have Māori control of their own destiny as the key mission. The desire to create institutions/practices where Māori control, within a Māori context, following a kaupapa Māori, is central and has received increasing support over the last 20 years. Power sharing is the critical factor. Adequate power sharing in key areas of decision-making will ensure that kaupapa-Māori-centred institutions/practices need not become separatist institutions. The delicate balance between the existing mainstream institutions, and kaupapa-Māori-centred institutions rests on factors associated with power sharing such as: (a) whether the provision of KKM keeps pace with the demand; (b) whether the constraints on Māori becoming elected members of boards of trustees can be facilitated; (c) whether the Anga Marautanga o Aotearoa (The New Zealand Curriculum Statement) can be developed from a Māori philosophical base; and (d) whether the system can accommodate the 
development, promulgation, and implementation of educational policy at the highest level where accountability to Māori is satisfied in Māori terms.

These are the themes explored in this final chapter. Education, to work in the interests of all New Zealanders, requires a strong 'mainstream' system, and an equally strong 'kaupapa Māori' system. The potential for an evolution of 


\section{Chapter 09}

\section{Towards a Theory of Education for Aotearoa/New Zealand - Beyond Mediating Structures}

\subsection{Summary}

There can be no authentic Māori education ${ }^{1}$ without a context in which te ao Māori (the Māori world) can find its true expression. There can be no authentic Māori education without its encompassing wairua (spiritual ethos) manifest in te reo Māori (the Māori language). There can be no authentic Māori education that does not set out from the beginning to enhance and strengthen, he tuakiri tangata (a Māori identity). There can be no authentic Māori education that ignores the relationship of tangata (people) with whenua (location) and the rangatiratanga (power and authority) that is embodied in this relationship. There can be no authentic Māori education that fails to recognise and accept the diversity of educations that already exist within our nation state beginning with the Pākehā system (mainstream education).

In Chapter 2 it is argued that the prevailing ideology of Māori education operates in a way that prioritises the processes of socialisation rather than education and is, therefore, a programme based on the mainstream socio-cultural ideology of 'getting them to fit in'. The mediating structures of reports on Māori education (Chapter 5) and processes of consultation (Chapter 6) facilitate this objective.

It is argued in Chapter 3 that the way Māori identity is constructed through processes of schooling, contribute to the 'fitting in'/socialisation agenda, less through the application of external constraints, and instead, through the far more subtle subterfuge of encouraging Māori acquiescence in their own exploitation. The mediating structures that facilitate this objective are described and analysed in Chapter 7 on institutional marae and Chapter 8 on Māori medium schooling.

\footnotetext{
${ }^{1}$ The sociologist, Etzioni suggests that an authentic social arrangement, "is one in which both the reality and the appearance are responsive to human needs" (in Sampson, 1976:502).
} 
The question of agency is raised in each of the chapters on mediating structures to ascertain whether the notion of choice or options, of the possibility of being able to act differently was realistic or not, possible or not, for those engaged.

The role mediating structures play in the education system (Chapter 4) is central to the dominant position of mainstream New Zealand and Pākehā power. On the other hand, like all modern democratic societies, how the education system caters for its diverse communities and ethnic groups is always of critical concern. Māori society has, from the earliest days of the missionary and settler societies, shown its willingness to 'fit in' to mainstream society but at no stage in that history has Māori sought to abdicate or extinguish its authentic identity as tangatawhenua (people of the land), its position as tuakana (seniority) in relation to all other groups, and its relations of partnership with Pākehā New Zealand under the Treaty of Waitangi. It is argued that mediating structures have the potential to both distort as well as transform relations.

It is this latter, transformative role of using mediating structures to shift the emphasis from one of socialisation to that of 'education' that this last chapter addresses. The major premise is that the construction of an authentic New Zealand identity must look to Māori people and their culture for its content. The role education plays in this construction is theorised in what is referred to as an 'imbricated relationship', that is, one that retains the integrity of both/all parties while seeking an education in the interests of all.

\subsection{An education 'to be Māori'}

The need to evoke new 'gods' is more critical today for Māori than it has ever been. However, it is foolish to believe that after about 150 years of cultural imperialism that Māori are seeking a return to the ancient 'atua'/gods for their salvation. For every one who is, there are a thousand who are not; fundamentalism 
is possible everywhere. The new gods include secular reasoning, it includes scientific objectivity and literacy, and it includes an ecologically sustainable vision of our society and planet. It is about asserting what O'Sullivan (1999:225) describes as "a relational totality" and what Māori have always believed to be the primal matrix, whakapapa /genealogy. If Māori were ever in doubt that they would get a fair deal in New Zealand society, the last, almost two decades has completely removed any uncertainty about that. The gaps between 'haves' and 'have nots', between rich and poor, between those who succeed and those who fail, and between Pākehā and Māori have continued to increase despite a series of, what Popper calls 'piecemeal interventions' from governments over generations. According to a report from the Ministry of Māori Development (2000:12) six critical factors affect the rate at which Māori economic development can expand and these are: fewer skilled managers; a low capital base; over-reliance on primary commodity exports; less familiarity with information technology; fewer skilled workers; and multiple-owned land. Māori society is marginalised to the extent that they suffer severely in terms of each of these factors. The report shows significant disparities between Māori and non-Māori in a variety of economic sectors such as in employment and income, in participation knowledge-based industries, in the percentage of Māori students who leave schools with no formal qualifications, in rates of home ownership, and in household income distribution, to name but a few.

If there is an emerging educational vision among Māori it is the desire for an education that enhances what it means to be Mãori; so simple and yet so profound. The sentiment behind the vision is encapsulated in the proverb:

He iti pou kapua, ka ngaro; Ka huna tini whetū i te rangi. (Although a cloud may be small, it may conceal many stars in the sky) Mead \& Grove (2001:77).

Henare (1995) uses the French statement 'plus etre' (to be more) rather than 'plus avoir' (to have more) as the crucial idea behind the current 'Māori renaissance'. Māori would argue that this notion of 'being more' is closer to what Māori would 
aspire to as a people than the latter which could be argued is more the inheritance of Pākehā society, of Western civilisation, of developed nations, of industrialised, modernised, capitalist societies. This does not mean that Māori lack an acquisitive inclination since that is patently not true as tribalism, disputes over territory, and traditional quarrels over boundaries often attest. It is more related to the idea of cultural identity and the loss of language, religion, and the symbolic significance of land that the need 'to be more' takes on a priority. The need is deeply rooted in their recent history of being a colonised people. Since Māori now have comparatively little arable land, whose language and knowledge is at a critical stage in terms of survival, and they, as a people, are so thoroughly perplexed in their apparent inability to sustain themselves as a viable entity within the nation state, that having more of anything is like temptation for 'forbidden' fruits. These fruits are still available to Mãori, so it seems, so long as they accept the hegemony of Pākehā culture.

What Māori really want and need are those fruits that originate in Te Moana-nui-āKiwa, the Pacific and in Aotearoa, New Zealand. These are the fruits that belong to them and for which they have been systematically denied for at least 150 years. This is what it means for Māori today when they assert they want to be more Māori. They want to know their language (te reo Māori); they want their traditional institutions to flourish (the marae, for example); they are hungry to learn about their ancient history as well as their interpretations of colonial history; they are aware their ancestors keenly sought much that belonged to European civilisation, and they want to honour that desire with at least the same amount of vigour as their tūpuna (ancestors) demonstrated; they want to maintain those aesthetics that derive from the Mãori world that make them unique in the world; and more than anything else, they do not want to be limited in any way, in terms of where and how they regain these fruits.

With the advent of te kōhanga reo (TKR-family early childhood), kura kaupapa Māori (KKM-Māori philosophy and language immersion primary school), whare 
kura (WK-Māori philosophy and language immersion secondary school), and wānanga (WAN-Māori tertiary institution) one could be bemused and bewildered by the way the all-powerful education system has turned its back on providing adequate resources for the sorts of initiatives I have suggested in the paragraph above. Pākehā teachers and a significant proportion of Māori teachers have habitually steered away from doing anything that was too seriously Māori. Most have been content to do something like talking about the Māori creation stories, visiting a marae (traditional Māori institution), putting down a hāngi (traditional cooking method), teaching some well rehearsed waiata (song poetry), the occasional haka (posture dance), studying traditional Māori ways and introducing a few greetings and commands in the Māori language, but very few indeed have done anything remotely Māori that progressed beyond kindergarten level. New Zealanders in general might benefit from a deeper cultural understanding of their country but whether they do or not is not the primary concern of this chapter. Māori want a deeper understanding of their country in every way possible because to know one's own land intimately is to know oneself and they want the education system to facilitate that desire. Euripides aptly expressed the negation of that desire in $431 \mathrm{BC}$ :

There is no greater sorrow on Earth than the loss of one's own native land.

The excuse of the majority for this lack of progression is fear: fear of getting it wrong; fear of making a mistake; fear of making fools of themselves; and fear of offending Māori. The reason for minimal progress is more sinister and is aligned with ignorance and arrogance rather than fear. The only reason these so-called fears persist is because the majority of Pākehā do not value Māori knowledge and culture themselves and therefore only consider them of exotic interest, as peripheral activities, and a distraction from the main agenda, which in today's world seems to be the identification of the New Zealander in the global market. Politicians will send Māori cultural groups overseas to accompany them in marketing some economic exchange because Māori indigeneity is a brand that is uniquely New Zealand. Of course, Māori groups do not have to accept being 
patronised but a trip overseas paid for by the tax payer to do 'what comes naturally' and to be feted by international hosts seems petulant to deny on the grounds that your own leadership is exploiting you.

The kaupapa Māori initiatives (TKR, KKM, WK, WAN) mentioned throughout this thesis have received substantial public moneys over the almost 20 years of their existence, nevertheless they are still seriously under resourced given the disparity of resourcing with mainstream comparative institutions. The resourcing has not kept pace with the demand. Millions of dollars have been spent and te kōhanga reo and the other kaupapa Māori intiatives have blossomed. Politicians and officials have been able to say with hands over hearts that they have been supporting the movement and can prove it. Governments have instituted legislation to enable the creation of kaupapa Māori institutions as well as the protection of their specific educational philosophy, Te Aho Matua. The Ministry of Education has been formally involved in negotiated partnerships with iwi/tribal groups to help create educational capacity at the family, community and regional levels. The Education Review Office has been working with KKM to find a review methodology that sits comfortably with KKM while still fulfilling the Review Office obligations to the Crown. The Ministry of Māori Development has responsibilities to monitor the performance government departments and agencies have with delivery of services to Māori. These are all highly important activities and contribute hugely to the success of the kaupapa Māori movement.

\section{Is justice possible?}

Early childhood institutions, primary schools, secondary schools, and even universities can say, we will put up a Māori option but if it is not of a high enough standard or does not have sufficient Māori content, the message to Māori students is, then go to one of these other institutions (kōhanga reo, wānanga etc.) that does offer what you want. This all sounds plausible and reasonable but there are at least two fundamental problems that I can see. Firstly, there are not enough of these other institutions around, that is, there is an access problem. Secondly, this re- 
direction of Māori clients suggests that the system-in-general, usually referred to as mainstream only has minimal responsibility for nurturing Māori history, language, arts and crafts, knowledge, customs and so on - there is an accountability problem. The quantity of Māori content in the curriculum is determined by what Pākehā deem to be sufficient for the population at large, that is, Pākehā society. Māori, like all other New Zealanders, have as much right to an education from the system-in-general as they have to any alternative such as Montessori, Catholic Schools, integrated or private, or wharekura. Twenty years after kōhanga reo most Māori students by far are still enrolled in mainstream institutions and most of those students, it could be argued, choose to be there; it is not a decision by default although that would be an argument difficult to prove or disprove without empirical research. This point is the crux of the matter in deciding how mainstream educational institutions might respond to contemporary developments in Māori education.

A fundamental premise of this chapter, then, is that the epistemological foundations of the educational enterprise in New Zealand must, necessarily, incorporate the 'traditions' of Mãori as well as Pākehā New Zealand. Without at least these two epistemologies and methodologies in education we have the privileging of one culture over another. As the subordinate minority Māori are historically and economically marginalised and as a result experience the ongoing colonisation of their culture. It is not realistic to suggest that the dual epistemologies called for should be an equal one since the Māori population at the time of the 1996 Census was $14.5 \%$ (523,400 people) of the total New Zealand population of 3.62 million people. At that time $83.1 \%$ of Māori were urban dwellers, $37 \%$ of them under the age of 15 compared with $20 \%$ of the non-Māori population (Ministry of Māori Development, 2000:12-13).

The fact that all who call themselves New Zealanders today arrived on these shores on a 'waka' whether that was on a canoe (the Tainui from Hawaiki), a settler ship (the Tory from England), or a plane (a Boeing 747 from Samoa) does 
not alter the fact that when the colonising nation arrived here, Māori were already inhabiting the whole of the country. The fact that the British were from a culture technologically more advanced than the Māori is, in social justice terms, immaterial to that prior fact. The suggestion that the British were a more enlightened nineteenth century colonising nation than some of the other European countries is immaterial. The fact that the British considered the Māori culturally superior to other indigenous peoples is immaterial. The only thing that is material is that the British took over Aotearoa, made it New Zealand and shaped it in their own image as though those who were resident did not matter. Māori education as perceived through the eyes of Māori are saying that being Māori does matter and that the education system, especially through the compulsory years of schooling must do much better in incorporating a Māori knowledge base through pedagogies based on Māori aspirations. This chapter has focused only on the first of these agendas, a Māori knowledge base within an appropriate context.

\subsection{Toward a theory of schooling}

What is needed in mainstream education, certainly for the compulsory sector, is a theory of schooling. To develop a theory of schooling we will also need theories of knowledge, of pedagogy, of child development, of learning, of assessment and evaluation, of the curriculum, and of community relations. None of this is easy to do but one would expect that a system of schooling that has been centralised, universal, and compulsory since 1877 would have a coherent philosophy of education tucked away in a text book somewhere. I suppose kura kaupapa Māori being a relatively new option could be expected to have such a theory of kura kaupapa Mãori schooling and indeed they do; Te Aho Matua is the name they give their philosophy and it is a theory of kaupapa Māori schooling.

In considering a theory of knowledge, or a theory of pedagogy, or a theory of any other aspect of education, consideration of the deep conceptual structures is called for (Young, 1983). In a simple version of systems theory, for example, inputs like 
ecological factors (geographical area, parental choice, and teacher-pupil ratios), school processes (academic emphasis, rewards and punishments, staff stability and expertise), and intake factors (socio-economic status, and ethnicity) must be empirically related to school outcomes such as academic attainments, ability to converse and communicate in the Maori language, attendance, participation, acceptable behaviour, enhanced job prospect and so on. To make an empirical distinction between school outcomes (those factors in the experience of pupils that are thought of as the effect or outcome of going to school) and what was done or needed to cause these effects, an explicit theory of schooling has to be developed otherwise the factors that are abstracted cannot be said to represent in some faithful way, the reality of school.

The reality of schooling as experienced by Māori makes schooling for the majority of them a fundamentally flawed experience to the degree that accusations of educational malpractice (Baugh, 1999) are not over-statements of their reality.

The current debate revolves around the strengthening of Māori education in both mainstream and kaupapa Māori. The idea of governance issues and the notion of a Māori Education Authority is the most recent development but is little more than the manifestation of the continued frustration of Māori to influence the system in a way that gives them an advantage.

A constant thread throughout these developments is a politicisation process where questions of representation, legitimation and voice are countered by the rhetoric of a conservative backlash arguing issues of separation, control, and authority.

The existing education system will never work in the real interests of Mãori so long as the central philosophical assumptions of the education system remain entrenched in the Western tradition. The TKR/KKM/ WK/ WAN developments are premised on the belief that 'Māori have the right to be Māori', that the existing education system will not deliver on that belief to the extent that the majority of 
Māori in the system will fail to gain an education, and that the only path to redress past and present injustices is to develop a separate system. The focus of the kaupapa Māori initiatives keeps the debate on Māori terms and is both an educational and a political agenda. The majority of Māori students remain in mainstream institutions; the introduction of at least two epistemological traditions into schools, it has been argued, can make a difference in the performance of all students in the New Zealand education system.

\subsection{Whānau, hapū, iwi education}

Organising education in the real interests of the community is the focus for this concluding chapter.

What counts as 'real interests' needs to be explained. According to Steven Lukes (1974: 34-35) "real interests are connected with (relative) autonomy and choice". I will argue that so long as the organisation of education at the levels of whānau, hapū, and iwi remains problematic the real interests of Māori will never be addressed. Organisation of education at whānau, hapū and iwi levels are necessary because Māori parents could then judge what they wanted and preferred, were they able to make the choice.

An education system of any size or description can only run efficiently and effectively when it is organised well enough to answer these kinds of questions to the satisfaction of those for whom it was meant to serve. A whānau/hapū/iwi education system would be expected to satisfy the same criterion for its clients with one further major problem to address: even if the majority of Māori wanted such a community based system would the existing mainstream system support such a move? According to Archer (1984:1):

\footnotetext{
Change occurs because new goals are pursued by those who have the power to modify education's previous structural form, definition of instruction and relationship to society.
} 
If this is true the establishment of a parallel community-based Māori system is extremely problematic. The mainstream system has proven over generations that it is not able to facilitate the improvements to Māori education performance it says it wants, even with the approximate one fifth of Vote Education (Making Education Work for Māori, 1997:9) dedicated to that purpose. Among Māori, at least two developments lend some credibility to arguments for support at the local level: firstly, the growing pressure from Mãori society for greater control of their own health, justice and education, and secondly, a slowly developing pool of expertise of Māori with managerial skills, administrative, analytic and academic know-how. The pool of expertise is the key component and no amount of posturing about Māori control will solve the problem of improving the organisation and delivery of Māori education at the level of whānau, hapū and iwi.

\section{The politics of educational change}

These questions cannot be addressed satisfactorily without developing a system which is well organised and which has some idea about where it is going, or at least, where it wants to go. Up to the last decade at least, the Department/Ministry of Education has had a more or less unfettered influence on the educational direction of the system, which is not to deny the influences of the political economy on it, but in today's market model educational environment (Middleton, Codd \& Jones, 1990) the Ministry struggles to maintain its hegemony over its own portfolio. There are several reasons for this: the rise of political conservatism, the growing globalisation of economies, the transformation of information technologies, and the human rights revolution to name but four. Several of these international phenomena also account for the educational changes that have emerged among Māori but it is probably the last of these that Māori society has mainly taken advantage of. Up to now Mãori aspirations have figured only minimally in giving direction to an education in their own interests let alone the system as a whole. That is not the case today. Durie (1998:17) describes the Māori capacity to: 
take advantage of changing situations in order to realise aspirations for cultural, social and economic advancement.

It might be suggested that Māori do not take advantage of schools in a way that they should. Is this because they can't, don't know how, are not really allowed to, or because they want their own schools?

\section{Problem definition}

The New Zealand education system, even before it could be justifiably described as a system, provided the strategic direction for Māori education. From the mission schools of 1816 to the native schools of 1867, to the Māori schools of the 1950s and $60 \mathrm{~s}$, right through to the kōhanga reo and kura kaupapa Māori of today, the government and its educational agencies have been directing and shaping, to a considerable degree, the Māori education option. This is not to suggest that Mãori have not contributed to these initiatives, in fact the opposite is true. However, Māori have been the least influential party in the resourcing decisions that have shaped these schools.

To quote from Archer (1984:2) again, Māori must have really lost badly because:

to understand the nature of education at any time we need to know not only who won the struggle for control, but also how: not merely who lost, but also how badly they lost out.

The education system has not worked for Māori in the 120 years since the original Education Act and no amount of piecemeal adjustment is going to change that nor any systemic reform. We must look elsewhere for solutions.

\section{Strategic directions}

The strategic directions underlying the state's support for Māori education were at different times: to Christianise, to civilize (Simon, 1992), to pacify (Nash, 1983), to assimilate (Shuker, 1987), and in today's environment, to revitalise (Smith, 1997). In only the last of these directions can the state be seen to be acting, even remotely in the interests of Māori. All the other strategies have seen the state 
impacting on Mãori but acting in the interests of the Pākehā population; this is the colonial legacy.

If Māori had to be convinced it was alright to be Māori and it was alright to be an educated Māori - and it seems many did need to be convinced - then the kōhanga reo movement, kura kaupapa Mãori, kura tuarua, and whare wānanga revolution has signalled the efficacy of a Māori inspired and operated system. The administrative or guardianship bodies which have arisen out of these initiatives, namely, the Kōhanga Reo Trust, Te Rūnanga nui o Ngā Kura Kaupapa Māori, and Te Tauihu permit a certain degree of confidence in those whose spirit and sweat rests with ensuring the successful operation of the kaupapa Māori system along side those actually in the institutions. These guardianship bodies are a communicative link, have a negotiation role, and provide policy advice to government education agencies on their respective organisations. The definition of the problem from the point of view of these Māori inspired organisations is that the system, at least for Māori, is broke and the best thing for Māori to do is to create their own system. The point of view of the existing system is that the system is not broke, not even for Māori, but must continuously improve its performance for everybody. Cracks are appearing in the establishment system. Mainstream reports on Māori education continue to be produced but the Cabinet decision to develop a long term strategic plan to improve Māori education is the first time this has ever been done by any government. At the heart of the problem (according to the system) are issues about differential achievement and participation.

\section{Assessment and performance}

The achievement gap between Māori and non-Māori has been an embarrassment to governments for at least 30 years. Over that time explanations have gradually shifted from deficit (blaming the victim) theories, to school inadequacy (blame the teachers) theories, to resource provision accountability theories. There is no empirical reason to believe Māori educational achievement levels are any worse today than they were three decades ago. The problem is they are hardly any better 
either although the survey by Chapple, Jefferies and Walker (1997) suggest there is some room for optimism in some areas, tertiary for example. The achievement gap is not referring to the gap between how well a student is performing and how well the student could or should be performing, but rather how well a Māori student at a certain level of the school is performing in science, for example, compared with a non-Mãori student in similar circumstances.

I have highlighted three components in a definition of the problem facing Mãori education: firstly, the need for Māori to contribute universally to the decisions related to an education in their own best interests; secondly, the need for Māori at the level of whānau/hapū/iwi to be better organised all-round so that they can mobilise their own mita (tribal dialect), tanga (tribal culture), and ranga (tribal leadership as in ranga-tira); and thirdly, certainly not to avoid the problems of differential achievement but rather to prioritise data about performance on the basis of information directly related to students and those with an immediate vested interest in their learning, that is, whānau and teachers rather than policy decision makers.

\subsection{The best of both worlds - A theory of education for all}

Developments in Māori medium and kaupapa Māori schooling have accelerated over the last 20 years. These developments have certainly captured the Māori imagination and have had a catalytic effect on whānau/hapū/iwi in terms of politicisation and a growing confidence in asserting the notion of 'being' Māori. There is still very little research in the field that can be used to substantiate increased resourcing on the basis of improved student performance as a result of Māori medium or kaupapa Māori intervention but neither is there any research which can be used to support a slow down or a shift away from continuing Māori medium provision. 
The only tangible, material, and measurable change in Māori education over the last 30 years is the growth and demand for Māori medium education. In the 5 year period between 1992 and 1996 the schools offering Mãori medium programmes increased from 318 to 1,129 , an increase of $255 \%$; the number of students represented in these figures over the same period increased from 17,426 to 33,438 , an increase of $92 \%$; while the number of non-Māori enrolments in these same programmes increased from 1,375 to 5,769 , which is an increase of $320 \%$.

Sir Apirana Ngata's famous visionary aphorism about pursuing the benefits of a dual heritage is as forceful today as it has ever been. Throughout the consultations outlined in Chapter 6, Māori parents were adamant their children should be exposed to the 'best of all worlds'. Most were not interested in restricting their children's education to any single world, Māori or Pākehā, sacred or secular, individualistic or communal, practical or academic. In classical postmodernist terms they wanted their children to inherit a rich spiritual, cultural and materialist world - what is more Ngata-related than that?

If the essence of Pākehā post-industrial, capitalist, market-oriented society is about the priority of possessive individualism (Handler, 1985, 1991) above everything else then that will not meet the standards of a future Aotearoa New Zealand society. If the essence of a Māori society in the future is about the priority of communality (Friedman, 1992; Johnston, 1989) above everything else, then that is merely the negative reflection of Pākehā society and is equally deterministic and reductionist in relation to the standards of a future Aotearoa New Zealand society. There is a moral poverty inherent in both models but Māori society suffers disproportionately because it does not have control of the resources, either material or symbolic, to mobilise its ideologies; it has to learn to make do with the benefits of goodwill within Pākehā frameworks and priorities.

Goodwill is a necessary condition but is not sufficient if learning to live together in Aotearoa New Zealand is to shift to a new benchmark in social relations. In very 
recent times, history has shown us how vulnerable relations between different peoples can be even when the difference is not obvious as in wars related to religious belief. Witness the atrocities in Northern Ireland, in Yugoslavia and the skirmishes among the Bosnians, Croats, and Serbs, as well as the terrible genocidal slaughter of Hutu tribesmen by the Tutsi. Only the arrogant, complacent and misguided could ever believe race relations in New Zealand were so sound that volatility on a scale similar to that experienced in Northern Ireland, Yugoslavia, and Rwanda could never happen in New Zealand.

\section{Principles for change}

The question for us today, as educational brokers for the next generation, and as the inspirational leaders of Māori society in the future is, are we going to be better organised to make things happen to our advantage or do we follow the well-worn paths of complaining about our circumstances, displaying our envy of those who have more of anything than we, and railing against those whose pace in pursuit of change sets the pace? The education system as it stands has much to do to address the inequalities between Māori and non-Māori but Māori have just as much to do to address the inequalities among its own peoples.

Māori society has a problem, that is, the uneven development of Māori education across and between whānau/hapū/iwi and the state education system. The solution, I argue (Penetito, 1998) is to improve whānau/hapū/iwi education by organising consciously, deliberately, and systematically at these levels right across the country. The expertise of the existing state system needs to be used in the interests of whānau/hapūiwi to organise education for whānau/hapū/iwi. It needs to because the system is already paying for it now with all the ambulances at the foot of the cliff, and with all the reports spelling out once again what the problems are but not fixing them. 
I suggest four basic principles should underly whānau/hapū/iwi education development:

- Māoridom as a whole is only as strong as its weakest iwi (benefits need to accrue to all iwi);

- Whānau/hapū/iwi survival depends on how well each is organised to ensure voice, history, tikanga, mātauranga, moteatea, and so on, and is recorded and offered to the rising generation as worthwhile knowledge;

- Community-based Māori education shifts the emphasis away from the over-powering influences of the central bureaucracies and assists in strengthening the sense of community, of whanaungatanga through establishing what Ivan Illich calls "convivial" institutions (Macklin,1976:914); and

- Urban-based Māori are sufficiently different from rural Māori to warrant education plans specifically designed in their interests.

We need to be content to follow Antony Flew's (1971:402) good advice at this time:

It is not necessary to hope in order to act, nor to succeed in order to persevere.

\section{Whānau/hapū/iwi education (WHIE) plans}

Strategic plans for Māori education originating from the existing system have only just preceded those that emanate from Māori sources - both have something to learn from each other; both can contribute to the design of each other's plans; both are needed if Māori education is to cease being an instrument for assimilation; and if whänau/hapü/iwi education is to make the sort of contribution for its young people it needs to make, then it needs to learn from the existing system. It needs to learn what to do as much as what not to do. 
The vision for change stated earlier was Māori control of Māori education. The idea has been in the public sphere, in a formal sense, since at least 1984 according to a discussion paper from the NZEI Māori group, Te Reo Areare. It seems the consensus in the logic behind Māori control is tino rangatiratanga (absolute authority), following the Treaty of Waitangi (Tapine and Waiti, 1997). The practicalities for implementation usually revolve around making decisions without the imposition of Pākehā veto; legitimate promotion of te reo Māori, tikanga and mātauranga; and accountability of the system to whānau/hapū/iwi.

I will argue that tino rangatiratanga, like autonomy, is a relational rather than an absolute concept so that interpretations like "unqualified exercise of chieftainship" (Kawharu, 1989:22) is impossible to understand if chieftainship, as part of its meaning, includes others who follow. Is a chief a chief if there are no followers, in which case the notion of chieftainship is qualified. Of course, a rangatira based on whakapapa is always a rangatira whether s/he chooses to exercise it or not or whether others choose to recognise it or not. However, this is not the same as 'tino rangatiratanga' that does require exercising and recognising.

Another way of looking at this issue is to claim rangatiratanga for relations between Māori and Māori and tino rangatiratanga for relations between Māori and Pākehā. This reading would, at least be historically correct and is probably closer to the mark in terms of the argument put forward in this thesis. My argument is more attached to the concept of kotahitanga (Cox, 1993:6) or solidarity through being united in a cause, than self-determination that might be a consequence of increased kotahitanga but is not my thesis at this time. Earlier attempts to build solidarity like kīngitanga and kotahitanga though Pāremata Māori (Māori Parliament) were mana motuhake (separate development) motivated, that is, to assert separate iwi and Māori authority and control over lands and possessions. Of course, circumstances have changed dramatically since the middle 1800 s yet some of the critical issues like authority and control persevere. I think it is important to pursue win-win strategies where one can. Where tino rangatiratanga (self- 
determination) and mana motuhake (separate development) will always attract negative responses from the establishment for whatever reasons, no one will oppose people getting together to improve the education of their young ones.

\section{Empowering 'voices from the margins'}

The goal for devising a strategic plan for Māori education is to improve the education of all Māori but especially those between the ages of 6 and 16, the compulsory school years. The problem to be addressed is how to do that. Virtually all the traditional resources for education reside within the existing system, that is, money (Vote Education), expertise (teachers, researchers, bureaucrats), and physical structures (early childhood centres, schools, tertiary institutions).

The existing mainstream system is also where most Māori students are enrolled. In most cases they have no choice about this; the centralised system of the last 100 years has put paid to virtually all independent Māori education activities. The native schools, later to be renamed Māori schools were mainstream schools. Private Mãori church colleges were at one time independent but are now all integrated and therefore part of mainstream schools. The kura kaupapa Māori movement purposefully manoeuvred to see its institutions embedded in legislation so that the system was required to assist, support, and resource them and not leave this form of schooling to whānau to resource. Like kura kaupapa Māori, kōhanga reo and wānanga have been mainstreamed.

There is no romantic notion in the kura kaupapa Māori movement about marginality, being at the fringes, resisting from the borders, or being radically 'other'. Their challenge to the dominant hegemonic discourse is from the inside out and from the outside in. They have made it clear they want for their children what the dominant society and its powerful groups want for their children (Nepe, 1991; Smith, 1997) and they want the benefit of their own Māori cultural heritage imparted through the education system. The demand is for radical change. The 
question is, what should be the locus of change given the basic principles listed earlier?

Critical mass is an important factor in capturing resources which means the number of Māori students either opting into kura kaupapa Māori or at least into Māori immersion programmes must increase dramatically every year until the majority of Māori children are in these programmes. This is necessary at this time because the establishment is using the fact the majority of Māori students are not in kura, and by implication, their whānau have made that a deliberate choice, to rationalise increases in resources rather than plan to meet the demand. There is no way of knowing whether that is true or not given most Māori families do not have easy access to kura.

Another important consideration for "an organising force that can change the hegemonic directionality of historical-geographical change" (Harvey, 1996:104) is the idea of "standpoint, of location, and of place" (ibid.). This idea is critical for interpreting the debate in Māori terms. Wren (1986:xv) states this point succinctly:

\footnotetext{
If we know we must take sides, the art of naming who we are supporting, who opposing, is a necessary step. It brings us out of the sheltered haven of rhetoric, into the ocean of real risks and real voyages. Say who and what you are FOR and who and what you are AGAINST.
}

Essential components of place in Māoritanga relate to tūrangawaewae (literally, the place where you have the right to stand), papatipu (the place where you belong before the granting of legal title), papakāinga (your home village or marae), whenua matua (homeland), kainga (home), and mana whenua (lore of authority and control related to land).

The Māori modern diaspora, from rural marae to the cities, and then from the cities to the international megalopolis like Auckland, Sydney, New York, and London has no more weakened Māori as a people than the traditional 'hekenga nui' from 
Hawaiki to Aotearoa. Indeed, we may in fact be enhanced by these experiences. In the words of bell hooks (1990:104):

\begin{abstract}
one confronts and accepts dispersal and fragmentation as part of the construction of a new world order that reveals more fully where we are, who we can become, an order that does not demand forgetting.
\end{abstract}

\title{
9.6 Whānau/hapū/iwi 'identity' as the locus for intervention
}

It is difficult to hear or read anything in Māori education that does not in some fundamental way link back to issues about identity. Identity is a much travelled concept in the academic literature (Hall \& Du Gay, 1997; Brock \& Tulasiewicz, 1985). In Māori education, focusing on identity was commonly put forward in past eras as a solution to combat problems of inadequate socialisation. Today the focus has shifted to correcting structures rather than personality, or child-rearing patterns, or cultural norms although these persist.

Common questions and answers continuously reflect the priority of identity concerns: why is there a problem with Māori student school performance - because the cultural discontinuity between Māori student home and family and the institution of school are gross; how will learning the Māori language improve Māori student educational performance - it will help them feel positive about themselves as Māori which is a necessary ingredient in their ability to successfully contest the ethnocentric values and sometimes racist practices of the school; how will the establishment of a Māori education authority improve the delivery of education to Mãori - it will do exactly what the system does now and with the equivalent bias but in favour of Māori rather than the dominant system; and what is it that accounts for the perceived success of kōhanga reo and kura kaupapa Māori - they acknowledge the Māori world as a valid option to be maintained in everyday life.

The state choice of loci for intervention throughout the history of Māori education has varied depending on the politics of the different times. Among Māori the focus 
for attention has gradually tightened around concerns to do with ownership, accountability, and control (Durie, 1995, 1998; Mahuta, 1993). Up to now the state has kept an iron grip on issues of control but in recent years ownership has arisen as a contestable idea.

The Secretary of Treasury during the peak of the state reforms, and latterly an international consultant, asked the question in a newspaper article, "Would society fly asunder were the state not to run our schools?" (Scott, The Independent, 1993). Ten years earlier it is inconceivable the question would even be contemplated. Accountability is almost a slogan today as governments push more and more of the responsibility out from the centre to the regions, but one should hasten to add, that contrary to commonsense knowledge this does not mean governments would have less control. Indeed, they have even greater control as a result of increased choices, tighter regulations, more precise legislation, eliminating the choice between compliance and non-compliance, and other similar control devices, all based on the principle of the institutionalisation of authority.

As already shown, educational intervention at the level of iwi has had some effect although it is difficult to substantiate, with any objective published evidence, the level of effectiveness. Educational intervention at the level of whānau, as already argued earlier, has had a profound affect on the Māori psyche as well as attracting a great deal of support from whānau and resources from the system (Smith, 1995). It is much more difficult in the context of Māori education to find support for intervention at the level of hapū or community (Marshall \& Peters, 1990). And yet, by far the most common form of education, that conducted through schooling, has traditionally occurred at the level of the community. One can only suppose the power of the reductionist ideology (families are no more than the sum of individuals from which it is composed; communities are no more than the sum of families from which they are composed; and societies are no more than the communities from which they are composed) also operates in the Māori community and yet the embedded notion of kin-based whānau/hapūiwi makes a 
mockery of that deduction. The more likely explanation is that the three forms of social organisation are probably taken for granted among Māori. This is not good practice either. The current legal debate about what constitutes an iwi (tribe) will also, inevitably, end up defining hapū (sub-tribe) and whānau (extended family) as well. This seems to be acceptable from the point of view of governments and the legal system because as Sheleff (1997:309) argues:

In the final analysis, law deals with social control, and the key question then becomes whether social control is to be extensively imposed and rigidly enforced, or whether it is to be no more than a flexible guideline for action.

From a Māori point of view the basic question is, can the law be trusted? Māori need to look at the ideology of iwi-tanga (or for that matter hapū-tanga and whānau-tanga) and ask, how does the formation of an entity called iwi occur? To paraphrase from Harvey (1996:99), "an iwi exists only as long as its specific enjoyment continues to be materialised in a set of social practices and transmitted through national myths that structure these practices" (emphasis in original). On this basis whānau certainly exists, albeit in a multitude of various forms in today's world, and can usually be located in places of residence (houses, flats, apartments, caravans). Multiplicity of forms is not new to Māori (Metge, 1995:51-60) but the additional constructions from the modern world add a complexity not envisaged in the traditional Mãori milieu.

We can also argue, hapū certainly exist and are usually located in residences close to a marae and form a village, community or Pa. Iwi, with some stretch of the imagination, constitute collectives of hapū. In many cases they are no longer geographical entities in that hapū associated through whakapapa with an iwi can be territorially in a different part of the country in today's world.

Enjoyment is a function of the number of occasions each whānau, hapū, or iwi can get together for some social practice that is meaningful for the whole (from experience each of these types of hui are reasonably frequent but seem to be more difficult to attend with each passing generation). Whānau hui are probably more 
common on occasions like re-unions, birthdays and other celebrations like Christmas. Hapū hui would include tangihanga, weddings, land meetings, and marae meetings; they tend to be more formal. Meetings at the level of iwi are usually less frequent, and deal with political issues such as raupatu, and other matters which might impinge on the mana of iwi. Enjoyment among Māori is usually a high priority at every level of social organisation.

My only interest at this point is to suggest what might be in an education philosophy for whānau/hapū/iwi and not to prescribe one. Since first being introduced to a very modest paper written by Bawden entitled, 'Praxis: The Essence of Systems for Being' (1991), I have been excited by the possibilities the paper raises for a Māori educational philosophy. His system illustrates three ways of knowing:

At the apex of the triangle is the idea of 'learning to be'; it relates to the experiences we have in life; it is about process. This is the dimension that mainstream schools and teachers are least successful with in dealing with Māori students. It is that part in the experience of school life which helps you to engage or to lose your way. It is reflected in the culture of the school. It is that aspect of school life that helps you to understand the interplay of passions, emotions, rationality and intellect - what Harvey (1996:11) refers to as "understanding processes of valuation".

An educational kaupapa has to spell out in some detail those experiences that count toward what it means to 'be' Māori. This section is highly vulnerable to stereotyping and propagandising yet, can there be any doubt schools in France, America, or Japan expect their children to graduate from their schools as young people who identify as French, American, and Japanese as well as being literate, numerate and contributing members of their respective societies? 
'Learning to know' is about propositional knowledge, it is about some thing, and is often expressed as fact or theory. Curriculum statements are filled with the content of what counts as knowledge. What is it that whānau/hapü/iwi believe their young people should know when it comes to understanding what it means to belong to whānau/hapū/iwi?

In 'Education Indigenous to Place', Kawagley and Barnhardt (1999) of the University of Alaska, write about a topic very dear to those involved in developing whānau/hapū/iwi. Māori need similar work to be done in every iwi geographical area, across all the disciplines, and relevant to all the stages of human development. Reclaiming whānau/hapū/iwi histories must be an important element in the knowledge-to-identity equation and one everybody can get involved in.

'Learning to do' involves the exploration and discovery of personal meaning; it is the place to resurrect the waning 'oral tradition'; it is about constructing the opportunities for learners to contribute (Hampton, 1995). Learning the words of a karakia (incantation) means doing a karakia at some authentic moment. Knowledge about harakeke (flax) has to be tested in activities related to planting, transplanting, pruning harakeke and so on. Understanding the transformational geometry in kowhaiwhai (design patterns) is important but even more so when the kowhaiwhai can be reproduced and even transformed.

\section{'The mobilisation of bias'}

The many important questions, as well as the kaupapa, have to have the right context in order to produce the kind of result that will make the difference in Māori student learning everywhere. By right context I have borrowed Schattschneider's phrase (in Lukes, 1974:17) 'mobilisation of bias' to give Māori a deliberate advantage in organising their own system independent of the influences of the mainstream system until such time as they feel prepared enough to decide whether to integrate and/or to separate and/or to imbricate. The need for this sort of advantage is played out in related activities such as TKR and KKM 
policies that keep researchers out until such time as these institutions feel strong enough and are coping well enough with what they are doing before allowing doors to be opened to the critics. This seems to me to be a sensible and reasonable response especially where innovations derived from Māori sources are concerned.

\subsection{Being Māori 'goes all the way down'}

There are many ways to be Māori but some things remain constant. In Māori terms, the collective has priority over the individual. The individual can only become truly a well-developed individual by evolving a consciousness of self in relation to objects (people, things, events etc.) outside or beyond the self. This state of consciousness is what Johnston, the Canadian legal scholar refers to as 'the self-collective'. One cannot avoid the essentialist nature of the Māori interpretation of the individual and nor is there any need to; e kore koe e ngaro he kakano i ruia mai i Rangiātea (you will never be lost (because) you are the seed sown from our origins - a proverb). In Māori-eyes, to seek justification for the Māori perspective is to admit they are merely brown versions of Pākehā. As Royal (1998:80) explains, 'He mea hanga te mātauranga na te tangata Māori kia mārama ai ia ki tōnā Ao, kia mārama rānei te Ao ki a ia' (All theories of human development are the outcome of investigations of events and processes, the object of which is to explain how these events and processes work or how they come to be). After more than 200 years of association with Pākehā, nobody should be surprised that the essentialist nature of the Māori being has also developed a constructivist identity usually packaged in terms of being bicultural. The world is full of influences and all of these have contributed in some way to the changing Māori perception of self. Such influences include urbanisation, inter-marriage, higher levels of formal education, growth of a middle-class, development of an indigenous consciousness, international travel and much more.

The cultural revitalisation of the 1980 s can be described as reactionary in that there is something of a return to a golden era culturally speaking, but reactionary in itself is far too conservative. The last 20 years can be characterised as being 
profoundly socially-critical in the sense that the Mãori perception that all time exists now and the future has to be organised in order to consider a new, radically different vision of humanity and society. The socially-critical accepts that all time exists now and turns to the future to create a new, radically different vision of people and society. The claim, as I have argued throughout this thesis, is that the future in education in Aotearoa is about Māori and mainstream education and the overlap between the two. Māori education should be focused on the tangata-Māori status of Māori as the indigenous people of this country. Its purpose is to strengthen the Māori cultural base. Mainstream education should be focused on the tangata-Pākehā status of Pākehā as the majority population of this country. The imbricated relationship is a function of the negotiated relationship between tangata-Māori, tangata-Pākehā and all other tangata of this land. Who knows best on any matter leads the way.

There is no question about the fact that Māori as tangatawhenua want, what the philosopher Dworkin (1978 cited in Phillips, 1986:287) stresses as the desire to be treated equally as their fundamental right. Under the law of the land, and in most cases, this right is realised. But Māori want more than that - as tangata-Māori (those who choose to be identified as Māori) they also want to be treated as equals. That has still to be achieved and paradoxically, is dependent on non-Māori New Zealanders choosing to know more and more about what it means to be tangata New Zealander, one who belongs to the land instead of owning it. 


\section{Appendices}

\section{Appendix 5A}

Part 1 (1960-1977): 'Ka awhi noa i waho...'

Reports on Māori education

Report 1 Report on Department of Māori Affairs - With Statistical Supplement. (1960). J.K. Hunn (Chairman), Wellington: Government Printer. [R]

Report 2 [Focus] Report on the Commission on Education in New Zealand. (1962). Sir G.Currie (Chairman), Wellington: Government Printer [R]

Report 3 Watson, John E. (1967) 'Horizons of Unknown Power - Some Issues of Māori Schooling. Wellington: New Zealand Council for Educational Research. [M]

Report 4 [Focus] Report of the National Advisory Committee on Māori Education (1970). Mr J.L.Hunter (Chairman) [R]

Report 5 [Focus] Department of Education. (1971a). 'Māori Children and the Teacher'. Prepared by School Publications Branch. Wellington: Government Printer. [HB]

Report 6 Department of Education. (1971b).'The Education of Māori Children - A Review'. Education, 20(4). School Publications Branch. [HB]

Report 7 Bender, Byron W. (1971). Linguistic Factors in Māori Education - A Report. New Zealand Council for Educational Research. [M]

Report 8 Watson, John E. (1972). 'Accommodating the Polynesian Heritage of the Māori Child - A New Zealand Problem'. Wellington: New Zealand Council for Educational Research. [M]

Report 9 [Focus] Report of the Committee on Communication Between Schools and Parents - 'Parent-School Communication'. (1973). Mr J.G Johnson (Chairman), Department of Education, Wellington. [R]

Report 10 Report of the Curriculum Review Group on the Education and Training of Secondary Teachers - 'Teachers in Change'(1974), Mr R.G.Munro (Chairman), New Zealand Post-Primary Teachers' Association. Longman Paul Ltd. [R]

Report 11 [Focus] Report of the Committee on Secondary Education - 'Towards Partnership'. (1976). Hon. Sir Terence H,McCombs (Chairman). Wellington: Department of Education. [R]

Report 12 Report of the Task Force on Economic and Social Planning - 'New Zealand at the Turning Point'. (1976). Professor Frank Holmes (Chairman) [R]

Report 13 Report of the Committee on Health and Social Education - 'Growing, Sharing, Learning'. (1977). Mr J.G.Johnson (Chairman) [R] 


\section{Appendix 5B}

\section{Part 2 (1978-2000): 'Ma te kanohi miromiro'}

Report 14 Campbell, Dr E.M. (1978). 'Realities of Curricula'. Department of Education. [R]

Report 15 [Focus] Report of the National Advisory Committee on Māori Education (1980). 'He Huarahi'. Mr P.W.Boag (Chairman) [R]

Report 16 New Zealand Educational Institute. (1981) 'Te Tatai Hono' - Report and Recommendations on Māori Education Presented to 1982 Annual Meeting. John McCaffery (Chairman). [R]

Report 17 The Report from the Conference on Priorities in Multi-Cultural Educational Research, Department of Education (1981). 'Priorities in Multi-cultural Educational Research' [CR]

Report 18 Race Relations Conciliator (Hiwi Tauroa). (1982). 'Race Against Time'. Wellington: Human Rights Commission. [R]

Report 19 Maori Education Development Conference. (1984). Turangawaewae Marae, 23-25 Mar. Sponsored by New Zealand Māori Council. [R]

Report 20 [Focus] Department of Education. (1984). 'A Review of the Core Curriculum for Schools'. Wellington. Mr J.A.Ross (Chairman). [R]

Report 21 Ministerial Advisory Committee on a Māori Perspective for the Department of Social Welfare - 'Puao-Te-Ata-Tu' with Appendix. (1986). Wellington [R]

Report 22 Finding of the Waitangi Tribunal Relating to Te Reo Maaori and a Claim Lodged by Huirangi Waikerepuru and Ngā Kaiwhakapumau i Te Reo Incorporated Society. (1986). Edward T. Durie (Chairman). [R]

Report 23 Scott, Raymond A. (1986). 'The Challenge of Taha Māori - A Pākehā Perspective [M]

Report $24 *$ The Treasury Brief to the Incoming Government (1987) [BP]

Report 25 Benton, Richard. (1987). How Fair is New Zealand Education? Part 2 'Fairness in Māori Education - A Review of Research and Information. (For Royal Commission on Social Policy). New Zealand Council for Educational Research. [M]

Report 26 Report of the Committee to Review the Curriculum for Schools. (1987). 'The Curriculum Review' Department of Education. Mr Peter Brice (Chairman). [R]

Report 27 [Focus] Report of the Task Force to Review Education Administration 'Administering for Excellence'. (1987). Mr B.Picot (Chairman). [R]

Report 28 Penetito, W.T. (1988). 'Māori Education for a Just Society', in 'The April Report', Report of the Royal Commission on Social Policy, Vol. IV, Social Perspectives, pp.91-114. [M]

Report 29 *The Matawaia Declaration (1988) [M]

Report 30 Report of the Maaori Affairs Committee (1995, 1996). 'Te Uiuitanga Mātauranga Māori - Inquiry into Māori Education. Mr K.T.Wetere (Chairman) $[\mathrm{R}]$ 
Report 31 [Focus] Chapple, Simon; Jefferies, Richard \& Walker, Rita. (1996). 'Māori Participation and Performance in Education - A Literature Review \& Research Programme. Report for the Ministry of Education. New Zealand Institute of Economic Research (Inc.). [RM]

Report 32 [Focus] Report to the Minister of Māori Affairs (1998a, 1998b, 1999a, 1999b). 'Maaori Education Commission, Reports 1-4, Feb/Aug/Feb/Sept. [R]

$$
\begin{aligned}
& \mathrm{R}=\text { Reports } \\
& \mathrm{M}=\text { Monographs } \\
& \mathrm{RM}=\text { Research Monographs } \\
& \mathrm{CR}=\text { Conference Report } \\
& \mathrm{PD}=\text { Policy Document } \\
& \mathrm{BP}=\text { Briefing Paper }
\end{aligned}
$$

\section{Appendix 5C}

\section{Subsidiary Reports (not central part of the research):}

Tomorrow's Schools (1988) [PD]

Assessment for Better Learning (1989) [R]

Māori Education in Pākehā Hands (1989) [RM]

Tomorrow's Schools - Kura Kaupapa Māori Working Group (1989) [R]

Te Kohao o Te Ngira - Joan Metge (1990) [M]

Hirsh Report (1990) [R]

The Sexton Report (1990) [R]

Tomorrow's Standards (1990) [R]

Aoteareo - Speaking for Ourselves (1992) [RM]

Te Kātete Korite - Moving Forward, NZEI (1992) [PD]

Mãori in Education - A Statistical Profile (1993) [M]

Education for the $21^{\text {st }}$ Century (1994) [R]

Making Education Work for Māori (1997) [P]

Review of the Ministry of Education - Service Delivery to Māori (1997)[RM]

Finding of Waitangi Tribunal Relating to Mokai School (2000) [R] 


\section{Appendix 6}

\section{Consultation documents}

Department of Internal Affairs. (2002). Community development group business Plan 2002/03, 1 July, Draft1. Guidelines on consultation with Māori.

Gardner, Wira. (1993). The consultative process between Crown and Māori - Discussion notes for State Services Commission Seminar on Māori issues in government. Cyclostyled notes from Te Puni Kōkiri, 22 March.

Minister of Māori Affairs. (1988). Partnership Response - Policy Statement/Te Urupare Rangapū - Te Rāranga Kaupapa, November.

Ministry of Justice. (1997). A guide for consultation with Māori, Draft.

State Services Commission. (1989). Partnership dialogue - A Māori consultation process. Prepared for the Responsiveness Unit, April.

Te Puni Kōkiri. (1993). A guide for departments on consultation with iwi.

\section{Appendix 7}

\section{Institutional marae}

Aoraki Polytechnic. (1996). Institutional marae. Letter/Memorandum.

Auckland Institute of Technology - Te Whare Takiura o Tamaki Makau Rau. (1996). Institutional marae. Letter/Memorandum.

Central Institute of Technology - Te Whare Wānanga o Whirinaki. (1996). No marae. Letter.

Dunedin College of Education - Te Kura Akau Taitoka. (1996). No marae. Letter.

Eastern Institute of Technology - Te Whare Takiura o Kahungunu. (1996). Institutional Marae. Letter/Memorandum.

Hamilton Teachers' College. (1987). Te Ao Hurihuri - Opening. Programme.

Hutt Valley Polytechnic- Te Whare Wānanga o te Awakairangi. (1996). No marae but uses local marae at Waiwhetū, 'Arohanui ki Te Tangata Marae'. Letter.

Manukau Institute of Technology - Te Whare Takiura o Manukau. (1996). Marau: He Rangahau Marae. Letter/Memorandum. 
Māori Studies Department, Palmerston North Teachers' College. (no date) Te Kupenga o Te Mātauranga (undated). Programme for opening ceremony.

Massey University. (1996). No marae until merger with Palmerston North College of Education this year. Letter.

National Advisory Committee on Māori Education. (1980). Marae on campus - Wiremu Kaa (17/4/23) Appendix 7. Proposal.

Open Polytechnic of New Zealand, The - Te Wharekura-tini Kaihautu o Aotearoa. (1996). No marae. Letter.

Te Kawa a Māui, Victoria University of Wellington. (undated). Te Herenga Waka Marae. (cyclostyled paper).

UNITEC Institute of Technology - Te Kura Pūkenga o Wairaka. (1996). Pūkenga building but no marae. Letter.

University of Auckland. (1996). Marae on campus. Memorandum.

Victoria University of Wellington. (1996). Te Herenga Waka Marae. Memorandum.

University of Otago - Te Whare Wānanga o Otago. (1996) No marae. Letter.

Wellington College of Education. (1996). Marae on campus. Memorandum.

Wellington Polytechnic - Te Kuratini o Te Whanganui a Tara. (1996). Letter/Memorandum.

Whitireia Community Polytechnic - Te Kura Matatini o Whitireia. (1996). Research about institutional marae. 


\section{Bibliography \\ [Theses added separately]}

Adams, Peter. (1977). Fatal necessity; British intervention in New Zealand 18301847. Auckland/Oxford: Auckland/Oxford University Press.

Adams, R.S. (1973). Differentiating Māori from Pākehā: Some educational and social implications. In Douglas Bray \& Clement Hill. (Eds.). Polynesian and Pākehā in New Zealand education - Vol. 1, The sharing of cultures (pp. 63-67). Auckland: Heinemann Educational Books.

Agbo, Seth, A. (2002). Decentralisation of First Nations education in Canada: Perspectives on ideals and realities of Indian control of Indian education. Interchange, 33 (3), 281-302.

Alaska Rural Systemic Initiative. (1997). Native pathways to education. Sharing our pathways, 2, 1 (Jan/Feb). Alaska Federation of Natives, University of Alaska.

Althusser, Louis \& Balibar, Etienne. (1983). Reading Capital (Ben Brewster Trans.). Verso (Second impression).

Appiah, Kwame Anthony. (1995). African identities. In L. Nicholson, \& S. Seidman. (Eds.). Social postmodernism - beyond identity politics (pp.103-115). Cambridge University Press.

Apple, Michael W. (1979). Ideology and curriculum. London: Routledge \& Kegan Paul.

Apple, Michael. (1998). Under the New Hegemonic Alliance: Conservatism and Educational Policy in the United States, in Keith Sullivan. (Ed.) Education and change in the Pacific Rim: meeting the challenges (pp.79-99). Triangle Journals Ltd: Oxford Studies in Comparative Education,.

Apple, Michael W. \& Franklin, Barry M. (1979). Curricula history and social control. In Carl A.Grant. (Ed.). Community participation in education. Allyn \& Bacon Inc.

Archer, Margaret S. (1984). Social origins of educational systems. London: Sage Publications.

Archer, Margaret S. (1995). Realist social theory: the morphogenetic approach. Cambridge University Press. 
Aron, Raymond. (1976). Main currents in sociological thought 2- Durkheim, Pareto, Weber. (Richard Howard \& Helen Weaver, Trans.). Middlesex, England: Penguin Books.

Ashton-Warner, Sylvia. (1980). Teacher - The testament of an inspired teacher. London: Virago.

Ayer, A.J. (1969). The problem of knowledge. Middlesex, England: Penguin Books.

Ball, Terence. (1978). Two concepts of coercion. Theory and Society, 5 (1):97112.

Ballara, Angela. (1998). Iwi - The dynamics of Māori tribal organisation from c.1769 to c. 1945 . Wellington: Victoria University Press.

Barnes, Barry. (1995). The elements of social theory, New Jersey: Princeton University Press.

Barrington, John. (1991). Report to the Ministry of Education-OECD: Education evaluation and reform strategies. Victoria University of Wellington.

Barrington, J.M. \& Beaglehole, T.H. (1974). Māori schools in a changing society - An historical review. Wellington: New Zealand Council for Educational Research.

Bates, Richard. (1978). The new sociology of education: directions for theory and research. New Zealand Journal of Educational Studies, 13(1): 3-22, May.

Baugh, John. (1999). Out of the mouths of slaves - African American language and educational malpractice. Austin: University of Texas Press.

Bawden, Richard. (1991). Praxis: The essence of systems for being. In Alison R. Viskovic (Ed.). Research and development in higher education. Volume 14, 1-7. Selected papers presented at the $17^{\text {th }}$ annual conference of the Higher Education Research and Development Society of Australasia (Inc.) held at Victoria University of Wellington, 29 August to 1 September. Conference theme: 'Towards 2000: Trends in Tertiary Education'.

Beeby, C.E. (1986). Introduction. In W.L. Renwick, Moving targets - Six essays in educational policy. Wellington: New Zealand Council for Educational Research.

Beeby, C.E. (1992). The biography of an idea - Beeby on education. Wellington: New Zealand Council for Educational Research. 
Benton, Nena. (1989). Education, language decline and language revitalisation the case of Māori in New Zealand. Language and Education, 3(2), 65-82.

Benton, Richard. (1973). Should bilingual schooling be fostered in New Zealand? Wellington: New Zealand Council for Educational Research.

Benton, Richard A. (1981). The flight of the Amokura: Oceanic languages and formal education in the Pacific. Wellington: New Zealand Council for Educational Research.

Benton, Richard. (1988). The Matawaia Declaration - Some Educational and Administrative Implications. A Report Prepared at the Request of the National Association for Kaupapa Māori Education, Working Paper No. 9, Te Wāhanga Māori, New Zealand Council for Educational Research: Wellington.

Benton, Richard A. (1991). Tomorrow's schools and the revitalisation of Māori: Stimulus or tranquiliser? In O. Garcia (Ed.) Bilingual education (pp. 135-144). Amsterdam, Philadelphia: John Benjamins,

Benton, Richard A. \& Smith, Lee. (1982). Survey of language use in Māori households and communities: a report to participants in the initial investigation 1973-78. Wellington: New Zealand Council for Educational Research.

Berger, Peter L. (1971). Invitation to sociology - A humanistic perspective. Middlesex, England: Penguin Books.

Berger, Peter L. (1977). Pyramids of sacrifice, political ethics and social change. Middlesex, England: Pelican Books.

Berger, Peter L. (1979). In praise of particularism: the concept of mediating structures. In Facing up to modernity - Excursions in society, politics and religion (pp.167-180). Middlesex, England: Penguin Books.

Berger, Peter L., \& Kellner, Hansfried. (1982). Sociology reinterpreted - An essay on method and vocation. Middlesex, England: Pelican Books.

Berger, Peter L., \& Luckmann, Thomas. (1967). The social construction of reality - A treatise in the sociology of knowledge. Garden City, New York: Anchor Books, Doubleday \& Coy., Inc.

Berger, Peter L., \& Neuhaus, Richard John. (1996). Respond. In To empower people - From state to civil society $\left(2^{\text {nd }}\right.$ ed.). Edited by Michael Novak (pp.145154). Washington: The AEI Press. 
Berger, Peter L., \& Neuhaus, Richard John. (1996). To empower people - From state to civil society $\left(2^{\text {nd }}\right.$ ed.). Edited by Michael Novak. Washington: The AEI Press.

Bernstein, Basil. (1971). On the classification and framing of educational knowledge. In Young, M.F.D. (Ed.). Knowledge and control: new directions for the sociology of education ( pp. 47-69). London: Collier Macmillan

Bernstein, Basil. (1973). A critique of the concept of compensatory education. In Class, codes and control, Vol. 1, Theoretical studies towards a sociology of language, chapter 10, (pp.214-226). London: Routledge \& Kegan Paul.

Bernstein, Basil. (1977). Class, codes and control. Vol. 3. Towards a theory of educational transmissions (Revised edition) London: Routledge \& Kegan Paul Ltd.

Best, Elsdon. (1972). Tuhoe - The children of the mist, Vol. 1. Wellington: A.H. \& A.W. Reed.

Best, Steven \& Kellner, Douglas. (1991). Postmodern theory - Critical interrogations. New York: The Guildford Press.

Bhola, Harbans. (1975). The grammar of artifactual action. Mimeo.

Bishop, Russell. (1996). The story of the Otago Māori Education Plan. In Collaborative research stories - Whakawhanaungatanga (pp. 177-211). Palmerston North: The Dunmore Press.

Bishop, Russell., Berryman, M. and Richardson, C. (2001). Te toi huarewa Effective teaching and learning strategies, and effective teaching materials for improving the reading and writing in te reo Māori of students aged 5 to 9 in Māorimedium education. Final Report to the Ministry of Education.

Bishop, Russell, \& Glynn, Ted. (1999). Culture counts: Changing power relations in education. Palmerston North: Dunmore Press.

Bishop, Russell \& Glynn, Ted. (2000). Kaupapa Māori messages for the mainstream. Wellington: New Zealand Council for Education Research, Set, pp.47.

Bourdieu, Pierre. (1975). Systems of Education and Systems of Thought. In Michael F.D. Young. (Ed.) Knowledge and control - New directions for the sociology of education. London: Collier-Macmillan Publishers.

Bourdieu, Pierre. (1989). Social space and symbolic power. Sociological Theory, 7(1), 14-25 (Spring). 
Bourdieu, Pierre. (1990). In other words - Essays towards a reflexive sociology (Matthew Adamson, Trans.). Stanford, California: Stanford University Press.

Bourdieu, Pierre. (2000). Pascalian meditations. (Translated by Richard Nice). Stanford, California: Stanford University Press.

Bourne, Jenny with the assistance of A.Sivanandan. (1980). Cheerleaders and ombudsmen: the sociology of race relations in Britain. Race and Class, 21(4): 331352.

Bowen, James \& Hobson, Peter R. (1974). Theories of education - Studies of significant innovation in Western educational thought. Sydney: John Wiley \& Sons Australia Pty. Ltd.

Bowles, Samuel \& Gintis, Herbert. (1977). Schooling in capitalist America Educational reform and the contradictions of economic life. New York: Basic Books, Inc., Publishers.

Bowles, Samuel \& Gintis, Herbert. (1987). Democracy and capitalism-Property, community, and the contradictions of modern social thought. London: Routledge \& Kegan Paul.

Bray, Douglas \& Hill, Clement. (1973). Polynesian and Pākehā in New Zealand education - Vol. 1, The sharing of cultures. Auckland: Heinemann Educational Books.

Brock, Colin \& Tulasiewicz, Witold. (1985). The concept of identity: editors introduction. In (Eds.). Cultural identity and educational policy. London: Croom Helm.

Burrell, Gibson \& Morgan, Gareth. (1979). Sociological paradigms and organisational analysis - Elements of the sociology of corporate life. London: Heinemann.

Butchers, A.G. (1932). The education system - A concise history of the New Zealand education system. Auckland: The National Printing Co., Ltd.

Butterworth, Susan. (1993). The Department of Education 1877-1989 - A guide to its development. Wellington: Ministry of Education.

Campbell, A.E. (1941). Educating New Zealand. Wellington: Department of Internal Affairs.

Carnoy, Martin. (1974). Education as cultural imperialism. New York: David McKay Co., Inc. 
Carr, Wilfred \& Kemmis, Stephen. (1986). Becoming critical - Education, Knowledge and action research. Geelong: Deakin University Press.

Centre for Māori Studies and Research. (1986). A Tainui education strategy 19871997. (Report to Tainui-Māori Trust Board). Hamilton: University of Waikato.

Centre for Māori Studies and Research. (1991). Tainui education strategy 19921997. (Second report to Tainui-Māori Trust Board). Hamilton: University of Waikato.

Chapple, Simon., Jefferies, Richard., \& Walker, Rita. (1996). Māori participation and performance in education - A literature review and research programme (Report for the Ministry of Education, Oct.). Wellington: New Zealand Institute of Economic Research (Inc.).

Chapple, Simon., Jefferies, Richard., \& Walker, Rita. (1997). Māori participation and performance in education - A literature review and research programme (Report for the Ministry of Education, May). Wellington: New Zealand Institute of Economic Research (Inc.).

Chomsky, Noam. (undated). Manufacturing consent - Noam Chomsky and the Media. A feature documentary by Mark Achbar and Peter Wintonick. Video Education Australasia Pty. Ltd. Bendigo, Victoria 3550, Australia.

Chomsky, Noam (2003). The function of schools - Subtler and cruder methods of control. In Kenneth J. Saltman \& David A. Gabbard (Eds.). Education as enforcement - The militarisation and corporatisation of schools. New York \&. London: Routledge Falmer.

Clarke, John; Hall, Stuart; Jefferson, Tony and Roberts, Brian. (1982). Subcultures, cultures and class. In Hall, Stuart \& Jefferson, Tony. (Eds.). Resistance through rituals - Youth subcultures in post-war Britain. London:

Hutchinson in Association with the Centre for Contemporary Cultural Studies: University of Birmingham.

Codd, J., Harker, R. and Nash, R. (Eds.). (1990). Political issues in New Zealand education ( $2^{\text {nd }}$ edn.). Palmerston North: Dunmore Press.

Collins, Patricia Hill. (1992). Transforming the inner circle: Dorothy Smith's challenge to sociological theory. Sociological Theory, 10(1), 73-80.

Combs, Arthur W. (1981). Humanistic education: Too tender for a tough world. Phi Delta Kappan, 62(6), 446-449, Feb. 
Coombe, Rosemary J. (1991) Objects of property and subjects of politics: Intellectual property laws and democratic dialogue. Texas Law Review, 69, 18531880 .

Coombe, Rosemary J. (1993) The properties of culture and the politics of possessing identity: Native claims in the cultural appropriation controversy. Canadian Journal of Law and Jurisprudence, 6, 249-285.

Connerton, Paul. (Ed.). (1978). Critical sociology - Selected readings. Middlesex, England: Penguin Education.

Cooke, Bill \& Kothari, Uma. (2001). Participation - The new tyranny? London/New York: Zed Books.

Cooper, Robert \& Gregory, Jack. (1976). Can community control of Indian education work? Journal of American Indian Education, May, pp.7-11.

Corson, David. (1990). Applying the stages of a social epistemology to school policy making. Draft paper submitted for publication in the British Journal of Educational Studies.

Coward, Rosalind \& Ellis, John. (1979). Language and materialism Developments in semiology and the theory of the subject. Boston: Routledge \& Kegan Paul.

Cox, Lindsay. (1993). Kotahitanga - The search for Mãori political unity. Auckland: Oxford University Press.

Cunningham, Chris. (1999). A framework for addressing Māori knowledge in research, science and technology. A discussion paper prepared for the Ministry of Research, Science and Technology, (June).

Dahrendorf, Ralf. (1979). Life chances - Approaches to social and political theory. Chicago: The University of Chicago Press.

Davies, Brian. (1994). Durkheim and the sociology of education in Britain. British Journal of Sociology of Education, 15(1), 3-25.

Department of Education. (1943). The Post-Primary School Curriculum - Report of the Committee appointed by the Minister of Education in November 1942. Wellington: Government Printer [The Thomas Report].

Department of Education. (1972). Language Programmes for Māori Children. Wellington. 
Department of Education. (1982). An evaluation of marae-based in-service training courses, research report. Wellington: Department of Education.

Department of Education. (undated). Marae on campus. Memorandum.

Dewey, John. (1966). Democracy and education. New York: The Free Press.

Dewey, John. (1974). Experience and education. The Kappa Delta Pi Lecture Series. London: Collier Macmillan Publishers.

Donzelot, Jacques. (1980). The policing of families - Welfare versus the state. London: Hutchinson.

Douglas, Edward Te Kohu \& Robertson-Shaw, Mark. (Eds.). (1999). Ngai Tātou Indigenous Governance and Accountability: Whakahaere-ā-iwi, Whakamārama-āiwi, The Foundation for Indigenous Research in Society \& Technology.

Durie, Arohia. (1997). Te aka matua: keeping a Māori identity. In Te Whaiti, Pania,. McCarthy, Marie \& Durie, Arohia. (Eds.) Mai i Rangiātea -Māori wellbeing and development (pp. 142-162). Auckland: Auckland University Press, Bridget Williams Books.

Durie, Mason. (1994). Whaiora - Māori health development. Auckland: Oxford University Press.

Durie, Mason. (1995). Tỉno rangatiratanga-Māori self-determination. He pūkenga kōrero, 1 (1), 44-53.

Durie, Mason. (1997). Representation, Governance and the Goals of Māori Self Determination, He Pukenga Kōrero, 2 (2): 1-7 (Autumn).

Durie, Mason. (1998). Te mana, Te kāwanatanga - The politics of Mãori selfdetermination. Auckland: Oxford University Press.

Durkheim, Emile. (1973). Moral education - A study in the theory and application of the sociology of education (E. Wilson \& H. Schnurer, Trans.) New York: Free Press.

Dworkin, Ronald. (1978). Taking rights seriously. Cited in Derek L. Phillips. (1986). Toward a just social order. Princeton, New Jersey: Princeton University Press.

Dyer, Richard. (1997). White. London: Routledge.

Education Development Conference. (1974). Proposals for change. The Advisory Council on Educational Planning. 
Ellsworth, Elizabeth. (1989). Why doesn't this feel empowering? Working through the repressive myths of critical pedagogy. Harvard Educational review, 59(3), 297-324.

Else, Anne. (1997). Māori participation and performance in education - A summary. Wellington: Ministry of Education.

Epstein, Erwin. (1978) The social control thesis and educational reform in dependent nations. Theory and Society, 5(2): 255-276.

Fanon, Frantz. (1970). Black skins white masks. (Translated by Charles Lamm Markmann). London: Paladin.

Finn, P.D. (1992). Fiduciary law and the modern commercial world. In Ewan McKendrick. (Ed.). Commercial aspects of trusts and fiduciary obligations. Oxford: Clarendon Press.

Fitzgerald, T.K. (1970). The first generation of Māori university graduates: a historical sketch, New Zealand Journal for Educational Studies, 5 (1): 47-62, May.

Fitzgerald, Thomas K. (1977). Education and identity - A study of the New Zealand Māori graduate. Wellington: New Zealand Council for Educational Research.

Flew, Antony. (1971). An introduction to Western philosophy - Ideas and argument from Plato to Sartre. London: Thames \& Hudson.

Flude, Michael \& Ahier, John. (Eds.). (1976). Educability, schools and ideology. London: Croom Helm.

Foucault, Michel. (1982). The subject and power. Critical Inquiry, 8: 777-795, Summer. 'Why Study Power? The Question of the Subject' was written in English by Foucault. 'How is power exercised?' was translated from the French by Leslie Sawyer.

Frame, Alex. (2002). Grey and Iwikau - A journey into custom. Kerei rāua ko Iwikau - te haerenga me ngā tikanga. Wellington: Victoria University Press.

Freeman, Michael. (1975). Sociology and utopia: some reflections on the social philosophy of Karl Popper. British Journal of Sociology, 26(1): 20-33, Mar.

Freire, Paulo. (1972). Cultural action for freedom. Middlesex, England: Penguin Books.

Freire, Paulo. (1977). Pedagogy of the oppressed. Middlesex, England: Penguin. 
Freire, Paulo. (1985). The politics of education - Culture, power, and liberation. London: Macmillan Publishers Ltd.

Friedenberg, Edgar Z. (1982). Core curriculum, nostalgia and anomie. McGill Journal of Education, 17(2): 99-108, Spr.

Friedman, Marilyn. (1992). Feminism and modern friendship: dislocating the community. In Shlomo Avineri \& Avner de Shalit (Eds.). Communitarianism and individualism. New York: Oxford University Press.

Garrett, Ephra M. (1973). Social relationships. In Douglas Bray, \& Clement Hill. (Eds.). Polynesian and Pākehã in New Zealand education - Vol. 1, The sharing of cultures, pp. 29-43.Auckland: Heinemann Educational Books.

Giddens, Anthony. (Ed.). (1977). Emile Durkheim : Selected writings (A.Giddens. Trans.). Cambridge: Cambridge University Press.

Giddens, Anthony. (2000). The third way - The renewal of social democracy. Polity Press.

Gilbert, Jane. (2001). Science and its "other": looking underneath "woman" and "science" for new directions on gender and science education. Gender and Education, 13 (3): 291-305.

Giroux, H.A. (1982). Power and resistance in the new sociology of education: beyond theories of social and cultural reproduction. Curriculum Perspectives, 2(3): 1-13.

Goodman, Paul. (1971). Compulsory miseducation. Middlesex, England: Penguin Books.

Graham, Doug. (1997). Trick or Treaty. Institute of Policy Studies. Wellington: Victoria University of Wellington.

Green, Andy. (1990). Education and state formation - The rise of education systems in England, France and the USA. New York: St.Martin's Press.

Green, Paul. (1978). Notes for sociology course on 'Sacred and secular societies'. Palmerston North: Massey University.

Guba, Egon E. \& Lincoln, Yvonna S. (1991). What is the constructivist paradigm? In Don S. Anderson, \& Bruce J Biddle. (Eds.). Knowledge for policy: Improving education through research, (pp.158-170). London: The Falmer Press. 
Gundara, Jagdish. (1982). Approaches to multicultural education. In J. Tierney. (Ed.). Race, migration and schooling, (pp.108-119). London: Holt, Rinehart \& Winston,

Haig-Brown, Celia (1996). Taking control: contradictions and First Nations adult education. In Marie Battiste, \& Jean Barman. (1996). (Eds.). First Nations in Canada: The circle unfolds. Seattle: University of Washington Press.

Hall, S. \& Du Gay, P. (Eds.). (1997). Questions of cultural identity. London: Sage Publications.

Hall, Stuart \& Jefferson, Tony. (Eds.). (1982). Resistance through rituals - Youth subcultures in post-war Britain. London: Hutchinson University Library.

Hall, Stuart. (1981). Cultural studies: two paradigms. In T. Bennett et al (Eds.). Culture, ideology and social process, (pp. 19-37). London: Batsford Academic and Educational Ltd in association with The Open University Press.

Hall, Stuart. (1981). The whites of their eyes - Racist ideologies and the media. In George Bridges \& Rosalind Brunt. (Eds.). Silver linings - Some strategies for the eighties - Contributions to the Communist University of London. London: Lawrence \& Wishart.

Hall, Stuart. (1997). Introduction : Who needs 'identity' ? In Stuart Hall \& Paul Du Gay. (Eds.) Questions of cultural identity. London: Sage Publications.

Hall, Stuart. (1997). Minimal selves. In Ann Gray \& Jim McGuigan. (Eds.). Studying culture - An introductory reader ( $2^{\text {nd }}$ ed.), (pp. 134-138). London: Arnold.

Hamilton, Bill. (1992). Māori education developments: a Māori unionist's view. New Zealand Annual Review of Education, 2: 119-133.

Hampton, Eber. (1995). Memory comes before knowledge: research may improve if researchers remember their motives. Canadian Journal of Native Education, 21, 46-54.

Handler, Richard. (1985). On having a culture-Nationalism and the preservation of Quebec's Patrimoine. In George W. Stocking Jr. (Ed.). Objects and others - essays on museums and material culture. History of Anthropology, Vol.3. Wisconsin: University of Wisconsin Press.

Handler, Richard. (1991). Who owns the past? History, cultural property, and the logic of possessive individualism. In Brett Williams. (Ed.). Objects and others. Wisconsin: University of Wisconsin Press. 
Hargreaves, Andy \& Fullan, Michael. (1998). What's worth fighting for out there? Ontario Public School Teachers' Federation. An Affiliate of the Ontario Teachers' Federation.

Hargreaves, Andy. (1982). Resistance and relative autonomy theories: problems of distortion and incoherence in recent Marxist analyses of education. British Journal of Sociology, 3(2): 107-126.

Harker, R.K. (1971). Māori education and research. The Australian and New Zealand Journal of Sociology, 7 (1): 46-57.

Harker, R.K. (1978). Achievement and ethnicity: Environmental deprivation or cultural difference. New Zealand Journal of Educational Studies 13 (2): 107-124.

Harker, Richard. (1990). Schooling and cultural reproduction. In J. Codd, R. Harker, and R. Nash. (Eds.) Political issues in New Zealand education $\left(2^{\text {nd }}\right.$ ed.), (pp. 25-42). Palmerston North: Dunmore Press.

Harker, R.K. \& McConnochie, K.R. (1985). Education as cultural artifacts: studies in Mãori and Aboriginal education. Palmerston North: The Dunmore Press Ltd.

Harris, Herbert W. (1995). Introduction: a conceptual overview of race, ethnicity and identity. In Herbert W. Harris, Howard C. Blue, \& Ezra E.H. Griffith. (eds.). Racial and ethnic identity - Psychological development and creative expression, (pp.1-14). NY: Routledge.

Harvard Educational Review. (1973). Challenging the myths - The schools, the blacks, and the poor. Reprint Series No. 5. HER.

Harvey, David. (1993) Class relations, social justice and the politics of difference. In Michael Keith, \& Steve Pile. (Eds.). (1993). Place and the politics of identity, (pp. 41-66). London \& New York: Routledge.

Harvey, David. (1996). Justice, nature \& the geography of difference. Cambridge MA: Blackwell Publishers.

Harvey, David. (1999). The condition of postmodernity - An enquiry into the origins of cultural change. Cambridge MA: Blackwell.

Harvey, David. (2000). Spaces of hope. Los Angeles: University of California Press, Berkeley.

Henare, Manuka. (1995). Te Tiriti, te tangata, te whānau: the Treaty, the human person, the family. In International Year of the Family, Rights and responsibilities. 
Papers from the International Year of the Family Symposium on Rights and Responsibilities of the Family, Wellington, 14-16 October.

Henry, Jules. (1971). Essays on education. Middlesex, England: Penguin Education Books.

Hippolite, C., Samuel, K., \& Winiata, P. (1996). The case for indigenous facilities in non-indigenous institutions. Draft paper for World Indigenous Peoples Conference on Education, Albuquerque.

Hirst, Paul Q. (1979). On ideology and law. London: The Macmillan Press Ltd.

Holmes, Brian. (1981). Comparative education: Some considerations of method. London: George Allen \& Unwin.

Holt, John. (1971). The underachieving school. Middlesex, England: Penguin Books.

hooks, bell. (1990). Choosing the margins as a space of radical openness. Cited in Harvey, David. (1999/1990). The condition of postmodernity - An enquiry into the origins of cultural change. Cambridge MA: Blackwell.

hooks, bell. (1990). Yearning - race, gender, and cultural politics. Boston: South End Press.

Illich, Ivan D. (1974). Deschooling society. Middlesex, England: Penguin Education.

Irwin, Kathleen. (1994). Māori education, policy and teaching: thinking globally, acting locally. In Elizabeth Hatton. (Ed.). Understanding teaching: curriculum and the social context of teaching. Harcourt Brace.

Jackson, Michael. (1999). Refugee experience, displacement, and the critique of cultural fundamentalism. Sites 37, 3-16.

Jackson, Moana. (1988). The Màori and the criminal justice system, a new perspective: He whaipaanga hou. Wellington: Department of Justice.

Jacoby, R. (1975). Social amnesia - A critique of conformist psychology from Adler to Laing. The Harvester Press.

Jenkins, Kuni \& Matthews, Morris Kay. (1995). Hukarere and the politics of Māori girls' schooling, 1875-1995. Hukarere Board of Trustees with Te Whānau 0 Hukarere. 
Johnston, Darlene M. (1989). Native rights as collective rights: a question of group self-preservation. Canadian Journal of Law and Jurisprudence: Vol. ii, (1), 19-34.

Jones, Alison. (1992). Writing feminist educational research: Am 'I' in the text. In Sue Middleton \& Alison Jones. (eds.). Women and education in Aotearoa 2. Wellington: Bridget Williams Books.

Karier, Lawrence J. (1976). Liberalism and the quest for orderly change. In Roger Dale, Geoff Esland and Madeleine MacDonald. (Eds.). Schooling and capitalism A sociological reader. London \& Henley: Routledge \& Kegan Paul in association with The Open University Press.

Kawagley, Angayuqaq Oscar \& Barnhardt, Ray. (1999). Education indigenous to place - Western science meets native reality. In Gregory A. Smith \& Dilafruz R. Williams. (1999). (Eds.). Ecological education in action - On weaving education, culture, and the environment, (pp.117-140). New York: State University of New York Press.

Kawharu, I.H. (1965). Education and the Māori Community: Orakei. Talk given to the $11^{\text {th }}$ New Zealand Science Congress, February. Auckland: University of Auckland.

Kawharu, I.H. (Ed.). (1989). Waitangi - Māori and Pākehã perspectives of the Treaty of Waitangi. Auckland: Oxford University Press.

Keddie, Nell. (Ed.). (1973). Tinker, tailor...The myth of cultural deprivation. Middlesex, England: Penguin Education.

Keesing, F.M. (1928). The changing Māori. Thomas\Avery \& Sons.

Kincheloe, Joe L. \& McLaren, Peter L. (1994). Rethinking critical theory and qualitative research. In Norman K. Denzin, \& Yvonna S. Lincoln, (Eds.).

Handbook of qualitative research. Sage Publications.

Kincheloe, J.L., Slattery, P., \& Steinberg, S.R. (2000). Contextualising teaching. New York: Longman.

King, Michael. (Ed.). (1978). Tihe Mauriora-Aspects of Māoritanga. Methuen.

King, Michael. (Ed). (1975). Te Ao Hurihuri-Aspects of Māoritanga. Wellington: Hicks Smith and Sons.

Kinloch, Graham C. (1977). Sociological theory - Its development and major paradigms. McGraw-Hill Book Company. 
Kirkness, Verna J. (1992). First Nations content: Programs and courses. In First Nations and Schools: Triumphs and Struggles, (pp.34-39). Toronto: Canadian Education Association.

Kohl, Herbert. (1967). 36 children. New York: New American Library.

Kuhn, Thomas. (1962). The structure of scientific revolutions. Chicago \& London: The University of Chicago Press.

Lawton, Denis. (1983). Curriculum studies and educational planning. London: Hodder \& Stoughton.

Levine, Hal B. (1997). Constructing collective identity - A comparative analysis of New Zealand Jews, Māori, and urban Papua New Guineans. Frankfurt am Main: Peter Lang.

Levy, Bernard-Henri. (1995). Adventures on the Freedom Road - The French intellectuals in the $20^{\text {th }}$ century. (Translated from the French and edited by Richard Veasey). London: The Harvill Press.

Lewis, Francione N. with Margold Jane. (undated). Responsive multicultural basic skills handbook for teachers and parents: Overview. San Francisco: Far West Laboratory for Educational Research and Development.

Lukes, Steven. (1974). Power - A radical view. London: Macmillan Press.

Macdonell, Diane. (1986). Theories of discourse - An introduction. Basil Blackwell.

Macklin, Michael. (1976). When schools are gone : A projection of the thought of Ivan Illich. St. Lucia: University of Queensland Press.

Mahuta, R.T. (1979). The ideology of myth. Paper delivered to Anthropology Section, $49^{\text {th }}$ ANZAAS Congress, January. Hamilton: University of Waikato.

Mahuta, R.T. (1993). Strategic planning - A traditional Māori concept with a new name. Paper presented at Australasian Evaluation Society Conference, 28-30 August, at Victoria University, Wellington.

Manning, Richard. (1999). History never repeats itself? Colonial historical trends confront National Administrative Guidelines. New Zealand Annual Review of Education, 9: 63-81. Edited by Ian Livingston, School of Education, Wellington: Victoria University of Wellington.

Māori Education Commission. (1998a). Report to the Minister of Mãori Affairs. Report 1 (Feb.). Wellington: Māori Education Commission. 
Māori Education Commission. (1998b). Report to the Minister of Māori Affairs. Report 2 (Aug.). Wellington: Māori Education Commission.

Māori Education Commission. (1999a). Report to the Minister of Māori Affairs. Report 3 (Feb.). Wellington: Māori Education Commission.

Māori Education Commission. (1999b) Report to the Minister of Māori Affairs. Report 4 (Sept.). Wellington: Māori Education Commission.

Māori Education Trust. (1997). Te nuka kōkiri a Te Kaupapa Mātauranga mo te Iwi Mãori - The strategic plan of the Mãori Education Trust, Wellington.

Māori Education Trust. (2002). Te nuka kōkiri a Te Tari o Te Kaitiaki mō Ngā Take Mātauranga Māori - Strategic plan of the Māori Education Trust, 2002/2003, Wellington.

Māori Language Commission. (1988). Media Release. The Matawaia Declaration - A proposal for the establishment of an independent Māori education authority, 25 February.

Marsden, Maori Rev., \& Henare, Te Aroha. (1992). Kaitiakitanga - A definitive introduction to the holistic world views of the Maori. Submission on the Resource Management Act 1991.

Marshall, J. \& Peters, M. (1990). Community and empowerment: Theory and practice in Tai Tokerau. In J. Codd, R. Harker \& R. Nash. (Eds.). Political issues in New Zealand education. Palmerston North: Dunmore Press.

Marshall, J., Peters, M. \& Smith, G.H. (1990). The Business Roundtable and the privatisation of education: Individualism and the attack on Māori. Paper presented at the NZARE Special Interest Conference, July 6.

Martindale, Don A. (1974). Sociological theory and the problem of values. Columbus, Ohio: Charles E. Merrill Pub., Coy.

Marx, K. \& Engels, F. (1974). The German ideology, chapter 1, part 3, article 30. New York: International Publishers.

May, Stephen. (1994). Making multicultural education work. Clevedon: Multilingual Matters; Toronto: Ontario Institute for Studies in Education.

Mazrui, Ali A. (1986). The Africans - A triple heritage. London: BBC Publications. 
McHugh, P.G. (1997). Law, history and the Treaty of Waitangi. The New Zealand Journal of History, 31(1): 38-57, April.

McKenzie, J.D.S. (1982). More than a show of justice? The enrolment of Māoris in European schools prior to 1900. New Zealand Journal of Educational Studies, 17(1): 1-20, May.

McLean, M. (1985). Private supplementary schools and the ethnic challenge to state education in Britain. In C. Brock and W. Tulasiewiez. (Eds). Cultural identity and educational policy, (pp. 326-345).London: Croom Helm.

Mead, Hirini Moko \& Grove, Neil. (2001). Ngā pēpeha a ngā tīpuna - The sayings of the ancestors. Wellington: Victoria University Press.

Mead, Hirini Moko. (2003). Tikanga Māori - Living by Mãori values. Wellington: Huia Publishers.

Metge, Joan. (1979). Setting up a school marae. Cyclostyled paper.

Metge, Joan. (1995). New growth from old - The whānau in the modern world. Wellington: Victoria University Press.

Michaels, Walter Benn. (1992). Race into culture: A critical genealogy of cultural identity. Critical Inquiry, 18 (Summer): 655-685.

Middleton, Sue. (1993). Educating feminists - Life histories and pedagogy. New York and London: Teachers College, Columbia University.

Middleton, Sue., Codd, John. \& Jones, Alison. (Eds.). (1990). New Zealand education policy today - Critical perspectives. Wellington: Allen \& Unwin.

Mikaere, Ani. (2000). Māori and self-determination in Aotearoa/New Zealand, Working Paper No. 5/2000, Development Studies Programme. Hamilton: University of Waikato.

Mills, C. Wright (1977). The sociological imagination. Middlesex, England: A Pelican Book.

Mills, C.Wright. (1977). The Marxists. Middlesex, England: A Pelican Book.

Ministry of Education. (1992). Annual Report on Māori Education - The Ten Point Plan. Wellington.

Ministry of Education. (1994). Education for the $21^{\text {st }}$ century. Wellington: Ministry of Education. 
Ministry of Education. (1997). Education strategy for Māori: Consultation strategy. Paper to Cabinet Committee on Education and Employment Policy, 22 Oct.

Ministry of Education \& Ministry of Māori Development. (1997). Making education work for Māori: Talking points for parents and whānau /Te Whakamahi i te mātauranga mồ te iwi Māori: Hei kōrero mā mātua me ngā whānau. Wellington: Ministry of Education.

Ministry of Education. (1997). Ngā haeata mātauranga-Annual report on Māori education 1996/97 and direction for 1998. Wellington: Ministry of Education.

Ministry of Education. (1999). Ngā Haeata Mātauranga - Annual Report on Māori Education 98/99 and Direction for 2000. Wellington: Ministry of Education.

Ministry of Education (2000). Discussion Paper: Inclusion of a Treaty of Waitangi Clause in Education Amendment Bill, No. 2. Wellington. Ministry of Education.

Ministry of Education. (2001). Cabinet Social Equity Committee Presentation (Background Material). Wellington: Ministry of Education.

Ministry of Education. (2001). Ngā Haeata Mātauranga. Annual Report on Māori Education 1999/2000 and Direction for 2001. Wellington: Ministry of Education.

Ministry of Education \& Te Puni Kōkiri. (1999). Background paper - Māori education strategy - Mainstream initiatives, 21 April.

Ministry of Māori Development and Māori Language Commission (Te Puni Kokiri and Te Taura Whiri i Te Reo Māori) (1995). Wellington.

Ministry of Māori Development. (2000). Mãori in the New Zealand Economy, $2^{\text {nd }}$ edn. (June). Wellington.

Moorehead, Alan. (1979). The fatal impact - An account of the invasion of the South Pacific 1767-1840. Middlesex, England: Penguin Books in association with Hamish Hamilton.

Morris-Matthews, Kay \& Jenkins, Kuni. (1999). Whose country is it anyway? The construction of a new identity through schooling for Māori in Aotearoa/New Zealand. History of Education, 28(3): 339-350.

Morrow, Raymond Allen \& Torres, Carlos Alberto. (1995). Social theory and education - A critique of theories of social and cultural reproduction. New York: State University of New York Press. 
Mulgan, Richard. (1989). Māori, Pākehā and democracy. Auckland: Oxford University Press.

Munn, Nancy D. (1996). Excluded spaces: The figure in the Australian Aboriginal landscape. Critical Inquiry, 22 (Spring): 446-465.

Munz, Peter. (1999). Open and closed research. In New Zealand Books - A review, 9(5): 6 .

Nader, Laura; Barabas, Alicia; Bartolome, Miguel Alberto; Bodley, John H.; Debert, Guita Grin; Drucker-Brown, Susan; Gusterson, Hugh; Hertz, Ellen; Lock, Margaret; and Pinxten, Rik. (1997). Controlling processes: tracing the dynamic components of power. Current Anthropology, 38 (5): 711-39.

Nash, Roy. (1983), Schools can't make jobs. Palmerston North: The Dunmore Press.

Nash, Roy. (1983). Measuring up and falling into line: The discourse of Māori education. Chapter 6. Schools can't make jobs, (pp. 67-86). Palmerston North: The Dunmore Press.

Nash, Roy. (1993). Succeeding generations - Family resources and access to education in New Zealand. Auckland: Oxford University Press.

Nash, Roy. (1997). Radical sociology of education: A contribution to the structure/agency debate. Sites, 34 (Autumn): 36-52.

Native Land Legislation and Native Affairs Generally During 1898 and 1899, Wellington. (1900). By authority John Mc Kay, Wellington: Government Printer.

New Zealand Educational Institute. (1981). Te tatai hono - Report of the New Zealand Educational Institute Committee on Māori Education, Wellington: NZEI.

New Zealand Educational Institute. (1998) Te Reo Areare - Māori education authority. Paper presented to Education Strategy for Māori project team, 5 March. Wellington: Education House.

New Zealand Educational Institute. (1996). Māori educational achievement, tino rangatiratanga and constitutional development. Paper presented to Annual General Meeting, Wellington.

Nisbet, R.A. (1973). The sociological tradition. London: Heinemann.

Orange, Claudia. (1987). The Treaty of Waitangi. Port Nicholson Press: Allen \& Unwin. 
O'Sullivan, Edmund. (1999). Transformative learning: Educational vision for the $21^{\text {st }}$ century. London: Zed Books.

Owen, Harrison. (1991). Learning as transformation.

[http://www.context.org/ICLIB/IC27/Owen.htm] The original article appears as The Learning Revolution. (1991). In Context 27, Winter, pp.16-25.

Parekh, Bhikhu. (1989). The hermeneutics of the Swann Report. In Gajendra Verma, (Ed.). Education for all - A landmark in pluralism (pp. 227-234). London: Macmillan Press.

Parker, Sharon. (1991). Understanding coalition. Stanford Law Review, 43 (6): 1193-1196, July.

Pattayanak, Dr. (1983). Paper to Linguistic Conference, Institute of Education, London: University of London (Personal notes).

Peang-Meth, Abdulgaffar. (2002). The rights of indigenous peoples and their fight for self-determination, World Affairs, Winter, Washington.

Penetito, W.T. (1975). Critique of paper: The principle of complementary education as it affects school programmes for educationally disadvantaged pupils, by A.D.Lopdell. Paper to Advisers on the Education of Māori and Pacific Education seminar, Auckland.

Penetito, W.T. (1984). Taha Māori and the core curriculum. Delta, 34: 35-43.

Penetito, W.T. (1988a). Māori education for a just society. In Royal Commission on Social Policy, The April Report-Social Perspectives, Vol. IV, (pp. 91-114), Wellington.

Penetito, W.T. (1988b). Tomorrow's Schools, The Rūnanga Matua and the politics of honour. Discussion paper to Te Rūnanga Matua, 15 December. Private papers.

Penetito, W.T. (1989). Integration or Māori control: A case for structural diversity. Discussion paper for Te Rūnanga Matua to the Officials Committee on the Implementation of Education Administrative Reform, 19 May. Private papers.

Penetito, W.T. (1998a). When is enough, enough? Breaking the 'zero-sum' ideology on the governance of Māori education. Paper presented to the Māori Education Commission in Rotorua, 14 November.

Penetito, W.T. (1998b) He haeata tiaho - Strategic planning for whānau, hapū and iwi education. Paper presented to Te Ohu Rangahau - Māori Research and Development Conference, 7-9 July at Te Pūtahi-ā-Toi, School of Māori Studies, Palmerston North: Massey University. 
Penetito, W.T. (1999). Submission to Komiti mo Ngā Take Māori on the Whakaturetanga o te Aho Matua, 26 February. Wellington.

Penetito, Wally. (2000). The social construction of Mãori identity: The role of tastes and preferences. In Lise Bird \& Wendy Drewery. (Eds.). Human development in Aotearoa - A journey through life, (pp. 52-65). Sydney: The McGraw-Hill Companies, Inc.

Penfold, Vern. (1973). New Zealanders: One people? Wellington: Hicks Smith \& Sons Ltd.

Pere, Rangimarie Turuki. 1985). Te wheke - A celebration of infinite wisdom Whaia te māramatanga me te aroha. In Sue Middleton. (Ed.).Women and education in Aotearoa. Wellington: Allen \& Unwin.

Pere, Rose. (1999) Te reo rangatira me ōna tikanga. In Māori Education Commission Newsletter, Issue 2, May, (pp.3-10).

Peters, Michael A. (2004). Educational research: 'games of truth' and the ethics of subjectivity. Journal of Educational Inquiry, 5(2): 50-62.

Popper, Karl. (1977). The open society and its enemies. Vol.2. The high tide of prophecy: Hegel, Marx, and the aftermath. London \& Henley: Routledge and Kegan Paul.

Postman, Neil \& Weingartner, Charles. (1971). Teaching as a subversive activity. Middlesex, England: Penguin Books in association with Pitman Publishing.

Preston, David. (1974). Educational planning in the context of national development planning. In Renwick \& Ingham. (Eds.). Educational planning in New Zealand, (pp. 54-82). Wellington: New Zealand Planning Council.

Rangihau, John. (1977). Māoritanga. Cyclostyled paper to inservice course.

Ransom, John S. (1997). Foucault's discipline: The politics of subjectivity. Duke University Press.

Rata, Elizabeth. (2000). Constructing the gaps. New Zealand Political Review, ix (3), Oct/Nov: 24-30.

Rawls, John. (1971). A theory of justice. Cambridge, Mass: Harvard University Press.

Reason, Peter \& Hawkins, Peter. (1988) Storytelling as inquiry. In P. Reason. (Ed.). Human inquiry in action, (pp. 79-101). Newbury Park, CA: Sage. 
Reedy, Tamati and Reedy, Tilly. (1993). Te Whāriki - He Tauira Marautanga, Pipiri. Wellington: Reedy Holdings Ltd.

Reiman, Jeffrey E. (1979). The rich get richer and the poor get prison-Ideology, class, and criminal justice. New York: John Wiley \& Sons.

Reimer, Everett. (1971). School is dead-An essay on alternatives in education. Middlesex, England: Penguin.

Renwick, W.L. (1964). The Currie report - A critique. In Association for the Study of Childhood, (pp.1-10). The 1963 Lectures governing views on public education, Part 1. Comments in chapter 1 of the Report of the Commission on Education. Wellington.

Renwick, W.L. (1978). Emblems of identity - New Zealand painting and carving as a case study of the arts in cultural diversity. A keynote address prepared for the International Society for Education Through Art, $23^{\text {rd }}$ World Congress, Adelaide, S.A. Australia.

Renwick, W.L. (1986). Issues behind the issues. In Moving targets - Six essays on educational policy, (pp.1-22). Wellington: NZCER.

Report of the Commission on Education in New Zealand (The Currie Report).

(1962). Wellington, Government Printer.

Report of the Department of Māori Affairs (Hunn Report). (1960). Wellington: Government Printer.

Richardson, Elwyn S. (1964). In the early world. Wellington: NZCER.

Richardson, Robin. (1984). Now listen children.... PPTA Journal, Term 2, pp.1213.

Ritchie, James S. (1971). One nation - or two? Māori and Pākehā in contemporary New Zealand. Wellington: New Zealand University Press.

Ritchie, Jane. (1978). Chance to be equal. Whatamongo Bay, Queen Charlotte Sound: Cape Catley Ltd.

Rogers, M.F. (1974). Instrumental and infra-resources: The bases of power. The American Journal of Sociology, 79(6): 1418-1433.

Rose, Steven; Kamin, Leon J. \& Lewontin, R.C. (1984). Not in our genes Biology, ideology and human nature. Middlesex, England: Penguin Books. 
Royal, Te Ahukaramu Charles. (1992). Te haurapa: An introduction to researching tribal histories and traditions. Wellington: Bridget Williams Books Ltd. \& Historical Branch, Department of Internal Affairs.

Royal, Te Ahukaramū Charles. (1998). Te ao mārama - A research paradigm. In Conference proceedings, Te Oru Rangahau - Māori Research and Development Conference, Schools of Māori Studies, Massey University, 7-9 July, 1998, pp.7992, Palmerston North.

Royal, Te Ahukaramū Charles. (2001). Native/Indigenous worldviews - A comparative study. Presentation to Te Puni Kōkiri, Wellington, 26 July.

Royal, Te Ahukaramū Charles. (2002). Native Hawaiian charter schools - An introduction. A Report prepared by Royal on behalf of Te Wānanga o Raukawa and for Te Puni Kōkiri Ministry for Māori Development. February. Te Wānanga o Raukawa.

Royal, Te Ahukaramū Charles. (Ed.). (2003). The woven universe - Selected writings of Rev. Māori Marsden. The Estate of Rev. Māori Marsden.

Sampson, Edward G. (1976). Social psychology and contemporary society $\left(^{\text {nd }}\right.$ ed.). New York: John Wiley \& Sons Ltd.

Sarap, Madan. (1978). Marxism and education. London: Routledge and Kegan Paul.

Savage, John. (1998). The economics of education - A course prepared for the Ministry of Education (Feb.).

Schwimmer, Erik. (1964). The sense of belonging. In Association for the Study of Childhood, The Curriculum Report - A Critique - The 1963 Lectures.

Schwimmer, Erik. (1973). Māori schooling and confusion of identity. In Douglas H. Bray \& Clement G.N. Hill. (Eds.). Polynesian and Pākehā in New Zealand education. Vol. l, The sharing of cultures, (pp.75-95). Auckland: Heinemann Educational Books.

Scott, Graham. (1993, September 3). Would society fly asunder were the state not to run our schools? The Independent.

Scott, Raymond A. (1986). The challenge of Taha Māori - A Pākehā perspective. Office of the Race Relations Conciliator.

Senese, Guy. (1986). Self-determination and American Indian education: An illusion of control, Educational Theory, 36 (2), 153-164. 
Sexton, Stuart. (1990). A report commissioned by the New Zealand Business

Round Table on New Zealand schools and current reforms. Wellington: Business

Round Table (February).

Sharp, Andrew. (1997). Justice and the Māori - The philosophy and practice of Mãori claims in New Zealand since the 1970s ( $2^{\text {nd }}$ ed.). Auckland: Oxford University Press.

Sharp, Rachel \& Green, Anthony with Lewis, Jacqueline. (1976). Education and social control: a study in progressive primary education. London: Routledge \& Kegan Paul.

Sharp, Rachel. (1980). Knowledge, ideology and the politics of schooling Towards a Marxist analysis of education. London: Routledge \& Kegan Paul.

Sheleff, Leon Shaskolsky. (1997). Social cohesion and legal coercion - A critique of Weber, Durkheim, and Marx. Volume 44, Value Inquiry Book Series. Amsterdam: Rodopi.

Shuker, Roy. (1986). The state, schooling and hegemony: Education in New Zealand prior to 1930. Sites, 12, Aut. pp. 15-28.

Shuker, Roy. (1987). Māori education: Schooling for assimilation. Chapter 8. The one best system - A revisionist history of state schooling in New Zealand (pp.191208). Palmerston North: The Dunmore Press Ltd.

Simmons, Laurence \& Worth, Heather. (Eds.). (2001). Derrida downunder. Palmerston North: Dunmore Press.

Simmons, Laurence; Worth, Heather; and Smith, Graham. (2001). Introduction: Powhiri for Jacques Derrida. In Laurence Simmons \& Heather Worth. (Eds.). Derrida downunder. Palmerston North: Dunmore Press.

Simon, Judith. (1984). Good intentions but... In National Education, 66(4), July.

Simon, Judith. (1986). Ideology in the schooling of Mãori children. Delta Research Monograph, No 7. Palmerston North: Massey University.

Simon, Judith A. (1992). European style schooling for Māori: The first century. ACCESS Critical Perspectives on Education Policies, 11(2), 31-43.

Simon, Judith. (1992). State schooling for Mãori: The control of access to knowledge. Paper presented at the AARE/NZARE Joint Conference, Deakin University, Geelong, Australia, 22-26 November. 
Simon, Judith. (1998). Ngā kura Māori - The Native Schools System 1867-1969, Auckland: Auckland University Press.

Simon, Judith \& Smith, Linda T. (Eds.). (2001). A civilising mission? Perceptions and representations of the New Zealand Native Schools System. Auckland: Auckland University Press.

Sinclair, Keith. (1986). A destiny apart - New Zealand's search for national identity. Wellington: Unwin Paperbacks in Association with The Port Nicholson Press.

Skutnabb-Kangas, Tove. (1981). Bilingualism or not: The education of minorities. Clevedon, Avon: Multilingual Matters Ltd.

Slemon, Stephen. (1997). The scramble for post-colonialism. In Bill Ashcroft, Gareth Griffiths and Helen Tiffin. (Eds.). (1997). The post-colonial studies reader. (pp.45-52). London \& New York: Routledge.

Smith, G.H. (1990). Taha Māori: Pākehā capture. In J.Codd, R.Harker, and R.Nash. (eds.) Political issues in New Zealand education ( $2^{\text {nd }}$ ed.). Palmerston North: The Dunmore Press.

Smith, G.H. (1990). The politics of reforming Māori education: The transforming potential of Kura Kaupapa Maōri. In Hugh Lauder \& Cathie Wylie. (eds.). Towards successful schooling. London: Falmer Press.

Smith, G.H. (1991). Tomorrow's schools and the development of Māori education. Monograph No.5, Research Unit for Māori Education. Auckland: University of Auckland.

Smith, G.H. (1992). Tāne-nui-a-Rangi’s legacy...Propping up the sky - Kaupapa Māori as resistance and intervention. Paper presented at NZARE/AARE Joint Conference, Deakin University, Australia, 20 Nov.

Smith, G.H. (1995). Whakaoho whānau: New formations of whānau as an innovative intervention into Māori cultural and educational crises, He Pukenga Kōrero, 1 (1), 18-36.

Smith, Linda T. (1999). Decolonising methodologies: Research and indigenous peoples. London \& New York: Zed Books.

Snook, Ivan. (1995). Democracy, equality and education in a bi-cultural society. Educational Philosophy and Theory, 27(2): 1-14. 
Soja, Edward W. \& Hooper, Barbara. (1993). The spaces that difference makes: Some notes on the geographical margins of the new cultural politics. In Michael Keith \& Steve Pile. (Eds.). Place and the politics of identity, (pp.183-205). London \& New York: Routledge.

Soja, Edward W. (1996). Thirdspace - Journeys to Los Angeles and other realand-imagined places. Cambridge, Mass: Blackwell Publishers.

Sorrenson, M.P.K. (1982). Polynesian corpuscles and Pacific anthropology: the home-made anthropology of Sir Apirana Ngata and Sir Peter Buck. The Journal of the Polynesian Society, 91(1): 7-27.

Spindler, George D. (Ed.).(1963). Education in a transforming American culture. In Education and culture - Anthropological approaches. New York: Holt, Rinehart \& Winston

Spolsky, Bernard. (2003). Reassessing Māori regeneration. Language in society 32(4): 553-578.

Spoonley, Paul. (1987). The politics of nostalgia-Racism and the extreme right in New Zealand. Palmerston North: The Dunmore Press.

Stanfield, John H. (1985). The ethnocentric basis of social science knowledge production. Review of Research in Education, 12:387-415, Ch.10. Edmund W. Gordon (Ed.). American Educational Research Assoc.

Stewart-Harawira, Margaret. (1993). Maori, who owns the definition? The politics of cultural identity. Te Pua, (1 \& 2): 27-34.

Stokes, Evelyn. (2002) The individualisation of Māori interests in land. (Te Mātāhauariki Institute Monograph Series). Hamilton: The University of Waikato.

Stone, Maureen. (1981). The education of the black child in Britain - The myth of multiracial education. Glasgow: Fontana Paperbacks.

Strike, Kenneth A. (1982). Educational policy and the just society. Urbana: University of Illinois Press.

Strike, Kenneth A. (1989). Liberal justice and the Marxist critique of educationA study of conflicting research programmes. New York/London: Routledge.

Sullivan, Ann. (1998). Self-determination and redistributive justice: The New Zealand Maori, He Pukenga Kōrero, Autumn, 5(2), 52-60. 
Tahi, Brenda. (1995). Biculturalism: The model of Te Ohu Whakatupu. In Margaret Wilson and Anna Yeatman, (Eds.). Justice and identity - Antipodean practices, (pp. 61-77). Wellington: Bridget Williams Books.

Tahuparae, John. (1995). Te Rangakura presentation to Te Tutukitanga - Māori Achievement Symposium, NZEI, Wellington High School, 31 Aug. - 2 Sept.

Tapine, Vyletta, \& Waiti, Danica. (Compiled by). (1997). He tirohanga ki mua Visions for Māori education. Wellington: New Zealand Council for Educational Research.

Te Puni Kōkiri. (1993). Mana tangata - Draft Declaration on the Rights of Indigenous Peoples - Background and discussion on key issues - An explanatory document.

Te Rūnanga Matua. (1989a) Te Rūnanga Matua perspective on reform of education administration. Personal papers. Wellington.

Te Rūnanga Matua (1989b). A Suggestion - Rūnanga Matua, 24 April. Personal papers. Wellington.

Te Rūnanga nui o ngā Kura Kaupapa Māori o Aotearoa. (1996). Te mahere rautaki mā ngā kura kaupapa Māori - The kura kaupapa Māori strategic plan. (Final Report to Rawiri Brell, Group Manager Māori, Ministry of Education, October). Palmerston North.

Te Rūnanga nui o Ngā Kura Kaupapa Māori o Aotearoa (Mana Topu). (1998). A Submission to the Associate Minister of Education, Hon Tau Henare, Including Te Aho Matua into s155 of the Education Act, 1989 (29 Sept.).

Te Whaiti, Pania; McCarthy, Marie \& Durie, Arohia. (Eds.). (1997). Mai $i$ Rangiātea - Māori wellbeing and development. Auckland: Auckland University Press, Bridget Williams Books.

Tierney, John; Dickinson, Peter; Syer, Michael; Mullard, Chris; Gundara, Jagdish; Jones, Crispin \& Kimberley, Keith. (1982). Race, migration and schooling. London: Holt, Rinehart \& Winston.

Tomlinson, John. (1997). Cultural imperialism - A critical introduction. London: Pinter publishers.

Treasury, The. (1987). Government Management - Brief to the Incoming Government 1987, Volume 11 - Educational Issues. Wellington: The Treasury.

Trochim, William M.K. (1999). The research methods knowledge base $\left(2^{\text {nd }}\right.$ ed.). Cornell University. 
Tū Tangata. (Undated). The 'Tü Tangata Way' in Hawaii and Mainland U.S.A. (Promotion brochure).

United Nations High Commission for Refugees. (1991). Images of exile. United Nations Organisation.

Urion, Carl. (1991). Changing academic discourse about Native Education - Using two pairs of eyes. Canadian Journal of Native Education, 18(1): 1-9.

Van Til, Jon. (1984). Citizen participation in the future. Policy Studies Review, 3(2): 311-322.

Vaughan, G. (1964). Development of ethnic awareness in Māori and Pākehā school children. In J.E. Ritchie. (Ed.). Race relations: Six New Zealand studies, Wellington: Victoria University Publications in Psychology, No.16.

Vercoe, Andrew. (1995). Resistance in Māori education: A critique of kura kaupapa Māori. Waikato Journal of Education, 1, 119-135.

Verma, Gajendra K. \& Bagley, Christopher. (Eds.). (1979). Race, education and identity. London: Macmillan Press.

Verma, Gajendra. (Ed.). (1989). Education for all - A landmark in pluralism. London: Falmer Press.

Waitangi Tribunal. (1986). Finding of the Waitangi Tribunal Relating to Te Reo Māori and a Claim Lodged by Huirangi Waikerepuru and Ngā Kaiwhakapūmau i Te Reo Inc. Soc. Wellington.

Waitangi Tribunal Report. (2003). Te Whanganui a Tara me ona Takiwa - Report on the Wellington District, Wellington. (WAI 145).

Walker, Ranginui. ( ) Te marae - Traditional form with modern relevance. Te Mãori, pp.41-47.

Walker, R.J. (1972). Assimilation or cultural continuity. In G.M.Vaughn. (Ed.). Racial Issues in New Zealand.

Walker, R.J. (1975). Marae: A place to stand. In Michael King (Ed.). Te ao hurihuri - The world moves on - Aspects of Mãoritanga, (pp.21-34). Wellington: Hicks Smith \& Sons Ltd.

Walker, R.J. (1984). The genesis of Māori activism. Journal of the Polynesian Society, 93(3): 267-281, Sept. 
Walker, R.J. (1985). Cultural domination of Taha Māori: The potential for radical transformation. In John Codd et al. (eds.) Political issues in New Zealand education. Palmerston North: The Dunmore Press Ltd.

Walker, R.J. (1987). Ngā tautohetohe - Years of anger. Auckland: Penguin Books.

Walker, R.J. (1990). Ka whawhai tonu mātou - Struggle without end. Auckland: Penguin Books.

Walker, Ranginui J. (1996). Contestation of power and knowledge in the politics of culture. He Pūkenga Körero, 1(2): 1-7.

Wallace, Anthony F.C. (1956). Revitalisation movements. American Anthropologist, 58(2): 264-281.

Wallace, Anthony F.C. (1973). Schools in revolutionary and conservative societies. In F.A.J. Ianni \& Edward Storey. (Eds.). Cultural relevance and educational issues - Readings in anthropology and education. Boston: Little, Brown \& Co.

Ward, Alan. (1999). An unsettled history - Treaty claims in New Zealand today. Wellington: Bridget Williams Books.

Watkins, Peter. (1992). The transformation of educational administration: The hegemony of consent and the hegemony of coercion. Australian Journal of education, 36(3): 237-259.

Watson, John E. (1967). Horizons of unknown power - Some issues of Māori schooling. Wellington: New Zealand Council for Educational Research.

Weaver, John C. (2003). The great land rush and the making of the modern world, 1650-1900. Montreal \& Kingston: McGill-Queen's University Press.

Webster, Peter. (1979). Rua and the Mãori millenium. Wellington: Price Milburn for Victoria University Press.

Webster, S. (1998). Patrons of Māori culture - Power, theory and ideology in the Māori Renaissance. Dunedin: University of Otago Press.

Weiss, Carol H. (1991). The many meanings of research utilisation. In Don S. Anderson, \& Bruce J Biddle. (Eds.). Knowledge for policy: Improving education through research, (pp. 173-182). London: The Falmer Press.

Wellington Evening Post. (2000, March 13). Review faults Vic's Māori Department. 
Williams, David V. (1999). Te kooti tango whenua - The Native Land Court 18641909. Wellington: Huia Publishers.

Williams, John A. (1965). The foundations of Apirana Ngata's career 1891-1909. In J.G.A. Pocock (Ed.). The Māori and New Zealand politics. Auckland: Blackwood \& Janet Paul Ltd.

Williams, Raymond. (1985). Keywords - A vocabulary of culture and society (Revised edition). New York: Oxford University Press.

Willinsky, John. (1998). The educational politics of identity and category. Interchange ,29(4): 385-402.

Willis, Paul E. (1981). Learning to labour - How working class kids get working class jobs. Hampshire, England: Gower Publishing Coy.

Wren, Brian. (1986). Education for justice ( $2^{\text {nd }}$ ed.). London: SCM Press Ltd.

Young, Michael F.D. (1975). Knowledge and control - New directions for the sociology of education. London: Collier-Macmillan Publishers.

Young, Michael F.D. (1983). A case study of the limitations of policy research. In Barbara Tizard et. al. Fifteen thousand hours - Secondary schools and their effect on children. London: University of London School of Education.

Young, Michael F.D. (2000). Rescuing the sociology of educational knowledge from the extremes of voice discourse: Towards a new theoretical basis for the sociology of the curriculum. British Journal of Sociology of Education, 21(4): 523-536.

Zeitlin, Irving M. (1968). Ideology and the development of sociological thought. New Jersey: Prentice-Hall.

\section{Theses}

Balcombe, Ann. (2000). Metamorphosis - Expanding the concept of equity in education. Unpublished thesis for the degree of Doctor of Philosophy in Education, Victoria University of Wellington, Wellington.

Castanha, Anthony. (1996). Roles of Non-Hawaiians in the Hawaiian Sovereignty Movement, thesis for Master of Arts in Political Science, University of Hawai'i.

Clareburt, Joy. (1992). He marae mo te kura: The changing role of a school-based marae. A dissertation presented to the University of Auckland in partial fulfillment of the requirements for the degree of Master of Education, February. 
Johnston, Patricia Maringi G. (1998). He ao rerekē - Education policy and Māori under-achievement: Mechanisms of power and difference. Unpublished thesis for the degree of Doctor of Philosophy in Education, University of Auckland, Auckland.

Mataira, Katarina. (1980). The effectiveness of the silent way method in the teaching of Mãori as a second language. A thesis submitted for the Degree of Master of Education, University of Waikato.

Nepe, T.M. (1991). E hae e tênei reanga Te Toi Huarewa Tipuna: Kaupapa Mãori: An educational intervention system. Unpublished thesis submitted in partial fulfilment of the requirement for the Degree of Master of Arts in Education, University of Auckland, Auckland.

Rata, Elizabeth. (1991). Māori survival and structural separateness - The History of Te Rūnanga o Ngā Kura Kaupapa Māori o Tamaki Makaurau, 1987-89. Thesis for MEd degree at University of Auckland.

Simon, Judith A. (1990). The place of schooling in Māori-Pākehā relations. Unpublished doctoral dissertation in anthropology, University of Auckland, Auckland, New Zealand.

Smith, Cherryl Waerea-i-te-rangi. (2002). He pou herenga ki te nui - Māori knowledge and the university. Unpublished thesis for the degree of Doctor of Philosophy in Education, University of Auckland, Auckland.

Smith, G.H. (1997). The development of kaupapa Māori: Theory and praxis. Unpublished dissertation for the Doctor of Philosophy in Education, University of Auckland, Auckland.

Tahana, A.W. (1980). A critical analysis of some studies of Māori schooling. Unpublished M.A. Thesis. Education Department, University of Auckland.

Verbitsky, J.E. (1993). Models of political development in Māori educational policies. A PhD Thesis in Political Studies, University of Auckland.

Wardill, Susan M. (2001). No room to land-The case for the return of Waharoa Airport. Two paper dissertation for Master of Laws, University of Waikato. 